\title{
PRODUCTION AND HARVEST OF MICROALGAE IN WASTEWATER RACEWAYS WITH RESOURCE RECYCLING
}

\author{
A Thesis \\ presented to \\ the Faculty of California Polytechnic State University, \\ San Luis Obispo
}

\author{
In Partial Fulfillment \\ of the Requirements for the Degree \\ Master of Science in Civil and Environmental Engineering
}

by

Alexander Colin Roberts

December 2015 
(C) 2015

Alexander Colin Roberts

ALL RIGHTS RESERVED 


\section{COMMITTEE MEMBERSHIP}

TITLE: $\quad$ Production and Harvest of Microalgae in Wastewater Raceways with Resource Recycling

AUTHOR: $\quad$ Alexander Colin Roberts

DATE SUBMITTED: December 2015

COMMITTE CHAIR: $\quad$ Tryg Lundquist, Ph.D.

Associate Professor of Civil and Environmental Engineering

COMMITTEE MEMBER: $\quad$ Dr. Tracy Thatcher, Ph.D.

Professor of Civil and Environmental Engineering

COMMITTEE MEMBER: $\quad$ Dr. Greg Schwartz, Ph.D.

Assistant Professor of BioResource and Agricultural Engineering 


\begin{abstract}
Production and Harvest of Microalgae in Wastewater Raceways with Resource Recycling
\end{abstract}

\title{
Alexander Colin Roberts
}

Microalgae can be grown on municipal wastewater media to both treat the wastewater and produce feedstock for algae biofuel production. However the reliability of treatment must be demonstrated, as well as high areal algae productivity on recycled wastewater media and efficient sedimentation harvesting. This processes was studied at pilot scale in the present research.

A pilot facility was operated with nine $\mathrm{CO}_{2}$-supplemented raceway ponds, each with a $33-\mathrm{m}^{2}$ surface area and a 0.3-m depth, continuously from March 6, 2013 through September 24, 2014. The ponds were operated as three sets of triplicates with two sets continuously fed primaryclarified municipal wastewater at either a 2-day or 3-day hydraulic residence time (HRT), and one set fed the clarified effluent of the 3-day pond set. This second pond-in-series was operated with a 3-day HRT.

Areal biomass productivity is reported as gross and net, the former based only on biomass in the pond effluents and the latter subtracting the volatile suspended solids in the influent from those in the effluent. An estimate was also made of autotrophic biomass productivity, as differentiated from heterotrophic growth. 
Over a year, net productivity averaged 83 metric tons per hectare per year (MT/ha-yr) for the 2day HRT ponds, $52 \mathrm{MT} / \mathrm{ha}$-yr for the 3-day HRT ponds, and $44 \mathrm{MT} / \mathrm{ha}$-yr for the 3-day HRT ponds receiving clarified effluent of the first set of 3-day HRT ponds (i.e., recycled water). The lower net productivity of the pond receiving water recycling was attributed to two factors. First, the relatively high influent suspended solids concentrations were subtracted from the effluent suspended solids concentrations before net productivity was calculated. Second, the recycled water contained less soluble organic matter than the primary-clarified wastewater leading to less heterotrophic biomass production. The accumulation of inhibitory allelochemicals is a possible third cause of lower productivity, but no specific information was collected on allelopathy.

Algae were harvested from pond effluent by sedimentation, with harvest efficiency most affected by the extent of natural bioflocculation occurring in the ponds. Some forms of bioflocculation are thought to be mediated by bacteria, which often make-up a substantial fraction of the settled flocs. Pond samples settled in 1-L Imhoff cones averaged $<20 \mathrm{mg} / \mathrm{L}$ total suspended solids after 24 hours of settling; but all ponds fell short of meeting an averaged $<30 \mathrm{mg} / \mathrm{L}$ total suspended solids after a 2 hour interval which would be ideally achieved for wastewater effluent. No relationship was seen between settling performance and the bacterial content of flocs.

Soluble carbonaceous biochemical oxygen demand $\left(\mathrm{scBOD}_{5}\right)$ removal by the raceway ponds was sufficient to meet wastewater treatment requirements year around. Influent $\mathrm{scBOD}_{5}$ concentrations averaged $83 \mathrm{mg} / \mathrm{L}$, and the effluent averaged $5.1 \mathrm{mg} / \mathrm{L}$ and $4.2 \mathrm{mg} / \mathrm{L}$ for the 2-day and 3-day HRT pond sets, respectively.

The variable with the greatest influence on productivity in all pond sets, and settling performance in the recycled water pond set, was season (i.e., co-correlated variables of solar insolation and 
pond temperature). Neither productivity nor settling appeared to be related to prominent algae genera or prevalence of grazers.

The high net productivity achieved with a growth medium of primary clarifier effluent and the generally high settleability of algal-bacterial flocs indicate a good potential for algae wastewater treatment and biofuel production. However, the settling of algae grown on recycled water needs improvement to achieve the full potential of wastewater-grown algae biofuel production. 


\section{ACKNOWLEDGMENTS}

I am sincerely grateful for everyone who has helped me with my research at Cal Poly.

I would like to thank Dr. Tryg Lundquist; you have been an inspiration for me to pursue passions and goals with relentless hard work. You have shown by example that education is best put to use for the advancement of knowledge and society; and your dedication to this field is known by everyone around you. I am sincerely grateful for all of the knowledge you have passed on to me over my time at Cal Poly.

Matt Hutton, thank you for all of your guidance and expertise that has helped me both inside this project and out. You have always been there to help, whether it was through long days of work or late night emails. I have the utmost respect for all that you have done for this project and will continue to do for future projects.

Thank you Dr. Tracy Thatcher and Dr. Greg Schwartz for all of your encouragement and interest in this project. It is an honor to have you as a part of my defense committee. I will always be grateful for your words of wisdom and support with my thesis.

To Shelley Blackwell, Ruth Spierling, Braden Crowe, Ian Woertz, and Neal Adler: I want to thank all of you for the countless hours that each of you has willingly offered a helping hand. You all have been an essential part of this project from the drawing boards, to the field and the lab. Each of you has directly made this project the success that it is.

To Justin Kraetsch and Carter Reiff, I am so grateful for your partnership in this project. We have spent countless hours working on this project together and I am glad that we have all come out on top and remained great friends. We did it! 
To Mike Chang, Christian Bowen, Erik Zardouzian, Tiffany Racz, Dylan Robertson, Katie Johnston, Ryan Stumpp, Yakov Surovov, Hunter Spence, Elai Fresco, Garrett Murawsky, Noelle Patterson and all of the many undergraduate Cal Poly students who have helped with this project, each of you made up the heart and soul of this project. Thank you for all the favors and good times we shared while working on this project. I wish you all the best of luck with your future endeavors.

To the San Luis Obispo Water Reclamation and Recovery Facility, thank you providing the location for this project to be possible and always being so accommodating to the project.

A big thanks goes out to the United States Department of Energy for funding this project and believing in the possibility of algal biofuels. With your backing this project has become a cornerstone for both students and faculty in the Cal Poly Civil and Environmental Engineering Department.

To my family, thank you for having been incredibly supportive of this endeavor. I am forever appreciative for the interest you have shown and help you offered me to accomplish this research. 


\section{TABLE OF CONTENTS}

Page

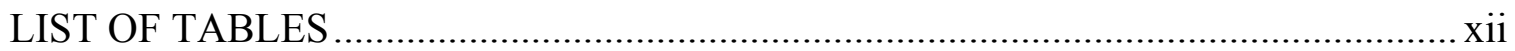

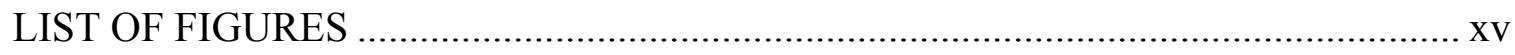

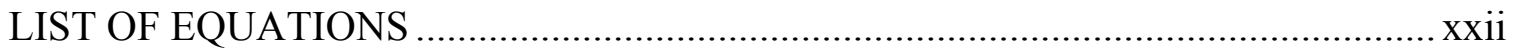

\section{CHAPTER}

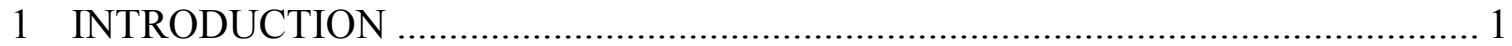

1.1 The Use of Municipal Wastewater as a Source of Resources ............................. 1

1.2 Recycling of Necessary Resources ................................................................ 3

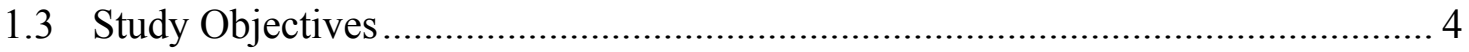

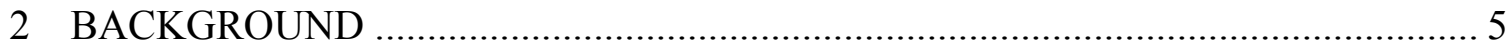

2.1 Input Variables for Microalgae Raceway Ponds ................................................ 5

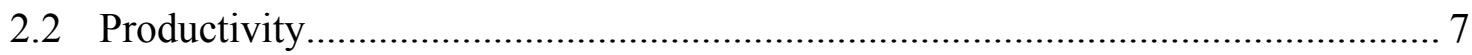

2.3 Carrying Capacity of Biomass in Raceway Ponds ......................................... 8

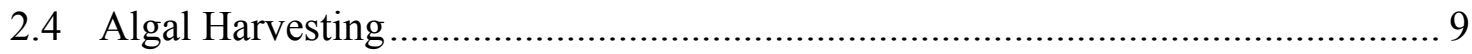

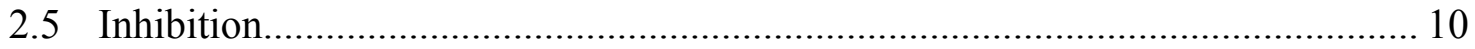

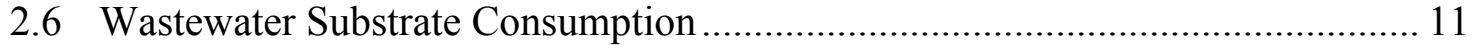

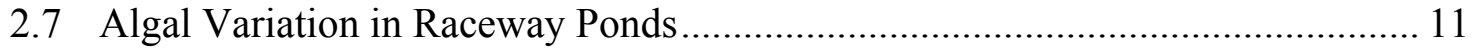

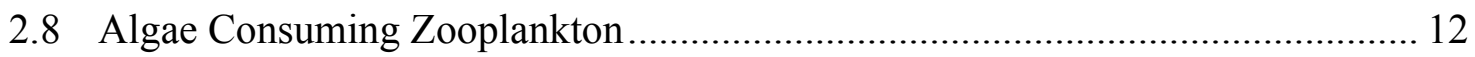

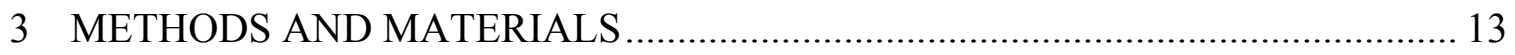

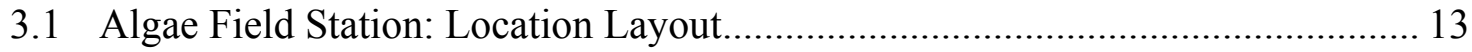

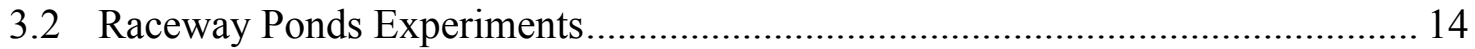

3.2.1 Experimental Concept and Purpose ........................................................... 15

3.2.2 Process Flow of the Algae Field Station .................................................. 17

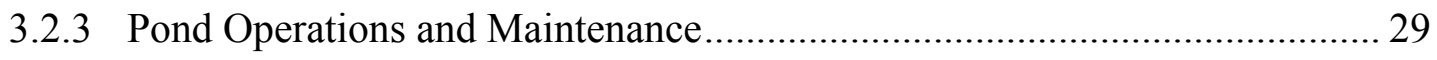

3.2.4 Weekly Pond System Sampling Procedures …......................................... 35

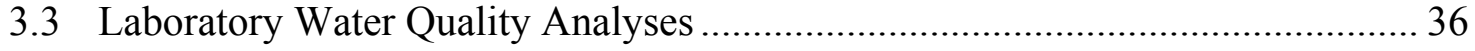

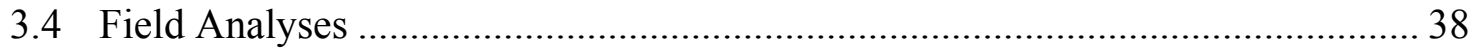

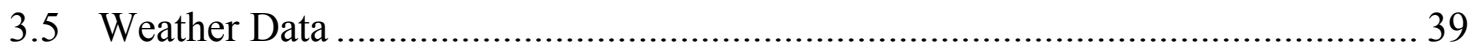




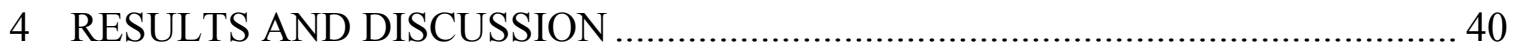

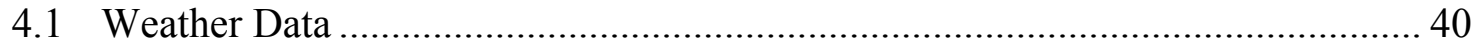

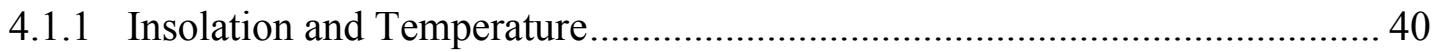

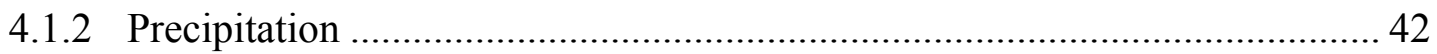

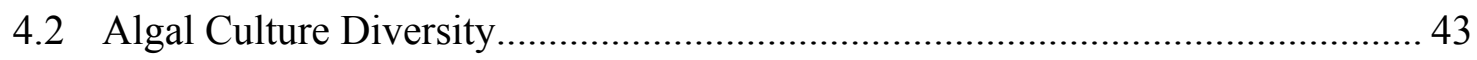

4.3 Diel Characteristics of Influent Wastewater ...................................................... 45

4.4 Biological Oxygen Demand Removal ............................................................ 51

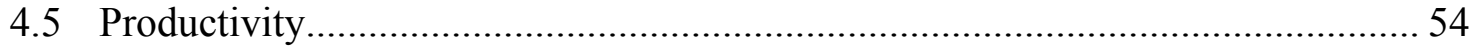

4.5.1 Net Areal Productivity ............................................................................... 55

4.5.2 Correlation of Insolation and Productivity ……………………………......... 57

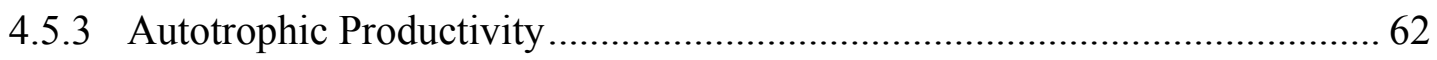

4.5.4 Characteristics of Productivity Peaks and Crashes ........................................ 74

4.5.5 Analysis of Pond Specific Productivity Crash ............................................... 77

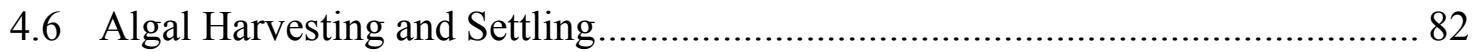

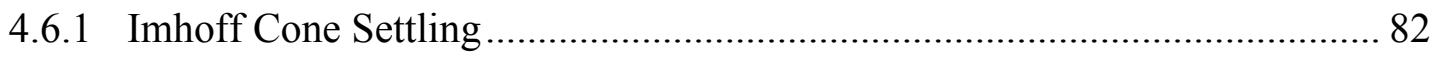

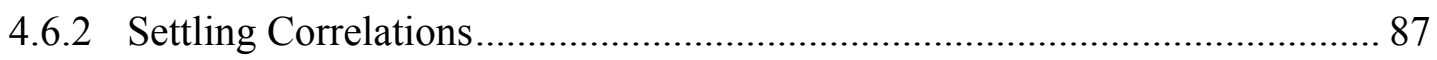

4.6.2.1 Bioflocculation and Settling …………………..................................... 87

4.6.2.2 Bacterial Content and Settling ............................................................... 89

4.6.2.3 Algal Genera and Settling.................................................................. 91

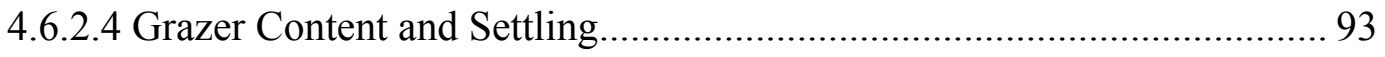

4.6.2.5 Productivity and Settling ...................................................................... 94

4.7 Ostracod Population Crash .................................................................................... 97

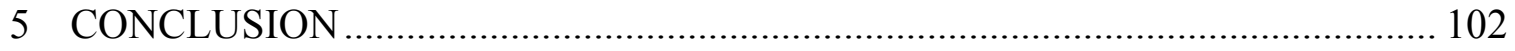

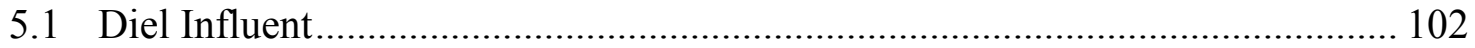

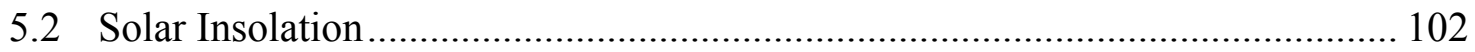

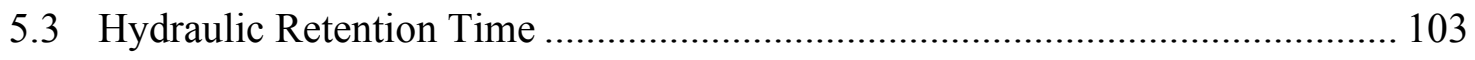

5.4 Effects of Water Recycling on Productivity ………........................................ 104

5.5 Maximum Operational Biomass Concentration .................................................... 105

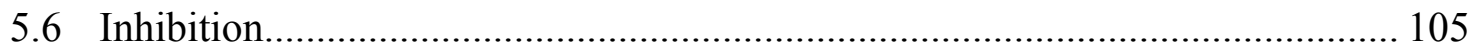

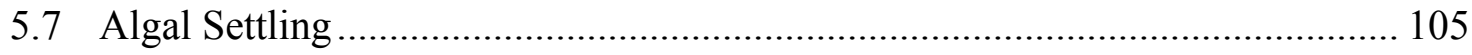

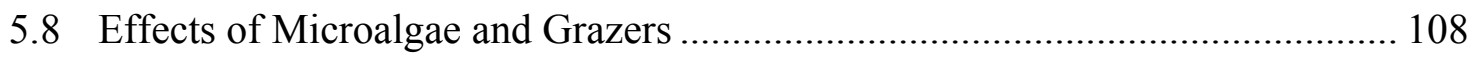

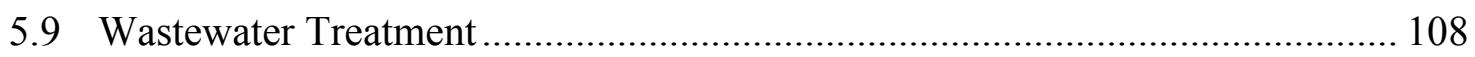




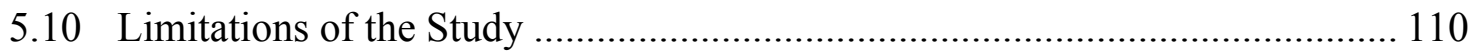

5.11 Recommended Future Research ………………..................................... 110

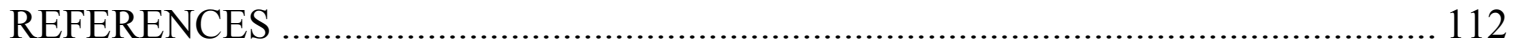
APPENDICES

A.1 Supervisory Control and Data Acquisition System ………………………........ 116

A.2 Complete List of Water Quality Analyses for the Algae Field Station ............. 119

A.3 Compiled Experimental Data........................................................................ 122

A.3.1 Total Suspended Solids (mg/L) ............................................................... 123

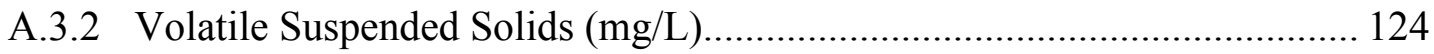

A.3.3 2-Hour Imhoff Cone Total Suspended Solids (mg/L) ................................. 126

A.3.4 24-Hour Imhoff Cone Total Suspended Solids (mg/L) ................................ 127

A.3.5 Biological Oxygen Demand $(\mathrm{mg} / \mathrm{L})$....................................................... 128

A.3.6 Chemical Oxygen Demand $(\mathrm{mg} / \mathrm{L})$......................................................... 128

A.3.7 Dissolved Oxygen (mg/L) ………………………............................. 129

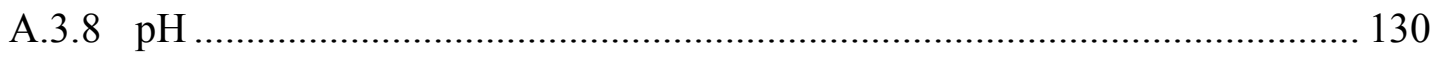

A.3.9 Pond Temperature (Degrees Celsius) ........................................................ 131 


\section{LIST OF TABLES}

Table

Page

Table 3-1: Actual experimental conditions of 9 raceway ponds at the Cal Poly AFS from December 2013 through September 2014.

Table 3-2: The experimental pond conditions for each pond set at the AFS that existed from March 2013 through September 2014.

Table 3-3: The table presents all water quality analysis methods used in this study. All methods were performed according to the publication Standard Methods for the Examination of Water and Wastewater.

Table 3-4: Review of significant method or experimental changes over the course of operation at the AFS from March 2013 to September 2014.

Table 4-1: Prominent algal genera in the experimental raceway ponds, from

December 2013 to October 2014.

Table 4-2: Comparison of TSS concentrations in 24-hr composite and grab samples of primary clarifier effluent at the Cal Poly Algae Field Station.

Table 4-3: Comparison of VSS concentrations in 24-hr composite and grab samples of primary clarifier effluent at the Cal Poly Algae Field Station.

Table 4-4: Comparison of total carbonaceous $\mathrm{BOD}_{5}$ concentrations in 24-hr composite and grab samples of primary clarifier effluent at the Cal Poly Algae Field Station.

Table 4-5: Comparison of soluble carbonaceous $\mathrm{BOD}_{5}$ concentrations in 24-hr composite and grab samples of primary clarifier effluent at the Cal Poly Algae Field Station.

Table 4-6: For the 2-day HRT pond set, autotrophic productivity, net productivity, gross productivity, and heterotrophic biomass concentrations are presented with the variables used for the calculations. The data were collected from the Cal Poly Algae Field Station from March 2013 to August 2014. The mean values and corresponding standard deviations are presented at the bottom of the table.

Table 4-7: For the Round-1, 3-day HRT pond set autotrophic productivity, net productivity, gross productivity, and heterotrophic biomass are presented with the 
required variables for the necessary calculations. The data were collected from the Algae Field Station from March 2013 to August 2014. The mean values and corresponding standard deviations are presented at the bottom of the table.

Table 4-8: For the Round-2, 3-day HRT pond set autotrophic productivity, net productivity, gross productivity, and heterotrophic biomass are presented with the required variables for the necessary calculations. The data were collected from the AFS from March 2013 to August 2014. The mean values and corresponding standard deviations are presented at the bottom of the table.

Table 4-9: Prominent algae genera during dates of high productivity. The increase of productivity over that expected from the insolation model is included, to show that productivity was abnormally high.

Table 4-10: Rotifer and ostracod density during dates of high productivity. The increase of productivity over that expected from the insolation model is included, to show that productivity was abnormally high.

Table 4-11: Prominent algae genera during dates of low productivity. The decrease of productivity below the insolation model is included, to show that productivity was abnormally low.

Table 4-12: Rotifer and ostracod densities during dates of low productivity. The decrease of productivity below the insolation model is included, to show that productivity was abnormally low. For the grazer density values denoted with a dash indicates the test was not performed for the given date.

Table 4-13: Insolation and VSS data are presented for the dates of peak productivity before a crash in productivity Pond 7, during 2014. These data show the maximum levels of VSS achieved before a steep decline in VSS began to occur.

Table 4-14: Insolation and VSS data are presented for the dates one week prior to peak productivity in productivity Pond 7, during 2014. The data show VSS concentrations that were increasing and had not reached their maximum levels of VSS yet.

Table 4-15: Prominent genera of algae are presented for periods of high settling performance.

Table 4-16: Prominent genera of algae are presented for periods of low settling performance. 
Table 4-17: The prevalence of both rotifers and ostracods during periods of high settling performance.

Table 4-18: The prevalence of both rotifers and ostracods during periods of low settling performance

Table 4-19: Pond 6 characteristics before and after the ostracod shell bloom during July 2014. For comparison purposes the average concentrations of DO, BOD, and COD were $6.0 \mathrm{mg} / \mathrm{L}, 3.3 \mathrm{mg} / \mathrm{L}$, and $367 \mathrm{mg} / \mathrm{L}$ respectively in Pond 6 over the course of the study. 100

Table 4-20: Prominent genera of algae are presented for the dates before and after the ostracod shell bloom of July $17^{\text {th }}, 2014$ in Pond 6. 100 


\section{LIST OF FIGURES}

Figure

Page

Figure 2-1: Complete integrated recycling process flow diagram for algal biomass

production on wastewater (Lundquist, Woertz, Quinn \& Benemann, 2010).

Figure 3-1: Areal view of the Cal Poly Algae Field Station. The 9 raceway ponds

featured in this study are arranged on the left of the image and the source of

clarified municipal wastewater was the primary clarifier's effluent water on the right of the image.

Figure 3-2: The nine experimental raceway ponds at the AFS are numbered and divided into triplicate sets.

Figure 3-3: Simplified process flow diagram of the raceway pond sets operated with influent wastewater. At the AFS primary clarifier effluent entered the ponds and displaced effluent pond water at steady state.

Figure 3-4: Simplified water process flow diagram for raceway ponds in series. The featured tube settlers are suspended solids removal devices that are further discussed in 3.2.2 AFS Process Flow. This system at the AFS acts as a continuation of the process in Figure 3-3, and the system is operated at steady state.

Figure 3-5: Overview of the operational conditions in each pond set, from December 2013 through September 2014 at the AFS.

Figure 3-6: The Algae Field Station's source of clarified municipal wastewater was collected from the WRRF's Western primary clarifier, in between the overflow weir and scum baffle (Kraetsch 2015).

Figure 3-7: Influent waterwheel distribution system is shown feeding ponds 7, 8 and 9 at the AFS.

Figure 3-8: The paddle wheels rotated along a shaft for each pond set in the experimental raceway ponds at the AFS.

Figure 3-9: Areal view of a 2-inch ramped effluent standpipe submerged in a raceway pond at the AFS (Chang, 2014). 
Figure 3-10: Areal view of a 4-inch vertical effluent standpipe submerged in a raceway pond at the AFS (Chang, 2014).

Figure 3-11: Layout of standpipe variations where an " $\mathrm{R}$ " represents a two inch ramped effluent standpipe and a "V" Represents a four-inch vertical Effluent Standpipe. This layout was in place from October 16th, 2013 until the end of the study.

Figure 3-12: Closed bottom ramped standpipe with inserted peristaltic pump tubing for collection of effluent water (Kraetsch, 2015)

Figure 3-13: Peristaltic pumps located in the pump house in front of ponds 4, 5, and 6 to move effluent pond water from the Round-1 to the Round-2 pond sets. Each pump had two pump heads that corresponded to a specific pond and an individual tube settler (Chang, 2014).

Figure 3-14: Profile view of a tube settler at the AFS. Effluent water from the Round-1 ponds entered the tube settler through the black tubing on the right of the device and exited through the black tubing located at the top left of the device (Chang, 2014).

Figure 3-15: Front view of three tube settlers at the AFS. The influent water lines are shown entering the front, and effluent sludge is drained from the valves placed at the bottom (Ripley, 2013)

Figure 3-16: The gravity-fed AFS effluent sump had two water removal pumps that carried effluent water to the primary clarifier effluent.

Figure 3-17: Variable frequency drives controlled the rotation speed of the water and paddle wheel motors (Chang, 2014).

Figure 3-18: Variable frequency drive used to operate the rotational speed of the waterwheel in the 2-day HRT pond set.

Figure 3-19: Neptune SCADA probes for DO, temperature, and $\mathrm{pH}$ were submerged at the edge of each raceway pond (Chang, 2014).

Figure 3-20: Carbon dioxide was sparged into raceways ponds through a black perforated tubing, attached to a PCV stand, that spanned the width of the channel $90 \mathrm{~cm}$ downstream of the paddle wheel. It was located on the surface of the pond floor and secured by a weighted PVC pipe. For the image shown the set up was removed from the pond (Kraetsch, 2015) 
Figure 3-21: The 50-1b $\mathrm{CO}_{2}$ tanks were secured in a housing unit at the AFS. One tank was used at time to release carbon dioxide into a specific pond with $\mathrm{pH}$ levels above the set limit (Chang, 2014).

Figure 3-22: Accumulated solids were being drained from the bottom of the tube settlers. The left image illustrates the thick effluent sludge, and the right image illustrates clear water coming through the underdrain after the sludge was removed (Chang, 2014).

Figure 3-23: The view from the top of tube settler reveals the submerged effluent drain and the perforated backpressure plate in place. In this image, water was drained from the tube settler, while under normal operating conditions the backpressure plated is submerged in water (Chang, 2014).

Figure 4-1: Insolation and pond water temperature recorded by CIMIS and SCADA instruments, respectively, for the Cal Poly Algae Field Station during 2014.

Figure 4-2: Insolation and air temperature for the Cal Poly Algae Field Station during 2013-2014.

Figure 4-3: Total weekly precipitation for the Cal Poly Algae Field Station during 2014.

Figure 4-4: Stigioclonium at 100 times zoom in Pond 7 on June 19, 2014.

Figure 4-5: Correlation of TSS concentrations in 7 am grab and 24-hour composite samples of clarified municipal wastewater from July 2014 to December 2014.

Figure 4-6: Correlation of VSS concentrations in 7 am grab and 24-hour composite samples of clarified municipal wastewater from July 2014 to December 2014.

Figure 4-7: Correlation of total carbonaceous biochemical oxygen demand concentrations in 7 am grab and 24-hour composite samples of clarified municipal wastewater from July 2014 to December 2014.

Figure 4-8: Correlation of soluble carbonaceous biochemical oxygen demand concentrations in 7 am grab and 24-hour composite samples of clarified municipal wastewater from July 2014 to December 2014.

Figure 4-9: Soluble carbonaceous $\mathrm{BOD}_{5}$ concentrations for continuously operated raceway ponds at the Cal Poly Algae Field Station, from August 8, 2013 to 
August 14, 2014, for given HRTs. The error bars represent the standard deviation of BOD removal for each pond set over the course of the experiment. The Round2, 3-day HRT pond set is shown as 6-day HRT.

Figure 4-10: Average removal of soluble carbonaceous biochemical oxygen demand for a given hydraulic residence time. The initial influent concentration had a standard deviation of $19 \mathrm{mg} / \mathrm{L}$. The data were average from August 8, 2013 to August 14, 2014 using all dates that passed analytical quality control criteria.

Figure 4-11: Average net productivity for each of the pond set operating conditions, from June 26, 2013 to September 24, 2014. The error bars represent the standard deviation averaged from week of the triplicate ponds in each pond set, shown in both the positive and negative direction.

Figure 4-12: Productivity and insolation for the 2-day HRT pond set from March 2013 to October 2014.

Figure 4-13: Productivity and insolation for the Round-1, 3-day HRT pond set from March 2013 to October 2014.

Figure 4-14: Productivity and insolation for the Round-2, 3-day HRT pond set from March 2013 to October 2014.

Figure 4-15: Correlation of insolation and net productivity for the 2-day HRT pond set, from March 6, 2014 to October 16, 2014.

Figure 4-16: Correlation of insolation and net productivity for the 3-day HRT pond set, from March 6, 2014 to September 24, 2014.

Figure 4-17: Correlation of insolation and net productivity for the Round-2, 3-day HRT pond set, from March 6, 2014 to September 24, 2014.

Figure 4-18: A micrograph of Pond 7 on May 29, 2014. This micrograph illustrates the diversity of autotrophic biomass, represented by filamentous and circular microalgae, and the heterotrophic biomass, represented by the dense bacteria on the right of the photo. The scale on the bottom left of the micrograph represents 200 microns.

Figure 4-19: Autotrophic, net, and gross productivity for the 2-day HRT pond set from March 2013 to August 2014. The data are also presented in Table 4-7. 68

Figure 4-20: Graph of autotrophic, net, and gross productivity for the Round-1, 3day HRT pond set from March 2013 to August 2014. The featured the data are presented in Table 4-8. 
Figure 4-21: Graph of autotrophic, net, and gross productivity for the Round 2, 3day HRT pond set from March 2013 to August 2014. The featured the data are presented in Table 4-7. It should be noted that the data point on March 20, 2013, represents the pond set operated as a Round-2, 4-day HRT.

Figure 4-22: The average composition of gross productivity. The Round-2 influent portion were VSS carried into the Round-2 pond from the Round-1 effluent settling tanks. The data were averaged from March 2013 to August 2014, and can be reviewed in Tables 4-7, 4-8 and 4-9. For the purposes of comparing pond sets, data were only used, to determine the shown average values, from dates that all pond sets had data for.

Figure 4-23: VSS productivity in Pond 7 compared to insolation data from March 12, 2014 to October 15, 2014

Figure 4-24: Images of weekly samples of pond water from Pond 7 in a glass beaker, placed on a light table. The images are listed in chronological order from March 12, 2014 to October 15, 2014. The dates with the lowest productivity and also corresponding VSS concentrations for the three crashes in pond 7 appeared on $4 / 17 / 2014,7 / 22 / 2015$, and $9 / 18 / 2014$. 80

Figure 4-25: Scatter plot of insolation and VSS concentration for the dates one week prior to a peak in productivity and dates of peak productivity with linear correlation lines. Theoretically ideal operation for biomass production is located somewhere above the lower correlation line and below top correlation line.

Figure 4-26: Percent TSS removal from 2-hour Imhoff cone settling from March 2013 to September 2014. Insolation data are included for the same time period.

Figure 4-27: Percent TSS removal over 24-hour of settling in Imhoff cones, from March 2013 to September 2014. Insolation data are included for the same time period. 85

Figure 4-28: Average Imhoff cone percent TSS removal for 2-hour and 24-hour settling. The presented data were averaged from December 4, 2013 to September 18,2014 . The error bars represent the standard deviation of the triplicate ponds in each pond set, averaged across each week of presented data.

Figure 4-29: Average residual TSS after 2- and 24-hour Imhoff cone settling. The presented data were averaged for December 4, 2013 to September 18, 2014. The error bars represent the standard deviation of the triplicate ponds in each pond set, averaged across each week of presented data. 
Figure 4-30: Pond water in glass beakers placed on a light table, from Ponds 1, 2 and 3 on May 29, 2014. The colloidal cultures and green supernatant show conditions of poor settling. On this day, the lab analysis for 2-hour settling had a percent removal of $69 \%$ and a residual TSS concentration of $73 \mathrm{mg} / \mathrm{L}$ for the pond set average.

Figure 4-31: Pond water in glass beakers placed on a light table, from Ponds 7, 8 and 9 on May 29, 2014. The clear supernatant and dense flocculated cultures show conditions of high settleability. On this day, the lab analysis for 2-hour settling had a percent removal of $94 \%$ and a residual TSS concentration of 19 $\mathrm{mg} / \mathrm{L}$ for the pond set average. Pond 7 had the best settling with a percent removal of $97 \%$.

Figure 4-32: The correlation of TSS percent removal over a 2-hour settling period and BOD removal. The data are from all pond sets during March 2013 to August 2014. The vertical cluster of data points showing roughly $0 \mathrm{mg} / \mathrm{L}$ of $\mathrm{BOD}_{5}$ removal is from the Round-2 pond set, where influent BOD concentrations were low.

Figure 4-33: The graph presents the correlation of residual TSS over 2-hour settling period and BOD removal. The featured data are from all pond sets and from March 2013 to August 2014. The vertical cluster of data points showing roughly $0 \mathrm{mg} / \mathrm{L}$ of $\mathrm{BOD}_{5}$ removal is comprised of data from the Round-2 pond set, where influent BOD concentrations were low.

Figure 4-34: The overlay of 2-hour settling performance and productivity for the 2-day HRT pond set from March 2013 to October 2014.

Figure 4-35: Overlay of 2-hour settling performance and productivity for the Round-1, 3-day HRT pond set from March 2013 to October 2014. 96

Figure 4-36: The overlay of settling performance and productivity for the Round2, 3-day HRT pond set from March 2013 to October 2014.

Figure 4-37: Pond 6 surface water with suspended ostracod exoskeletons on July 18,2014 . 98

Figure 4-38: Ostracod exoskeleton from Pond 6 on July 17, 2014 at 100-fold magnification. 98

Figure 4-39: Beaker photos of pond 6 during the time period before and after the bloom of ostracod exoskeletons, from left to right: July 3, July 10, July 17, and July 22. All photos were from the year 2014 ... 99 
Figure 5-1: One year of net areal productivity. The presented data are averaged from September 25, 2013 to September 25, 2013. The error bars represent the standard deviation of the time series pond average where $n=3$ for the triplicate ponds.

Figure 5-2: Averaged net areal autotrophic productivity represented in terms of conventional yield of metric tons per hectare per year, from March 2013 to August 2014. These results stem from dates when BOD quality control samples passed and thus represent a scattering of dates over a year rather than weekly sampling.

Figure 5-3: Comparison of 2-hour Imhoff cone percent TSS removal and insolation for the Round-2, 3-day HRT pond set from March 2013 to September 2014.

Figure 5-4: Comparison of 2-hour Imhoff cone percent TSS removal and insolation for the 2-day HRT and Round-1, 3-day HRT pond sets from March 2013 to September 2014.

Figure 5-5: Residual TSS concentrations after 24-hour imhoff cone settling, from December 2013 to September 2014. The error bars represent the average standard deviation of the triplicate ponds in each pond set. 


\section{LIST OF EQUATIONS}

$\begin{array}{lll}\text { Equation } & \text { Page }\end{array}$

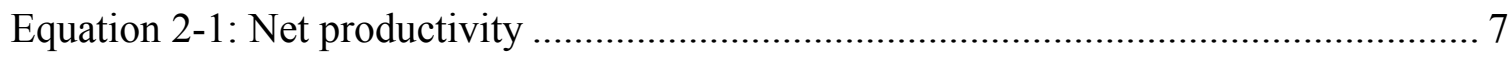

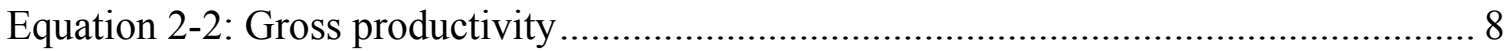

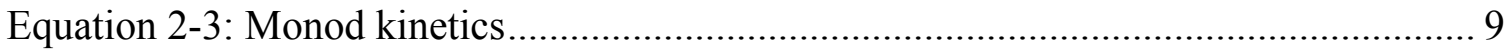

Equation 4-1: Soluble carbonaceous $\mathrm{BOD}_{5}$ removal................................................. 53

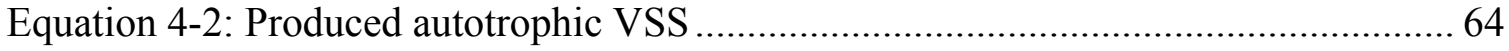

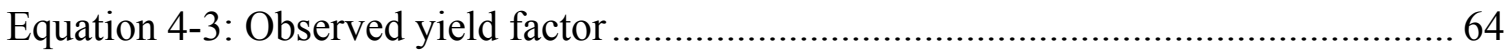

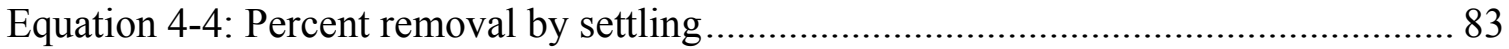




\section{INTRODUCTION}

The world demand for energy has increased by more than $50 \%$ in the last 15 years and is expected to increase another 56\% from 2010 to 2040 (EIA, 2015). Climate change and fossil fuel depletion have increased the need for improved conservation, efficiency and cleaner and renewable sources of energy.

Petroleum-based fuels, such as gasoline and diesel, are difficult to replace due to the vast existing infrastructure supporting their production and use, but ethanol and biodiesel are successful liquid biofuels which are essentially fungible with the petroleum fuels. One promising biofuel feedstock is microalgae biomass which can be converted to biodiesel or biocrude oil. According to the United States Department of Energy, microalgae can potentially

produce up to 60 times more oil per acre than land based plants, potentially giving algae biofuels a big advantage over other types of biodiesel and ethanol (DOE, 2015). However, the projected cost of algae biofuel is currently far above petroleum fuels, and lowering this cost has been a topic of intense research in recent years.

\subsection{The Use of Municipal Wastewater as a Source of Resources}

Photoautotrophic microalgae rely on sources of water, nutrients, light, and carbon dioxide for growth. With sunlight available, the key resources needed to produce large quantities of algae are carbon dioxide, water and nutrients. At the scale of production needed to make a noticeable contribution to the US liquid fuel supply, the amount of these required resources will be tremendous (Venteris, 2014). 
By utilizing municipal wastewater as a water source, an abundant source of nutrients is provided. Wastewater stabilization ponds are a common wastewater treatment technology that benefits from harboring microalgae, which grow on waste nutrients and produce dissolved oxygen beneficial to the treatment process. The high rate algal raceway type of pond used for commercial algae production is also well suited to treat wastewater using algae. High rate algal ponds (HRAPs) can provide secondary wastewater treatment and algal biomass production through a system that combines oxidation ponds and algal reactors into a single process (Araki, et al., 2001). If wastewater is treated during production of algae biofuel feedstock, revenue might be derived from the wastewater treatment function (Lundquist et al., 2010). Thus, combining algae biofuel production and wastewater treatment might be a benefit to both processes.

For efficient algal growth in large scale systems, nutrients can be provided as an addition to source waters. While municipal wastewater typically contains most of the required nutrients, additions of carbon, nitrogen, phosphorus, iron and other trace metals can be added to increase growth potential on unit volumes of water. Microalgae are typically composed of approximately $50 \%$ to $55 \%$ carbon (Biller, et al., 2010), and even though wastewater is often rich with organic carbon, an oxidized form of carbon is needed for algal uptake. In most circumstances sufficient nutrient concentrations of nitrogen, phosphorus and other trace metals are contained within the wastewater therefore eliminate the need for nutrient supplementations. However in certain wastewater sources, phosphorus and some traces metals can potentially be the limiting substrate for algal growth depending on the amount of algae produced on a specific volume of water. 


\subsection{Recycling of Necessary Resources}

Even with the advantages presented by utilizing wastewater for microalgae production, further steps can be taken to increase biofuel production. For example, additional carbon can be supplemented through means of combustion gas or industrial flue gas (Lundquist et al., 2010) in addition to obtaining carbon dioxide from the atmosphere. By sequestering the carbon dioxide emissions from onsite generators and boilers, or other offsite factories and power plants, the oxidized carbon can be again made into a reduced carbon fuel source by means of biofuel production.

Cultivating microalgae for biofuel requires a large amount of water. To produce one liter gasoline equivalent of algal biofuels, without recycling water up to 3,650 liters of water are required due to evaporation and processing losses (NAS, 2012). Even with the use of wastewater as the fresh water source, acquiring the needed amount of water for effective production is challenging. Furthermore, a full-scale production facility would need to be placed outside of major urban areas due to the large cultivation area requirements. This could potentially decrease the supply of available wastewater and increase hydraulic transportation costs. However, if water used for algal production can be removed of produced biomass, it can be recycled for repeated use within a raceway pond. This would allow the supply of available water to greatly increase. Using this method of recycling wastewater, the demand for the water to produce algal biofuels can be met realistically and feasibly.

Similarly to the use of water, large quantities of nutrients are needed for the full-scale production of algal biofuels. To produce the equivalent of 5\% of the demand for transportation fuels in the 
US, $44 \%$ to $107 \%$ of current nitrogen use and $20 \%$ to $51 \%$ of current phosphorus use, in the US, would be required (NAS, 2012). Aside from using wastewater for a source of nutrients, nutrient availability can be greatly increased from recycling nutrients previously used to grow microalgae. One way to accomplish nutrient recycling is anaerobic digestion of the harvested algal biomass, after the oils used to produce biodiesel have been extracted. By anaerobically digesting microalgae, nutrients in the biomass are resolublized and can be used for algal biofuel production. By digesting spent biomass, not only are nutrients conserved and recycled, but also methane is produced, which can be used as another fuel.

\subsection{Study Objectives}

This biofuel feedstock production study examined questions regarding the process of using wastewater and recycled wastewater media in raceway ponds for the purposes of microalgae production and wastewater treatment. The main analyses of the study focus on three specific aspects:

(1) Determine characteristics that lead to changes in algal biomass yields to increase biofuel production and evaluate the productivity of wastewater media to recycled wastewater media.

(2) Determine characteristics that lead to changes in biological algal biomass settling, to reduce dewatering expenses associated algal harvests.

(3) Evaluate the extent of wastewater treatment in regards to effluent oxygen demand and suspend solids in raceway ponds receiving recycled and non-recycled wastewater media. 


\section{BACKGROUND}

This study seeks maximize the use of resources input into raceway ponds and increase the output of harvested microalgae. However many potential parameters can affect the output productivity of microalgae and its ability to be harvested. Therefore understanding the specific parameters researched in this study are crucial for algal production in raceway ponds.

\subsection{Input Variables for Microalgae Raceway Ponds}

The operator controlled input parameter that was an independent variable in this study was the hydraulic retention time. Hydraulic retention time, also known as HRT, is the average length of time that water remains in the raceway ponds. By allowing for longer HRTs, more time is provided for growth on a specific volume of water. However growth rates may decrease over time as substrate is consumed by other competing algae (Boggess, 2011).

Non-operator controlled input parameters in this study included influent water quality and weather. Influent water quality Municipal wastewater provides a reliable source of fresh water and nutrients, however concentrations of wastewater constituents can vary over the course of a day and seasonally over the course of a year (Metcalf, 2003). This alters influent nutrient concentrations which can have an effect on algal productivity.

Like all plants, microalgae require a location where they can receive insolation to perform photosynthesis. It has been shown in previous studies that high levels of insolation provided by solar insolation from weather are needed for effective algal biomass production (Chang, 2014). 
However, an analysis of areas with high solar insolation in the United States (NREL, 2008), show that non-saline sources of water are limited in these regions (Venteris, et al., 2013).

In addition, due to the large area of land required to treat wastewater through the use of raceway ponds, many locations with high population densities are too crowded for such an operation. This causes an issue because locations with high populations can contribute a significant amount of wastewater for algal production. However if rural locations with the necessary space can effectively utilize their resources, there is greater potential for a future in algal biofuels.

The same approach of recycling water can be applied to nutrients as well. Soluble nutrients, such as nitrogen and phosphorus, are essential for growth of microalgae. During the initial production of microalgae in wastewater, much of the soluble nutrients are assimilated during algal growth and reside as organic constituents within the algal cells. To produce the highest quantity of algal biofuels, after lipid extraction is completed for biodiesel production, residual biomass can be anaerobically digested. Through anaerobic digestion organic cells are broken down to resolublize nutrients, producing large quantities of methane gas in the process (Fresco, 2015). In a system with complete integrated recycling (Figure 2-1), this produced digestate can be reintroduced as a nutrient source to nutrient depleted water (Lundquist et al., 2010). 


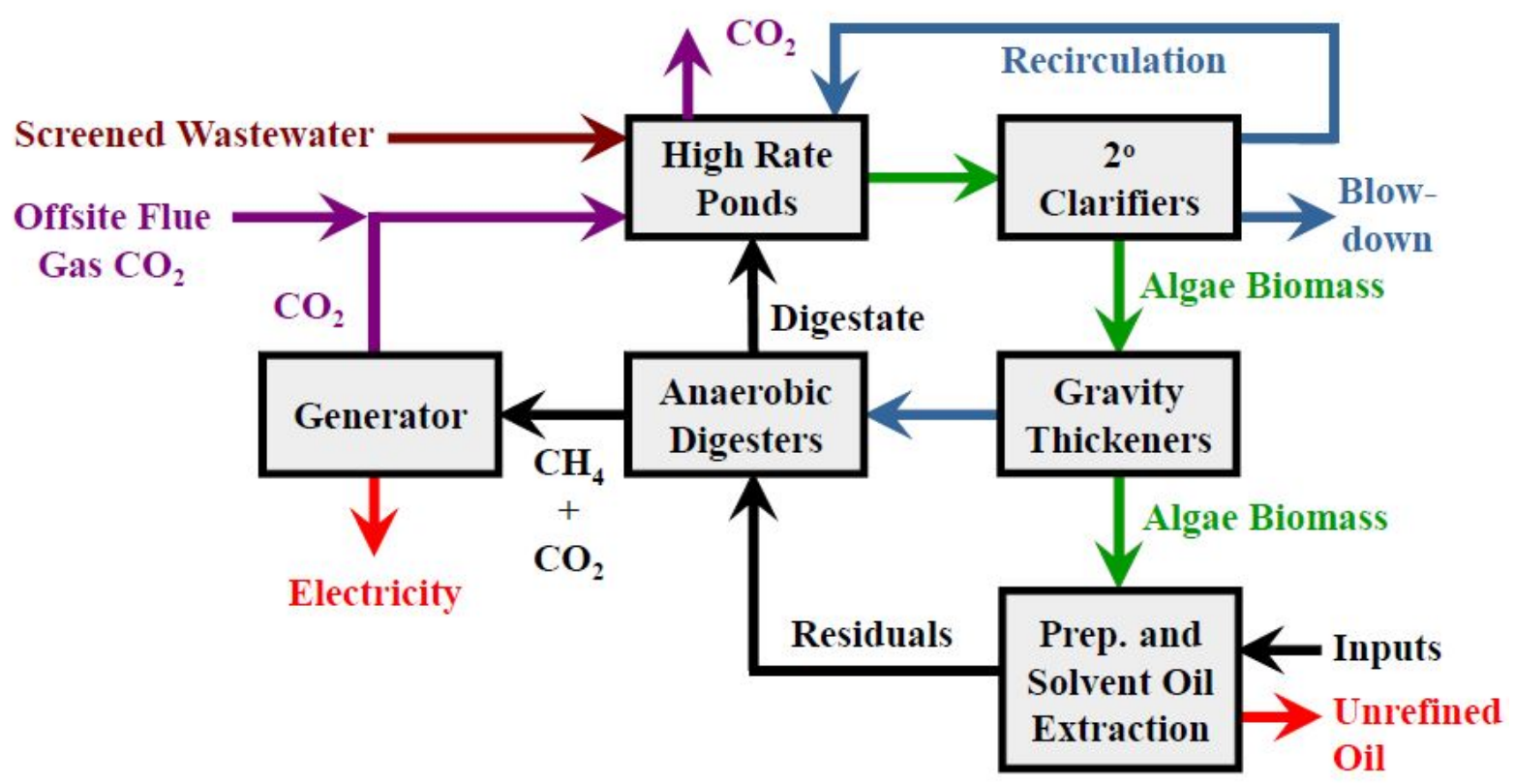

Figure 2-1: Complete integrated recycling process flow diagram for algal biomass production on wastewater (Lundquist, Woertz, Quinn \& Benemann, 2010).

\subsection{Productivity}

To measure the rate of biomass growth within a raceway pond, the term net productivity is used.

This term represents the biomass production over a given area and time. Net productivity is calculated with Equation 2-1.

Equation 2-1: Net productivity

$$
\text { Net Productivity }=\frac{\left(\left(V S S_{\text {Pond }}-V S S_{\text {Inf }}\right) *\right. \text { Water Depth }}{H R T}
$$

Where the variables have the following units:

Net Productivity: $\frac{g V s S}{m^{2} * d a y}$

VSS (Volatile Suspended Solids): mg/L

Water Depth: meters 
HRT (Hydraulic Retention Time): days

A broader term, known as gross productivity, can also be used, which does not account for initial biomass entering in the ponds. This can be used to demonstrate the overall biomass over a given area and set amount of time and can be calculated using Equation 2-2, with the same variables used in Equation 2-1.

Equation 2-2: Gross productivity

$$
\text { Gross Productivity }=\frac{\left(V S S_{\text {Pond }}\right) * \text { Depth }}{H R T}
$$

Production of biomass within raceway ponds is one of the major focuses of this study. The rate at which biomass can be produced can be compared to numerous other variables and the circumstances under which higher productivity is achieved can be discovered.

\subsection{Carrying Capacity of Biomass in Raceway Ponds}

It has been shown in laboratory tests that microalgae can reach growth limitations based on the conditions of its environment (Boggess, 2014). When producing microalgae for biofuel production, the highest growth rates that can be supported within a raceway pond are desired. However, if a biomass concentration exceeds the carrying capacity of a raceway pond, significant loss of algal production would occur. This circumstance can be explained in terms of Monod kinetics using Equation 2-3, where an unknown substrate is limiting the algal growth potential. 
Equation 2-3: Monod Kinetics

$$
\mu=\mu_{\max } \frac{S}{K_{s}+S}
$$

Where the variables are defined as follows:

Specific Growth Rate: $\mu$

Maximum Specific Growth Rate: $\mu_{\max }$

Substrate: S

Half-velocity Constant: $\mathrm{K}_{\mathrm{s}}$

This study looks to determine the effect of rapid declines in productivity in a pilot scale system; which may be attributed to biomass exceeding the carrying capacity of the raceway ponds.

\subsection{Algal Harvesting}

Currently one of biggest obstacles of algal biofuel production is the lack of a cost effective method of algal harvesting. After microalgae cells have been grown in a raceway pond, the microalgae must be separated from the water for harvest. Traditionally in wastewater treatment plants, produced biomass is settled out of water through gravity-operated clarifiers. However one of the key factors required for effective settling of biomass is flocculation (Frost, 2008). Microalgae produced in wastewater raceway ponds can range from large flocculated clusters of algal cells to colloidal cells, causing enhanced and poor settling, respectively. If effective settling can be achieved for harvesting of algal biomass from raceway ponds, their potential as a source of biofuels is greatly increased. High settling ability of algal biomass creates a low cost method of collection and reduces construction and operational costs in collection systems. 
Furthermore regulations on effluent suspended solids are put in place on wastewater treatment facilities. A general limit of effluent TSS is $30 \mathrm{mg} / \mathrm{L}$ (EPA, 2013). Therefore if the produced microalgae can be easily settled it would be beneficial for wastewater treatment and biofuel production.

If sufficient settling is not met, mechanical or chemical separation can be utilized, but with added cost. A dewatering device such a centrifuges, belt press, screw press or other methods are common in the treatment of wastewater to separate residual suspended solids from water (Metcalf, 2003). A polymer can also be used to increase flocculation if bioflocculation is not sufficient. Polymers are added in wastewater plants that use raceway ponds for treatment and can effectively reduce suspended solids concentrations below regulatory requirements (Surovov, 2015). However these methods of removing biomass come at an additional cost and, therefore, conditions that lead to natural bioflocculation are preferable and are discussed in this study.

\subsection{Inhibition}

There are potential concerns of reusing water that was previously used for algal production. For example, various species of microalgae are able to excrete compounds inhibiting the growth of competing organisms through a process called allelopathy (Graneli, 2010). The excreted growth inhibiting compounds, known as allelochemicals, could remain in the raceway pond water after biomass has been harvested. This causes concern for the future productivity of algal growth on recycled raceway pond water. If algal biomass productivity is significantly reduced on recycled water, it could prove that recycling water is not an effective method for biofuel production. 


\subsection{Wastewater Substrate Consumption}

In wastewater treatment, restrictions are placed on effluent water biological oxygen demand, BOD, concentration. BOD arises largely from organic carbon sources and a general limit of 30 $\mathrm{mg} / \mathrm{L}$ of $\mathrm{BOD}_{5}$ is placed on wastewater facilities (EPA, 2013). Soluble BOD is commonly removed from wastewater by the growth of heterotrophic organisms, such as bacteria, which consume organic carbon as substrate for growth (Metcalf, 2003). Heterotrophic consumption of organic carbon can occur in raceway ponds to reduce BOD concentrations. This study looks to determine the effectiveness of BOD removal in raceway ponds designed for algal biofuel production.

\subsection{Algal Variation in Raceway Ponds}

With over a 100,000 species of algae, many of them have characteristics that could potentially aid in the production of biofuels. It is known that some species have unique features that lead to high growth rates and some have a high lipid content ideal for biofuel extraction. However, while some species have enhanced characteristics, polycultures have been proven to be far more stable than monocultures (Hamilton and Rossmeissl, 2014). By selecting for some algal species by controlling the input parameters, the settling performance, for example, could be altered even with in polycultures. This has been shown by certain characteristics of filamentous microalgae having the ability to promote easier harvesting through screening processes (Christenson, 2011), which could also influence higher harvesting capabilities with in polycultures. The effect of various species can be hard to determine for polyculture systems, but trends in cultures over long periods could provide evidence for correlations with settling and productivity. 


\subsection{Algae Consuming Zooplankton}

The presence zooplankton, also known as grazers, feeding on microalgae can potentially have a wide range of effects on raceway pond productivities and settling abilities. One study suggests that high amplitudes for predator-prey oscillations lead to crashes of algal cultures (Owen-Smith, 2008). Another study showed that one particular grazer specie, Daphnia, would excrete 90 percent of algal cells still intact (Porter, 1976), which would likely cause little effect on productivity, but would potentially destroy bioflocculation. The effect that various grazer species have on productivity and settling is largely undetermined from the background research in this study. 


\section{METHODS AND MATERIALS}

In this chapter the experimental approach to the project is outlined. Relevant details of the experimental set up and purpose are discussed, as well as methods of determining data from laboratory analyses.

\subsection{Algae Field Station: Location Layout}

The experimental research of this project was based upon 9 pilot scale high rate algal ponds located at Cal Poly's Algae Field Station (AFS). This site is located at the Water Resource Recovery Facility (WRRF) at 35 Prado Road, San Luis Obispo. The site consists of 15 operational raceway ponds, approximately 25 meters away from the WRRF's Western primary clarifier (Figure 3-1). The positioning of this site enables the AFS to receive a constant supply of fresh clarified municipal wastewater. The research of this thesis is focused on the 9 larger raceway ponds. These ponds were constructed in 2011 and divided into triplicates sets. Each pond holds a designed volume of 10,000 liters and has a surface area of 33 square meters.

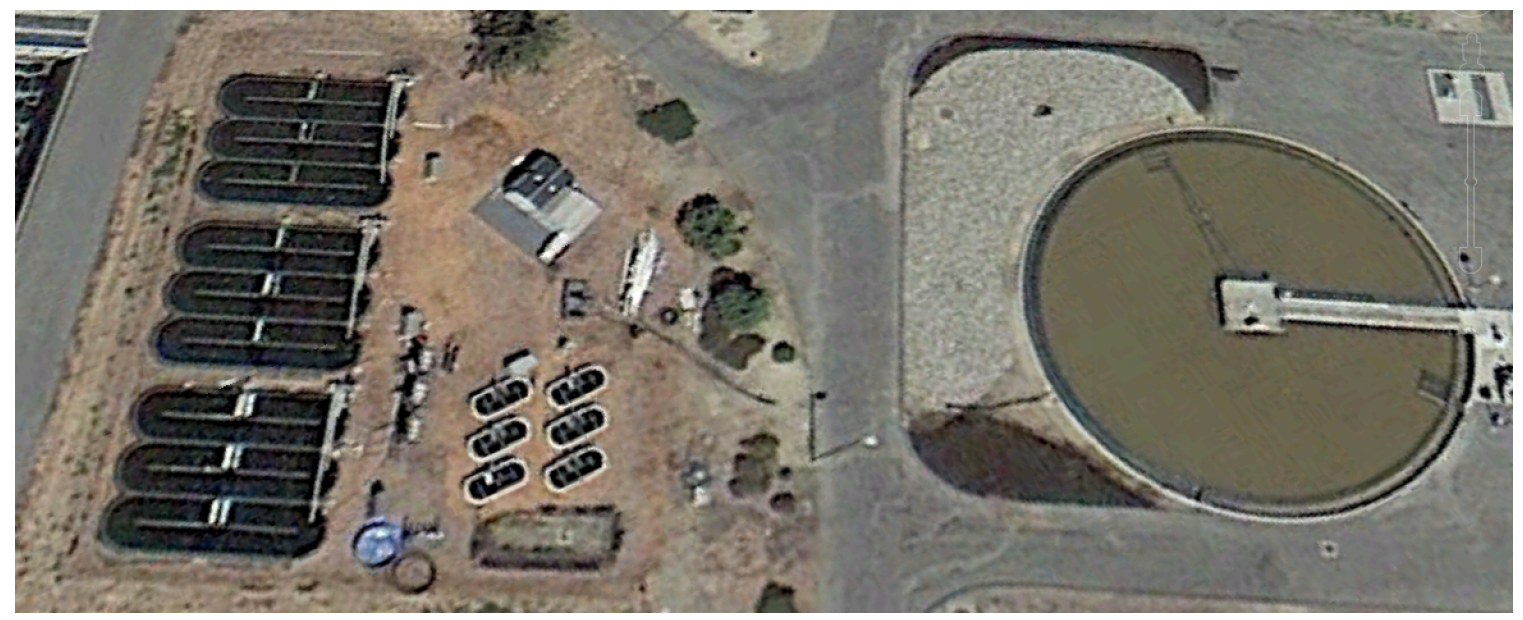

Figure 3-1: Areal view of the Cal Poly Algae Field Station. The 9 raceway ponds featured in this study are arranged on the left of the image and the source of clarified municipal wastewater was the primary clarifier's effluent water on the right of the image. 
The 9 larger raceway ponds are referred to by their number in this study, ranging from numbers 1 to 9 (Figure 3-2), with pond 1 located at the bottom left and pond 9 located at the top left of Figure 3-1.
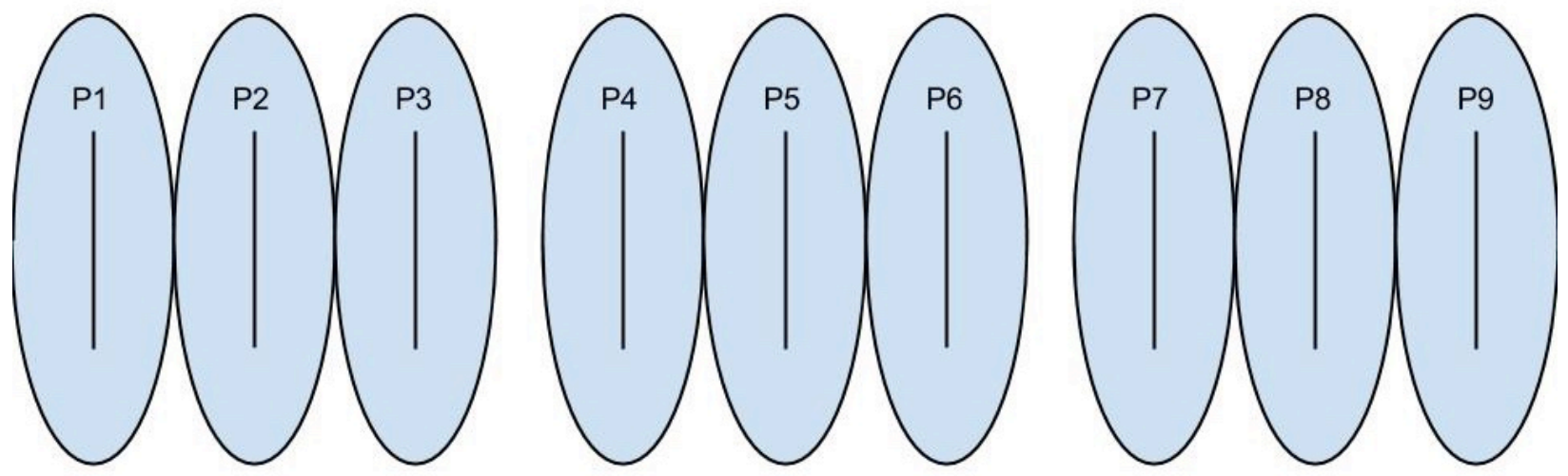

Figure 3-2: The nine experimental raceway ponds at the AFS are numbered and divided into triplicate sets.

\subsection{Raceway Ponds Experiments}

The research goals of the experiment in this study were designed to specifically address pond biomass production, algal settling and oxygen demand removal. In conjunction with these goals, data was collected for one experiment operated on the pilot-scale raceway ponds from March 2013 through September 2014. The data collected specifically for this thesis ranges from December 2013 to December 2014; however, the primary focus of this study covers the experiment ending in September 2014. During this time, from March 2013 through September 2014, two pond sets were operated at steady state and fed primary effluent wastewater, with one triplicate pond set operating on a 2-day hydraulic retention time (HRT) and another pond set operating on a 3-day HRT. The third and final pond set operated on a steady state 3-day HRT which was fed recycled clarified pond water from the previous 3-day HRT pond set (excluding the 4-day operating HRT time period from March to June 2013). 


\subsubsection{Experimental Concept and Purpose}

The pilot scale raceway ponds were operated to determine the conditions for optimal biofuel production and wastewater treatment. To achieve this goal, ponds 4, 5, 6 and ponds 7, 8, 9 were operated on a 3-day HRT and a 2-day HRT respectively, with clarified municipal wastewater for influent water (Figure 3-3).

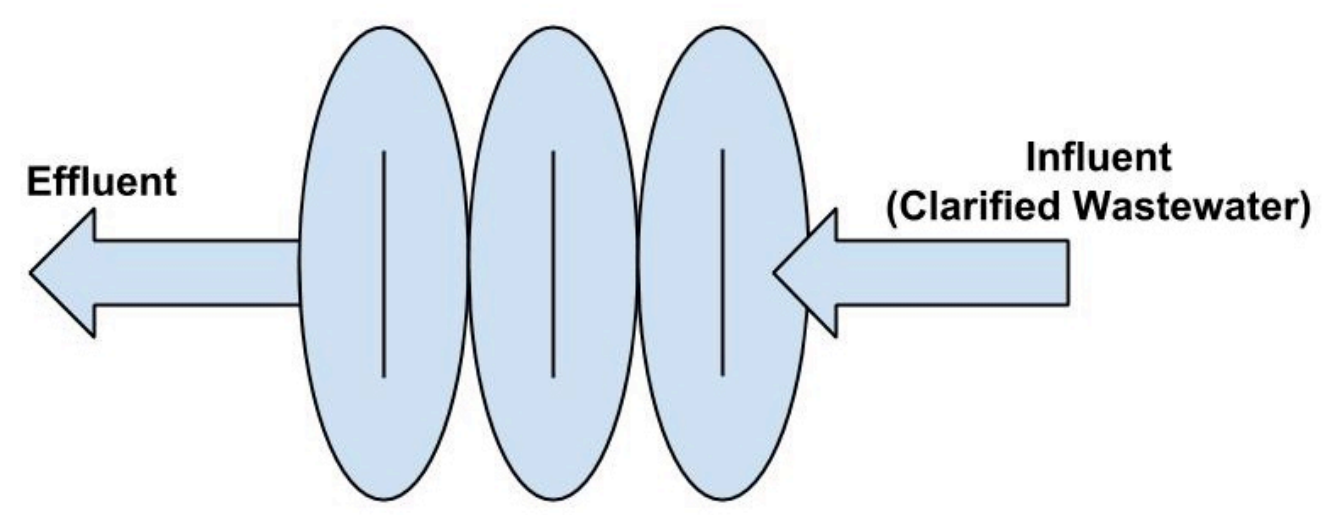

Figure 3-3: Simplified process flow diagram of the raceway pond sets operated with influent wastewater. At the AFS primary clarifier effluent entered the ponds and displaced effluent pond water at steady state.

To test the effects of recycling water that was previously used in a raceway pond for algal production, two pond sets were used in series. Ideally this would give increased biofuel production and wastewater treatment on a set volume of water. Operating the ponds in series required the recycling of water from an initial pond set, referred to as the Round-1 pond set (ponds 4, 5, and 6), into a second pond set, referred to as the Round-2 pond set (ponds 1, 2, and 3) (Figure 3-4). 
Round-2

Round-1

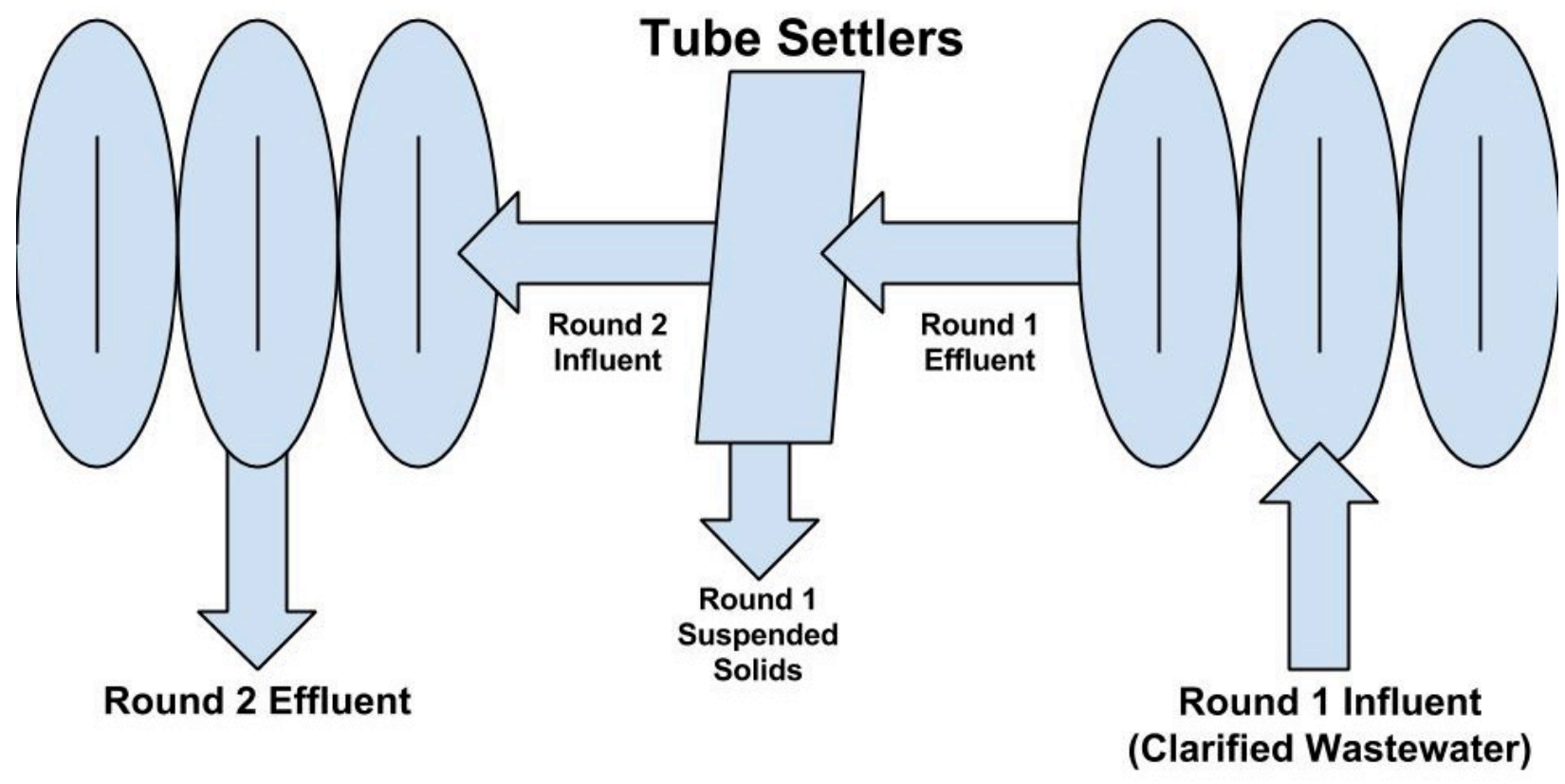

Figure 3-4: Simplified water process flow diagram for raceway ponds in series. The featured tube settlers are suspended solids removal devices that are further discussed in 3.2.2 AFS Process Flow. This system at the AFS acts as a continuation of the process in Figure 3-3, and the system is operated at steady state.

For this experiment the Round-1 pond set consisted of ponds 4, 5, and 6; and the Round-2 pond set consisted of ponds 1, 2, and 3, which all operated at a 3-day HRT (Figure 3-5). 


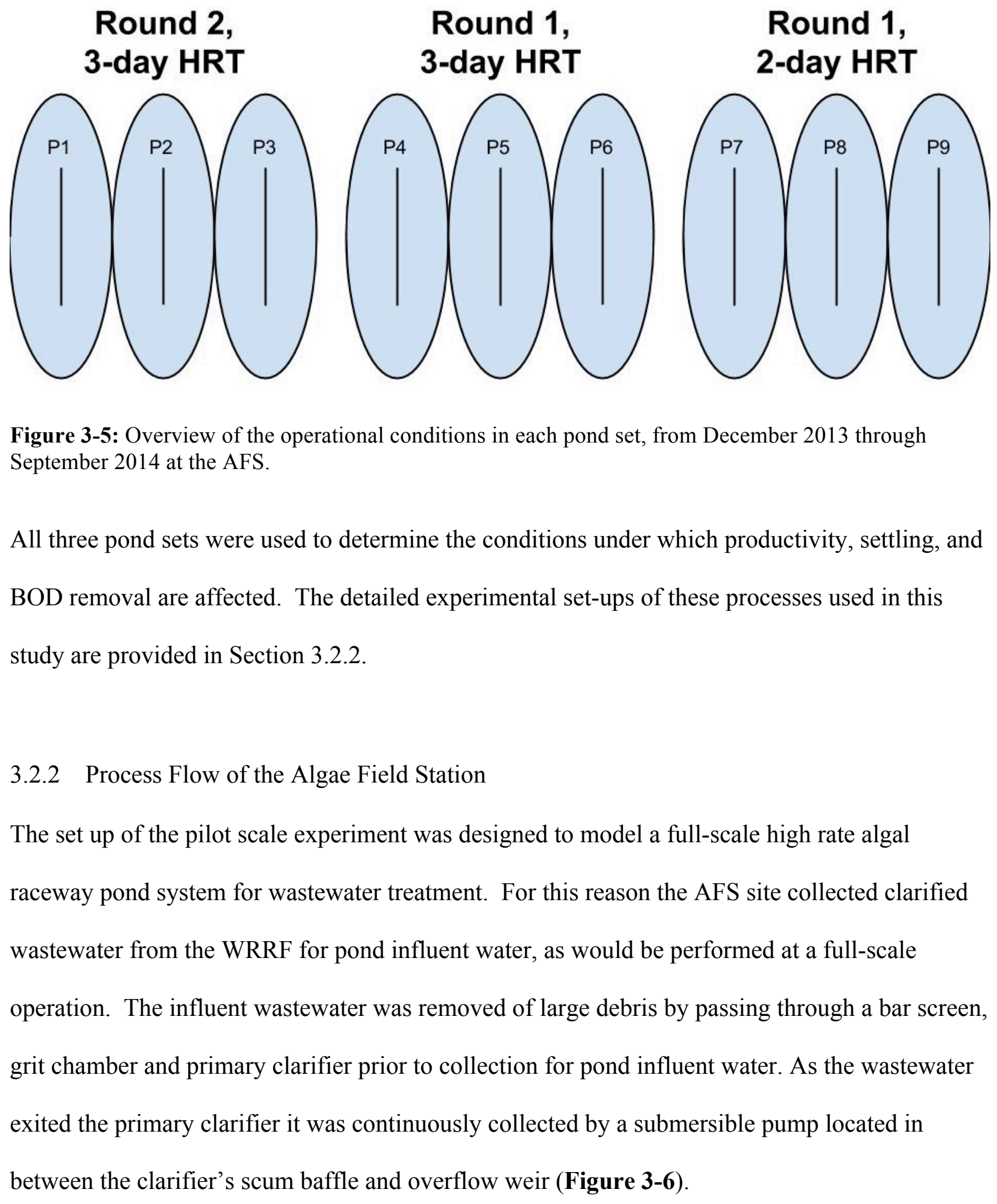




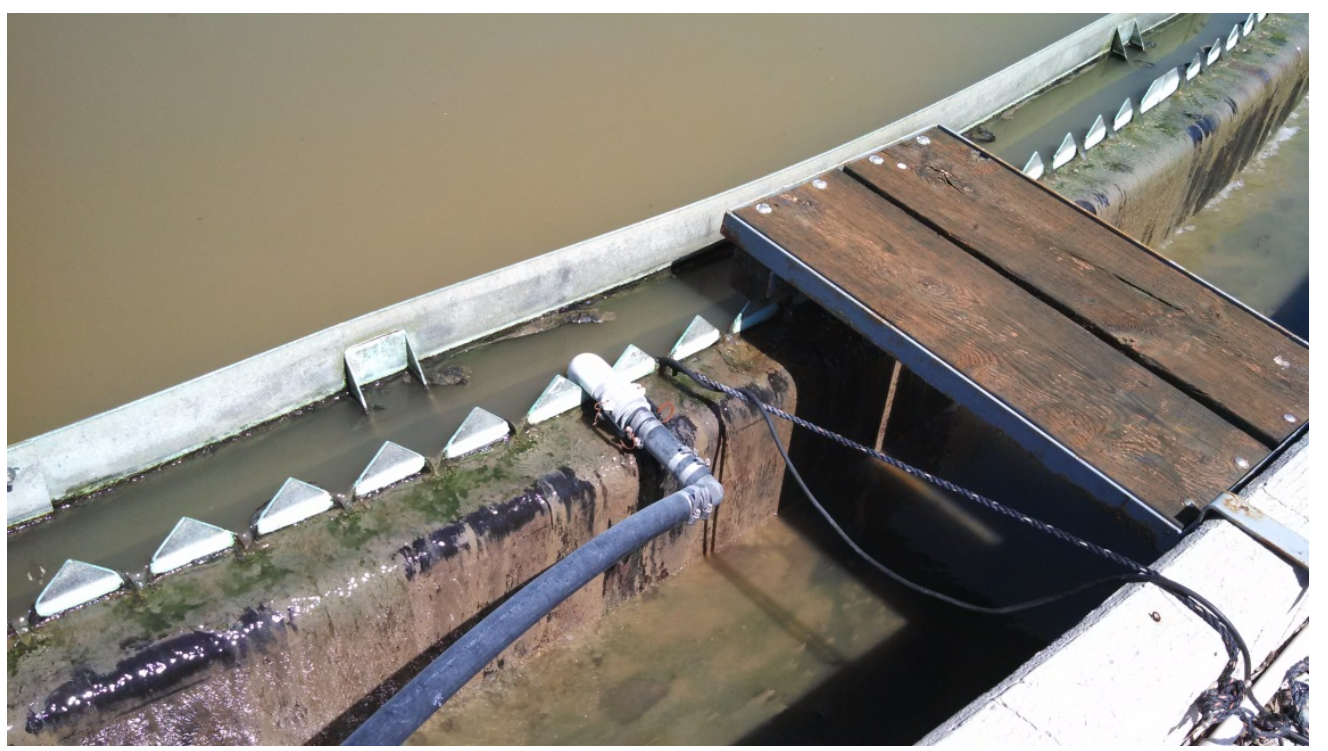

Figure 3-6: The Algae Field Station's source of clarified municipal wastewater was collected from the WRRF's Western primary clarifier, in between the overflow weir and scum baffle (Kraetsch 2015).

The primary clarifier effluent water was piped directly from this source to the three head tanks located at each pond set. A gate valve at each pond set allowed or prevented primary clarifier effluent water to flow into the head tanks, depending on the experiment. The unique design of the head tank allowed for a constant supply of fresh primary effluent to enter the system by allowing excess water to flow out of the head tank via an effluent standpipe. This standpipe also ensured constant head remained in the head tank, giving a consistent volume captured by the pond influent distribution system.

The influent distribution system consisted of rotating scoops collecting water from the head tank. This system, known as the waterwheel, directed the wastewater via PVC piping through the distribution system (Figure 3-7). The water from the distribution system entered each pond down flow of its effluent standpipe, to prevent any short-circuiting of influent water. The flow rate of this system, which controlled the HRT of the pond sets, was adjusted as needed by 
altering the length of the individual scoops and by adjusting the motor's speed with a VFD, discussed further in this study.

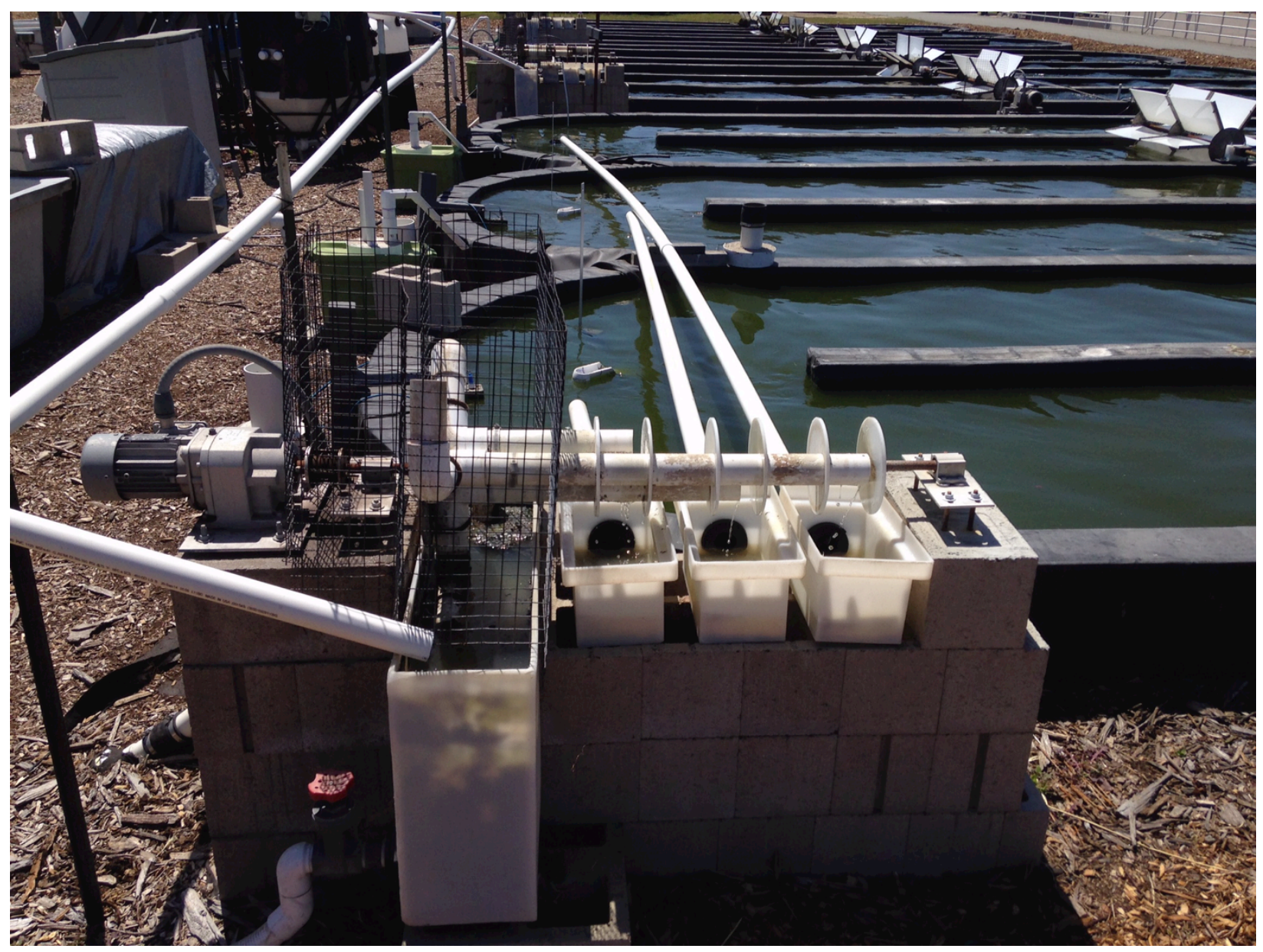

Figure 3-7: Influent waterwheel distribution system is shown feeding ponds 7, 8 and 9 at the AFS.

Each pond was constructed to contain a volume of 10,000 liters while maintaining a shallow 0.3 meter depth. To achieve this volume to depth ratio each pond channel is approximately 1.4 meters wide with a total pond surface area of 33.3 meter squared. Each pond was constructed of concrete and cinderblocks and lined with EPDM rubber to contain the water within the pond. 
The high rate algal raceway ponds were operated with sufficient velocities to keep algal biomass suspended and provided mixing for photosynthetic growth to occur. In the pilot scale system, a six bladed paddle wheel spanned the channel width. Each paddle wheel was constructed of rigid HPDE plastic, held in place with metal braces. All paddle wheels in each pond set rotated along the same shaft, at a set speed maintained by a VFD controlled motor (Figure 3-8). The average channel velocity for each pond was about $19.5 \mathrm{~cm} / \mathrm{s}$ (Roberts, 2014).

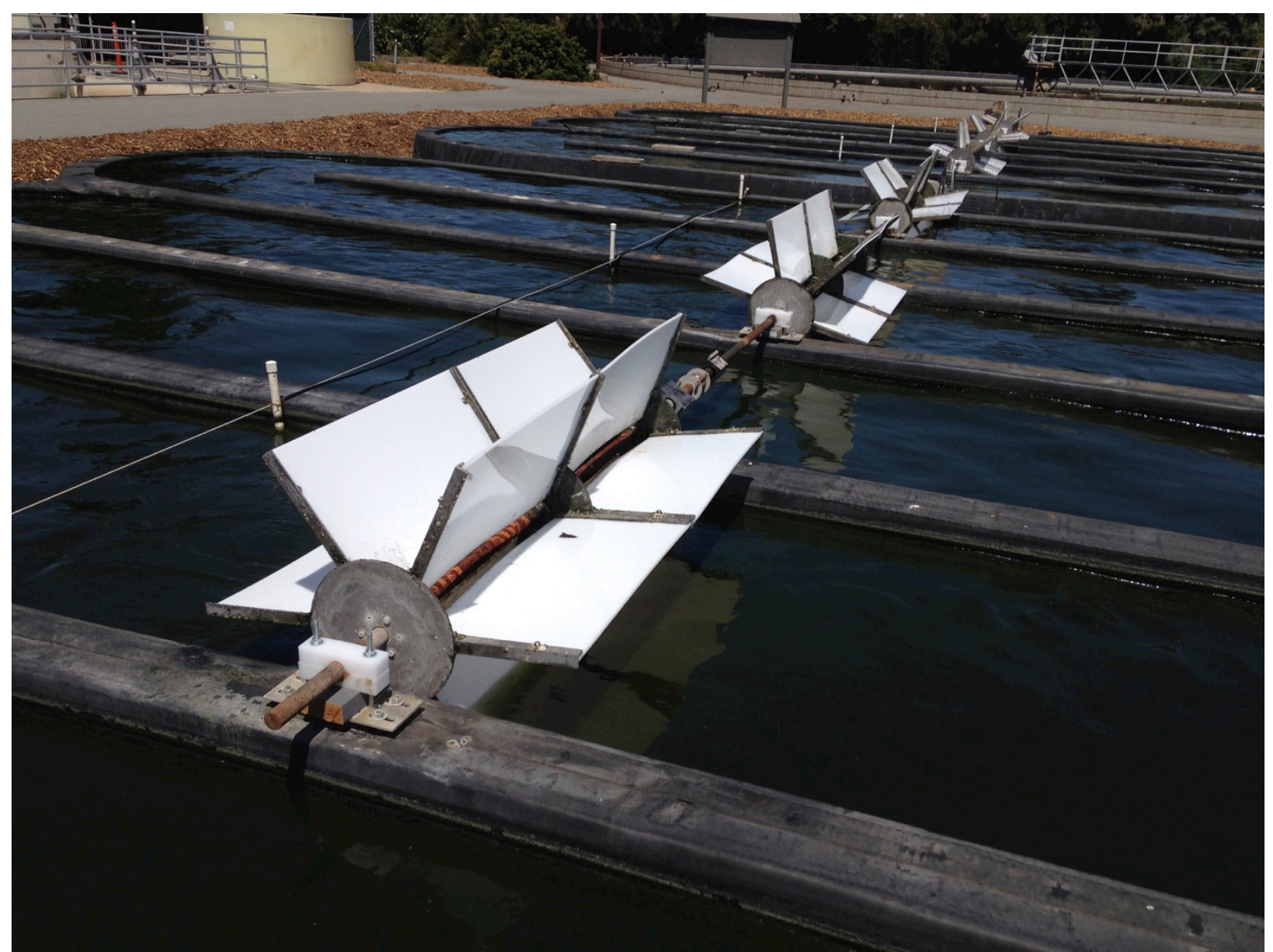

Figure 3-8: The paddle wheels rotated along a shaft for each pond set in the experimental raceway ponds at the AFS.

Since the ponds were operated at steady state, as water entered the ponds through the influent distribution system, the water was displaced over an effluent standpipe and exited the pond. The 
standpipes have a designed height of 0.3 meters ( 1 foot) above to the pond floor to create the desired pond depth. During the extent of the experiment two standpipe designs were used, a 2inch ramped standpipe (Figure 3-9) and a 4-inch vertical standpipe (Figure 3-10). Mike Chang further explains differences between the two standpipe designs in the 2014 study Water and Nutrient Recycling by High Rate Algae Ponds Fed in Primary Treated Municipal Wastewater.

Figure 3-9: Areal view of a 2-inch ramped effluent standpipe submerged in a raceway pond at the AFS (Chang, 2014). 


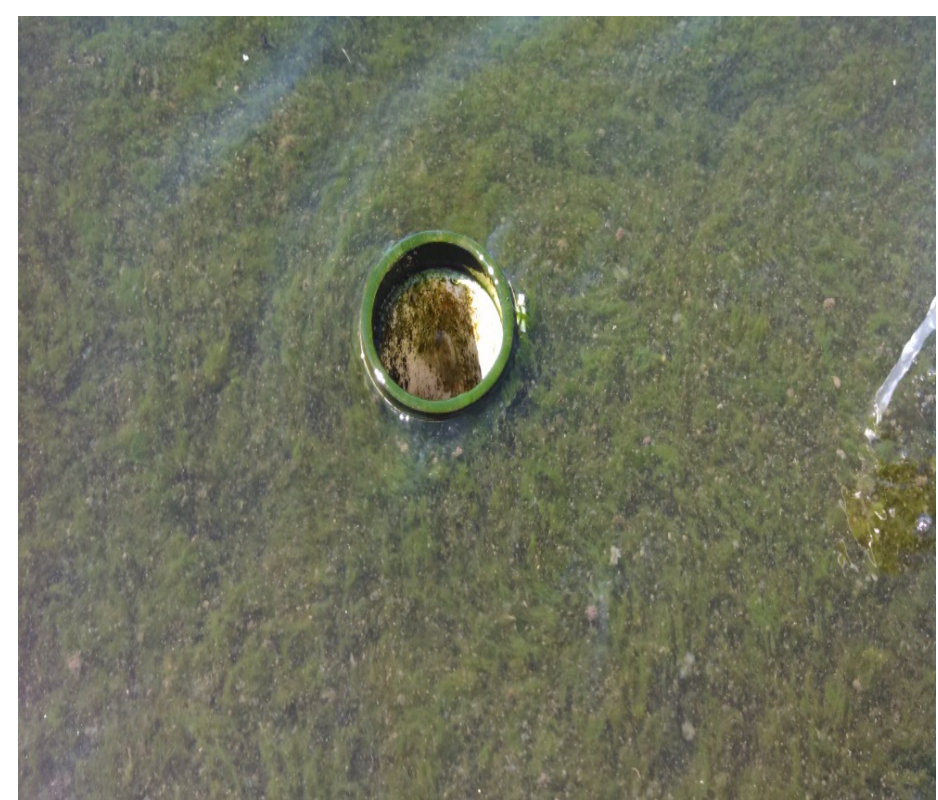

Figure 3-10: Areal view of a 4-inch vertical effluent standpipe submerged in a raceway pond at the AFS (Chang, 2014).

During the course of this study, two ponds were equipped with a ramped standpipe and 1 pond was equipped with a vertical standpipe per each triplicate pond set (Figure 3-11). This standpipe set up was installed on October $16^{\text {th }}, 2013$ and other studies, performed at the AFS, prior to that date were operated with vertical standpipes in each pond.
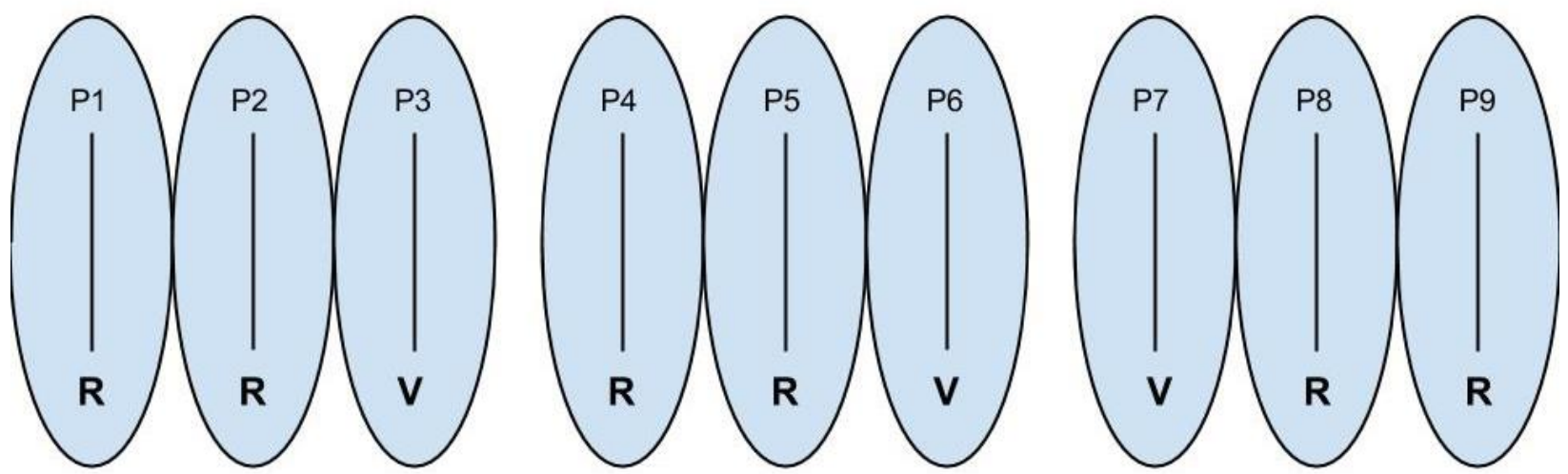

Figure 3-11: Layout of standpipe variations where an " $R$ " represents a two inch ramped effluent standpipe and a "V" Represents a four-inch vertical Effluent Standpipe. This layout was in place from October 16th, 2013 until the end of the study. 
To achieve recycled water for the Round-2 pond set, displaced effluent pond water from the

Round-1 ponds was contained within the standpipe with no bottom exit. Within the standpipe a tube was placed to withdraw the effluent water from the standpipe via a peristaltic pump (Figure

\section{3-12, Figure 3-13).}

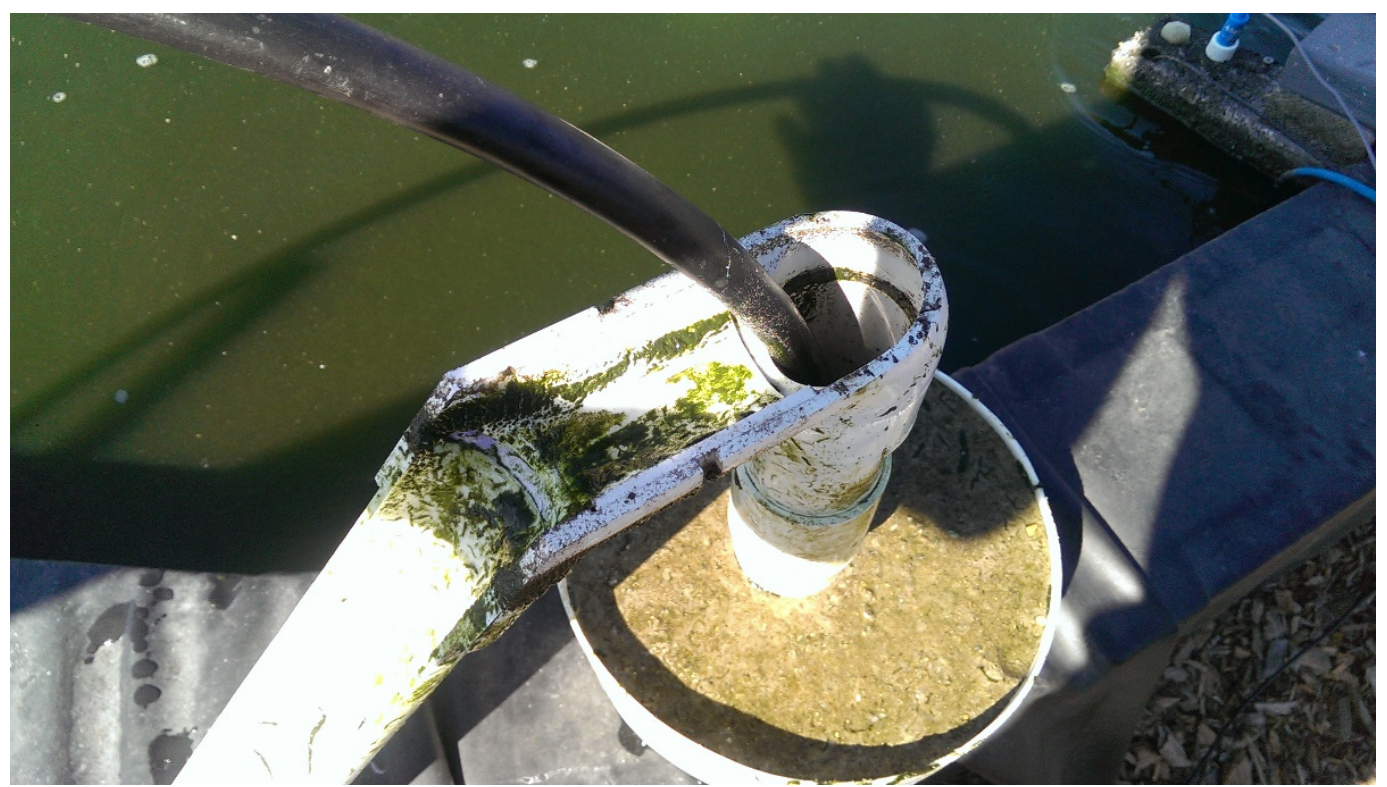

Figure 3-12: Closed bottom ramped standpipe with inserted peristaltic pump tubing for collection of effluent water (Kraetsch, 2015).

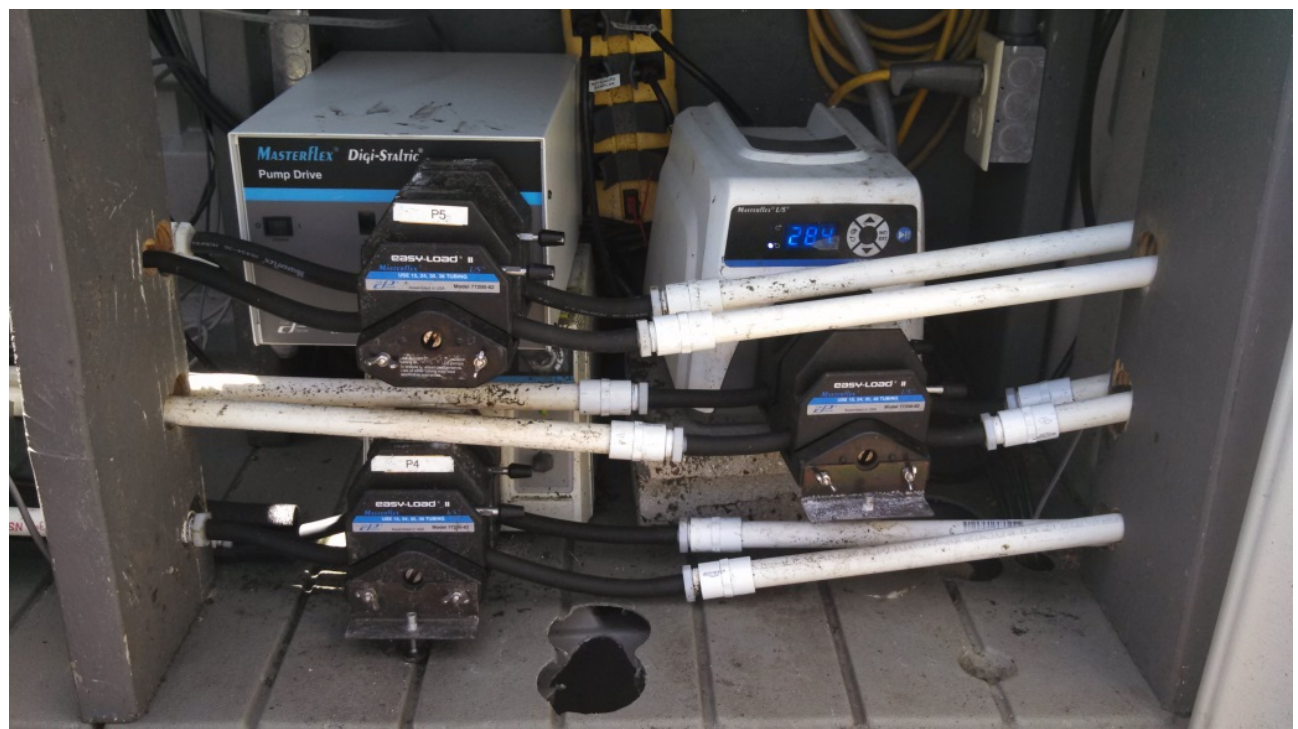

Figure 3-13: Peristaltic pumps located in the pump house in front of ponds 4,5 , and 6 to move effluent pond water from the Round- 1 to the Round- 2 pond sets. Each pump had two pump heads that corresponded to a specific pond and an individual tube settler (Chang, 2014). 
Each peristaltic pump head fed a gravity-settling device, known as a tube settler, which provided the method of clarifying settable solids for the ponds in series experiment (Figure 3-14, Figure 3-15). For the ponds in series experiment, each Round-1 pond standpipe was pumped into two tube settlers. As water continuously entered the system, with head supplied by the peristaltic pumps, it was pushed to the top of the device where it flowed out through a submerged drain. However as water rose through the system, enough residence time was provided for microalgae floccs to settle to the bottom of the tubesettler since they are denser than the rising water. This settling was enhanced, by reducing the vertical distance the biomass was required to settle. This was done by the nine 3-inch PVC pipes at a $60^{\circ}$ degree angles inside the tube settlers. By placing the PVC pipes at an angle, the height of settling required to remove biomass from the water was greatly reduced. Rising water carrying the biomass was able to settle inside the pipes, allowing biomass to slide down the tube settler, where it was collected. Once at the bottom of the device the thickened algal biomass sludge was drained off through a $3 / 4$ inch ball valve and either harvested or used in an onsite anaerobic digester. For more information on anaerobic digestion and the use of collected algal biomass sludge at the AFS refer to Anaerobic Digestion of Microalgae for Methane Production and Nutrient Recycling by Elai Fresco. 


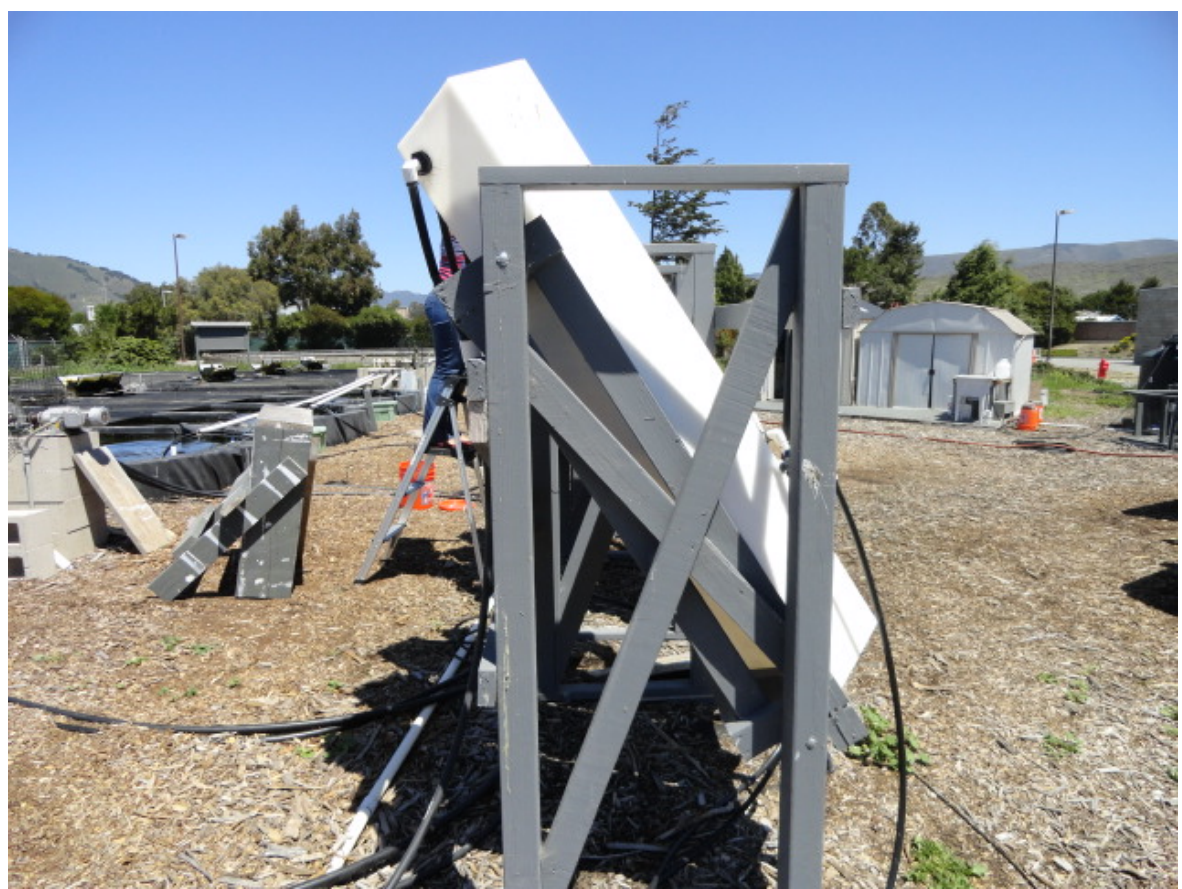

Figure 3-14: Profile view of a tube settler at the AFS. Effluent water from the Round-1 ponds entered the tube settler through the black tubing on the right of the device and exited through the black tubing located at the top left of the device (Chang, 2014). 


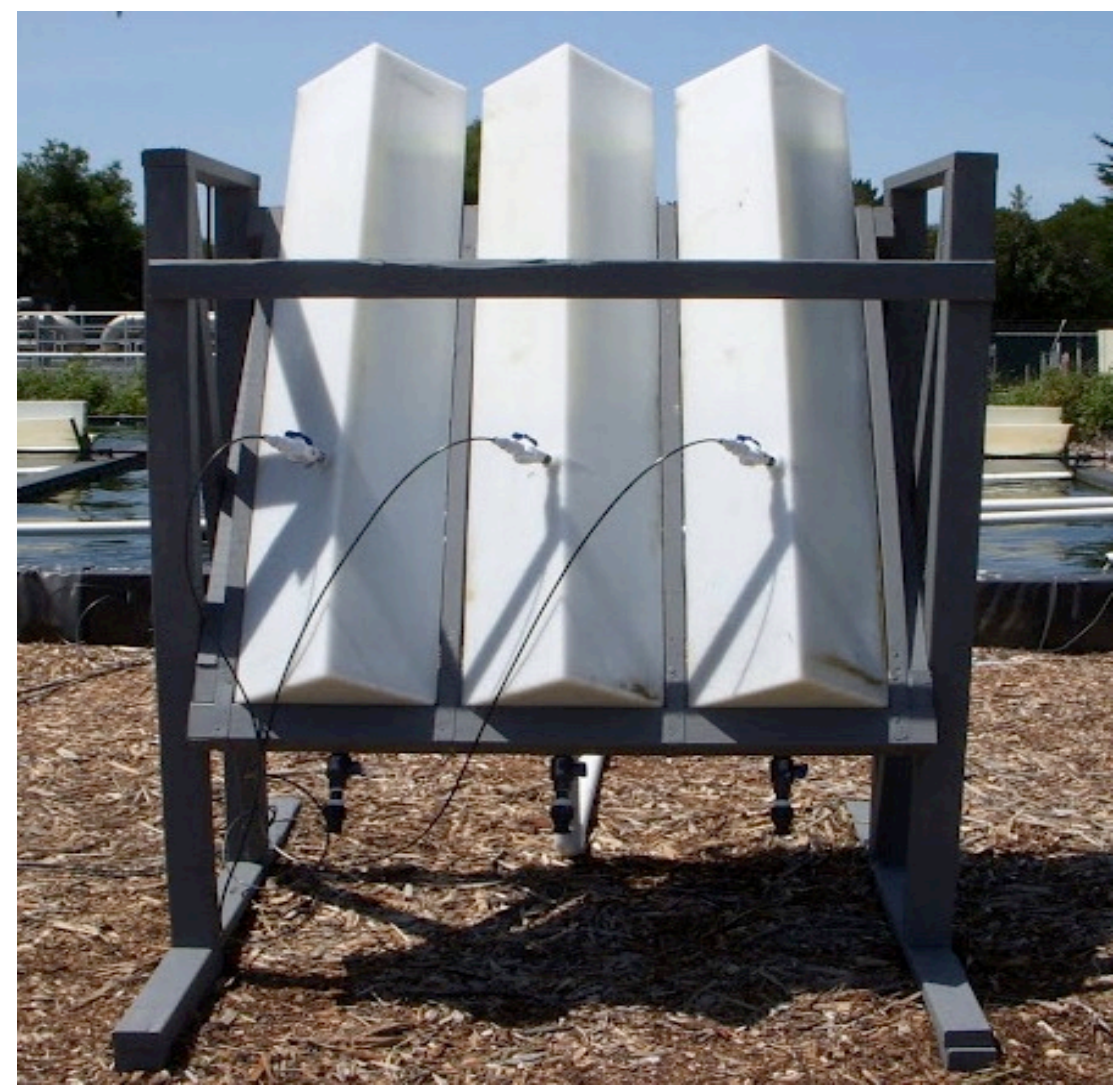

Figure 3-15: Front view of three tube settlers at the AFS. The influent water lines are shown entering the front, and effluent sludge is drained from the valves placed at the bottom (Ripley, 2013).

The clarified supernatant from all the tube settlers, was combined into the head tank of the Round-2 pond set. From there the supernatant was redistributed as influent and the Round-2 ponds were operated in the same manner as the rest of the ponds in the experiment.

For effluent pond water not being recycled, the effluent water exited directly via an open bottom standpipe. This standpipe was connected to a piping network beneath the ponds where the overflow water was transported by gravity to the AFS effluent sump (Figure 3-16). This standpipe system was also in place for the Round-1 pond set, which had raised open bottom standpipes to serve as an emergency overflow in case of a peristaltic pump failure. 


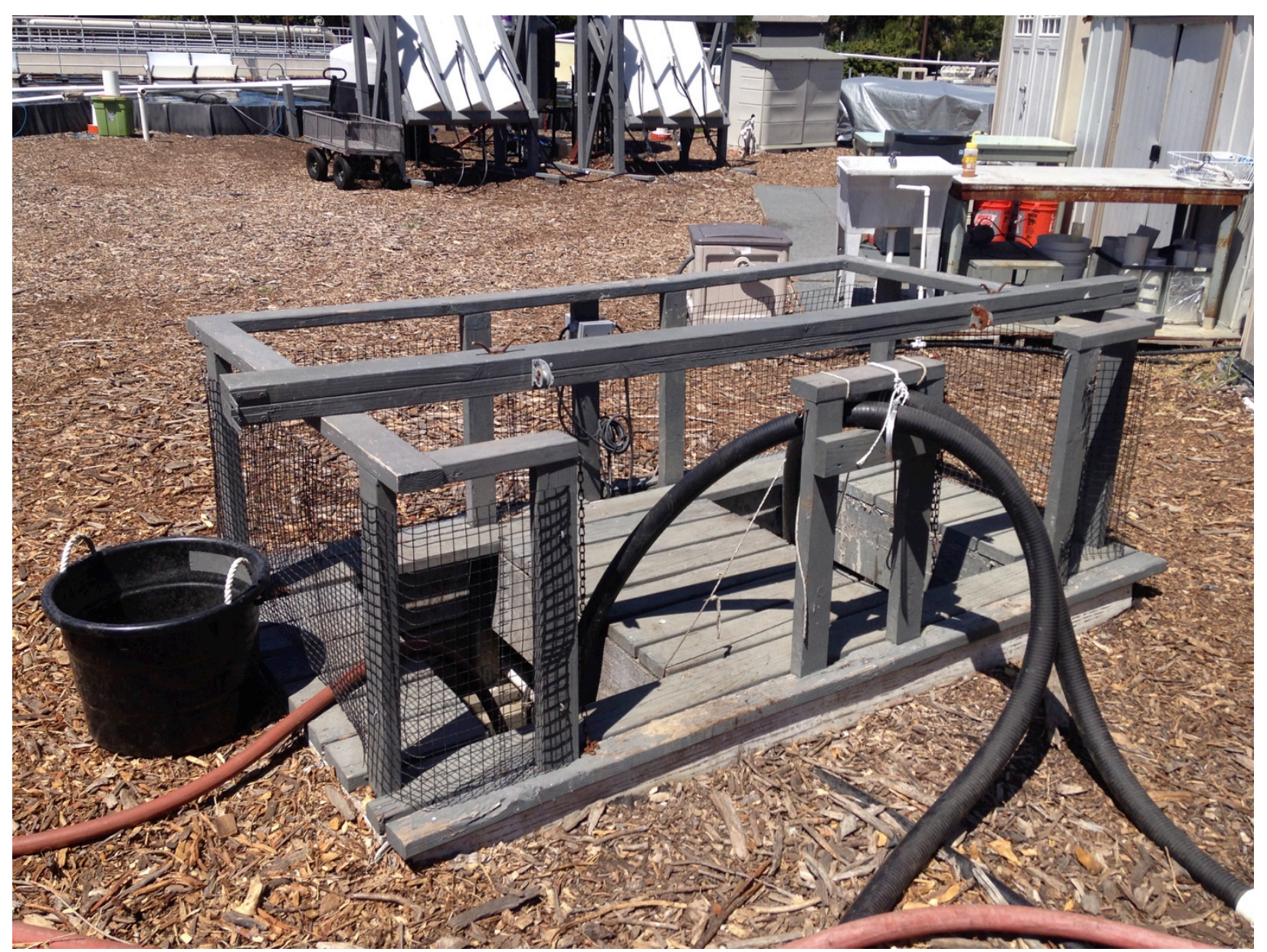

Figure 3-16: The gravity-fed AFS effluent sump had two water removal pumps that carried effluent water to the primary clarifier effluent.

The effluent sump contained two submersible pumps that removed the water from the sump back to the WRRF's primary clarifier.

In review, the set up of this system was able to achieve the experimental conditions for this study such as pond depth, channel velocity, HRT and water recycling (Table 3-1). 
Table 3-1: Actual experimental conditions of 9 raceway ponds at the Cal Poly AFS from December 2013 through September 2014.

Ponds 1, 2, $3 \quad$ Ponds 4, 5, 6 Ponds 7, 8, 9

\begin{tabular}{cccc}
\hline Depth (m) & 0.3 & 0.3 & 0.3 \\
Channel Velocity (cm/s) & 19.8 & 19.2 & 19.5 \\
Influent (L/min) & 2.25 & 2.25 & 3.30 \\
HRT (days) & 3.0 & 3.0 & 2.0 \\
Influent Source & Recycled Pond Water & Wastewater & Wastewater \\
\hline
\end{tabular}

To further understand how the experimental conditions affect the results of this study over an extended period of time, past data collected at the AFS are presented in the results of this study when applicable. The operation of the experimental raceway ponds was carried out mostly unaltered from March 6, 2013 to September 28, 2014 aside from the installation of ramped standpipes on October $16^{\text {th }}, 2013$ and a change in HRT for the Round-2 pond set (Table 3-2).

Table 3-2: The experimental pond conditions for each pond set at the AFS that existed from March 2013 through September 2014.

\begin{tabular}{ccc} 
Pond & Date & Timeline of Experimental Conditions \\
\hline $1,2,3$ & 3/6/2013 to $6 / 13 / 2013$ & Round-2, 4-day HRT \\
& $6 / 26 / 2013$ to $9 / 28 / 2014$ & Round-2, 3-day HRT \\
$4,5,6$ & $3 / 6 / 2013$ to $9 / 28 / 2014$ & Round-1, 3-day HRT \\
$7,8,9$ & $3 / 6 / 2013$ to $9 / 28 / 2014$ & 2-day HRT \\
\hline
\end{tabular}

For further operational details of data collected at the AFS prior to December 2013, reference the 2015 report by Justin Kraetsch titled: Nutrient Removal from Clarified Municipal Wastewater Using Microalgae Raceway Ponds. 


\subsubsection{Pond Operations and Maintenance}

Over the course of the experimental study, frequent maintenance was required for the up-keep of the raceway ponds.

Each pond set had a pump house containing the two VFDs required to control the rotational speed of the waterwheel motor and paddle wheel motor (Figure 3-17). The VFD controlling the waterwheel was adjusted on occasion to deliver the correct influent flow rate, producing the desired HRT in the pond set (Figure 3-18). To test the influent rate for adjustment, a large 2liter container was placed under the stream of influent water and the time required to fill the container was monitored, producing a flow rate. This process was repeated as needed until the variable frequency drive, VFD, was correctly adjusted to give the desired flow rate. This operation was performed approximately once a fortnight, and rarely required adjustment. The VFD controlling paddlewheel speed was left untouched for the duration of the experiment and was assumed to give consistent velocities in the pond throughout the experiment.

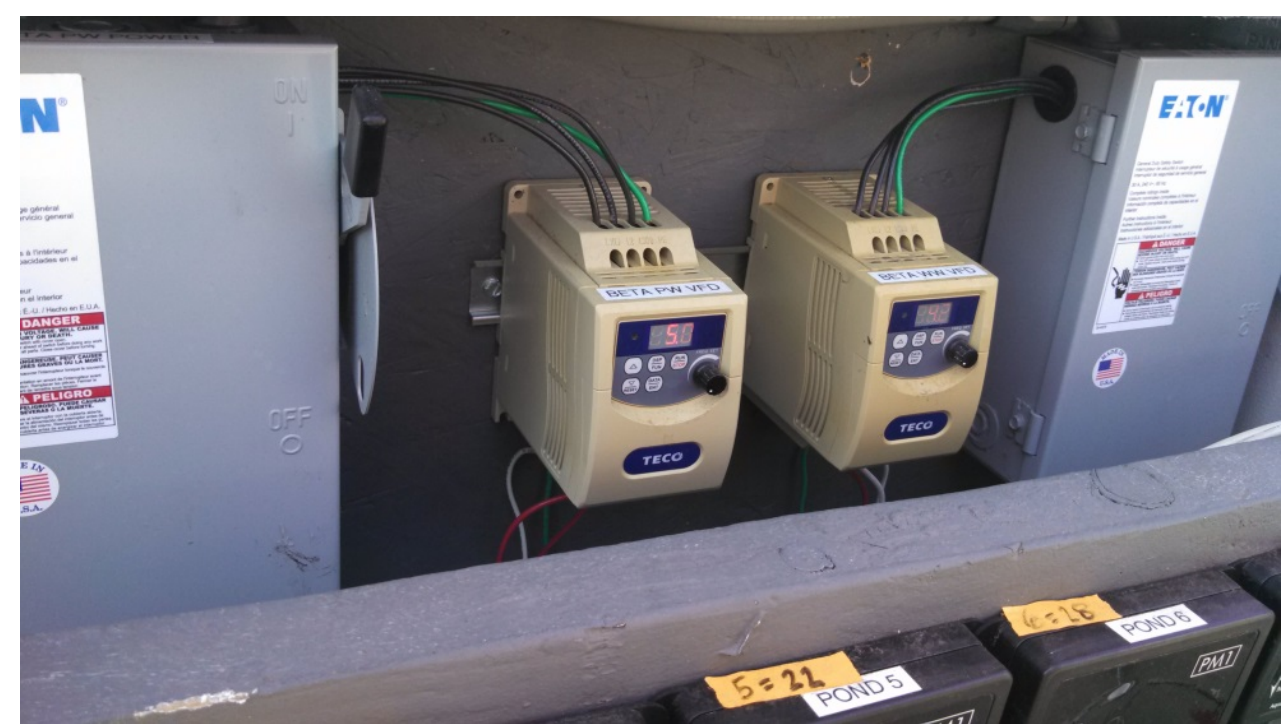

Figure 3-17: Variable frequency drives controlled the rotation speed of the water and paddle wheel motors (Chang, 2014). 


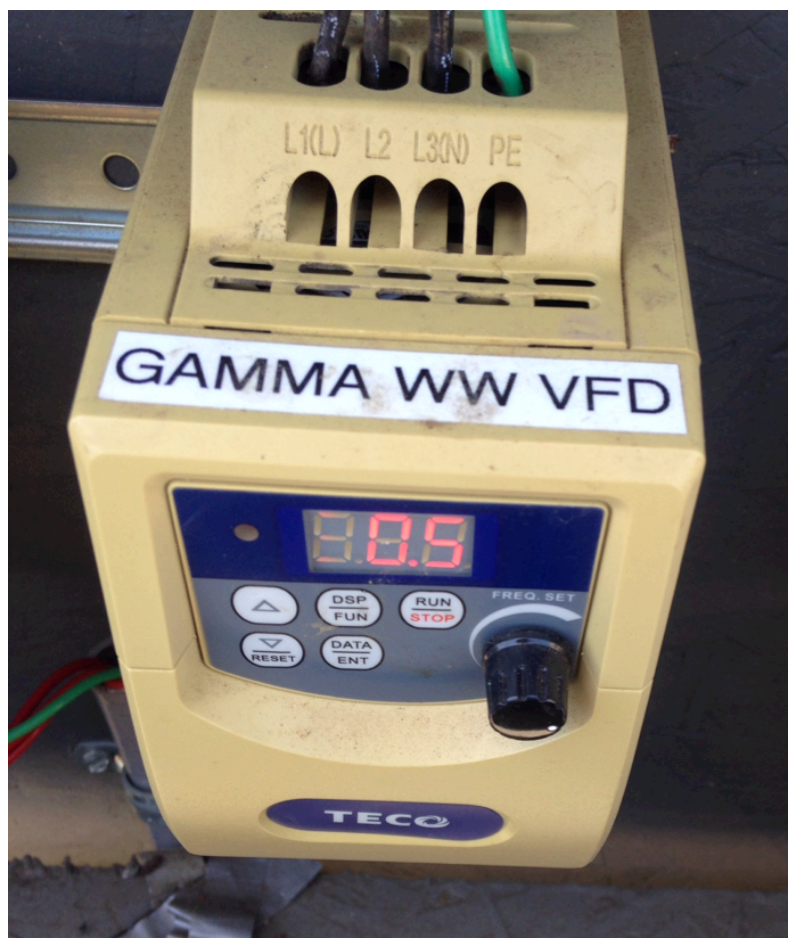

Figure 3-18: Variable frequency drive used to operate the rotational speed of the waterwheel in the 2-day HRT pond set.

A supervisory control and data acquisition, known as SCADA, system was used at the Algae Field Station; to give constant readings of $\mathrm{pH}$, temperature and dissolved oxygen, also known as DO (Figure 3-19). Neptune's Apex SCADA system was installed prior to the study and required routine weekly calibration of $\mathrm{DO}$ and $\mathrm{pH}$ probes to ensure reliable measurements. 


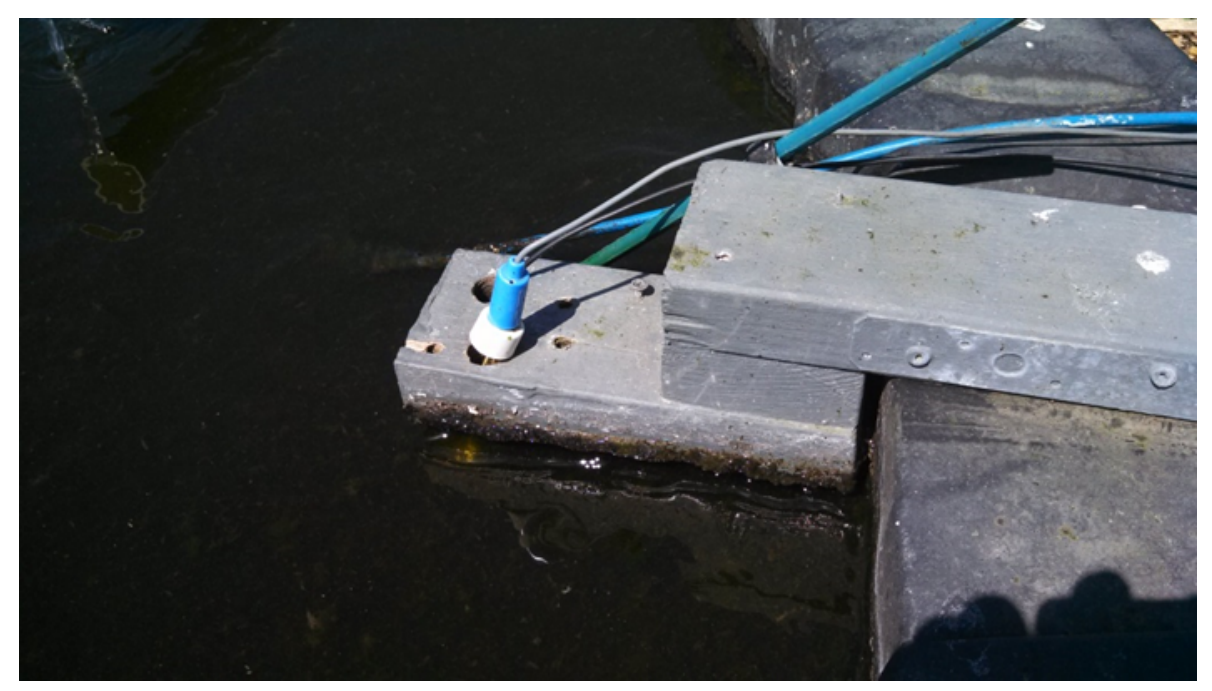

Figure 3-19: Neptune SCADA probes for DO, temperature, and $\mathrm{pH}$ were submerged at the edge of each raceway pond (Chang, 2014).

For further information on how the SCADA system operated reference Appendix Section 7.1 Supervisory Control and Data Acquisition.

To prevent the raceway ponds from reaching an exceedingly high $\mathrm{pH}$ and becoming carbon limited, carbon dioxide was supplied. Carbon Dioxide, known as $\mathrm{CO}_{2}$, was sparged into each individual raceway pond for the Round-1, 3-day HRT and the Round-2, 3-day HRT pond sets. The 2-day HRT pond set did not receive $\mathrm{CO}_{2}$ during the course of this study (Figure 3-20). 


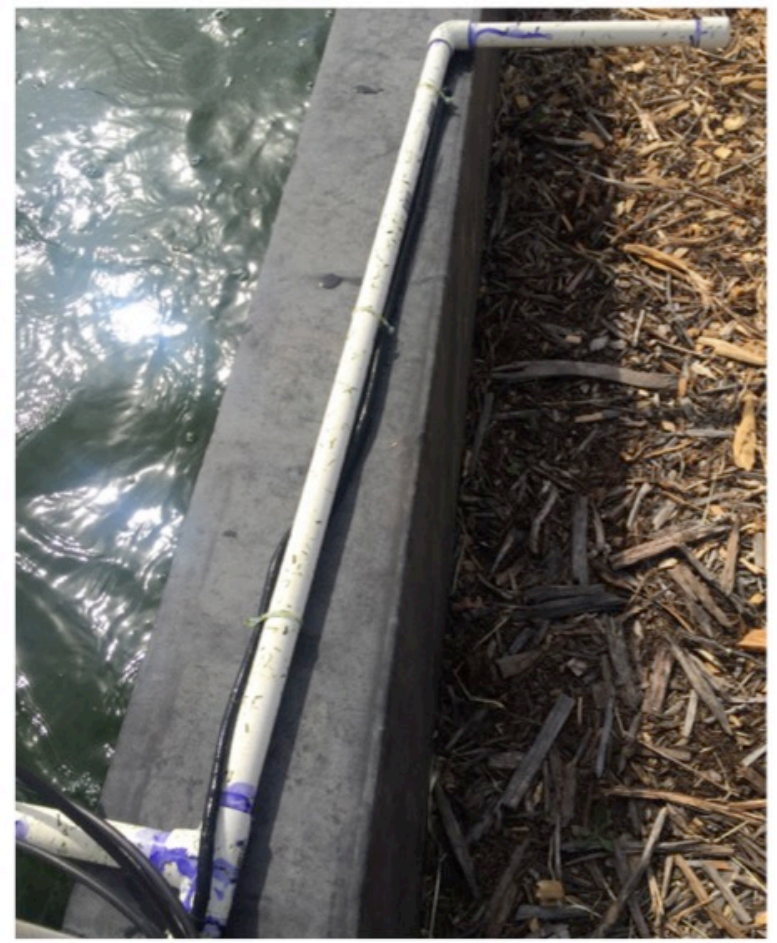

Figure 3-20: Carbon dioxide was sparged into raceways ponds through a black perforated tubing, attached to a PCV stand, that spanned the width of the channel $90 \mathrm{~cm}$ downstream of the paddle wheel. It was located on the surface of the pond floor and secured by a weighted PVC pipe. For the image shown the set up was removed from the pond (Kraetsch, 2015).

$\mathrm{CO}_{2}$ was supplied to the ponds when the $\mathrm{pH}$ of the pond reached a set specified value. For all data collected from 2013 until June 5, 2014 the acceptable $\mathrm{pH}$ range was set from 8.4 to 8.5. For all data collected after June 5, 2014 the acceptable $\mathrm{pH}$ range was set from 8.0 to 8.4. The system would supply $\mathrm{CO}_{2}$ from the time the upper $\mathrm{pH}$ limit was reached, until the lower $\mathrm{pH}$ limit was reached. The $\mathrm{CO}_{2}$ was triggered by the continuous $\mathrm{pH}$ readings of the SCADA system in real time through the use of automated solenoid switches. The $\mathrm{CO}_{2}$ was supplied from 50 pound pressurized tanks, at 99.5\% purity that were delivered as needed from Airgas, Inc. (Figure 3-21). 


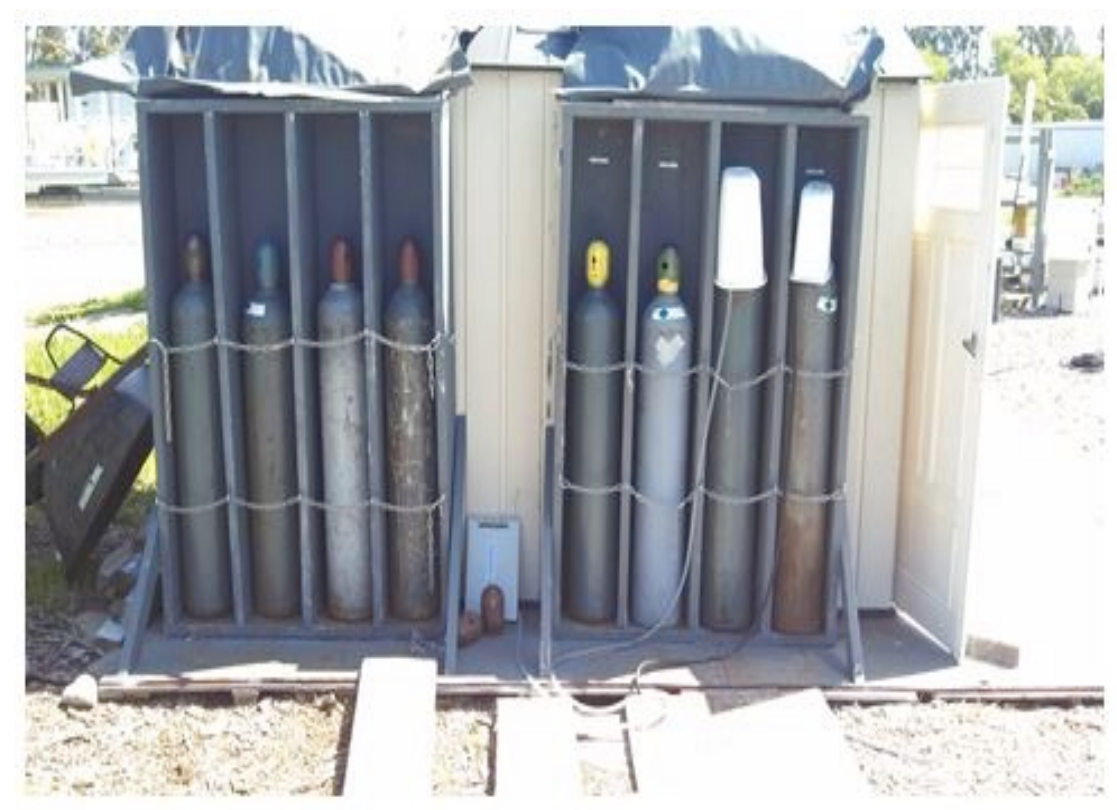

Figure 3-21: The 50- $\mathrm{lb} \mathrm{CO}_{2}$ tanks were secured in a housing unit at the AFS. One tank was used at time to release carbon dioxide into a specific pond with $\mathrm{pH}$ levels above the set limit (Chang, 2014).

The pump house corresponding to ponds 4, 5 and 6 included peristaltic pumps, which transferred effluent water from the Round-1 pond set to the tube settlers for clarification. Frequent replacement of peristaltic pumping tubing was required, as the tubing would lose its rigidity and ability to expand over time.

The tube settlers used for clarifying the Round-2 influent water also required routine maintenance on an as needed basis. As solids were settled from the passing water they settled to the bottom, which required removal through the drain placed on the bottom. To drain the built up solids a container was placed under each tube settler and the valve was opened allowing the solids to be removed. The valve was slowly opened to prevent short-circuiting, which would allow for the cleaner water to escape prior to the denser solids slurry. The draining was continued until visibly clear water drained from the system (Figure 3-23). 

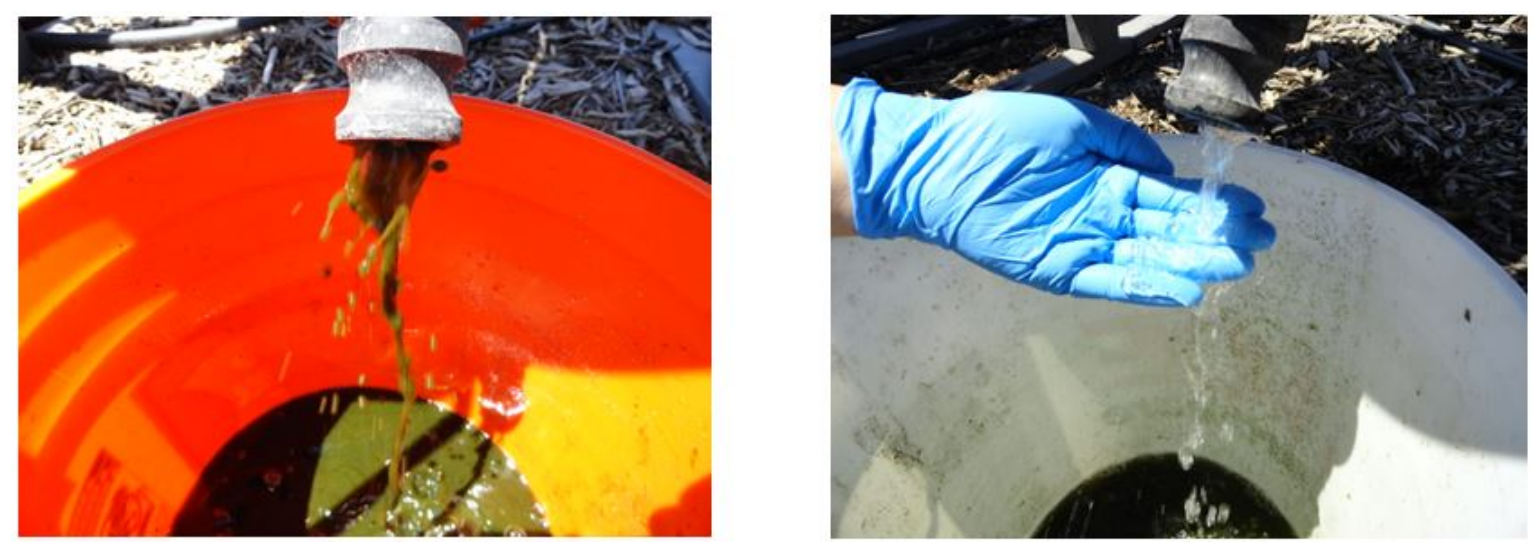

Figure 3-22: Accumulated solids were being drained from the bottom of the tube settlers. The left image illustrates the thick effluent sludge, and the right image illustrates clear water coming through the underdrain after the sludge was removed (Chang, 2014).

In addition to solids removal from the bottom of the tube settlers, algal biomass would collect at the top of the tube settlers. To prevent solids from entering the Round-2 pond set, a perforated plated and submerged effluent drain were installed (Figure 3-24). Trapped biomass was collected by hand or with a small net from top of tube settlers as needed.

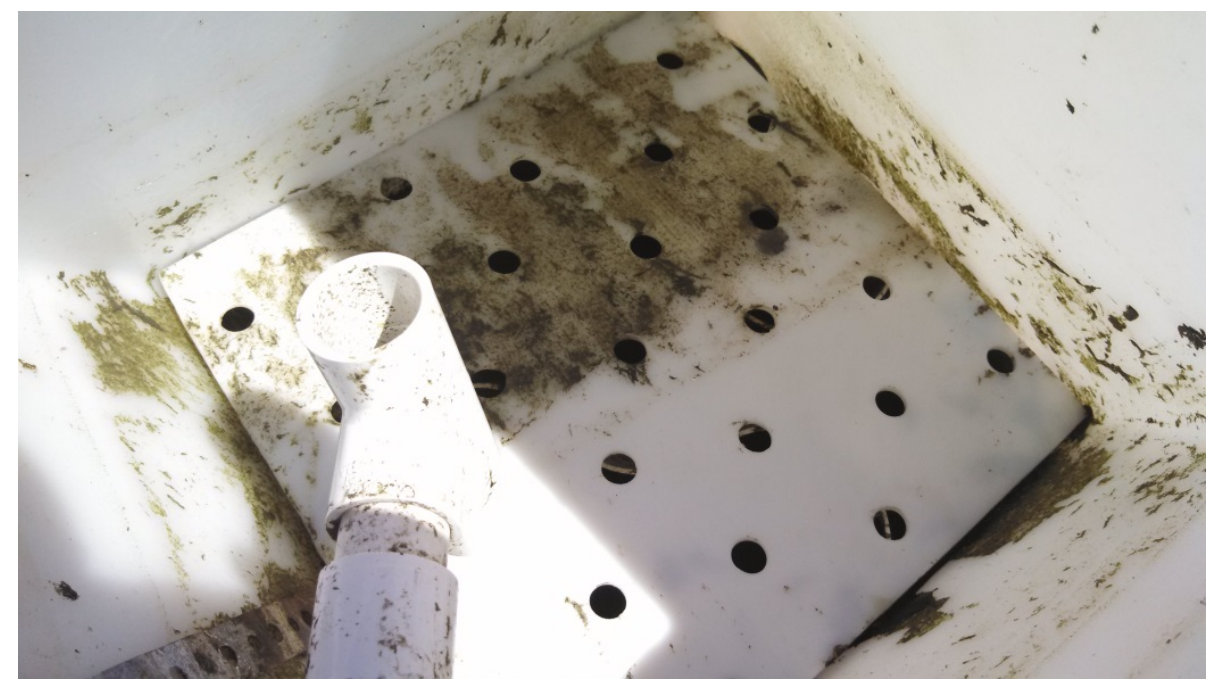

Figure 3-23: The view from the top of tube settler reveals the submerged effluent drain and the perforated backpressure plate in place. In this image, water was drained from the tube settler, while under normal operating conditions the backpressure plated is submerged in water (Chang, 2014). 


\subsubsection{Weekly Pond System Sampling Procedures}

Weekly sampling was performed for the majority of laboratory quality analyses. To ensure the comparability of the collected results, a specific method of sampling was used each week. The majority of samples collected are referred to as grab samples, where a small instantaneous sample is collected and is assumed to represent the entire body of water being sampled (well mixed). This sampling was carried out at the same time each week to ensure comparable values. To perform a grab sample of pond water a large wide-mouthed 2-liter container was submerged upside down to the middle of the pond, and slowly tilted to upwards as the container was brought back up to the pond surface. Samples were collected between the hours of 7 am and $8 \mathrm{am}$. This method was adopted on June 19, 2014. Prior to June 19, 2014, a 1-gallon container shaped like a milk jug was submerged to perform a grab sample. This milk container was submerged in the same way, however the small opening may have affected the solids content entering the container due to the higher entrance velocity.

The grab samples used to collect influent water to the ponds were collected by placing a container at the edge of the PVC pipe that delivered influent water to the ponds. This allowed all influent pond water to fill the container that would have normally entered the pond. For the ponds receiving wastewater from the primary clarifier effluent, only one pond influent was collected and assumed to be the same for all other ponds. The influent sample for the Round-2 pond set was collected equally from the influent of each pond to provide the best representative sample. 
The final method of sampling used in this study was performed only on the ponds with vertical 4-inch effluent standpipes. This procedure was adopted on September 4, 2014 to effectively calculate productivity values based on the respective pond's effluent water. This sampling method was performed by lowering a plastic container into the effluent standpipe. This allowed water to enter the standpipe and be collected in the container before the water entered the standpipe's effluent. All data presented, after September 4, 2014, for ponds with vertical effluent standpipes were derived from this sampling method; and all data prior to that was collected from the previously stated grab sampling method.

Aside from the grab samples used for analysis, a composite sample was also collected on influent pond water in the fall of 2014. A HACH Sigma automated sampler, known as an autosampler, was used to collect hourly samples over a 24 -hour period. This sample was collected by the autosampler from the primary clarifier effluent wastewater head tank, where the waterwheel collected water for pond influent. This sampling operation began at 8 am and collected hourly samples of the same volume, which were stored on ice, until 7 am the next day.

Once all samples had been collected, they were stored in a dark cooler and transported directly to Cal Poly for analysis.

\subsection{Laboratory Water Quality Analyses}

The analyses performed for this study were completed in the environmental engineering laboratories at Cal Poly. The analyses performed for this test include total suspended solids (TSS), volatile suspended solids (VSS), 2-Hr total suspend solids, 24-Hr total suspend solids, 5- 
day soluble carbonaceous biochemical oxygen demand $\left(\mathrm{scBOD}_{5}\right)$, 5-day total carbonaceous biochemical oxygen demand $\left(\mathrm{cBOD}_{5}\right)$, total chemical oxygen demand (tCOD), algal identification, and finally zooplankton enumeration. The analysis methods were performed according to the official methods stated in Standard Methods for the Examination of Water and Wastewater (Table 3-3).

Table 3-3: The table presents all water quality analysis methods used in this study. All methods were performed according to the publication Standard Methods for the Examination of Water and Wastewater.

\begin{tabular}{|l|l|}
\hline \multicolumn{1}{|c|}{ Test } & \multicolumn{1}{c|}{ Method } \\
\hline $\begin{array}{l}\text { Total and Volatile } \\
\text { Suspended Solids }\end{array}$ & $\begin{array}{l}\text { Gravimetric with 1.2- } \mu \mathrm{m} \text { Fisher brand G4 Glass Fiber filters filtration } \\
\text { (APHA Standard Methods 1995, sections 2540 D and E) }\end{array}$ \\
\hline $\begin{array}{l}\text { 2 and 24-Hr Total } \\
\text { Suspended Solids }\end{array}$ & $\begin{array}{l}\text { Imhoff Cone Settling at an ambient temperature of 20 }{ }^{\circ} \mathrm{C},+-3^{\circ} \mathrm{C} \\
\text { (APHA Standard Methods 1995, sections 2540 Solids A, B \& E) }\end{array}$ \\
\hline $\begin{array}{l}\text { 5-Day Soluble and } \\
\text { Total Carbonaceous } \\
\text { Biochemical Oxygen } \\
\text { Demand }\end{array}$ & $\begin{array}{l}\text { 5-day incubation at 20 }{ }^{\circ} \mathrm{C} \text { in autoclaved bottles, 1.2- } \mu \mathrm{m} \text { Fisher brand } \\
\text { 5210 B) }\end{array}$ \\
\hline $\begin{array}{l}\text { Total Chemical Oxygen } \\
\text { Demand }\end{array}$ & $\begin{array}{l}\text { HACH DR/890 Colormetric Method (APHA Standard Methods } \\
\text { 1995, sections 5220-COD A \& D) }\end{array}$ \\
\hline Algal Identification & $\begin{array}{l}\text { Selected Taxonomic References, Optical Microscope (APHA } \\
\text { Standard Methods 1995, section 10900 E. 2.) }\end{array}$ \\
\hline $\begin{array}{l}\text { Zooplankton } \\
\text { Enumeration }\end{array}$ & $\begin{array}{l}\text { Numerical enumeration, Optical Microscope (APHA Standard } \\
\text { Methods 1995, sections 10900 E. 6, 9, 17.) }\end{array}$ \\
\hline
\end{tabular}

All analyses took place as soon as possible after collection to ensure the greatest accuracy. For TSS, VSS, 2-hr and 24-hr settling the analysis began within in 2 hours of sample collection. Analysis for $\mathrm{BOD}_{5}$ commenced within 5 hours of sample collection, including the time required for 1.2- $\mu \mathrm{m}$ filtration as preparation. Both algal identification and zooplankton enumeration took place within 8 hours of sample collection. Due to the constraints of laboratory personnel tCOD analysis was preserved, according to the method, with sulfuric acid and refrigerated to be ran with in a month of the collection date. 
In addition to the stated method of analysis for both VSS, TSS and tCOD, all samples were blended prior to being analyzed. This was done to assure a homogeneous distribution of particulate content throughout the sample. This was done by placing the analytical sample into an upright food grade blender, and blended on high until all visible floccs were destroyed. This method was introduced on July 3, 2014 and preceded by the use of a less intense immersion blender, which was used at the start of the experiment (Table 3-4).

Table 3-4: Review of significant method or experimental changes over the course of operation at the AFS from March 2013 to September 2014.

\begin{tabular}{cl} 
Date & \multicolumn{1}{c}{ Method or Experimental Change } \\
\hline $10 / 16 / 2013$ & Effluent standpipe ramps installed in 2 ponds per pond set \\
$6 / 19 / 2014$ & Pond grab samples collected with wide-mouthed containers \\
$7 / 3 / 2014$ & Immersion blender replaced by an upright food grade blender \\
$9 / 4 / 2014$ & Vertical standpipe overflow water used for pond grab sampling \\
\hline
\end{tabular}

For complete walk through of each laboratory analysis method reference the 2014 study, Water and Nutrient Recycling by High Rate Algae Ponds Fed in Primary Treated Municipal Wastewater, by Mike Chang.

\subsection{Field Analyses}

Due to the nature and requirements of some tests, they could be best carried out at the water reclamation facility with out an operator present. As mentioned prior in this section a supervisory control and data acquisition system was installed to collect consistent data on $\mathrm{pH}$, water temperature, and dissolved oxygen concentration. The SCADA system selected for this 
operation was called Neptune by APEX. All analytical methods for these tests were performed in accordance with Neptune guidelines for their products.

\subsection{Weather Data}

The California Irrigation Management Information Systems tracks weather across the state, with a station located about six kilometers north of the water reclamation facility. Solar insolation, precipitation and temperature data from this location were used for analysis in this thesis. 


\section{RESULTS AND DISCUSSION}

This section presents the collected data and calculated results in this study. The first results presented cover weather conditions, algal cultures, and the level of representativeness of the sampling method. The BOD removals of the three ponds sets are compared for the purpose of wastewater treatment. Results and correlations are presented for productivity and followed by settling. Finally, conditions surrounding a crash in algal biomass and zooplankton population are examined.

\subsection{Weather Data}

Environmental conditions such as insolation, temperature, and precipitation play a major role in species dominance and growth characteristics.

\subsubsection{Insolation and Temperature}

When algal growth nutrients are present in sufficient concentrations, two main environmental factors that typically affect biomass growth are temperature and incoming solar insolation (Washington State Department of Ecology, 2015). As these two variables increase, within a range, the potential productivity of microalgae also increases.

As described in the Methods chapter 3, insolation data came from a CIMIS weather station, and pond temperature data came from a SCADA system. These data were logged at intervals of 5 to 60 minutes, but many water quality variables were determined only in weekly grab samples. To facilitate correlation analysis using the weekly water quality data, CIMIS and SCADA data collected between grab samples were averaged. Each weekly grab sample data set was paired 
with a temperature and insolation date, averaged since the previous grab sample. An averaged weekly value was used for all CIMIS and SCADA data throughout this study unless otherwise noted.

An average temperature from all nine ponds is used for evaluation because the pond temperatures were similar in all ponds: the average of the weekly standard deviations was 0.4 ${ }^{\mathrm{O}} \mathrm{C}$, with the largest standard deviation across all ponds being only $1.0^{\circ} \mathrm{C}$. Peak weekly insolation during 2014 was nearly $200 \mathrm{~W} / \mathrm{m}^{2}$, occurring the same week as the summer solstice (Figure 4-1).

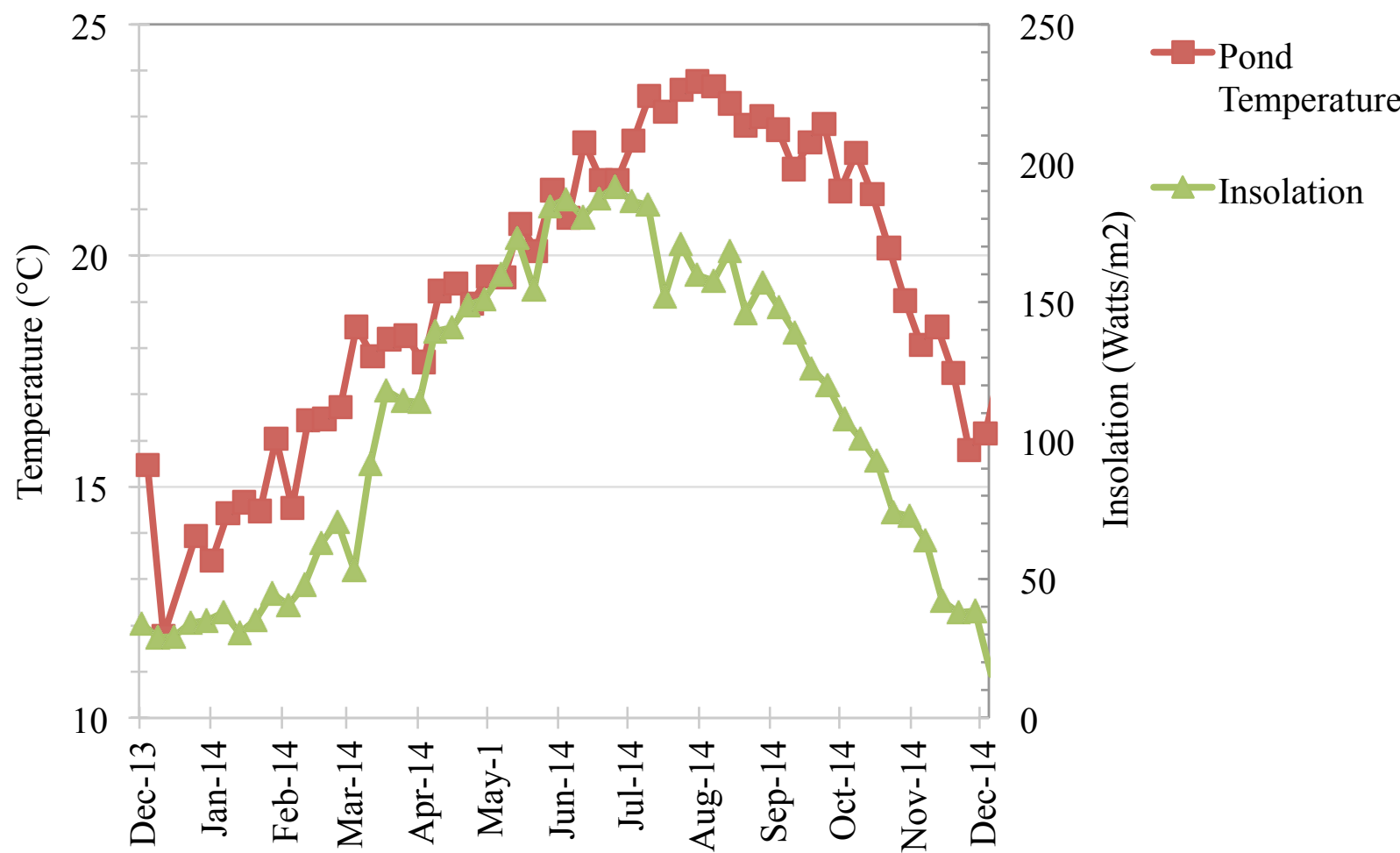

Figure 4-1: Insolation and pond water temperature recorded by CIMIS and SCADA instruments, respectively, for the Cal Poly Algae Field Station during 2014. 
Pond temperature did not correspond consistently to insolation throughout the year, with temperature water peaking in late July and continuing into early October. However, this pattern may not be typical. Air temperature in fall of 2014 was abnormally warm compared to the previous year (Figure 4-2).

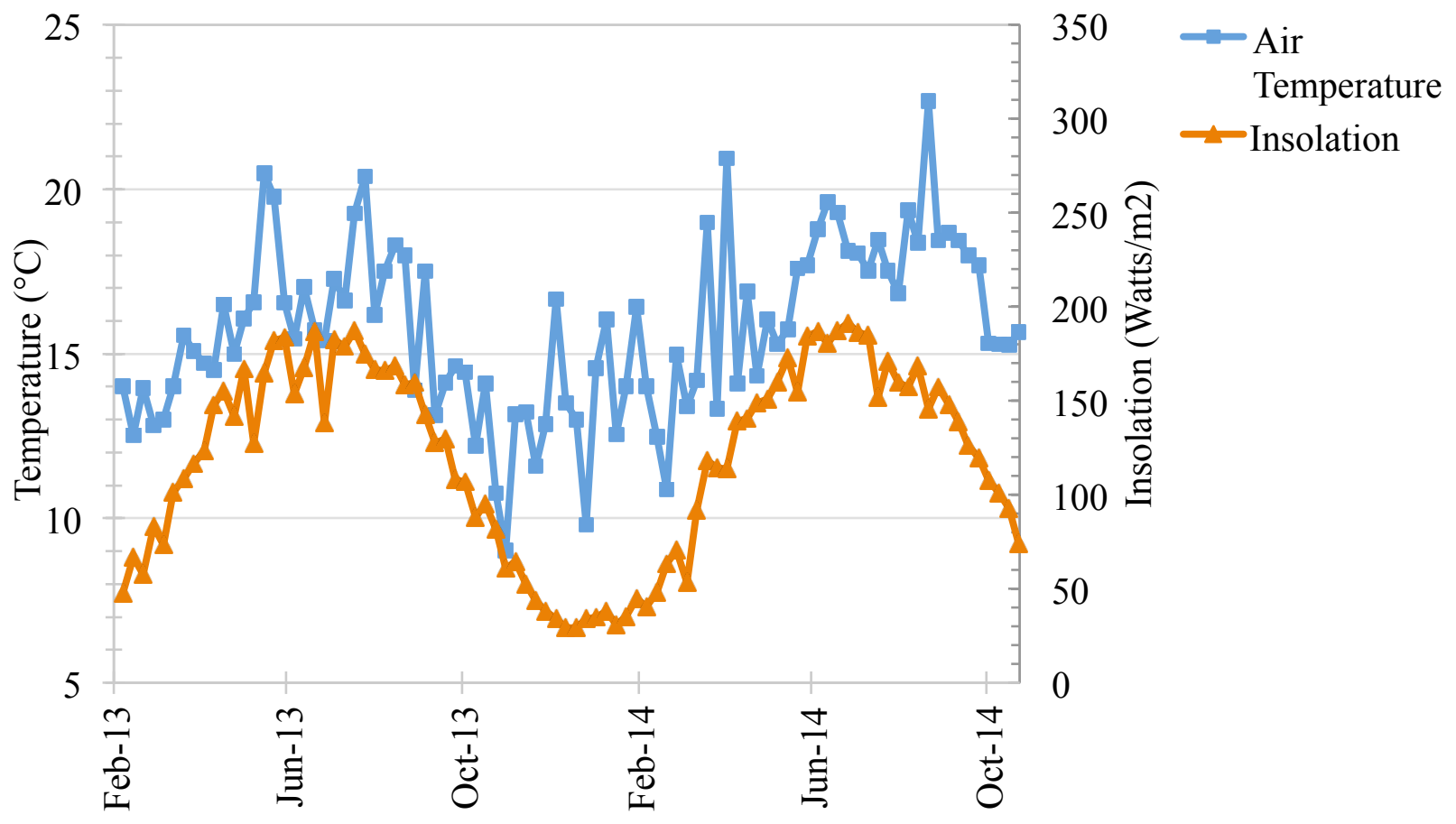

Figure 4-2: Insolation and air temperature for the Cal Poly Algae Field Station during 2013-2014.

\subsubsection{Precipitation}

Precipitation is another significant weather factor in microalgae production. Heavy rains can dilute cultures and nutrient concentrations and deliver dissolved $\mathrm{CO}_{2}$ to ponds. All of precipitation recorded during the experiment was rainfall, with no snow. Total rainfall data measured by CIMIS has been summed across weekly periods corresponding to the grab sample interval (Figure 4-3). 


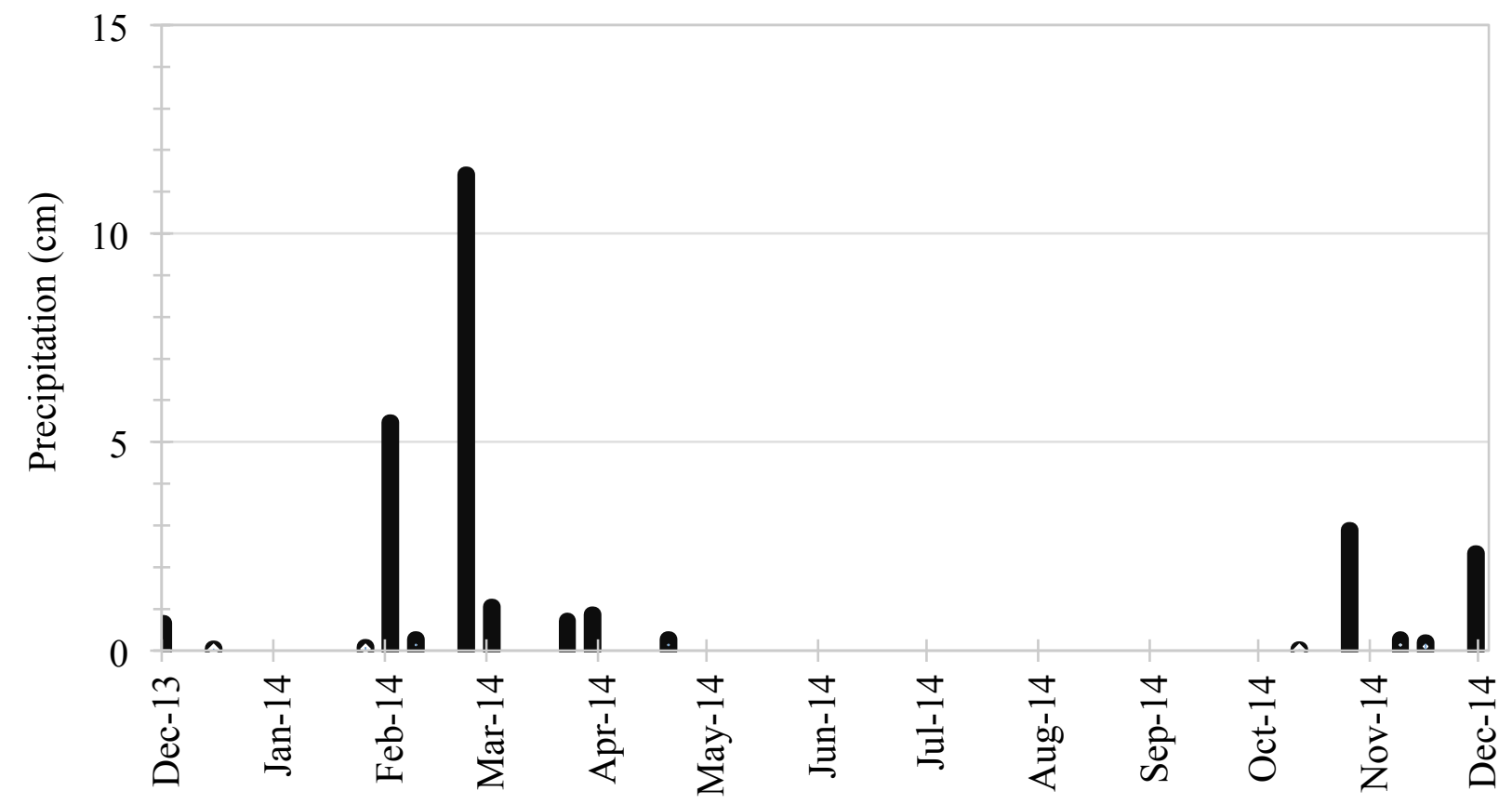

Figure 4-3: Total weekly precipitation for the Cal Poly Algae Field Station during 2014.

The ponds were operated at a depth of $30 \mathrm{~cm}$ with 2 and 3-day residence times, so only a few storms were large enough to significantly impact of the measured pond constituents. For example, during the highest week of precipitation, ending February 23, 2014, the rainfall reached $11.4 \mathrm{~cm}$, which was equivalent to only $16 \%$ and $11 \%$ of the feed water flow in the 3 -day and 2 day HRT ponds, respectively. For this reason, precipitation dilution was not accounted for in reporting the results of this study.

\subsection{Algal Culture Diversity}

Many algal genera were identified in the ponds during the experiments in weekly microscopic investigations. The selected of micrograph of Stigeoclonium is an example of one of the many micrographs collected, which were used in the determination of prominent algal genera (Figure 4-4). 


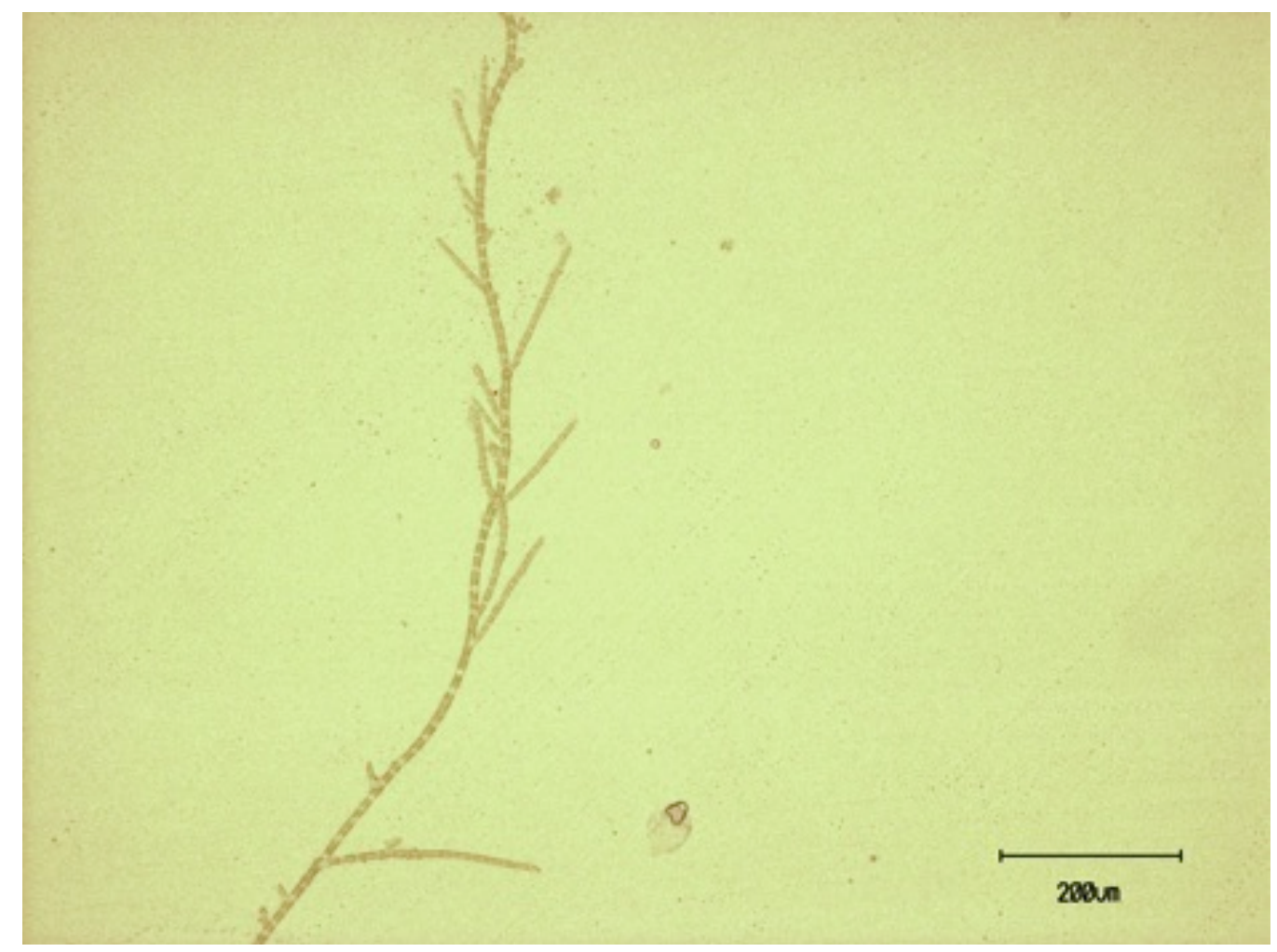

Figure 4-4: Stigioclonium at 100 times zoom in Pond 7 on June 19, 2014.

The 2-day HRT pond set appear to have had less diversity than the 3-d HRT ponds, and the Round-2 ponds mostly maintained the same prominent genera as the Round-1 ponds (Table 4-1). The criterion for the presented genera was that they were prominent genera within the raceway ponds for at least one week; however, most all of the species were repeatedly prominent over the course of the year. Prominence was defined as comprising a minimum of roughly $15 \%$ of the biomass visible on a representative sample on a microscope slide. The effect of various algal genera on productivity and settling are presented in a later section. 
Table 4-1: Prominent algal genera in the experimental raceway ponds, from December 2013 to October 2014.

\begin{tabular}{lccc} 
Algal Genera & 2-Day HRT & $\begin{array}{c}\text { Round-1, } \\
\text { 3-Day HRT }\end{array}$ & $\begin{array}{c}\text { Round-2, } \\
\text { 3-Day HRT }\end{array}$ \\
\hline Coelastrum & & $\mathrm{X}$ & \\
Chlorella & $\mathrm{X}$ & $\mathrm{X}$ & $\mathrm{X}$ \\
Chlorococcum & $\mathrm{X}$ & $\mathrm{X}$ & $\mathrm{X}$ \\
Closteridium & & $\mathrm{X}$ & $\mathrm{X}$ \\
Cyclotella & $\mathrm{X}$ & $\mathrm{X}$ & $\mathrm{X}$ \\
Micractinium & & $\mathrm{X}$ & $\mathrm{X}$ \\
Nitzschia & $\mathrm{X}$ & $\mathrm{X}$ & $\mathrm{X}$ \\
Oscillatoria & & $\mathrm{X}$ & $\mathrm{X}$ \\
Pediastrum & & $\mathrm{X}$ & $\mathrm{X}$ \\
Scenedesmus & $\mathrm{X}$ & $\mathrm{X}$ & $\mathrm{X}$ \\
Stigeoclonium & $\mathrm{X}$ & $\mathrm{X}$ & $\mathrm{X}$ \\
\hline
\end{tabular}

\subsection{Diel Characteristics of Influent Wastewater}

The characteristics of the primary clarifier effluent entering the raceway ponds were used in assessing productivity and treatment performance. However, primary effluent quality changes over the course of each day in a diel pattern (Metcalf, 2003), and only 7 am grab samples were collected during part of the present study. The differences in TSS, VSS and BOD concentrations in grab samples and 24-hour composite samples are compared in this section.

As described in the Methods chapter, an automatic sampler was used to collect composite samples for comparison to the routine morning grab samples. Composite samples were drawn hourly, from the influent head tank of the 2-day HRT pond set, over a 24-hour period. The composite sample was assumed to provide the most accurate practical representation of total 
pond influent. A correlation equation was determined for composite and grab sampling water quality results, which was meant to be used as a correction factor to estimate actual influent pollutant loads from grab sample results.

Except for one date, the TSS concentrations obtained from influent grab samples were consistently lower than the composite samples. On average the composite samples had a $20 \%$ higher TSS concentration (Table 4-2).

Table 4-2: Comparison of TSS concentrations in 24-hr composite and grab samples of primary clarifier effluent at the Cal Poly Algae Field Station.

\begin{tabular}{cccc} 
Influent Grab & $\begin{array}{c}\text { Influent Composite } \\
\text { Sample } \\
\text { TSS (mg/L) }\end{array}$ & $\begin{array}{c}\text { Percent } \\
\text { TSS (mg/L) }\end{array}$ & $\begin{array}{c}\text { Difference } \\
(\%)\end{array}$ \\
\hline $7 / 31 / 14$ & 48 & 84 & $43 \%$ \\
$8 / 7 / 14$ & 51 & 61 & $17 \%$ \\
$8 / 21 / 14$ & 66 & 55 & $-19 \%$ \\
$8 / 28 / 14$ & 66 & 67 & $1 \%$ \\
$9 / 12 / 14$ & 71 & 89 & $21 \%$ \\
$10 / 8 / 14$ & 143 & 252 & $43 \%$ \\
$10 / 15 / 14$ & 60 & 91 & $34 \%$ \\
$10 / 22 / 14$ & 62 & 112 & $45 \%$ \\
$11 / 5 / 14$ & 82 & 91 & $10 \%$ \\
$11 / 12 / 14$ & 84 & 111 & $24 \%$ \\
$12 / 3 / 14$ & 79 & 81 & $3 \%$ \\
\hline Average & 74 & 99 & $20 \%$ \\
\hline
\end{tabular}

Despite the inconsistent percent differences between grab and composite samples, a correlation of the two variables is provided (Figure 4-5) to allow a rough estimate of composite sample averages given grab sample averages. 


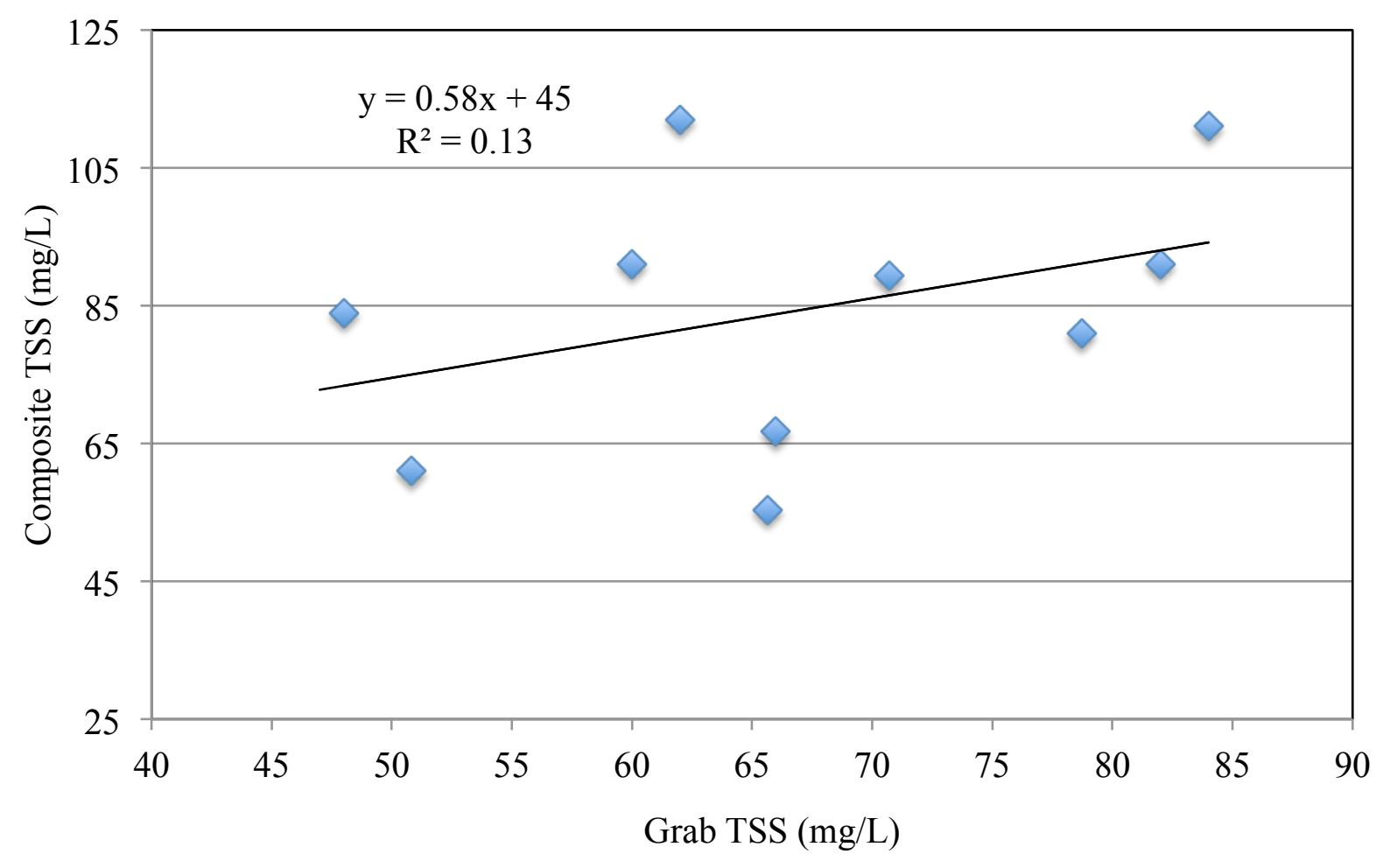

Figure 4-5: Correlation of TSS concentrations in $7 \mathrm{am}$ grab and 24-hour composite samples of clarified municipal wastewater from July 2014 to December 2014.

The same approach was used for VSS as used for TSS (Table 4-3, Figure 4-6).

Table 4-3: Comparison of VSS concentrations in 24-hr composite and grab samples of primary clarifier effluent at the Cal Poly Algae Field Station.

\begin{tabular}{cccc} 
Date & $\begin{array}{c}\text { Influent Grab } \\
\text { Sample } \\
\text { VSS (mg/L) }\end{array}$ & $\begin{array}{c}\text { Composite } \\
\text { Influent Sample } \\
\text { VSS (mg/L) }\end{array}$ & $\begin{array}{c}\text { Percent } \\
\text { Difference } \\
(\%)\end{array}$ \\
\hline $7 / 31 / 14$ & 37 & 73 & $49 \%$ \\
$8 / 21 / 14$ & 60 & 52 & $-15 \%$ \\
$8 / 28 / 14$ & 57 & 60 & $4 \%$ \\
$9 / 12 / 14$ & 63 & 75 & $16 \%$ \\
$10 / 8 / 14$ & 131 & 227 & $42 \%$ \\
$10 / 15 / 14$ & 57 & 82 & $30 \%$ \\
$10 / 22 / 14$ & 59 & 101 & $42 \%$ \\
$11 / 5 / 14$ & 73 & 79 & $8 \%$ \\
$11 / 12 / 14$ & 76 & 99 & $23 \%$ \\
$12 / 3 / 14$ & 69 & 75 & $8 \%$ \\
\hline Average & 68 & 92 & $21 \%$ \\
\hline
\end{tabular}




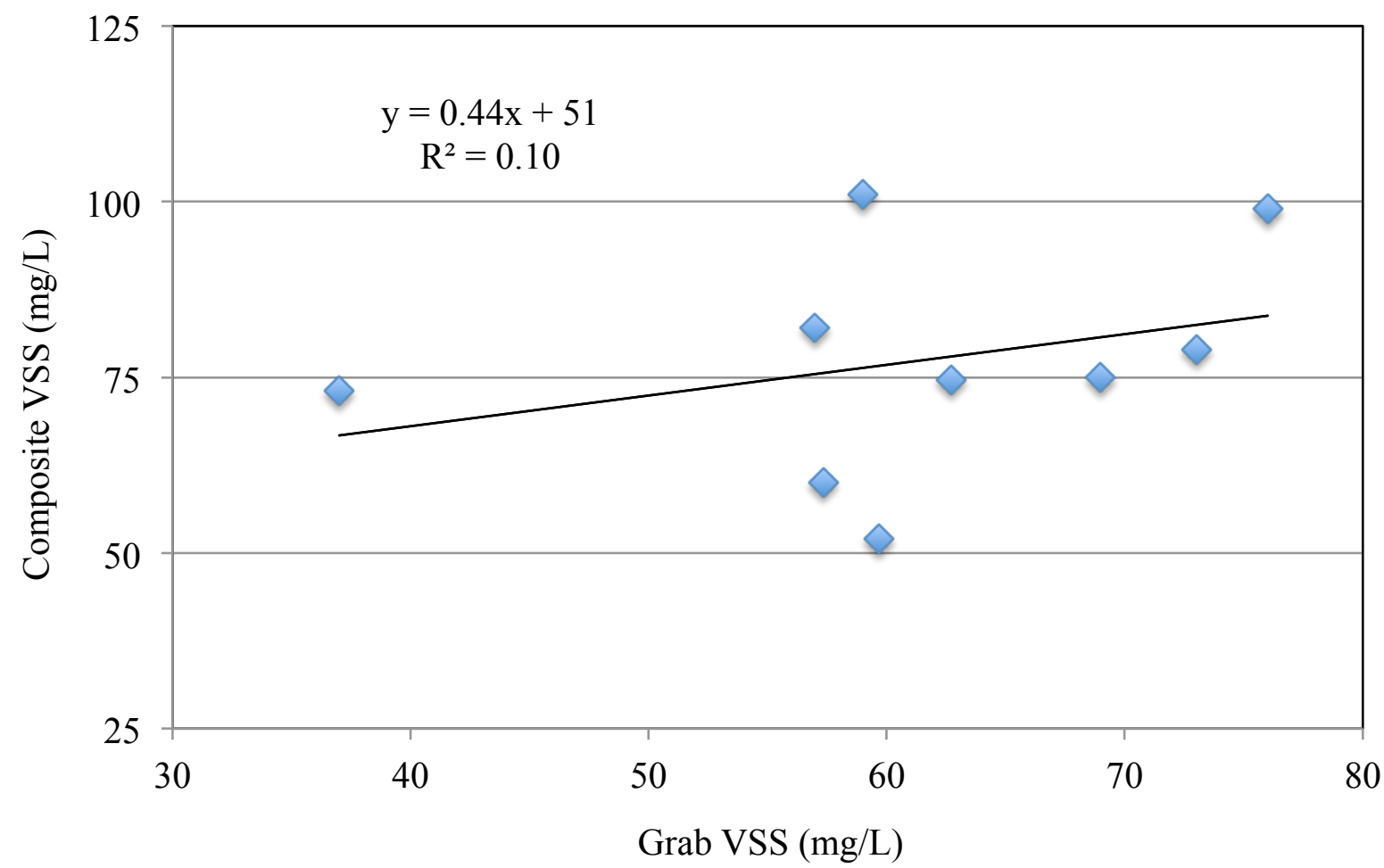

Figure 4-6: Correlation of VSS concentrations in 7 am grab and 24-hour composite samples of clarified municipal wastewater from July 2014 to December 2014.

The low r-squared values of the correlations and the disparate average concentrations for TSS and VSS indicate that any single factor for estimating composite concentrations from grab concentrations will have poor accuracy. The most that can be said is that TSS and VSS concentrations are typically higher 24-hour composite samples.

Influent biochemical oxygen demand also varied over the course of each day, but the average percent difference of grab and composite sampling for total carbonaceous $\mathrm{BOD}_{5}$ was $0 \%$ (Table 4-4). 
Table 4-4: Comparison of total carbonaceous $\mathrm{BOD}_{5}$ concentrations in 24-hr composite and grab samples of primary clarifier effluent at the Cal Poly Algae Field Station.

\begin{tabular}{cccc} 
Date & $\begin{array}{c}\text { Influent Grab } \\
\text { Sample } \\
\text { cBOD }_{5}(\mathrm{mg} / \mathrm{L})\end{array}$ & $\begin{array}{c}\text { Composite } \\
\text { Influent Sample } \\
\mathrm{cBOD}_{5}(\mathrm{mg} / \mathrm{L})\end{array}$ & $\begin{array}{c}\text { Percent } \\
\text { Difference } \\
(\%)\end{array}$ \\
\hline $10 / 15 / 14$ & 139 & 152 & $8 \%$ \\
$10 / 22 / 14$ & 121 & 108 & $-12 \%$ \\
$10 / 29 / 14$ & 147 & 143 & $-3 \%$ \\
$11 / 5 / 14$ & 146 & 170 & $14 \%$ \\
$11 / 12 / 14$ & 175 & 184 & $5 \%$ \\
$11 / 19 / 14$ & 172 & 147 & $-16 \%$ \\
$12 / 3 / 14$ & 133 & 136 & $2 \%$ \\
\hline Average & 148 & 149 & $0 \%$ \\
\hline
\end{tabular}

On average the composite and grab samples had the same concentrations; however, the correlation between the two was scattered, with an r-squared of 0.14 (Figure 4-7). This shows that the correlation was still poor despite the average percent difference of $0 \%$.

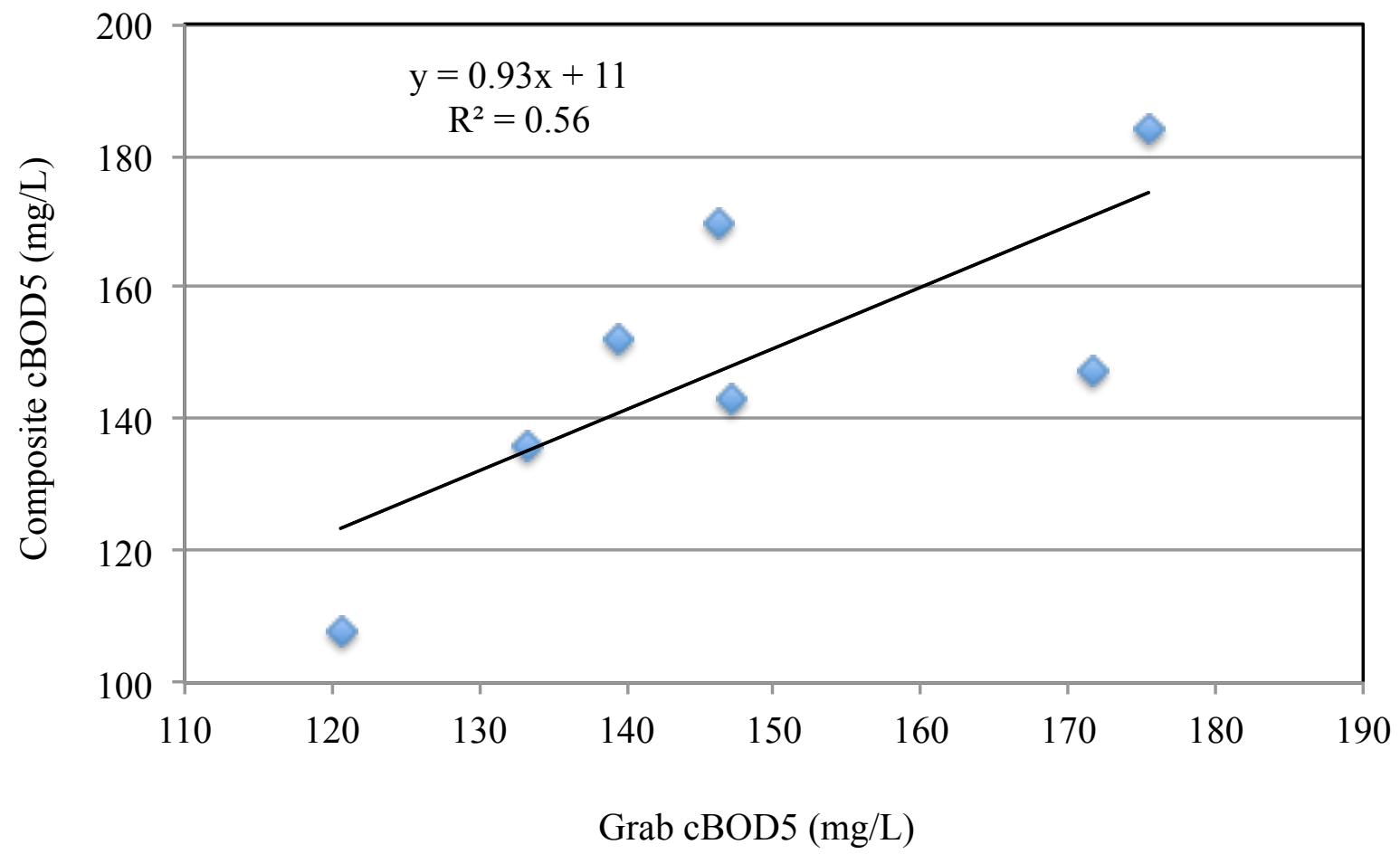

Figure 4-7: Correlation of total carbonaceous biochemical oxygen demand concentrations in 7 am grab and 24-hour composite samples of clarified municipal wastewater from July 2014 to December 2014. 
A previous Cal Poly study (Ripley, 2014) found that the autosampling equipment (Hach Sigma autosampler) selectively captured suspended solids, especially in cultures containing filamentous organisms. However, waters with only small flocs or colloids (e.g., primary clarifier effluent) were sampled representatively by the autosampler. This earlier study on composite sampling of primary clarifier effluent suggests that, in this study, the differences in TSS and VSS concentration between grab and composite samples are indeed due to diel variation and not sampling error.

The same approach was used for soluble carbonaceous $\mathrm{BOD}_{5}$ as was used for total carbonaceous $\mathrm{BOD}_{5}$ (Table 4-5).

Table 4-5: Comparison of soluble carbonaceous $\mathrm{BOD}_{5}$ concentrations in 24-hr composite and grab samples of primary clarifier effluent at the Cal Poly Algae Field Station.

\begin{tabular}{cccc} 
Date & $\begin{array}{c}\text { Influent Grab } \\
\text { Sample } \\
\text { csBOD }_{5}(\mathrm{mg} / \mathrm{L})\end{array}$ & $\begin{array}{c}\text { Composite } \\
\text { Influent Sample } \\
\text { csBOD }_{5}(\mathrm{mg} / \mathrm{L})\end{array}$ & $\begin{array}{c}\text { Percent } \\
\text { Difference } \\
(\%)\end{array}$ \\
\hline $10 / 15 / 14$ & 98 & 103 & $5 \%$ \\
$10 / 22 / 14$ & 85 & 80 & $-7 \%$ \\
$10 / 29 / 14$ & 106 & 83 & $-27 \%$ \\
$11 / 5 / 14$ & 102 & 113 & $10 \%$ \\
$11 / 12 / 14$ & 130 & 122 & $-7 \%$ \\
$11 / 19 / 14$ & 77 & 95 & $19 \%$ \\
$12 / 3 / 14$ & 93 & 89 & $-5 \%$ \\
\hline Average & 99 & 98 & $-2 \%$ \\
\hline
\end{tabular}

The correlation of composite and grab samples produced an r-squared value of 0.46 , the highest of all the composite and grab sample correlations (Figure 4-8). However, the resulting correlation still has substantial scatter and cannot be used to accurate estimate 24-hour concentration from grab sample data for individual samples. 


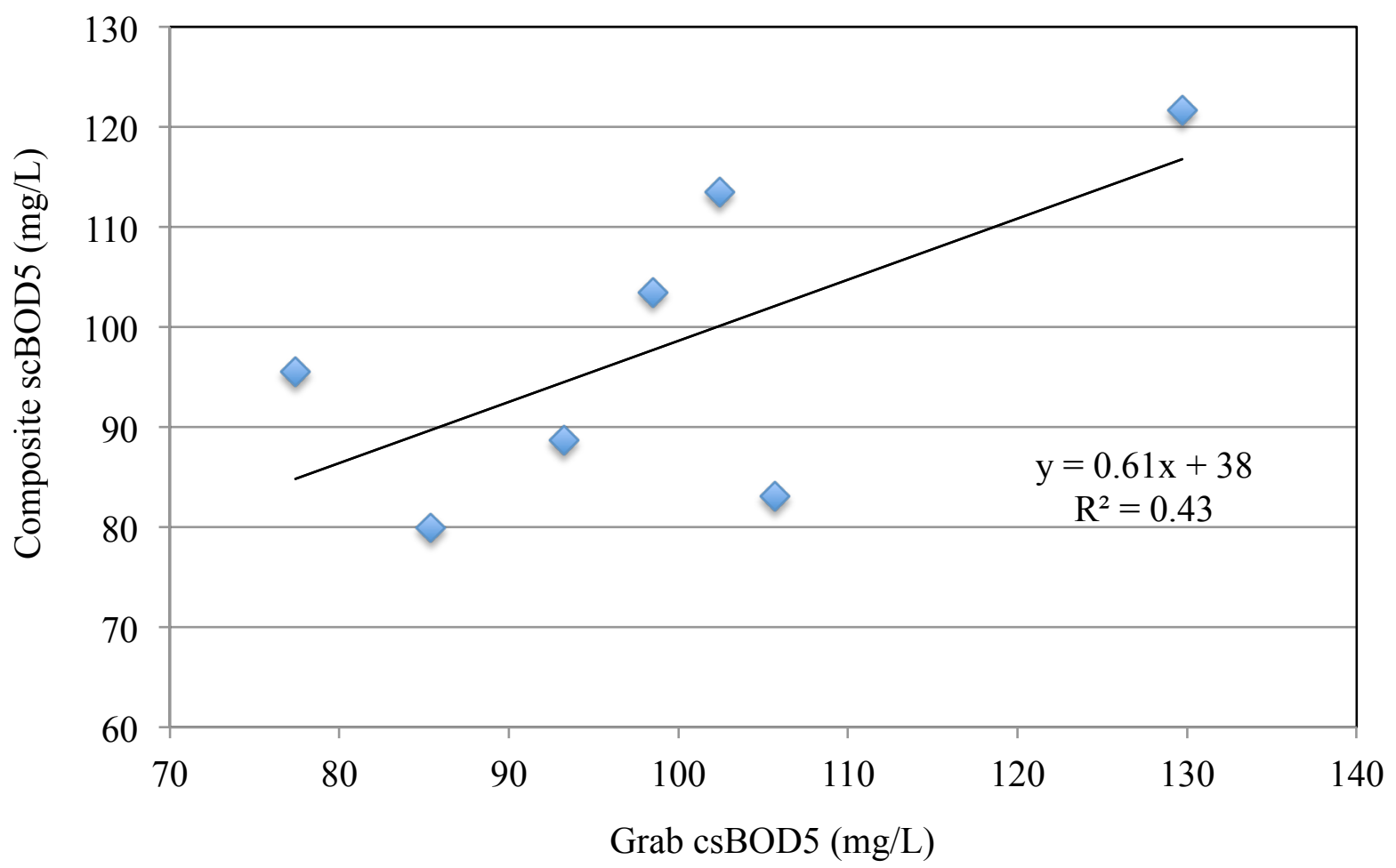

Figure 4-8: Correlation of soluble carbonaceous biochemical oxygen demand concentrations in 7 am grab and 24-hour composite samples of clarified municipal wastewater from July 2014 to December 2014.

Overall, the average difference between grab and composite samples was large, and only a loose correlation was found for TSS, VSS, $\mathrm{cBOD}_{5}$ and soluble carbonaceous $\mathrm{BOD}_{5}$. This study showed that a composite sample of the diel flow does not consistently match the 7 am grab sample with a simple correlation or ratio. For this reason, all influent pond data presented in this study were derived from grab samples and not corrected to represent the influent diel flow.

\subsection{Biological Oxygen Demand Removal}

Oxygen demand reduction is a key requirement of wastewater treatment. To determine the effectiveness of BOD removal from the experimental raceway ponds, soluble carbonaceous $\mathrm{BOD}_{5}$ concentrations were determined for the influent and pond grab samples. Soluble 
carbonaceous $\mathrm{BOD}_{5}$ was selected as a measure of treatment because any residual suspended solids in the effluent could be removed by filtration and soluble carbonaceous $\mathrm{BOD}_{5}$ removal better represents the satisfaction of oxygen demand. Similarly, nitrogenous BOD information could be derived from the ammonia measurements also made on the samples (Reiff, 2015).

Achieving low soluble carbonaceous $\mathrm{BOD}_{5}$ concentrations is a key in demonstrating the practicality of raceway pond systems for wastewater treatment. The soluble carbonaceous $\mathrm{BOD}_{5}$ concentrations in the raceway ponds all averaged $<6 \mathrm{mg} / \mathrm{L}$ (Figure 4-9).

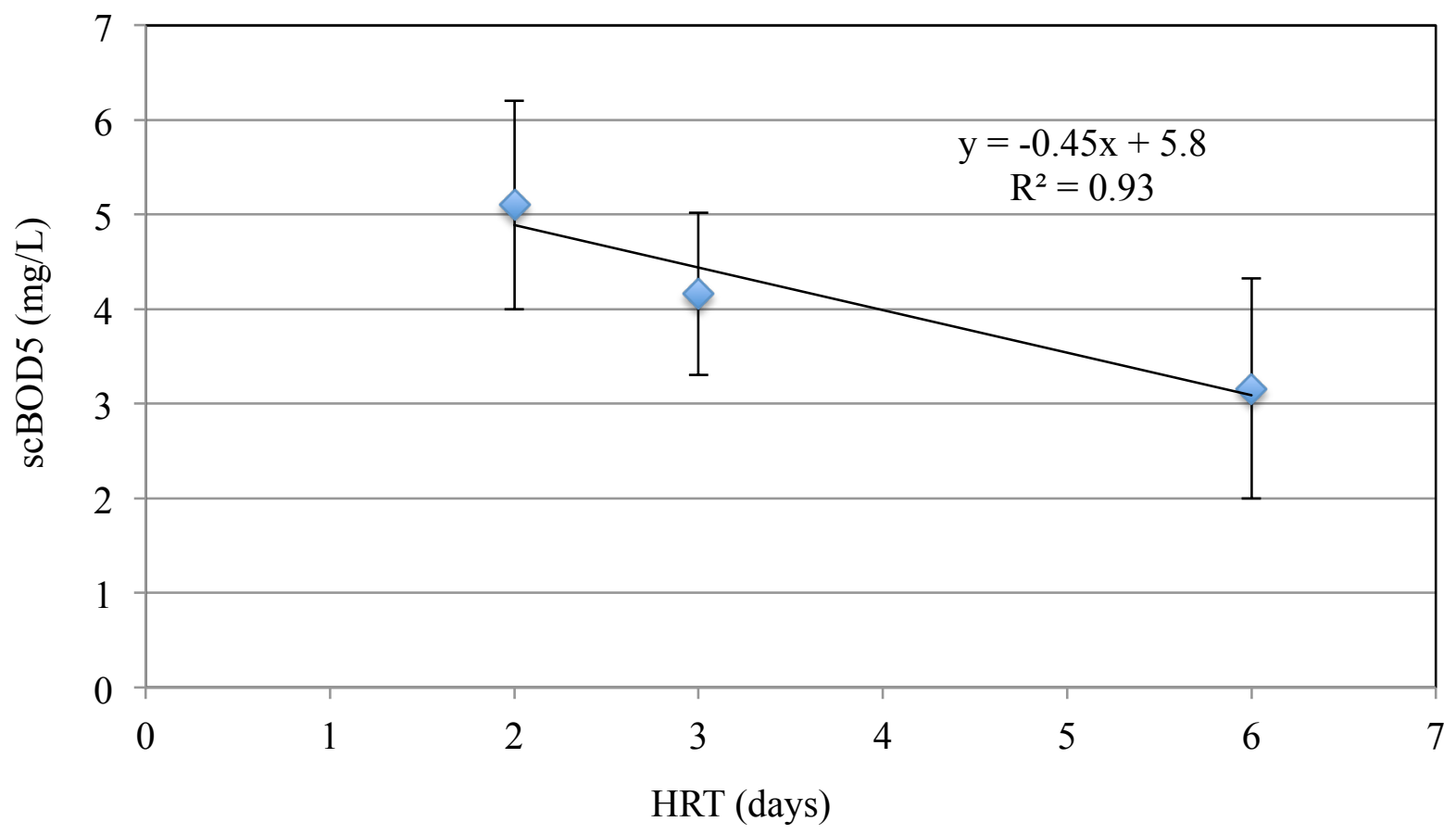

Figure 4-9: Soluble carbonaceous $\mathrm{BOD}_{5}$ concentrations for continuously operated raceway ponds at the Cal Poly Algae Field Station, from August 8, 2013 to August 14, 2014, for given HRTs. The error bars represent the standard deviation of BOD removal for each pond set over the course of the experiment. The Round-2, 3-day HRT pond set is shown as 6-day HRT. 
The correlation line illustrates the impact of additional days of treatment on BOD concentration. The additional day of treatment (from 2-day to 3-day) removed an additional $0.9 \mathrm{mg} / \mathrm{L}$ BOD. Similarly, an additional $1.0 \mathrm{mg} / \mathrm{L}$ was removed in the second set of 3-day ponds in series (6-day total treatment). BOD removal did not improve substantially with longer residence time, indicated that near-maximum removal was already achieved in a 2-day HRT.

To further understand the performance of BOD treatment, BOD removal is calculated using Equation 4-1.

Equation 4-1: Soluble carbonaceous $\mathrm{BOD}_{5}$ removal

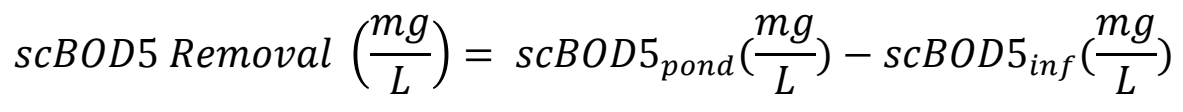

It should be noted that the BOD concentrations were derived from grabs sample of the ponds. Also the soluble carbonaceous $\mathrm{BOD}_{5}$ concentration of the Round-2 pond influent water was assumed to be to the Round-1 pond concentration, since soluble constituents are not removed in the tube settlers.

The Round-1, 3-day HRT and the 2-day HRT pond sets provided essentially the same concentration removal (78.3 mg/L and $77.4 \mathrm{mg} / \mathrm{L}$ removed, respectively) (Figure 4-10). 


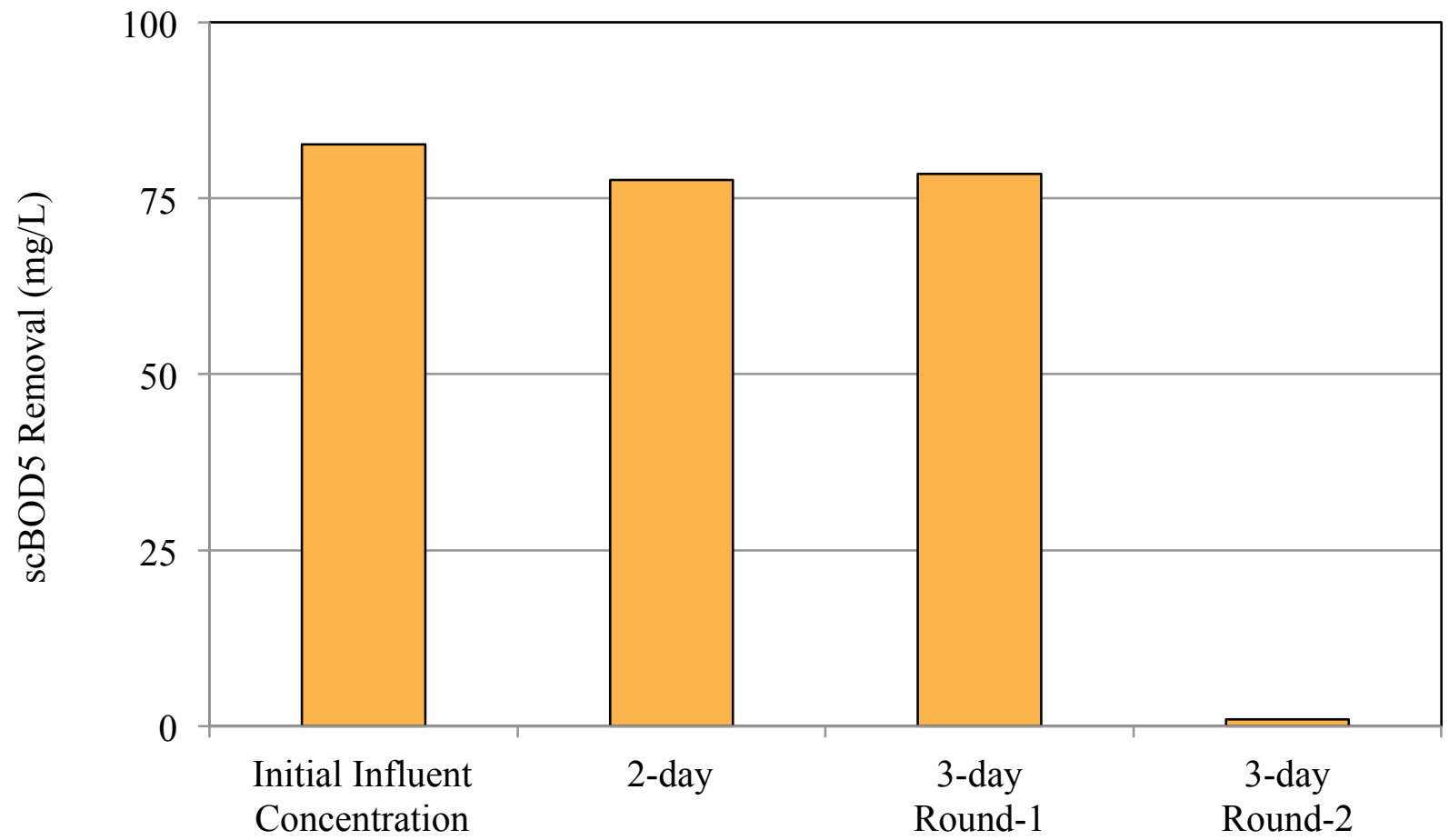

Figure 4-10: Average removal of soluble carbonaceous biochemical oxygen demand for a given hydraulic residence time. The initial influent concentration had a standard deviation of $19 \mathrm{mg} / \mathrm{L}$. The data were average from August 8, 2013 to August 14, 2014 using all dates that passed analytical quality control criteria.

In an additional 3 days of treatment in the Round-2 ponds, only an additional $1 \mathrm{mg} / \mathrm{L}$ of soluble carbonaceous $\mathrm{BOD}_{5}$ was removed on average. Therefore, $\mathrm{BOD}$ concentration is greatly reduced in the ponds receiving primary clarifier effluent, and a prolonged HRT is unlikely needed to only slightly increase BOD removal.

\subsection{Productivity}

The biomass productivity of the raceway ponds is the primary concern for the future development of algal biofuel production. Throughout this section, data previously collected and interpreted data from Chang (2014) has been included where applicable to present a longer period of uninterrupted data trends. 


\subsubsection{Net Areal Productivity}

All productivity data presented in this section are net areal productivity (g VSS $/ \mathrm{m}^{2}$-day) based on the difference between influent and effluent VSS concentrations. No distinction has been made in this section between heterotrophic and autotrophic growth. Subtracting influent VSS from effluent VSS for calculation of net productivity underestimates actual growth. Wastewater VSS is comprised of biodegradable and nonbiodegradable fractions. During biodegradation, some of the organic matter supports new heterotrophic biomass growth (assimilation) and the rest of the organic matter is lost to respiration or remains soluble and escapes in the pond effluent (dissimilation). By subtracting influent from effluent VSS concentration the dissimulated portion of the organic matter is incorrectly subtracted from the pond productivity. Thus, net productivity is underestimated and conservative. The average productivity from June 26, 2013 to September 24, 2014 showed that higher productivities, on average, were achieved in the pond sets with lower HRTs (Figure 4-11). 


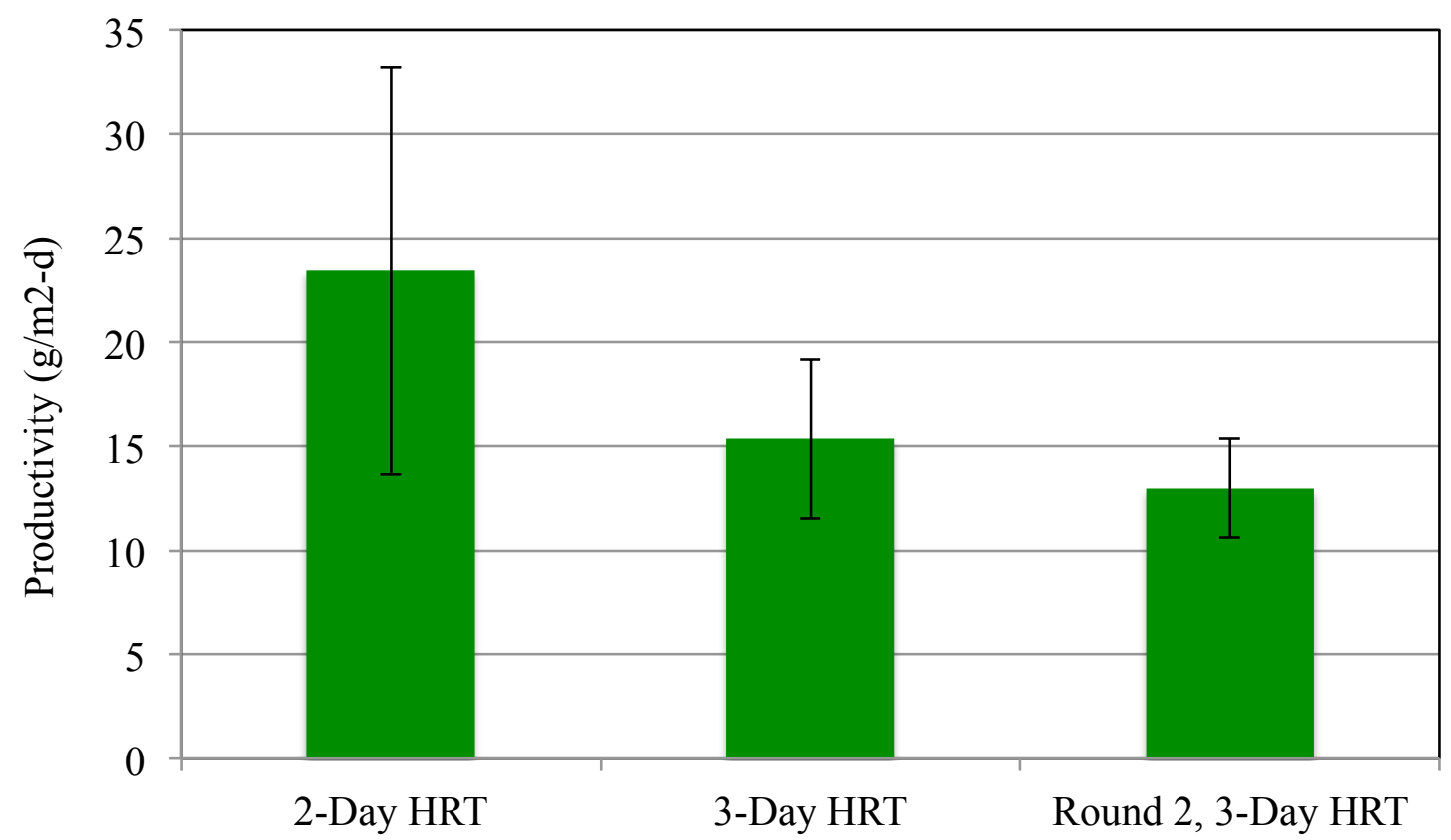

Figure 4-11: Average net productivity for each of the pond set operating conditions, from June 26, 2013 to September 24, 2014. The error bars represent the standard deviation averaged from week of the triplicate ponds in each pond set, shown in both the positive and negative direction.

The lower mean productivity (not statistically significant) observed in the ponds receiving recycled water (Round-2 set) is a potential concern for biofuel production, where the majority of water would need to be recycled to minimize water consumption while maintaining high productivity. A potential cause of the lower productivities associated with longer HRTs and recycling water is the release of allelochemicals by algae. This potential is being studied in a separate Cal Poly thesis project currently underway (W.H. Spence). However, evidence against the presence of allelopathic inhibition in the present studies is further discussed at the end of sections 4.5.2 Autotrophic Productivity and 4.5.4 Analysis of Pond Specific Productivity Crash.

Aside from a source of water for algal growth, the other primary requirements for growth are solar insolation, tolerable temperature, and a source of nutrients. In this study, soluble nitrogen and phosphorus were never diminished to the point of limit algal growth rates, based on typical 
Monod half-saturation constants for green algae (Fulton 2009). Therefore, insolation was assumed to be the main growth limiting factor (Reiff, 2015 and Kraetsch, 2015), and all the ponds received equal levels of solar radiation.

\subsubsection{Correlation of Insolation and Productivity}

Assuming that insolation was the largest limiting factor in algal growth, a strong correlation between productivity and insolation was expected. The average productivity of each triplicate pond set graphed with insolation illustrates the general similarities of the two patterns (Figures 4-12, 4-13, and 4-14).

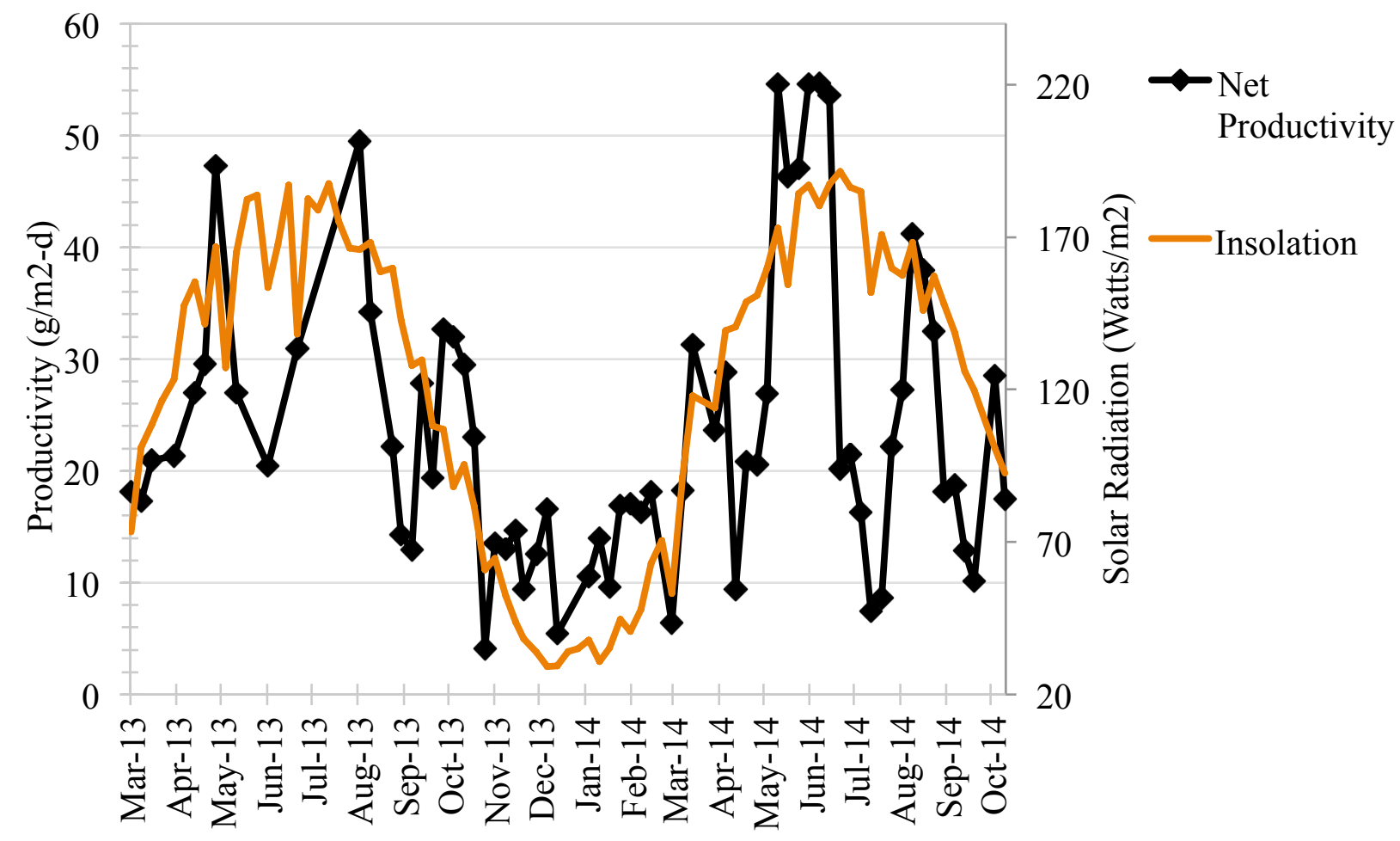

Figure 4-12: Productivity and insolation for the 2-day HRT pond set from March 2013 to October 2014. 


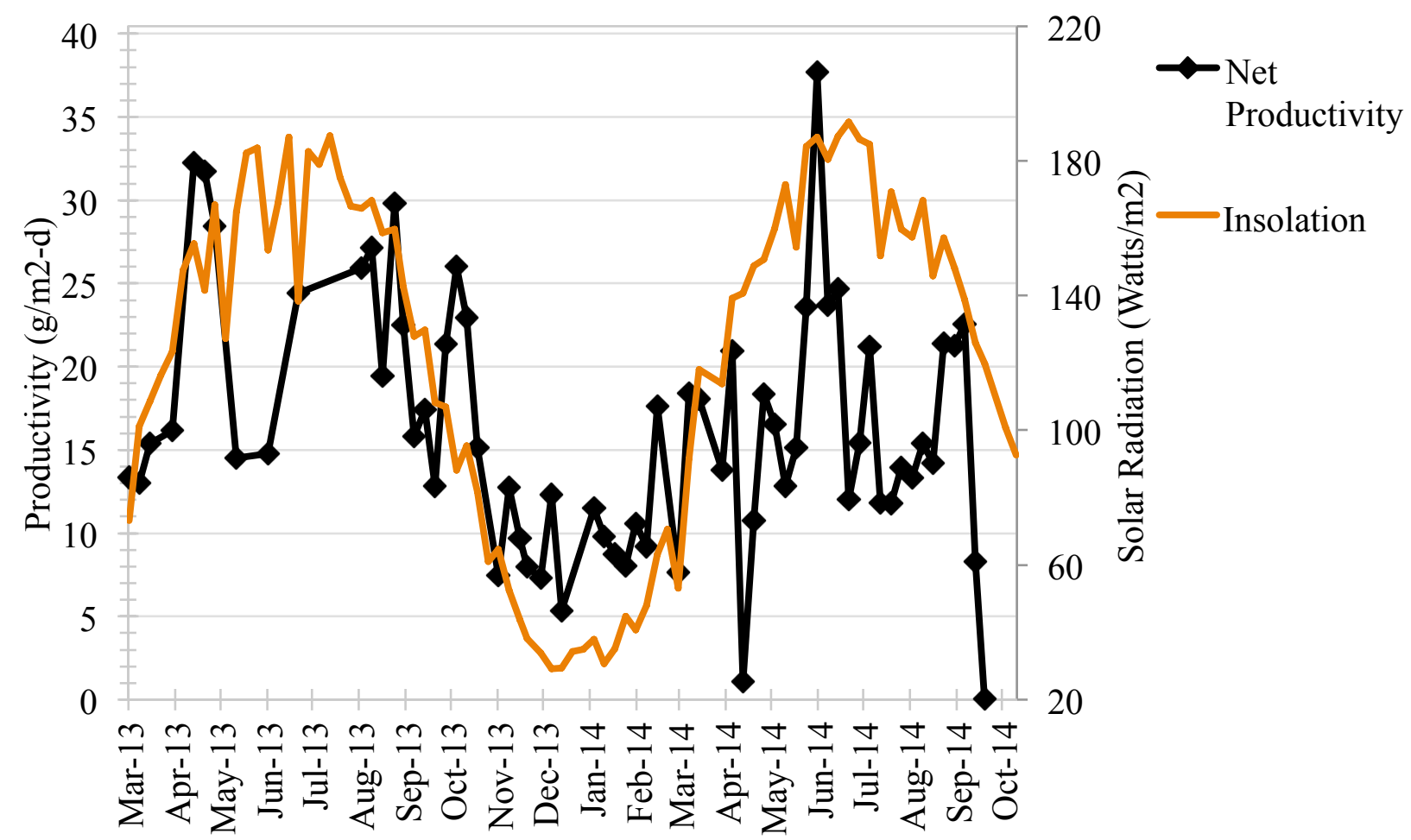

Figure 4-13: Productivity and insolation for the Round-1, 3-day HRT pond set from March 2013 to October 2014. 


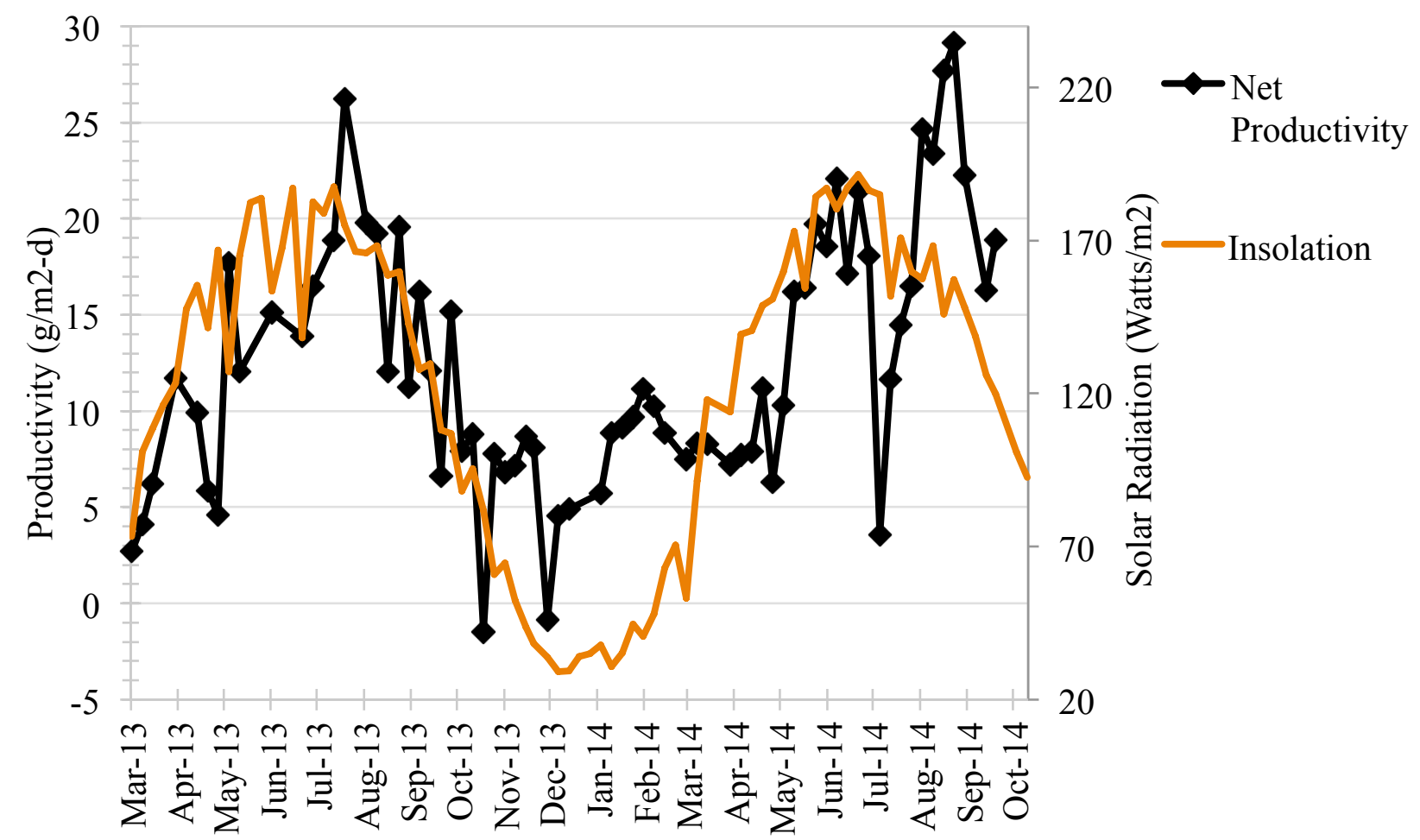

Figure 4-14: Productivity and insolation for the Round-2, 3-day HRT pond set from March 2013 to October 2014.

The graphs of productivity in each pond set illustrate that higher productivities tended to occur when insolation was higher, as expected. However, the frequent deviations of productivity from insolation trends reveal that other factors have a large influence on algal growth as well.

To quantify abnormally high or low productivities, a model has been created for with each pond sets' HRT. Because insolation was the major controlling factor of productivity, a linear correlation line was fit to a scatter plot of productivity versus insolation for each pond set. This model roughly described the productivity expected for any given insolation (Figure 4-20, Figure 4-21, Figure 4-22). 


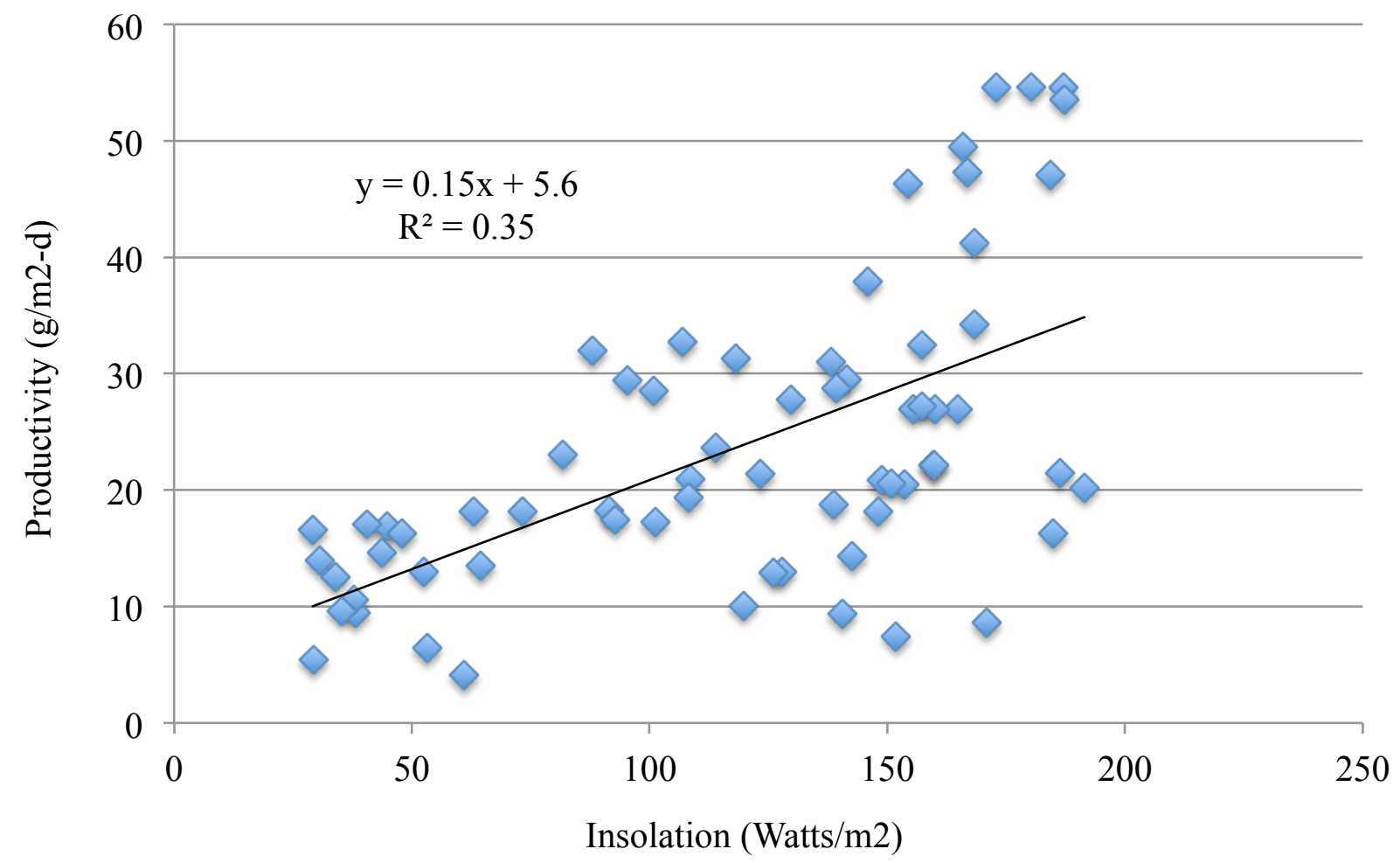

Figure 4-15: Correlation of insolation and net productivity for the 2-day HRT pond set, from March 6, 2014 to October 16, 2014. 


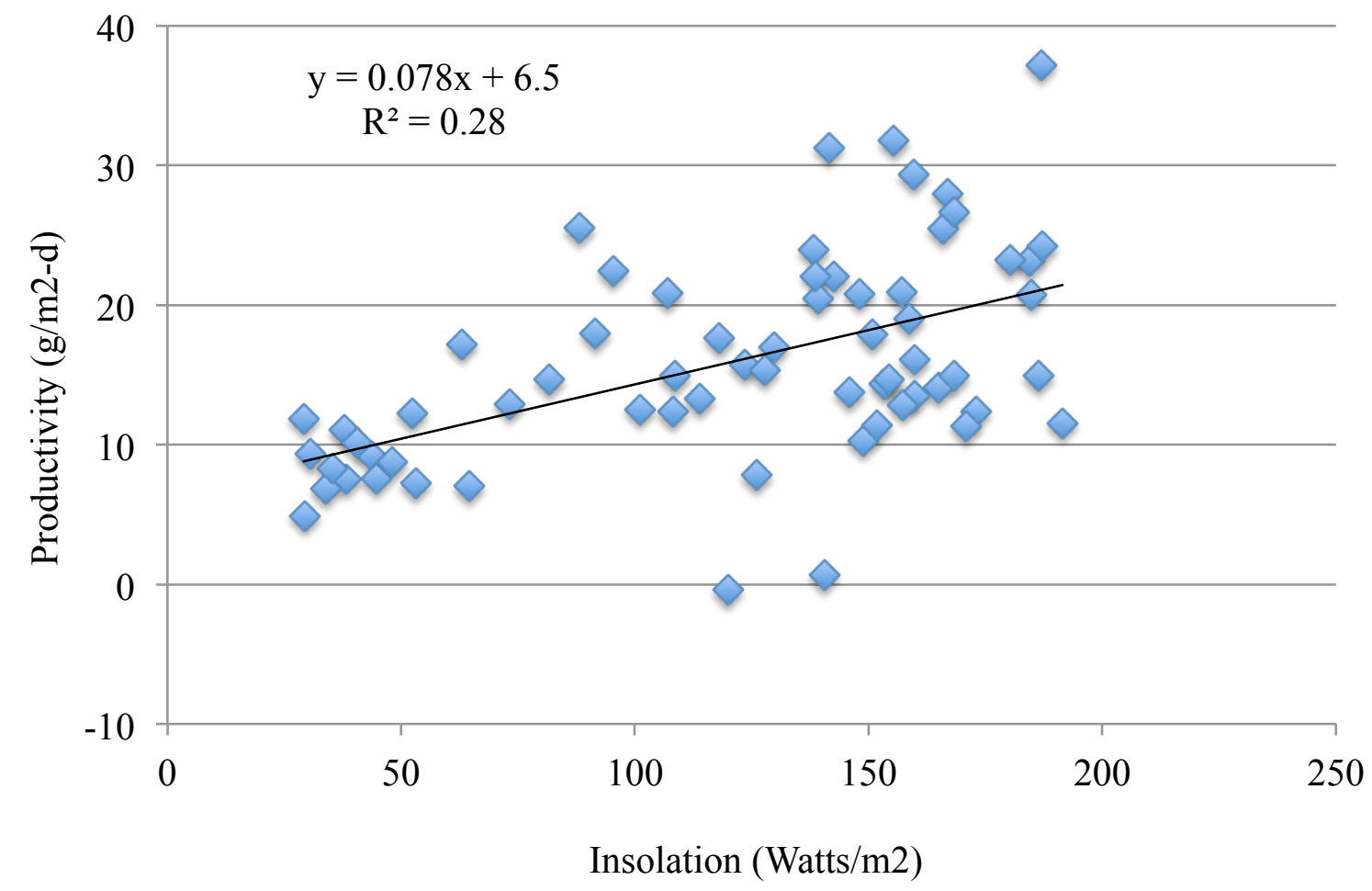

Figure 4-16: Correlation of insolation and net productivity for the 3-day HRT pond set, from March 6, 2014 to September 24, 2014. 


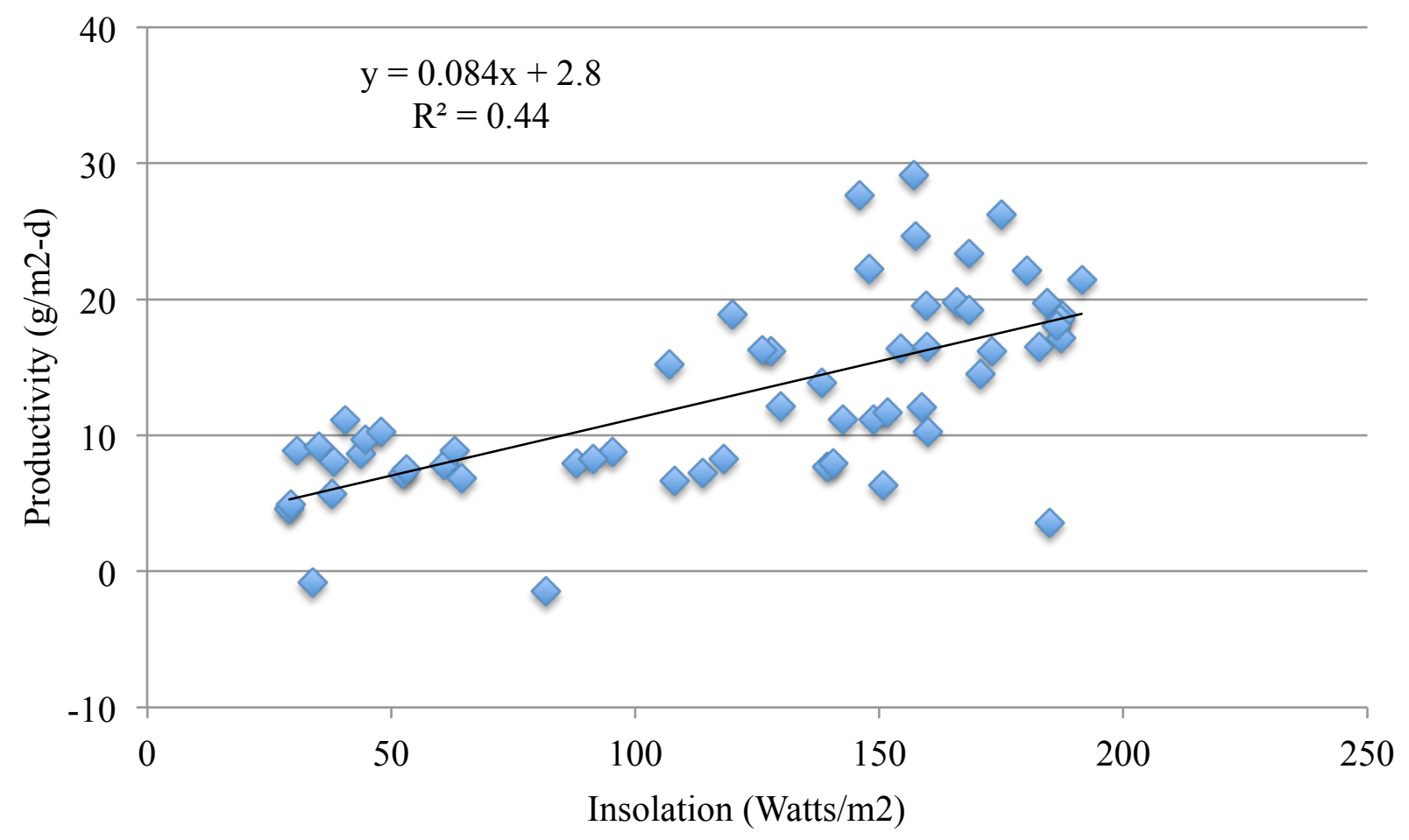

Figure 4-17: Correlation of insolation and net productivity for the Round-2, 3-day HRT pond set, from March 6, 2014 to September 24, 2014.

The models of productivity given insolation provide an estimate of typical productivity would be like for a given insolation value, albeit with low $\mathrm{r}^{2}$ values for the correlations. The models can at least reveal if productivity is low or high due to a factor aside from insolation. As seen in the correlations of productivity and insolation (Figures 4-20 to 22), deviation from the model correlation was greater when insolation was high. Although, on a percentage basis, the deviations might be similar in the high and low insolation periods.

\subsubsection{Autotrophic Productivity}

Net areal productivity, as calculated herein, includes both autotrophic growth (mainly algae) and heterotrophic growth (bacteria and some algae) (Figure 4-15). Both algal and bacterial biomass can be used as biofuel feedstock (e.g., for anaerobic digestion and hydrothermal liquefaction), 
but it is important to know the autotrophic algae productivity separately from heterotrophic productivity. In biofuel productions systems, wastewater would be recycled and would have lower dissolved organic matter content than wastewater and consequently lower heterotrophic productivity. Photoautotrophy would be the main source of reduced carbon for biofuel feedstock.

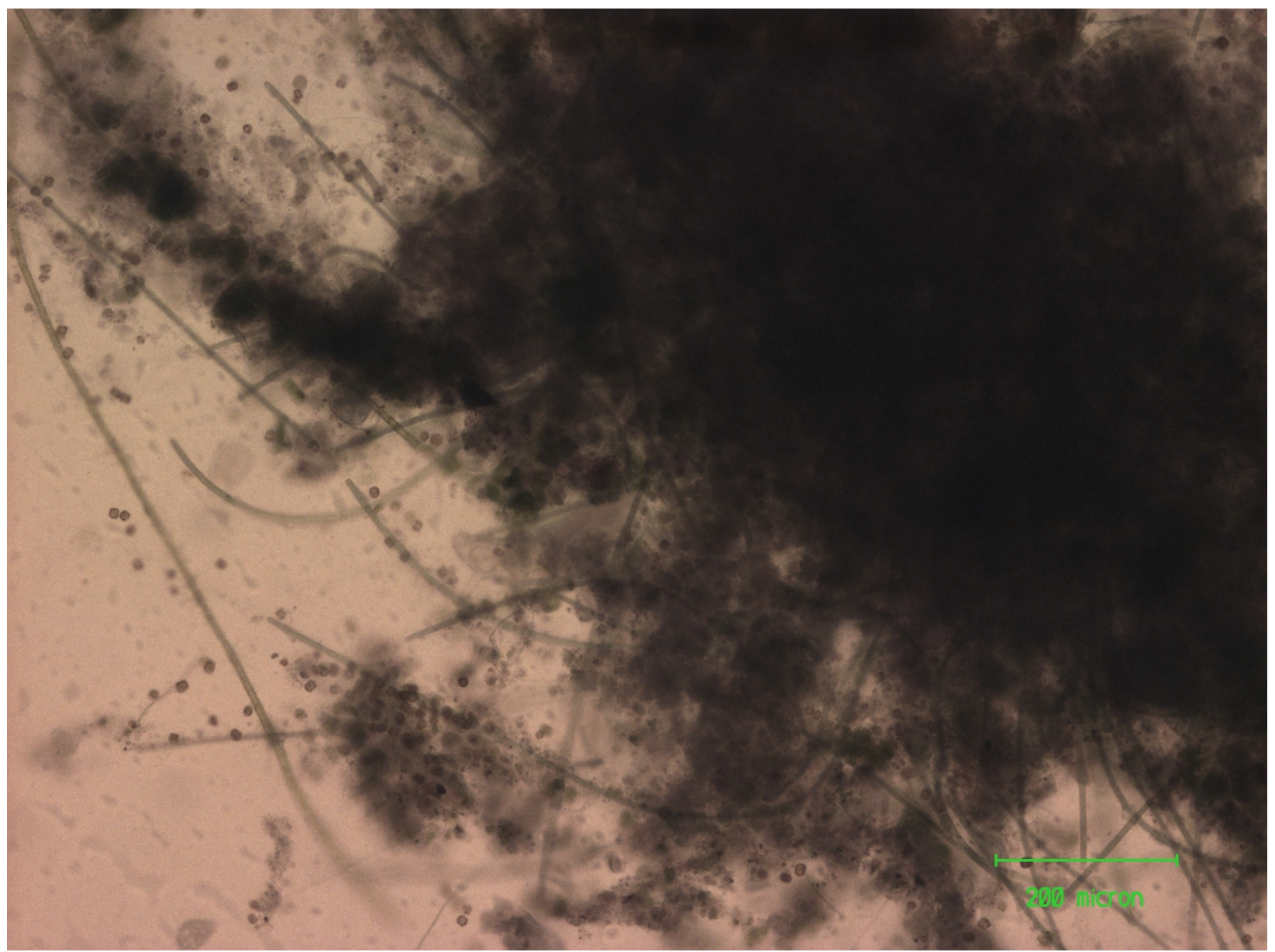

Figure 4-18: A micrograph of Pond 7 on May 29, 2014. This micrograph illustrates the diversity of autotrophic biomass, represented by filamentous and circular microalgae, and the heterotrophic biomass, represented by the dense bacteria on the right of the photo. The scale on the bottom left of the micrograph represents 200 microns.

Net heterotrophic growth can be estimated from organic matter consumption multiplied by a yield coefficient, as commonly done in engineering analysis of bacteria-based wastewater 
treatment processes. In the present case, soluble carbonaceous $\mathrm{BOD}_{5}$ removal and a textbook yield coefficient were used (Metcalf and Eddy, 2003). Autotrophic growth can be estimated by subtracting the calculated heterotrophic VSS concentration from total net VSS concentration

\section{(Equation 4-2).}

Equation 4-2: Produced autotrophic VSS

$$
V S S_{\text {auto }}=V S S_{\text {net }}-Y_{\text {obs }} \times\left(\operatorname{scBOD5_{\text {consumed}})}\right.
$$

where

$$
\begin{aligned}
& \mathrm{VSS}_{\text {auto }}=\text { increase of autotrophic volatile suspended solids }(\mathrm{mg} / \mathrm{L}) \\
& \mathrm{VSS}_{\text {net }}=\text { net increase of volatile suspend solids }(\mathrm{mg} / \mathrm{L}) \\
& \left.\mathrm{Y}_{\mathrm{obs}}=\text { observed heterotrophic yield (mg VSS/mg scBOD }{ }_{5}\right) \\
& \operatorname{scBOD}_{5 \text { consumed }}=\text { consumed soluble carbonaceous biological oxygen demand }
\end{aligned}
$$

$(\mathrm{mg} / \mathrm{L})$

The observed yield coefficient is comprised of two factors, which consider biomass production and decay (Equation 4-3) (Metcalf and Eddy, 2003).

Equation 4-3: Observed yield factor

$$
Y_{o b s}=\frac{Y}{1+\left(k_{d}\right) S R T}+\frac{\left(f_{d}\right)\left(k_{d}\right)(Y) S R T}{1+\left(k_{d}\right) S R T}
$$

where

$$
\begin{aligned}
& \mathrm{Y}_{\mathrm{obs}}=\text { observed heterotrophic yield }\left(\mathrm{g} \mathrm{VSS}_{\mathrm{g}} \mathrm{scBOD}_{5}\right. \text { ) } \\
& \mathrm{Y}=\text { theoretical biomass yield ( } \mathrm{g} \mathrm{VSS} / \mathrm{g} \mathrm{scBOD}_{5} \text { ) } \\
& \mathrm{k}_{\mathrm{d}}=\text { endogenous decay coefficient (g VSS/g VSS-day) } \\
& \mathrm{SRT}=\text { solids residence time (day) }
\end{aligned}
$$




$$
f_{\mathrm{d}}=\text { fraction of degraded biomass that remains as cell debris (g VSS/g VSS) }
$$

Influent VSS was assumed to be $100 \%$ non-biodegradable and was subtracted from effluent VSS to obtain net VSS increase. It is also assumed in observed yield equation that solids retention time, SRT, is equivalent to HRT, however it is possible that the SRT did not equal the HRT due to the solids retention by the effluent standpipes (Chang, 2014 and Kraetsch, 2015).

In the observed yield equation, the values for the coefficients $\mathrm{Y}, \mathrm{k}_{\mathrm{d}}$, and $f_{\mathrm{d}}$ were gathered from empirically derived sources in attempt to create a realistic model of heterotrophic growth. The typical Y value of $0.6 \mathrm{mg} \mathrm{VSS} / \mathrm{mg}$ BOD was selected from the range of 0.4 to $0.8 \mathrm{mg} \mathrm{VSS} / \mathrm{mg}$ BOD at $20^{\circ} \mathrm{C}$, which was assumed to best represent the estimated yield value (Metcalf and Eddy, 2003). Similarly a typical value of $\mathrm{k}_{\mathrm{d}}, 0.10 \mathrm{~g}$ VSS/g VSS-d, for wastewater bacteria at $20^{\circ} \mathrm{C}$ was selected from the range of 0.06 to $0.15 \mathrm{~g}$ VSS/g VSS-d (Metcalf and Eddy, 2003). An estimated value of $f_{\mathrm{d}}$ for municipal wastewater of $0.15 \mathrm{~g} \mathrm{VSS} / \mathrm{g}$ VSS was selected (Metcalf, 2003). More refined future analyses could use temperature-corrected coefficients to better represent seasonal differences in heterotrophic growth.

The above discussion has referred to autotrophy, but estimating photoautotrophy by algae is the actual goal. In addition to the need to use default parameter values in the yield estimation, the underestimation inherent in the net productivity calculation, and many other uncertainties inherent in the overall sampling and measurements, the presence of nitrification in the ponds adds to the error in the autotropic productivity estimates. The autotrophic process of nitrification was a common occurrence in the raceway ponds, as evidenced by the frequent appearance of 
nitrate in the pond waters. The above method for estimating autotrophic productivity includes nitrifying biomass, leading to an unknown amount of overestimation of photoautotrophic growth. This error due to nitrification cannot be determined accurately and is ignored in the present analysis.

The calculation for autotrophic VSS production illustrates that, on average, in the 2-day HRT pond set, autotrophic growth provided $72 \%$ of total net productivity (Table 4-6). This percentage was similar to the Round-1, 3-day HRT pond set which showed that $75 \%$ of the productivity was due to autotrophy (Table 4-7). It is interesting to note that for the ponds receiving primary clarifier effluent, BOD removal and therefore heterotrophic growth were higher in the winter than in the summer. However to draw a conclusion on the apparent pattern more data would be required for confirmation and comparison purposes. 
Table 4-6: For the 2-day HRT pond set, autotrophic productivity, net productivity, gross productivity, and heterotrophic biomass concentrations are presented with the variables used for the calculations. The data were collected from the Cal Poly Algae Field Station from March 2013 to August 2014. The mean values and corresponding standard deviations are presented at the bottom of the table.

\begin{tabular}{cccccccc} 
Sample Date & $\begin{array}{c}\text { Influent } \\
\text { (VSS mg/L) }\end{array}$ & $\begin{array}{c}\text { Pond Avg. } \\
(\text { VSS mg/L) }\end{array}$ & $\begin{array}{c}\text { BOD removal } \\
(\mathrm{scBOD} 5 \mathrm{mg} / \mathrm{L})\end{array}$ & $\begin{array}{c}\text { Heterotrophic } \\
\text { Biomass } \\
(\text { VSS mg/L) }\end{array}$ & $\begin{array}{c}\text { Gross } \\
\text { Productivity } \\
\left(\mathrm{g} / \mathrm{m}^{2}-\mathrm{d}\right)\end{array}$ & $\begin{array}{c}\text { Net } \\
\text { Productivity } \\
\left(\mathrm{g} / \mathrm{m}^{2}-\mathrm{d}\right)\end{array}$ & $\begin{array}{c}\text { Autotrophic } \\
\text { Productivity } \\
\left(\mathrm{g} / \mathrm{m}^{2}-\mathrm{d}\right)\end{array}$ \\
\hline $3 / 20 / 13$ & 29 & 169 & 75 & 67 & 25 & 21 & 15 \\
$8 / 29 / 13$ & 47 & 195 & 44 & 70 & 29 & 22 & 19 \\
$9 / 11 / 13$ & 45 & 131 & 59 & 76 & 20 & 13 & 8 \\
$9 / 18 / 13$ & 51 & 236 & 82 & 93 & 35 & 28 & 21 \\
$9 / 25 / 13$ & 63 & 192 & 81 & 105 & 29 & 19 & 13 \\
$10 / 2 / 13$ & 74 & 292 & 76 & 113 & 44 & 33 & 27 \\
$10 / 16 / 13$ & 29 & 225 & 75 & 67 & 34 & 29 & 24 \\
$10 / 30 / 13$ & 173 & 215 & 88 & 218 & 32 & 6 & 0 \\
$1 / 15 / 14$ & 55 & 148 & 91 & 102 & 22 & 14 & 7 \\
$1 / 22 / 14$ & 69 & 133 & 73 & 106 & 20 & 10 & 4 \\
$1 / 29 / 14$ & 73 & 158 & 80 & 115 & 24 & 13 & 7 \\
$2 / 12 / 14$ & 50 & 158 & 115 & 109 & 24 & 16 & 7 \\
$2 / 19 / 14$ & 60 & 181 & 94 & 108 & 27 & 18 & 11 \\
$3 / 5 / 14$ & 133 & 176 & 81 & 175 & 26 & 6 & 0 \\
$3 / 12 / 14$ & 60 & 182 & 73 & 98 & 27 & 18 & 13 \\
$5 / 22 / 14$ & 49 & 357 & 98 & 99 & 54 & 46 & 39 \\
$7 / 24 / 14$ & 34 & 92 & 48 & 59 & 14 & 9 & 5 \\
$8 / 14 / 14$ & 51 & 326 & 53 & 78 & 49 & 41 & 37 \\
$8 / 28 / 14$ & 57 & 274 & 64 & 90 & 41 & 32 & 28 \\
\hline Mean & 63 & 202 & 76 & 103 & 30 & 21 & 15 \\
Std. Deviation & 35 & 69 & 18 & 38 & 10 & 11 & 12 \\
\hline & & & & & & & \\
\hline
\end{tabular}




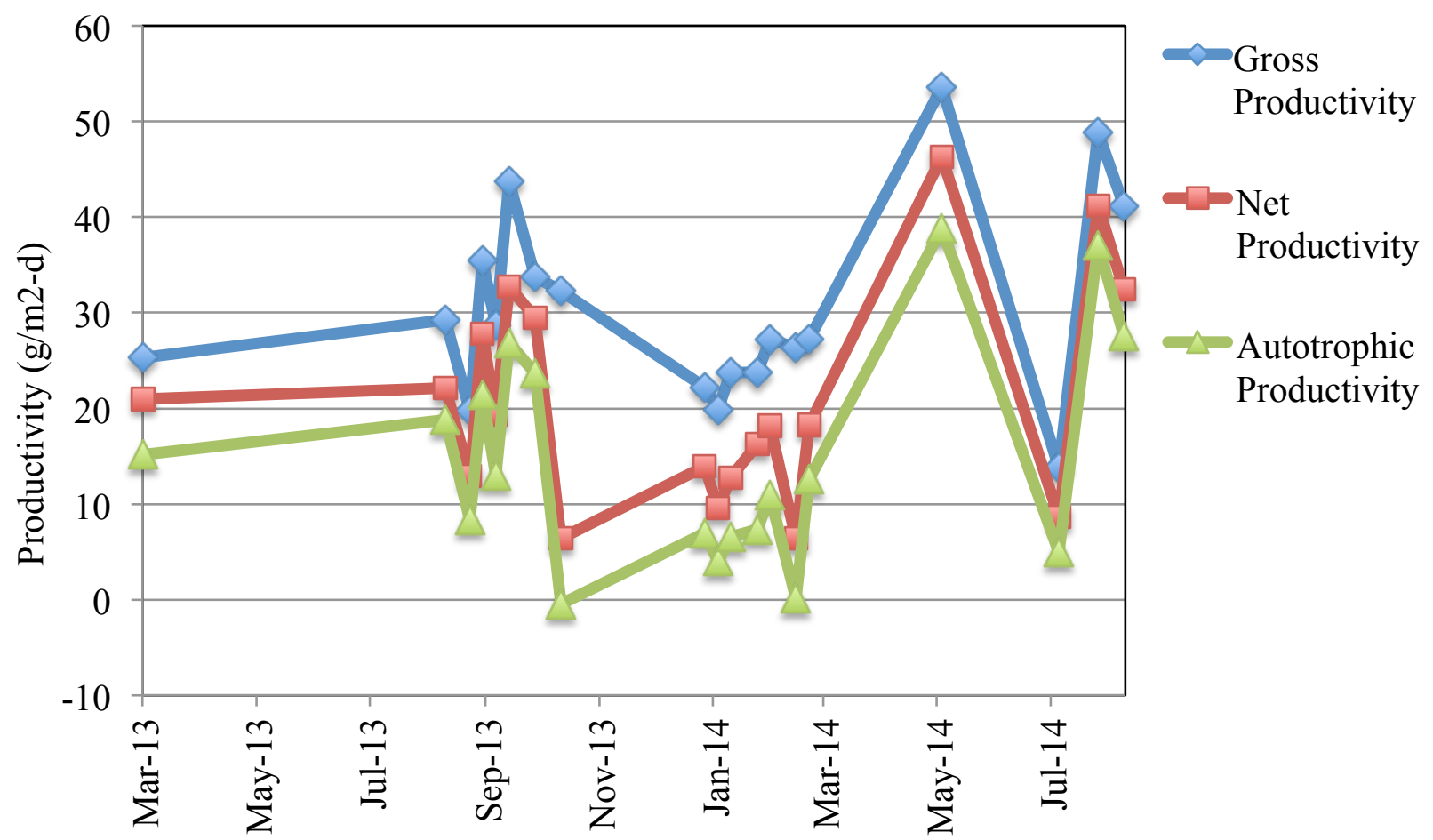

Figure 4-19: Autotrophic, net, and gross productivity for the 2-day HRT pond set from March 2013 to August 2014. The data are also presented in Table 4-7. 
Table 4-7: For the Round-1, 3-day HRT pond set autotrophic productivity, net productivity, gross productivity, and heterotrophic biomass are presented with the required variables for the necessary calculations. The data were collected from the Algae Field Station from March 2013 to August 2014. The mean values and corresponding standard deviations are presented at the bottom of the table.

\begin{tabular}{cccccccc} 
Sample Date & $\begin{array}{c}\text { Influent } \\
\text { (VSS mg/L) }\end{array}$ & $\begin{array}{c}\text { Pond Avg. } \\
\text { (VSS mg/L) }\end{array}$ & $\begin{array}{c}\text { BOD removal } \\
\text { (scBOD } 5 \mathrm{~m} / \mathrm{L})\end{array}$ & $\begin{array}{c}\text { Heterotrophic } \\
\text { Biomass } \\
\text { (VSS mg/L) }\end{array}$ & $\begin{array}{c}\text { Gross } \\
\text { Productivity } \\
\text { (g/m2-d) }\end{array}$ & $\begin{array}{c}\text { Net } \\
\text { Productivity } \\
\text { (g/m2-d) }\end{array}$ & $\begin{array}{c}\text { Autotrophic } \\
\text { Productivity } \\
\text { (g/m2-d) }\end{array}$ \\
\hline $3 / 20 / 13$ & 29 & 178 & 75 & 65 & 18 & 15 & 11 \\
$8 / 29 / 13$ & 47 & 341 & 46 & 69 & 34 & 29 & 27 \\
$9 / 11 / 13$ & 45 & 199 & 61 & 74 & 20 & 15 & 12 \\
$9 / 18 / 13$ & 51 & 221 & 83 & 91 & 22 & 17 & 13 \\
$9 / 25 / 13$ & 63 & 187 & 81 & 102 & 19 & 12 & 8 \\
$10 / 2 / 13$ & 74 & 282 & 76 & 110 & 28 & 21 & 17 \\
$10 / 16 / 13$ & 29 & 253 & 75 & 65 & 25 & 22 & 19 \\
$1 / 15 / 14$ & 55 & 149 & 92 & 99 & 15 & 9 & 5 \\
$1 / 22 / 14$ & 69 & 151 & 72 & 103 & 15 & 8 & 5 \\
$1 / 29 / 14$ & 73 & 149 & 82 & 113 & 15 & 8 & 4 \\
$2 / 5 / 14$ & 61 & 148 & 87 & 103 & 15 & 9 & 5 \\
$2 / 12 / 14$ & 50 & 138 & 116 & 106 & 14 & 9 & 3 \\
$2 / 19 / 14$ & 60 & 232 & 97 & 107 & 23 & 17 & 12 \\
$3 / 5 / 14$ & 133 & 205 & 83 & 173 & 21 & 7 & 3 \\
$3 / 12 / 14$ & 60 & 240 & 74 & 95 & 24 & 18 & 14 \\
$5 / 22 / 14$ & 49 & 160 & 98 & 96 & 16 & 11 & 6 \\
$6 / 26 / 14$ & 43 & 224 & 39 & 62 & 22 & 18 & 16 \\
$7 / 24 / 14$ & 34 & 147 & 52 & 59 & 15 & 11 & 9 \\
$8 / 14 / 14$ & 51 & 200 & 52 & 76 & 20 & 15 & 12 \\
$8 / 28 / 14$ & 57 & 267 & 66 & 89 & 27 & 21 & 18 \\
$9 / 4 / 14$ & 30 & 238 & 101 & 79 & 24 & 21 & 16 \\
\hline Mean & 55 & 205 & 76 & 92 & 21 & 15 & 11 \\
Std. Deviation & 22 & 54 & 19 & 25 & 5 & 6 & 6 \\
\hline
\end{tabular}




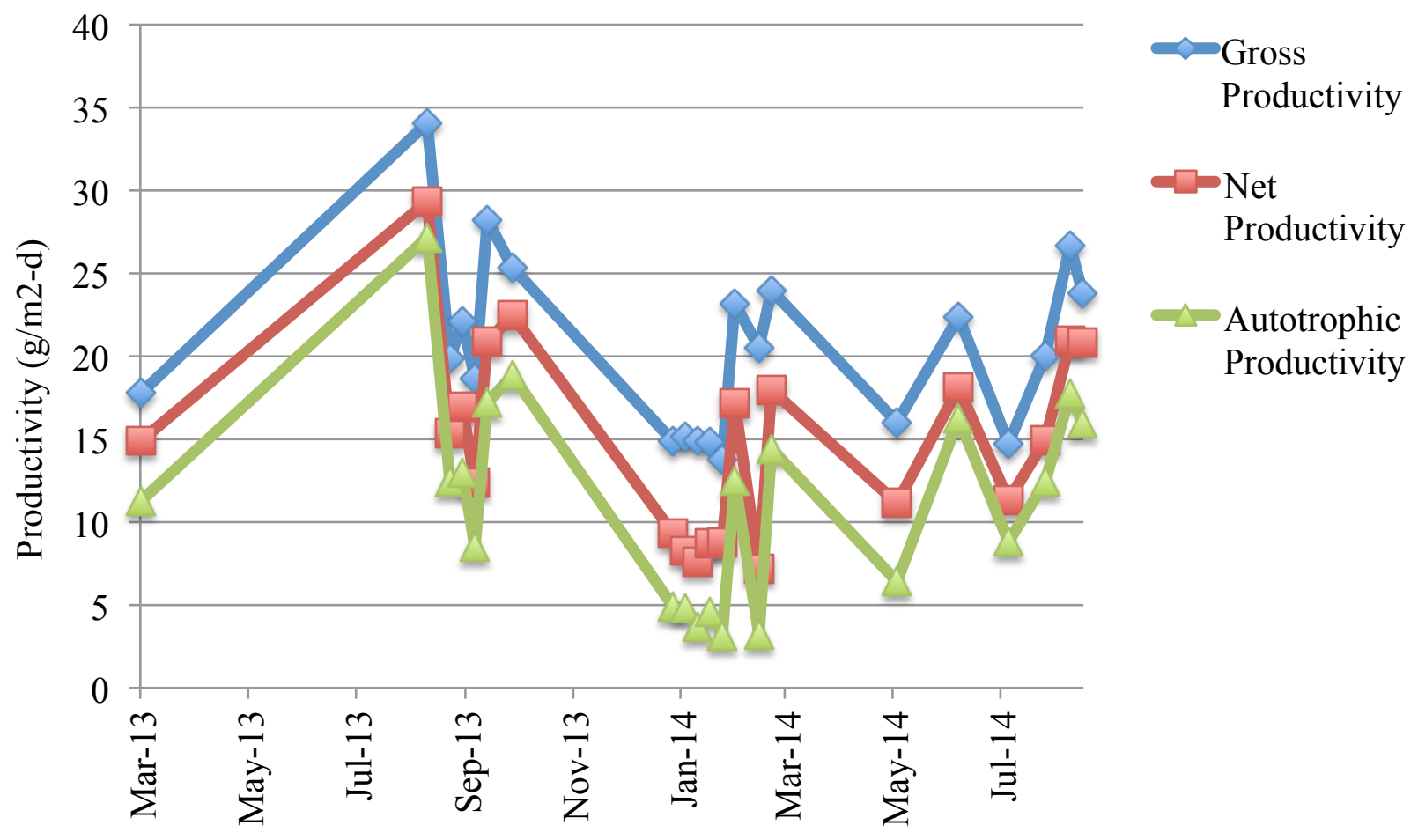

Figure 4-20: Graph of autotrophic, net, and gross productivity for the Round-1, 3-day HRT pond set from March 2013 to August 2014. The featured the data are presented in Table 4-8.

The calculation for autotrophic VSS production illustrates that on average in the 2-day HRT pond set, autotrophic growth is $100 \%$ of total net productivity, which can be attributed to the lack of $\mathrm{BOD}_{5}$ (Table 4-8). 
Table 4-8: For the Round-2, 3-day HRT pond set autotrophic productivity, net productivity, gross productivity, and heterotrophic biomass are presented with the required variables for the necessary calculations. The data were collected from the AFS from March 2013 to August 2014. The mean values and corresponding standard deviations are presented at the bottom of the table.

\begin{tabular}{|c|c|c|c|c|c|c|c|}
\hline Sample Date & $\begin{array}{c}\text { Influent } \\
\text { (VSS mg/L) }\end{array}$ & $\begin{array}{l}\text { Pond Avg. } \\
\text { (VSS mg/L) }\end{array}$ & $\begin{array}{c}\text { BOD removal } \\
\left(\mathrm{scBOD}_{5} \mathrm{mg} / \mathrm{L}\right)\end{array}$ & $\begin{array}{l}\text { Heterotrophic } \\
\text { Biomass } \\
\text { (VSS mg/L) }\end{array}$ & $\begin{array}{c}\text { Gross } \\
\text { Productivity } \\
(\mathrm{g} / \mathrm{m} 2-\mathrm{d}) \\
\end{array}$ & $\begin{array}{c}\text { Net } \\
\text { Productivity } \\
(\mathrm{g} / \mathrm{m} 2-\mathrm{d}) \\
\end{array}$ & $\begin{array}{c}\text { Autotrophic } \\
\text { Productivity } \\
\text { (g/m2-d) }\end{array}$ \\
\hline $3 / 20 / 13$ & 57 & 139 & 1 & 57 & 13 & 8 & 8 \\
\hline $8 / 29 / 13$ & 96 & 291 & 0 & 96 & 29 & 19 & 19 \\
\hline $9 / 18 / 13$ & 100 & 221 & 2 & 101 & 22 & 12 & 12 \\
\hline $9 / 25 / 13$ & 173 & 240 & 2 & 174 & 24 & 6 & 6 \\
\hline $10 / 2 / 13$ & 72 & 231 & -3 & 71 & 23 & 15 & 16 \\
\hline $10 / 16 / 13$ & 76 & 177 & 2 & 78 & 17 & 10 & 9 \\
\hline $1 / 15 / 14$ & 28 & 129 & 3 & 30 & 12 & 10 & 10 \\
\hline $1 / 22 / 14$ & 37 & 126 & 3 & 38 & 12 & 8 & 8 \\
\hline $1 / 29 / 14$ & 40 & 137 & -1 & 40 & 13 & 9 & 9 \\
\hline $2 / 5 / 14$ & 45 & 157 & 2 & 46 & 15 & 11 & 11 \\
\hline $2 / 12 / 14$ & 56 & 158 & 1 & 56 & 15 & 10 & 10 \\
\hline $2 / 19 / 14$ & 68 & 157 & 0 & 68 & 15 & 8 & 8 \\
\hline $3 / 5 / 14$ & 37 & 134 & 1 & 37 & 13 & 9 & 9 \\
\hline $3 / 12 / 14$ & 53 & 139 & 1 & 54 & 13 & 8 & 8 \\
\hline $5 / 22 / 14$ & 52 & 228 & 1 & 52 & 22 & 17 & 17 \\
\hline $7 / 24 / 14$ & 54 & 150 & 1 & 54 & 15 & 9 & 9 \\
\hline $8 / 14 / 14$ & 34 & 196 & 1 & 34 & 19 & 16 & 16 \\
\hline Mean & 63 & 177 & 1 & 64 & 18 & 11 & 11 \\
\hline Std. Deviation & 35 & 49 & 1 & 35 & 5 & 4 & 4 \\
\hline
\end{tabular}




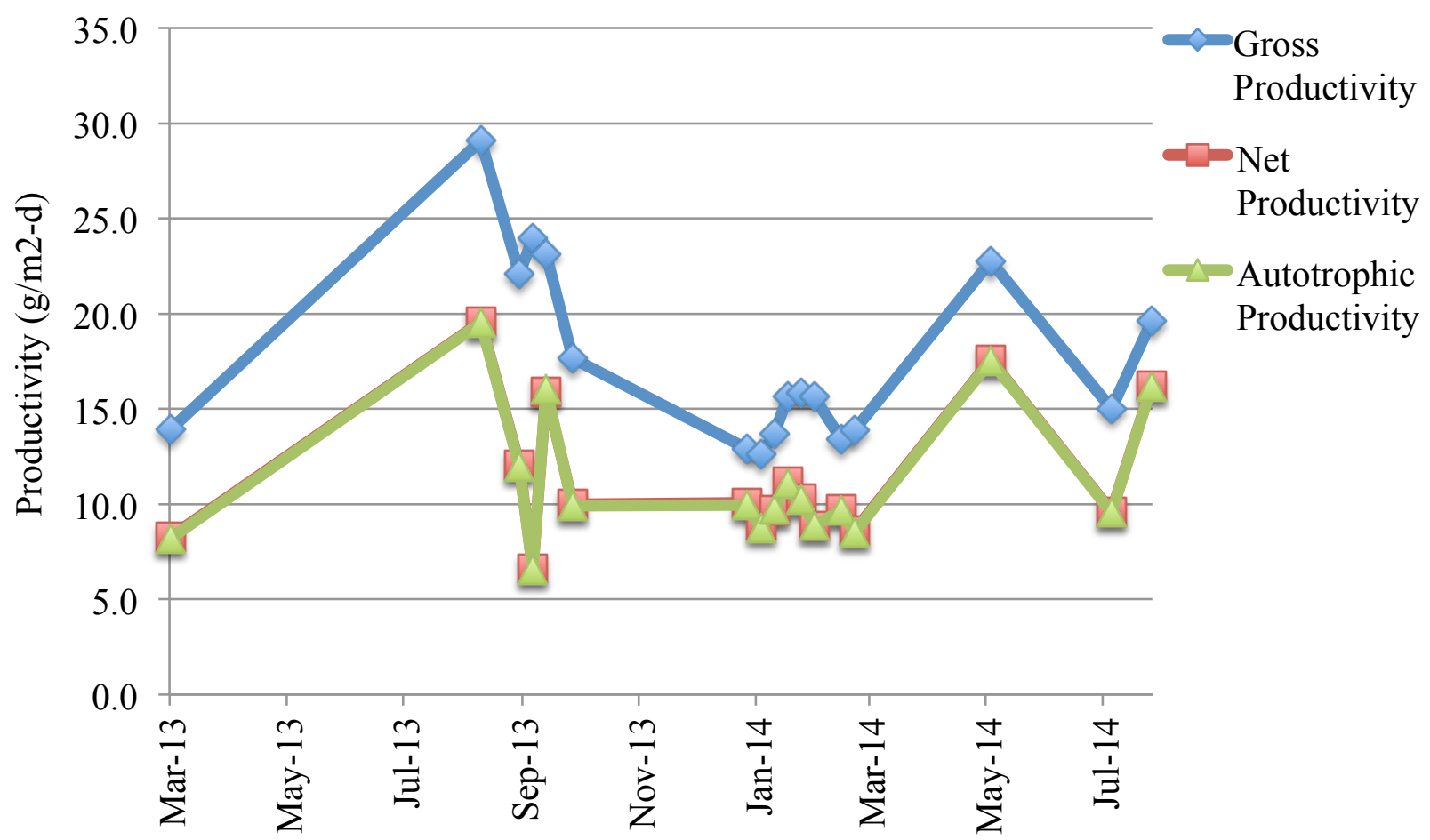

Figure 4-21: Graph of autotrophic, net, and gross productivity for the Round 2, 3-day HRT pond set from March 2013 to August 2014. The featured the data are presented in Table 4-7. It should be noted that the data point on March 20, 2013, represents the pond set operated as a Round-2, 4-day HRT.

The missing data points, from March 2013 to December 2014, are due to the lack of $\mathrm{BOD}_{5}$ data. While $\mathrm{BOD}_{5}$ data were analyzed weekly, quality control samples often were outside of acceptable limits and those weeks of data were omitted from the analysis.

A significant portion of productivity was due to heterotrophic growth in the pond sets receiving clarified municipal wastewater for their influent feed. Since the Round-2 pond set, receiving clarified the Round-1 water, lacked the high levels of influent BOD concentration, it was unable to produce almost any heterotrophic growth (Figure 4-22). 


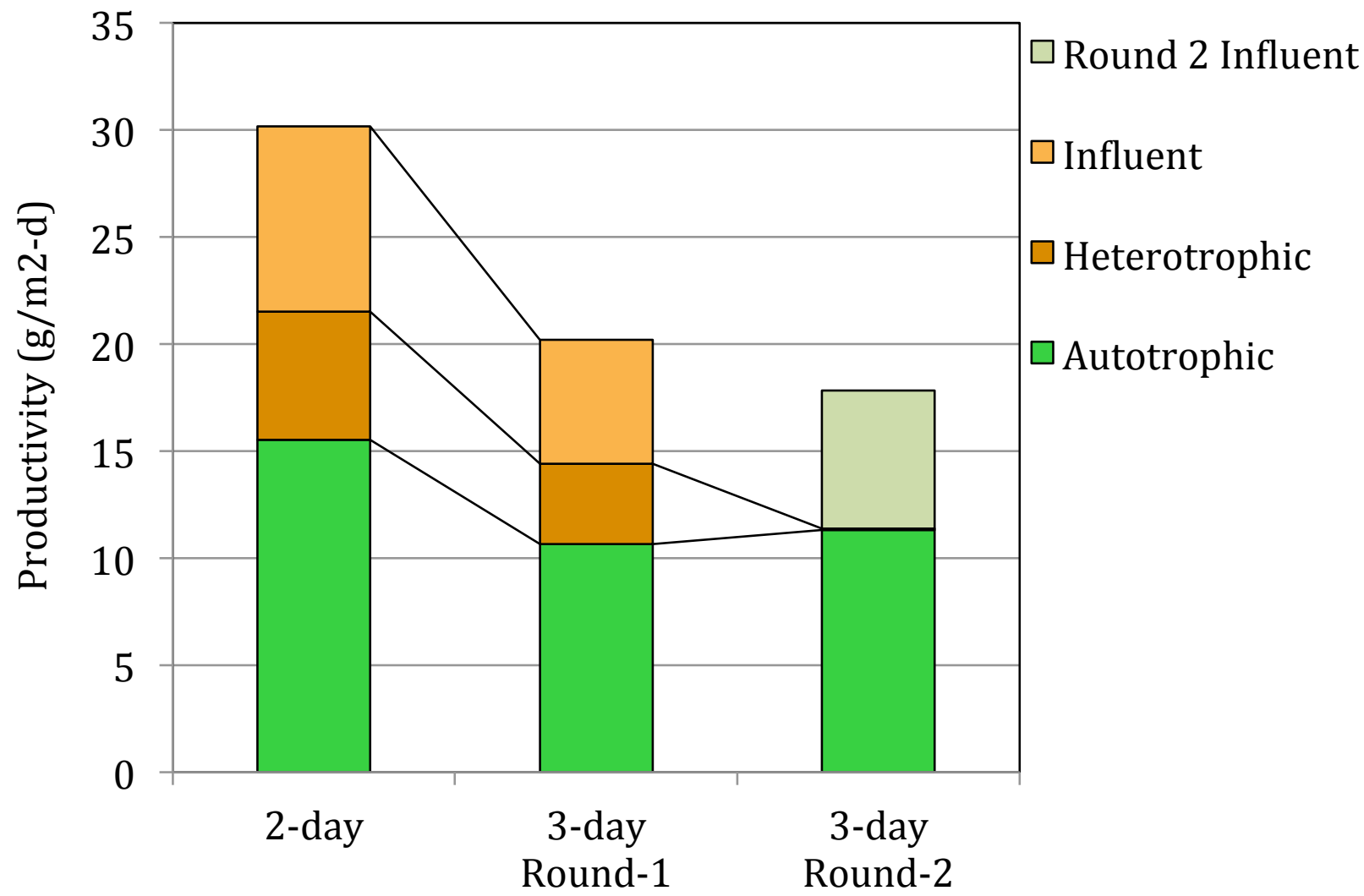

Figure 4-22: The average composition of gross productivity. The Round-2 influent portion were VSS carried into the Round-2 pond from the Round-1 effluent settling tanks. The data were averaged from March 2013 to August 2014, and can be reviewed in Tables 4-7, 4-8 and 4-9. For the purposes of comparing pond sets, data were only used, to determine the shown average values, from dates that all pond sets had data for.

When comparing autotrophic productivity, the Round-2 pond set was slightly more productive than the Round-1 pond set for the same 3-day HRT, which suggests that autotrophic productivity was not decreased due to use of recycled water. In terms of net productivity, the lower value in the Round-2 set seems to have been due to the greater heterotrophic growth in the Round-1 pond sets. 


\subsubsection{Characteristics of Productivity Peaks and Crashes}

As seen in the above sections on productivity, at times productivity was abnormally high relative to insolation. Similarly productivity was severely reduced over short time periods (culture “crashes"). To further understand productivity, the prevalence of both algal genera and microalgae-consuming zooplankton ("grazers" mainly rotifers and ostracods) have been compiled for periods of exceptional high and low productivity. Only periods of high and low productivity were analyzed, rather than normal periods, with the idea that any patterns would be more apparent between the extreme cases. A link between the types of microalgae or organisms consuming microalgae, to productivity would be useful knowledge for the production of algal biofuels.

Periods of high and low productivity, determined by productivity and insolation correlations prior in this section, were compared in terms of prominent algae genera and grazer densities. During times of high productivity many of the same genera of microalgae were present, such as Chlorella and Cyclotella (Table 4-9). However, in the same time periods, the rotifer and ostracod densities did not appear to correlate with productivity (Table 4-10). 
Table 4-9: Prominent algae genera during dates of high productivity. The increase of productivity over that expected from the insolation model is included, to show that productivity was abnormally high.

\begin{tabular}{|c|c|c|c|c|}
\hline Pond & Date & $\begin{array}{l}\text { Productivity } \\
\left(\mathrm{g} / \mathrm{m}^{2} \text {-day }\right)\end{array}$ & $\begin{array}{l}\text { Productivity Increase } \\
\text { over Model (g/m²-day) }\end{array}$ & Prominent Algae Genera \\
\hline 5 & $5 / 29 / 14-6 / 5 / 14$ & 31 & 10 & $\begin{array}{l}\text { Chlorella, Cyclotella, Scenedesmus, } \\
\text { Ulothrix }\end{array}$ \\
\hline 6 & $6 / 5 / 14-6 / 12 / 14$ & 41 & 21 & $\begin{array}{l}\text { Chlorella, Cyclotella, Oscillatoria, } \\
\text { Scenedesmus }\end{array}$ \\
\hline 7 & $3 / 19 / 14-4 / 10 / 14$ & 47 & 23 & $\begin{array}{l}\text { Chlorella, Cyclotella, Nitzschia, } \\
\text { Scenedesmus, Stigioclonium }\end{array}$ \\
\hline 7 & $5 / 22 / 14-6 / 5 / 14$ & 93 & 61 & $\begin{array}{l}\text { Chlorella, Cyclotella, Nitzschia, } \\
\text { Oscillatoria, Scenedesmus, Stigioclonium, }\end{array}$ \\
\hline 7 & $7 / 31 / 14-8 / 21 / 14$ & 58 & 28 & $\begin{array}{l}\text { Chlorella, Closterium, Cyclotella, } \\
\text { Nitzschia, Oscillatoria, Scenedesmus, } \\
\text { Stigioclonium }\end{array}$ \\
\hline 8 & $6 / 12 / 14-6 / 19 / 14$ & 44 & 11 & Chlorella, Cyclotella, Oscillatoria \\
\hline 9 & $6 / 12 / 14-6 / 19 / 14$ & 39 & 5 & $\begin{array}{l}\text { Chlorella, Closterium, Cyclotella, } \\
\text { Oscillatoria, Stigeoclonium }\end{array}$ \\
\hline
\end{tabular}


Table 4-10: Rotifer and ostracod density during dates of high productivity. The increase of productivity over that expected from the insolation model is included, to show that productivity was abnormally high.

\begin{tabular}{cccccc} 
& & & & \multicolumn{2}{c}{$\begin{array}{c}\text { Suspended Grazer Density } \\
(\text { Count } / \mathrm{mL})\end{array}$} \\
Pond & Date & $\begin{array}{c}\text { Productivity Increase } \\
\left(\mathrm{g} / \mathrm{m}^{2} \text {-day }\right)\end{array}$ & $\begin{array}{c}\text { Rover Model }\left(\mathrm{g} / \mathrm{m}^{2}-\right. \\
\text { day })\end{array}$ & Rotifers & Ostracods \\
\hline 5 & $5 / 29 / 14-6 / 5 / 14$ & 31 & 10 & 13 & 1 \\
6 & $6 / 5 / 14-6 / 12 / 14$ & 41 & 21 & 8 & 1 \\
7 & $3 / 19 / 14-4 / 10 / 14$ & 47 & 23 & 40 & 0 \\
7 & $5 / 22 / 14-6 / 5 / 14$ & 93 & 61 & 12 & 0 \\
7 & $7 / 31 / 14-8 / 21 / 14$ & 58 & 28 & 1 & 6 \\
8 & $6 / 12 / 14-6 / 19 / 14$ & 44 & 11 & 8 & 1 \\
9 & $6 / 12 / 14-6 / 19 / 14$ & 39 & 5 & 1 & 11 \\
\hline
\end{tabular}

The comparison, of prominent algae genera to dates of low productivity, shows that many of the same genera that existed during times of high productivity (Table 4-11).

Table 4-11: Prominent algae genera during dates of low productivity. The decrease of productivity below the insolation model is included, to show that productivity was abnormally low.

\begin{tabular}{|c|c|c|c|c|}
\hline Pond & Date & $\begin{array}{l}\text { Productivity } \\
\left(\mathrm{g} / \mathrm{m}^{2}-\text { day }\right)\end{array}$ & $\begin{array}{c}\text { Productivity Decrease } \\
\text { under Model }\left(\mathrm{g} / \mathrm{m}^{2}-\right. \\
\text { day) }\end{array}$ & Prominent Algae Genera \\
\hline 5 & $6 / 26 / 14$ & 9 & 12 & $\begin{array}{l}\text { Chlorella, Closterium, Cyclotella, } \\
\text { Micractinium, Scenedesmus }\end{array}$ \\
\hline 6 & $6 / 26 / 14$ & 8 & 13 & $\begin{array}{l}\text { Chlorella, Cyclotella, Nitzschia, } \\
\text { Scenedesmus, Ulothrix }\end{array}$ \\
\hline 7 & $4 / 17 / 14$ & 3 & 24 & Cyclotella, Stigioclonium \\
\hline 7 & $7 / 24 / 14$ & 12 & 20 & Chlorella, Cyclotella, Stigeoclonium \\
\hline 7 & $9 / 18 / 14$ & 7 & 18 & Closterium, Cyclotella, Stigioclonium \\
\hline 8 & $7 / 17 / 14$ & -2 & 31 & $\begin{array}{l}\text { Ankistrodesmus, Chlorella, Chlorococcum, } \\
\text { Cyclotella, Oscillatoria, Scenedesmus }\end{array}$ \\
\hline 9 & $7 / 3 / 14$ & 5 & 29 & $\begin{array}{l}\text { Chlorella, Closterium, Cyclotella, } \\
\text { Stigioclonium, Scenedesmus }\end{array}$ \\
\hline
\end{tabular}


While the peak ostracod density was higher for periods of low productivity, the peak rotifer density was only marginally greater. Furthermore, the densities of both grazers fluctuated from low to high levels within periods of low productivity (Table 4-12).

Table 4-12: Rotifer and ostracod densities during dates of low productivity. The decrease of productivity below the insolation model is included, to show that productivity was abnormally low. For the grazer density values denoted with a dash indicates the test was not performed for the given date.

\begin{tabular}{cccccc} 
& & Productivity & $\begin{array}{c}\text { Productivity Decrease } \\
\text { below Model }\left(\mathrm{g} / \mathrm{m}^{2}-\right.\end{array}$ & $\begin{array}{c}\text { Suspended Grazer Density } \\
\text { (Count } / \mathrm{mL})\end{array}$ \\
Pond & Date & $\left(\mathrm{g} / \mathrm{m}^{2}\right.$-day $)$ & $\begin{array}{c}\text { Rotifers } \\
\text { day }\end{array}$ & Ostracods \\
\hline 5 & $6 / 26 / 14$ & 9 & 12 & 24 & 0 \\
6 & $6 / 26 / 14$ & 8 & 13 & - & - \\
7 & $4 / 17 / 14$ & 3 & 24 & 43 & 2 \\
7 & $7 / 24 / 14$ & 12 & 20 & 2 & 1 \\
7 & $9 / 18 / 14$ & 7 & 18 & 1 & 2 \\
8 & $7 / 17 / 14$ & -2 & 31 & 6 & 3 \\
9 & $7 / 3 / 14$ & 5 & 29 & 2 & 22 \\
\hline
\end{tabular}

It was hypothesized that high or low productivities could be associated with specific algae genera or grazer concentration. However, the tables above show that high and low periods of productivity cannot be solely associated with insolation and either algae genera predominance or grazer density in the ponds. While these factors might have an effect on productivity, it was not a sole cause and no conclusions can be determined from this analysis.

\subsubsection{Analysis of Pond Specific Productivity Crash}

To further understand why productivity can reach such high and low values over a short period of time, a case study of Pond 7 was analyzed for the summer of 2014. Pond 7 was selected due 
to having had the largest productivity and VSS concentration peaks and crashes; as well as pronounced filamentous growth.

During the summer of 2014, Pond 7 appeared to have three distinct crashes in productivity (Figure 4-23).

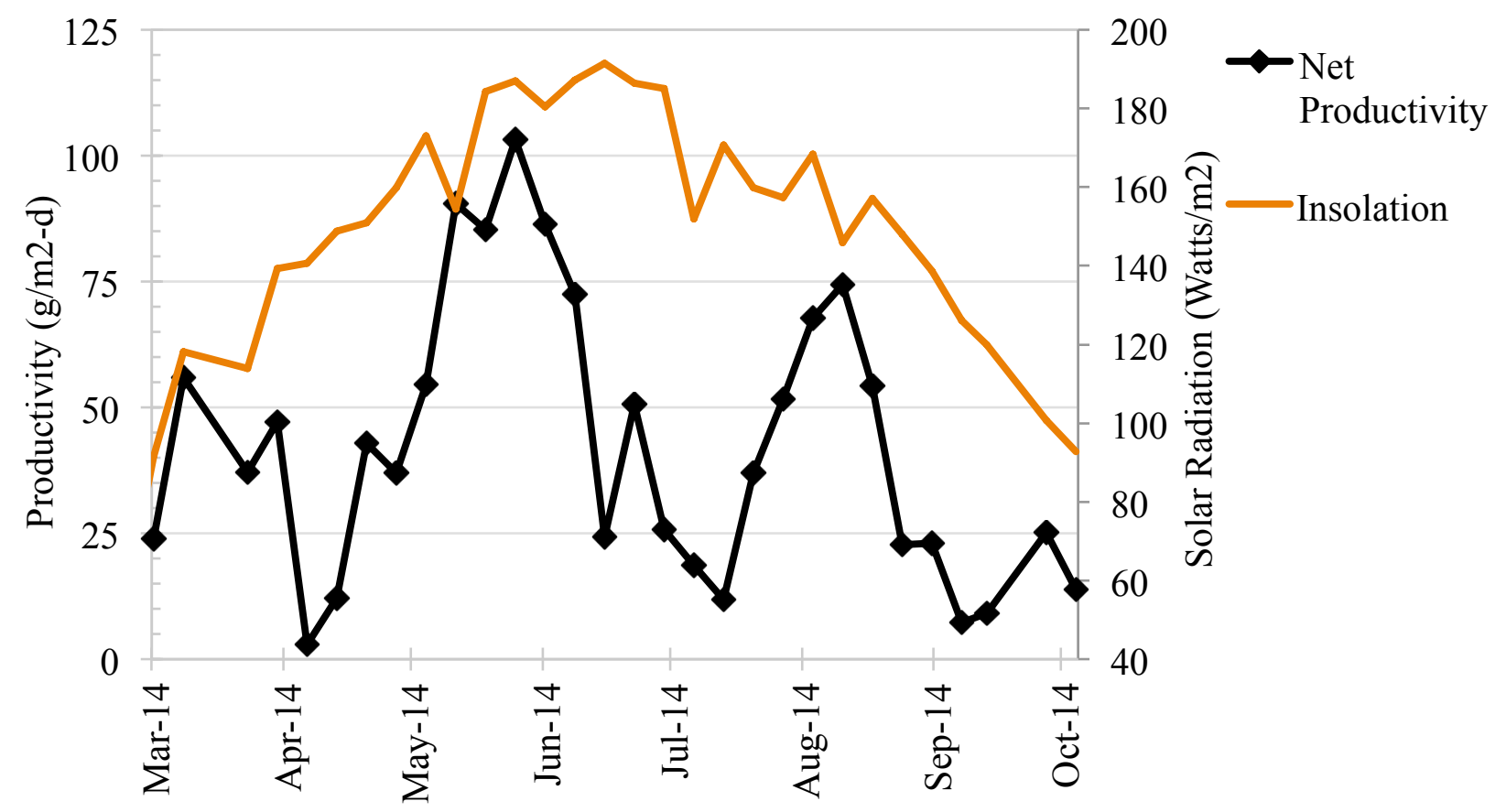

Figure 4-23: VSS productivity in Pond 7 compared to insolation data from March 12, 2014 to October 15, 2014.

During this time in 2014, the three distinct drops in productivity can also visibly be seen in the grab samples of pond water in pond 7 (Figure 4-24). 


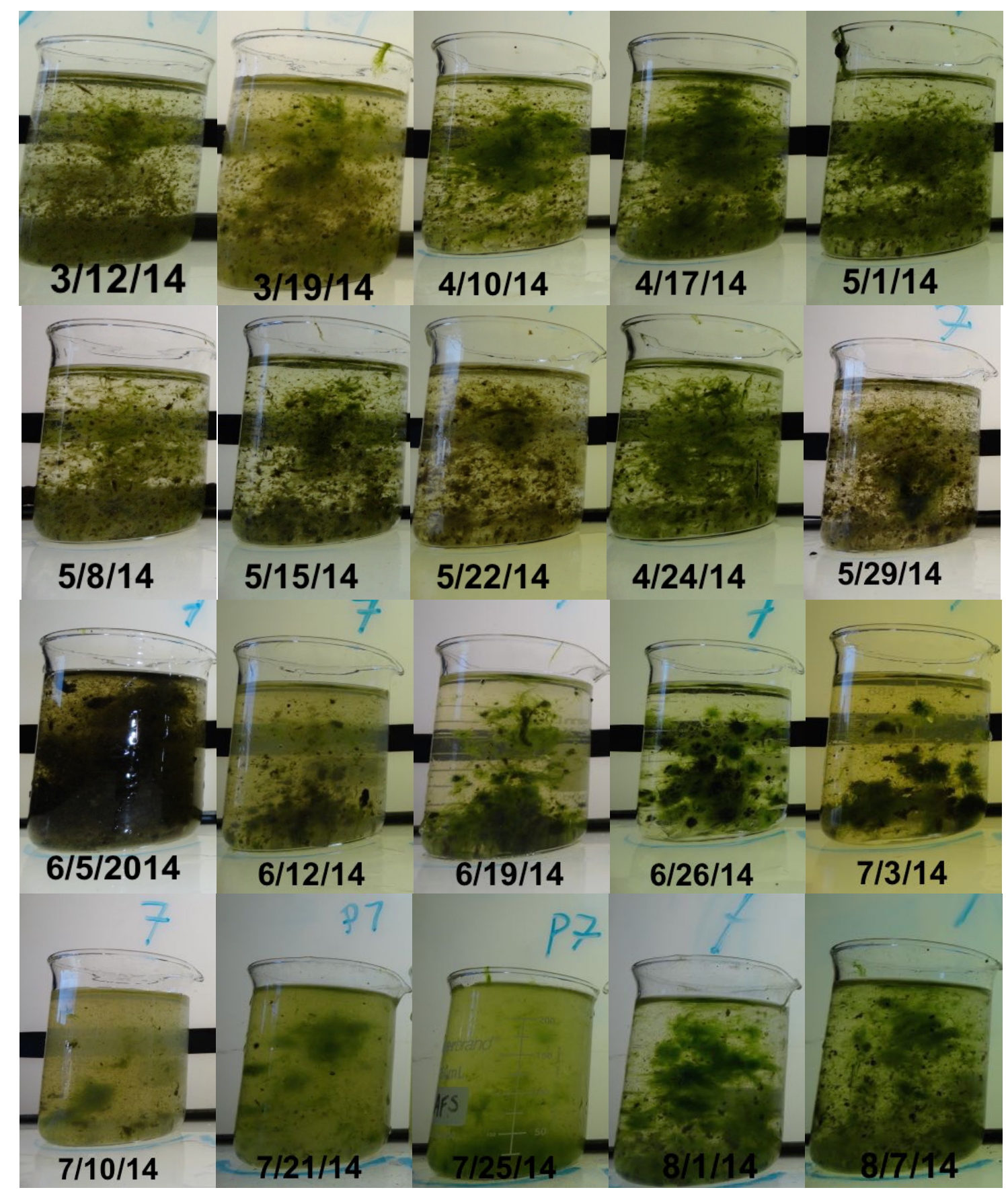




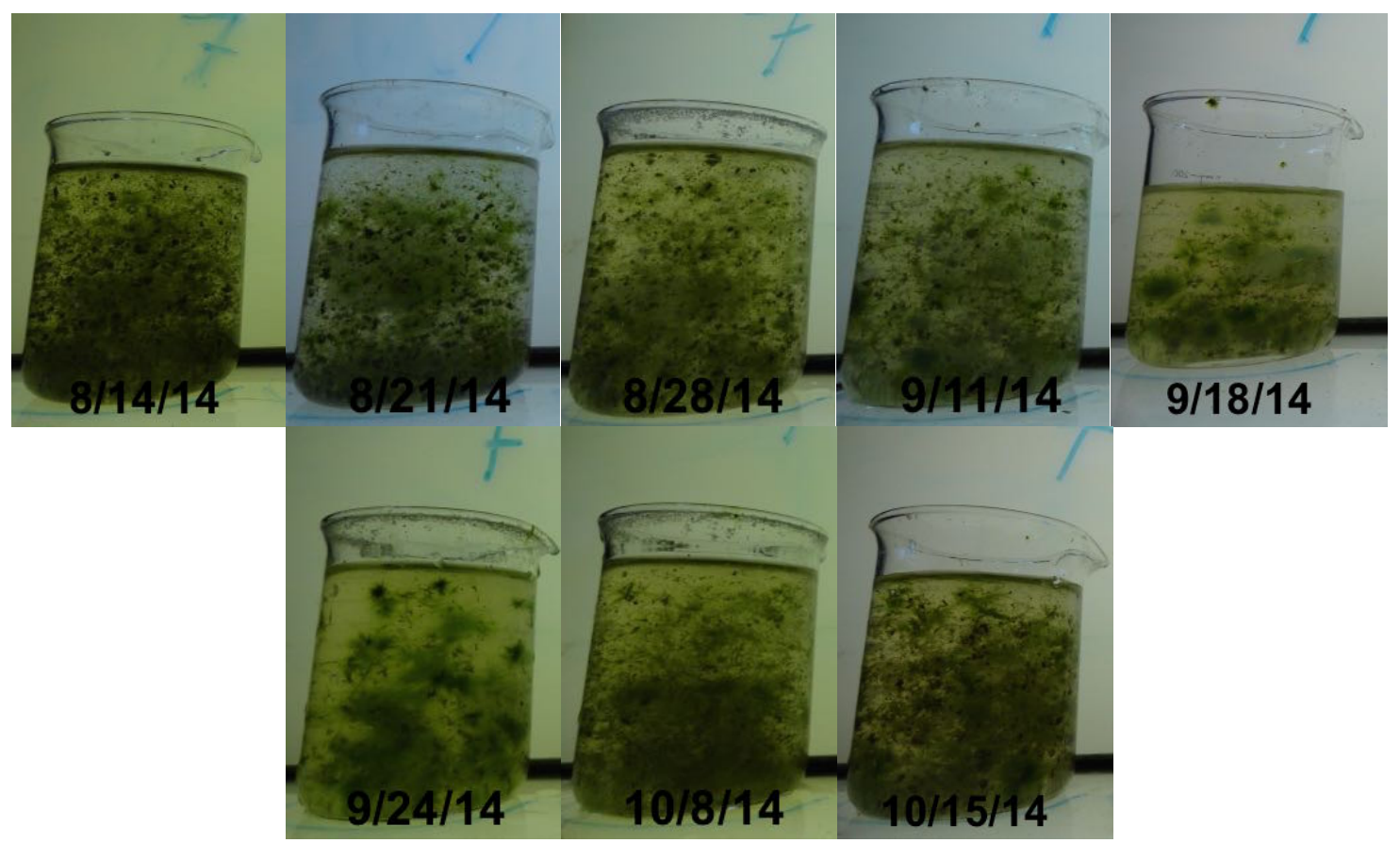

Figure 4-24: Images of weekly samples of pond water from Pond 7 in a glass beaker, placed on a light table. The images are listed in chronological order from March 12, 2014 to October 15, 2014. The dates with the lowest productivity and also corresponding VSS concentrations for the three crashes in pond 7 appeared on $4 / 17 / 2014,7 / 22 / 2015$, and $9 / 18 / 2014$.

The hypothesis for the cause of drastic peaks and crashes of biomass productivity is due to excessive VSS concentrations. This explains why pond 7 with the vertical stand pipe and filamentous algal growth experienced higher levels of solids accumulation when compared to the other two ponds, in the triplicate set; which did not have such drastic productivity peaks and crashes. Therefore when filamentous microalgae begin to dominate, the filaments are not freely able to flow over the standpipe, and solids concentrations then exceed the carrying capacity causing the pond to crash.

As seen in the beaker photos, the algal growth was dense with highly visible flocculation when Stigeoclonium was the most prevalent genera, such as time June $26^{\text {th }}$ and July $3^{\text {rd }}$. However, the crashes were potentially caused from the high VSS concentrations in the pond reaching levels that could not be supported by insolation. This was a potential concern of operating the raceway 
ponds with a vertical effluent standpipe, which can cause solids accumulation, and was further intensified by filamentous algae such as Stigeoclonium.

Since insolation was a primary factor limiting algal growth, it is assumed that the levels of maximum supportable VSS in the raceways pond were largely dependent on insolation. The maximum VSS that can be supported by a given insolation can be surmised from the pre-crash VSS concentrations observed (Table 4-13). It is assumed that the VSS concentration one-week prior to crashes was the maximum supportable VSS (Table 4-14).

Table 4-13: Insolation and VSS data are presented for the dates of peak productivity before a crash in productivity Pond 7, during 2014. These data show the maximum levels of VSS achieved before a steep decline in VSS began to occur.

\begin{tabular}{ccc} 
Date & $\begin{array}{c}\text { VSS } \\
(\mathrm{mg} / \mathrm{L})\end{array}$ & $\begin{array}{c}\text { Solar Insolation } \\
\left(\text { Watts } / \mathrm{m}^{2}\right)\end{array}$ \\
\hline $3 / 19 / 14$ & 432 & 118 \\
$6 / 5 / 14$ & 748 & 187 \\
$8 / 21 / 14$ & 556 & 146 \\
\hline
\end{tabular}

Table 4-14: Insolation and VSS data are presented for the dates one week prior to peak productivity in productivity Pond 7, during 2014. The data show VSS concentrations that were increasing and had not reached their maximum levels of VSS yet.

\begin{tabular}{ccc} 
Date & $\begin{array}{c}\text { VSS } \\
(\mathrm{mg} / \mathrm{L})\end{array}$ & $\begin{array}{c}\text { Solar Insolation } \\
\left(\text { Watts } / \mathrm{m}^{2}\right)\end{array}$ \\
\hline $3 / 12 / 14$ & 220 & 92 \\
$5 / 29 / 14$ & 616 & 184 \\
$8 / 14 / 14$ & 503 & 168 \\
\hline
\end{tabular}

It can be assumed that the ideal maximum VSS the raceway pond can sustain falls in between the values of the two tables for a given insolation. The relationship of VSS concentration and 
insolation can be used to estimate safe VSS concentrations (Figure 4-25). The VSS concentration can be controlled by how much harvested biomass is recycled to the ponds versus being wasted.

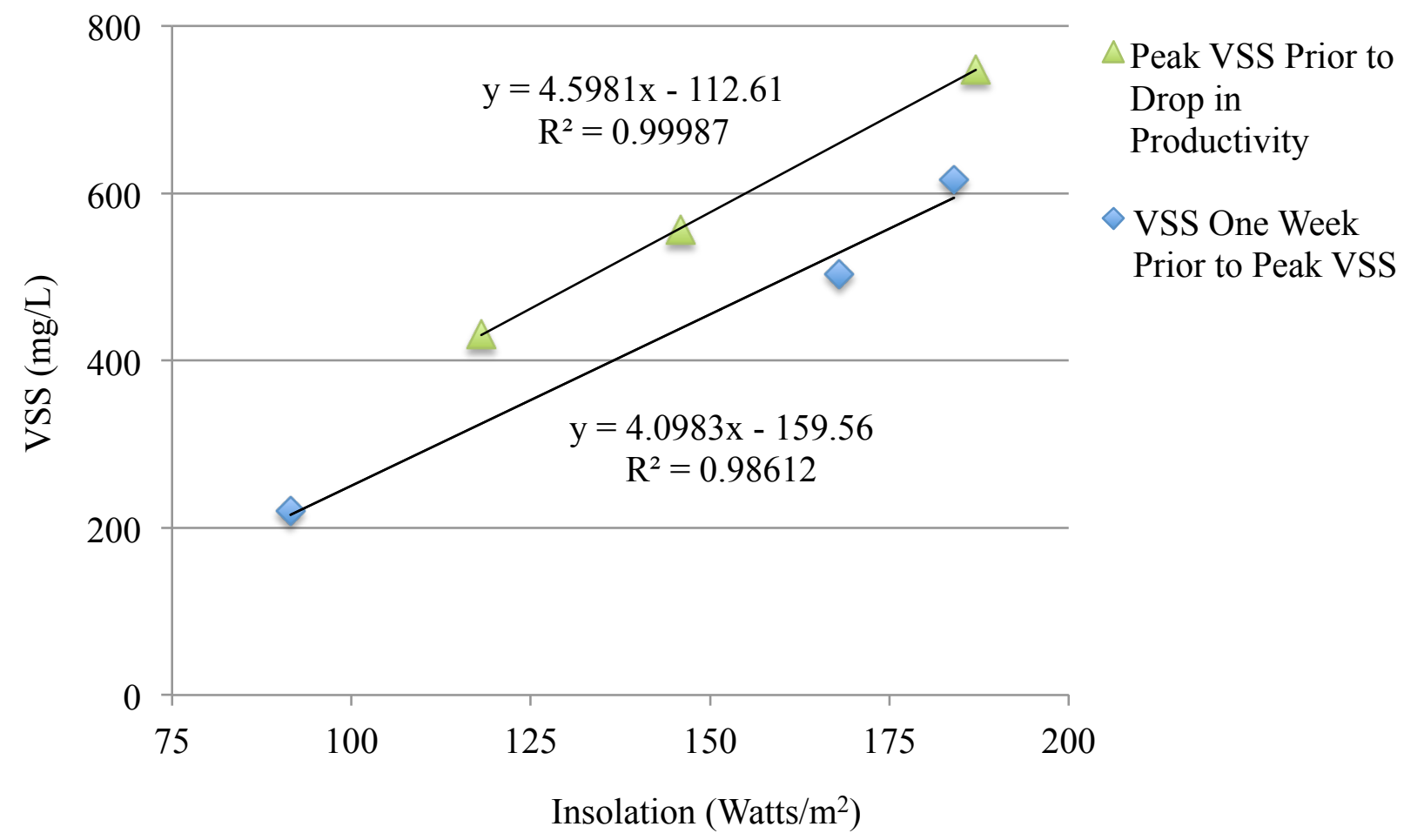

Figure 4-25: Scatter plot of insolation and VSS concentration for the dates one week prior to a peak in productivity and dates of peak productivity with linear correlation lines. Theoretically ideal operation for biomass production is located somewhere above the lower correlation line and below top correlation line.

\subsection{Algal Harvesting and Settling}

The ability to harvest microalgae by sedimentation is crucial for avoiding higher cost harvesting methods, which is especially important for biofuel production.

\subsubsection{Imhoff Cone Settling}

Imhoff cones allow evaluation of algae settleability in a controlled environment. Settleability is evaluated as percent removal and as residual supernatant TSS concentration, after two hours and 
24 hours of settling. Percent removal is the measurement of how much of the total biomass was removed through settling (Equation 4-4).

Equation 4-4: Percent removal by settling

$$
\text { Percent Removal }(\%)=\frac{0 \operatorname{Hour} \operatorname{TSS}\left(\frac{m g}{L}\right)-2 \operatorname{Hour} \operatorname{TSS}\left(\frac{m g}{L}\right)}{0 \operatorname{Hour} \operatorname{TSS}\left(\frac{m g}{L}\right)}
$$

Settling in terms of percent removal seemed to be more complete in the summer than winter (Figure 4-26). Due to co-correlation of insolation, VSS concentration, and other variables, it cannot be determined from the presented data if insolation was directly the cause of higher settling. One hypothesis is that higher settling occurs at times when the algal concentration in the raceway ponds is higher. 


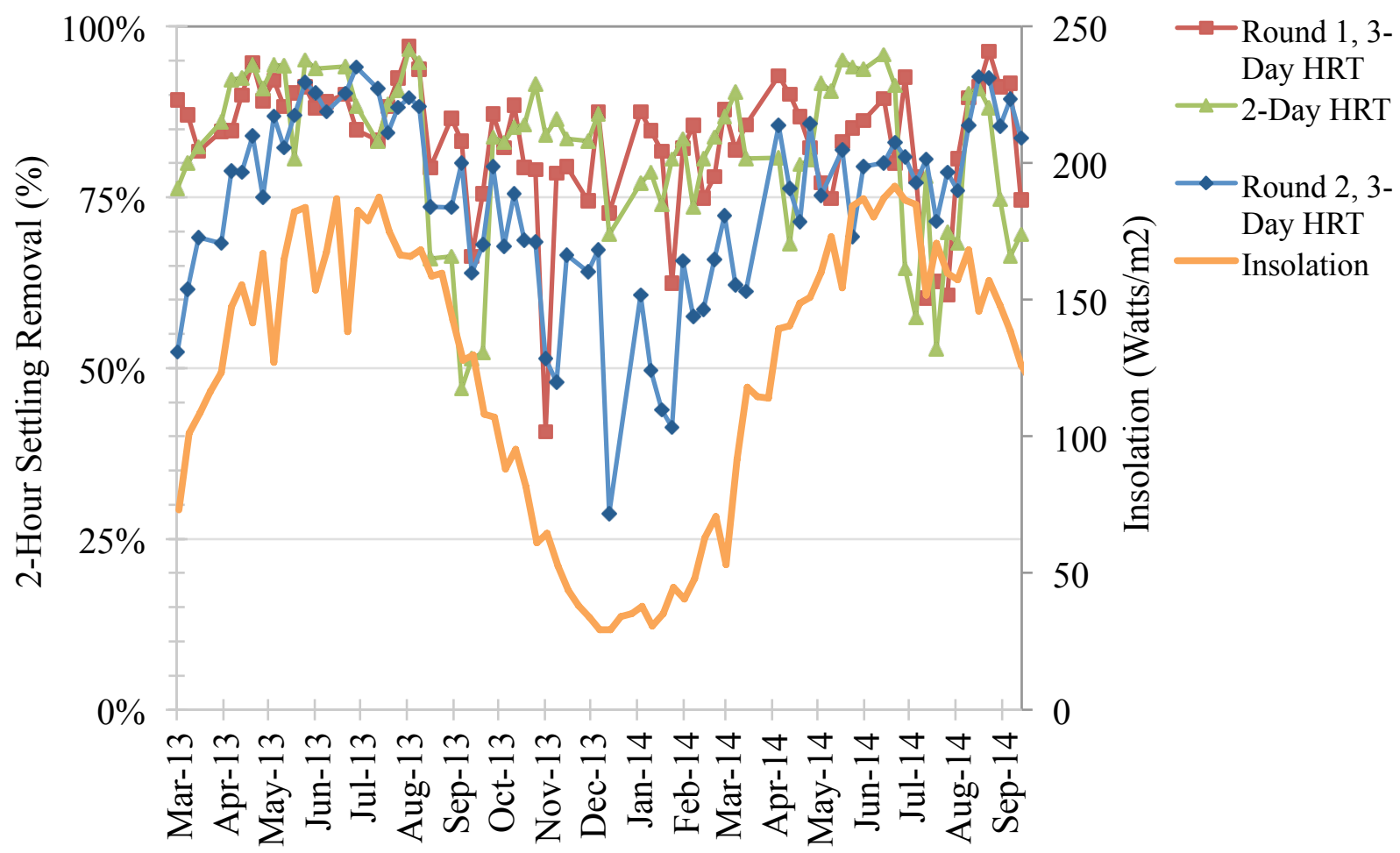

Figure 4-26: Percent TSS removal from 2-hour Imhoff cone settling from March 2013 to September 2014. Insolation data are included for the same time period.

Frequently the Round-2 pond set had lower percent removal from settling which may be promoted by transfer of residual unsettled algae from the Round- 1 effluent settling units. This process might be selecting for microalgae that do not settle well. Further data correlating settling and various pond conditions are presented in the following section.

Given 24-hours, biomass settling remained over $75 \%$ for most of the study, with little correlation to insolation (Figure 4-27). 


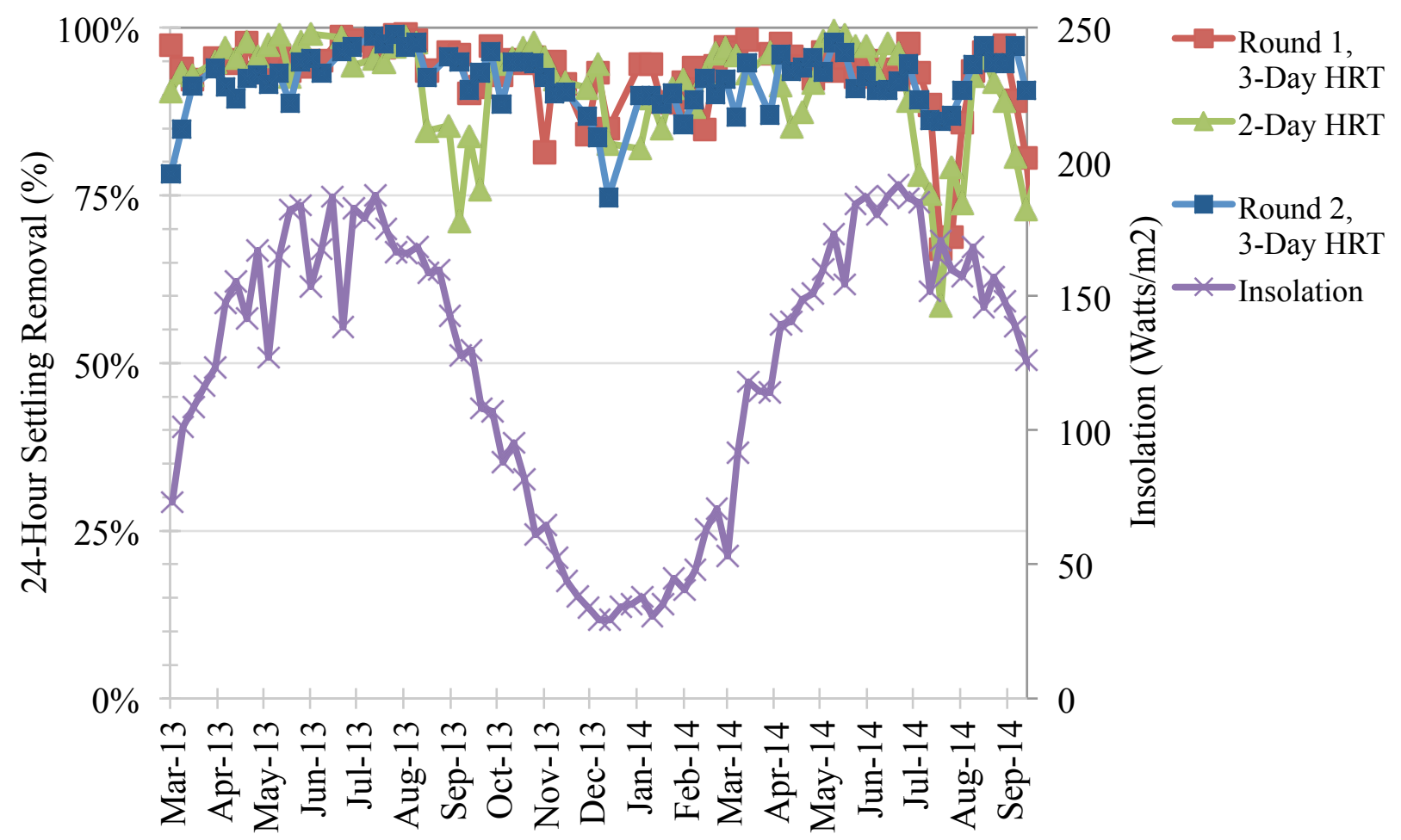

Figure 4-27: Percent TSS removal over 24-hour of settling in Imhoff cones, from March 2013 to September 2014. Insolation data are included for the same time period.

Percent removal or percent harvested is an important metric for biofuel production. On average, TSS removal was $>90 \%$ over 24 hours for each of the three pond sets, and for the pond sets receiving primary clarifier effluent, 2-hour settling was over 80\% on average (Figure 4-28). 


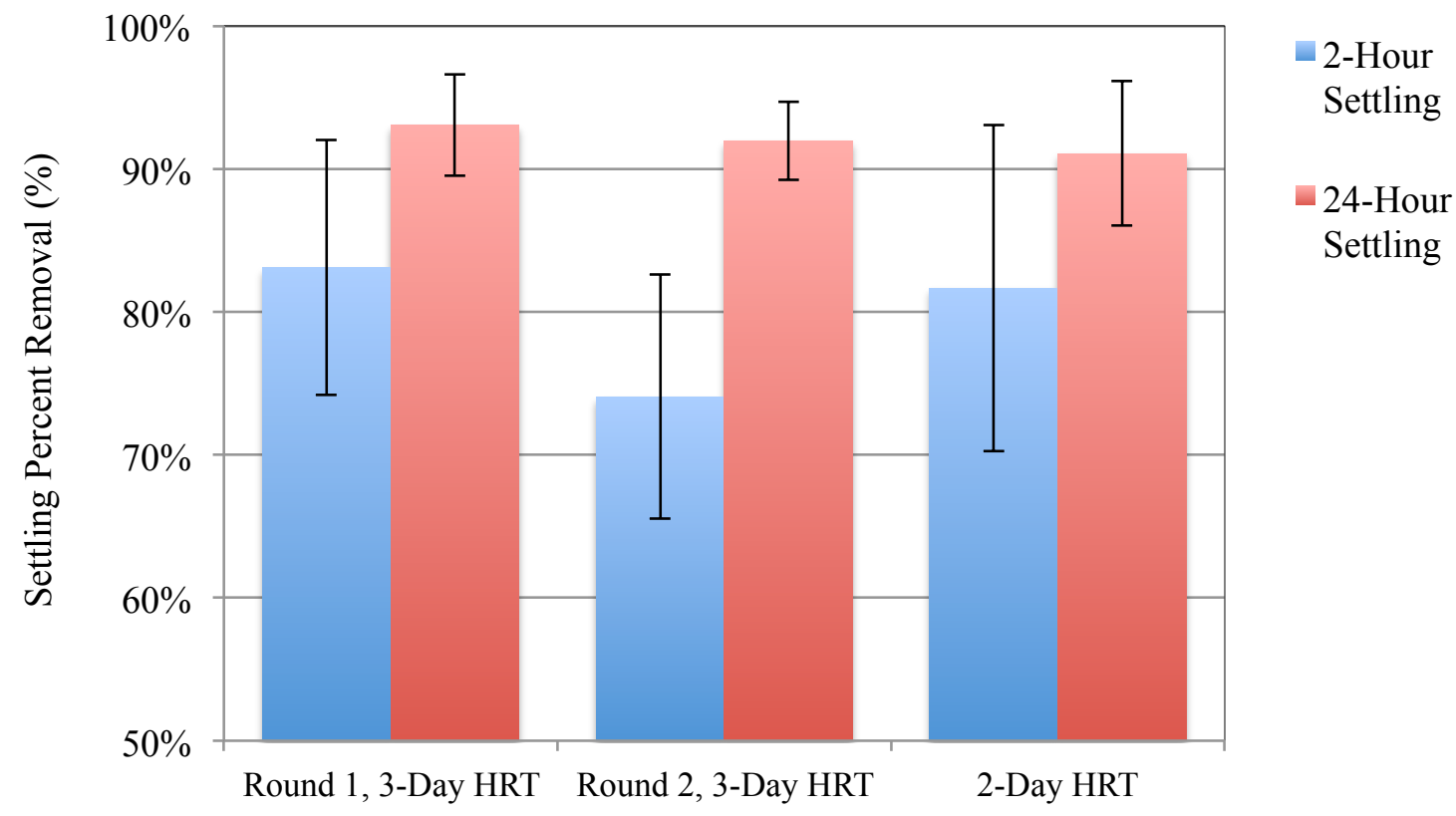

Figure 4-28: Average Imhoff cone percent TSS removal for 2-hour and 24-hour settling. The presented data were averaged from December 4, 2013 to September 18, 2014. The error bars represent the standard deviation of the triplicate ponds in each pond set, averaged across each week of presented data.

Discharge requirements for TSS concentration must be met in wastewater treatment. For 2-hour settling, remaining TSS concentrations were lower in the pond sets receiving primary clarifier effluent (Figure 4-29). 


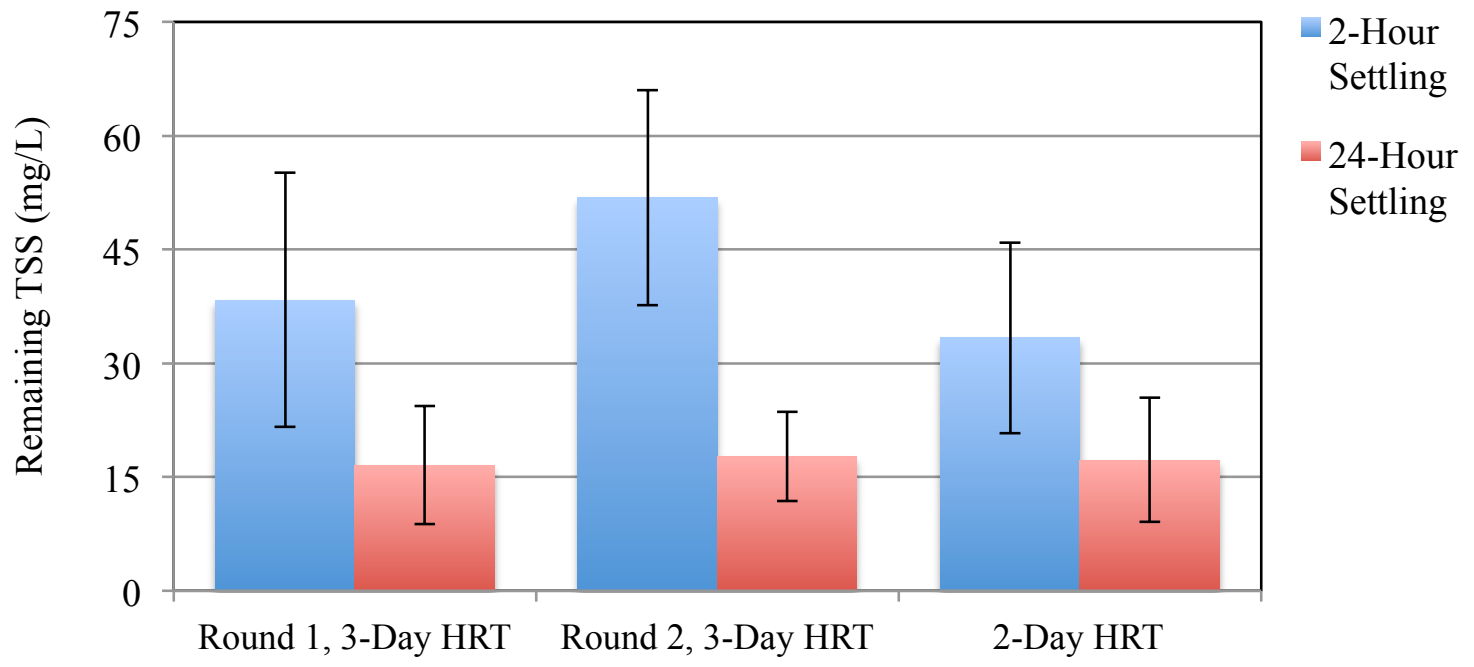

Figure 4-29: Average residual TSS after 2- and 24-hour Imhoff cone settling. The presented data were averaged for December 4, 2013 to September 18, 2014. The error bars represent the standard deviation of the triplicate ponds in each pond set, averaged across each week of presented data.

\subsubsection{Settling Correlations}

As shown in the 2-hour Imhoff cone data, the ability to settle microalgae fluctuates from week to week. To better understand the periods of high settling, various potential factors have been compared for correlation purposes. By linking specific factors to increased algal settling, it was hoped the cause of microalgae flocculation can be better understood.

\subsubsection{Bioflocculation and Settling}

An apparent factor contributing to the settling ability of microalgae was the extent of natural bioflocculation. The bioflocculation of microalgae cultures can be judged by the clarity of its supernatant and densely suspended flocs (Figure 4-30, Figure 4-31). 


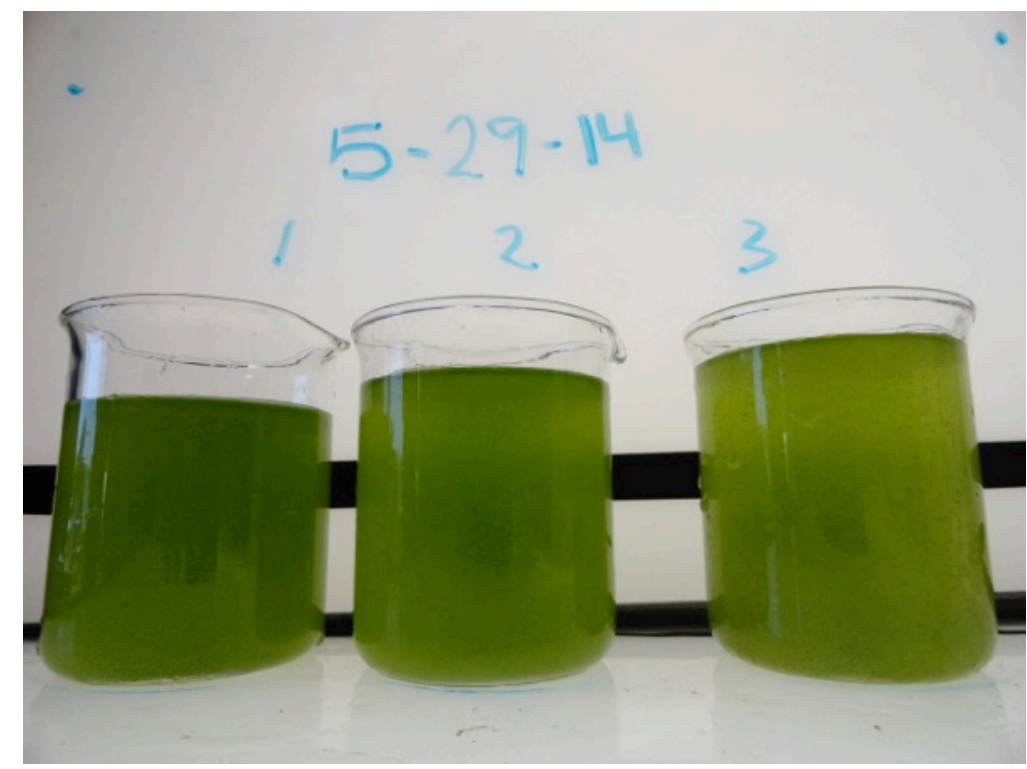

Figure 4-30: Pond water in glass beakers placed on a light table, from Ponds 1, 2 and 3 on May 29, 2014. The colloidal cultures and green supernatant show conditions of poor settling. On this day, the lab analysis for 2-hour settling had a percent removal of $69 \%$ and a residual TSS concentration of $73 \mathrm{mg} / \mathrm{L}$ for the pond set average.

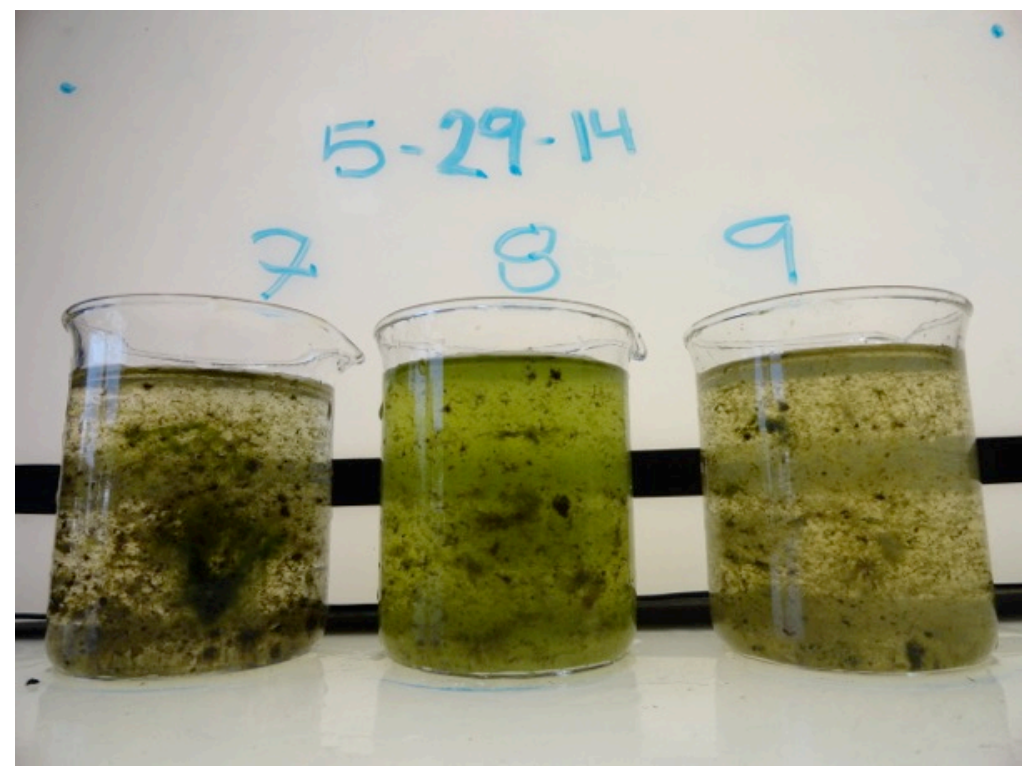

Figure 4-31: Pond water in glass beakers placed on a light table, from Ponds 7, 8 and 9 on May 29, 2014. The clear supernatant and dense flocculated cultures show conditions of high settleability. On this day, the lab analysis for 2-hour settling had a percent removal of $94 \%$ and a residual TSS concentration of 19 $\mathrm{mg} / \mathrm{L}$ for the pond set average. Pond 7 had the best settling with a percent removal of $97 \%$. 
Periods of poor bioflocculation were recognized by the colloidal cultures and green supernatant, which contributed to poor settling of TSS. While periods of high TSS settling can be distinguished by clear supernatant with flocculated cultures in suspension.

\subsubsection{Bacterial Content and Settling}

The Round-1 pond cultures were more settleable than the Round-2 sets possibly due to higher bacterial content. BOD removal was used as a proxy for bacterial growth in an analysis of settleability.

Settleability was judged in terms of 2-hour settling performance. Furthermore, all ponds have been included in the calculation to solely isolate settling performance and bacterial content as the two varying parameters of interest. The data presented are limited to only weeks when BOD removal data are available for all ponds sets.

This comparison of BOD removal and 2-hour suspend solids settling, expressed in both percent removal and residual TSS concentration, illustrates that settling performance fluctuated regardless of BOD removal (Figures 4-32, Figure 4-33). 


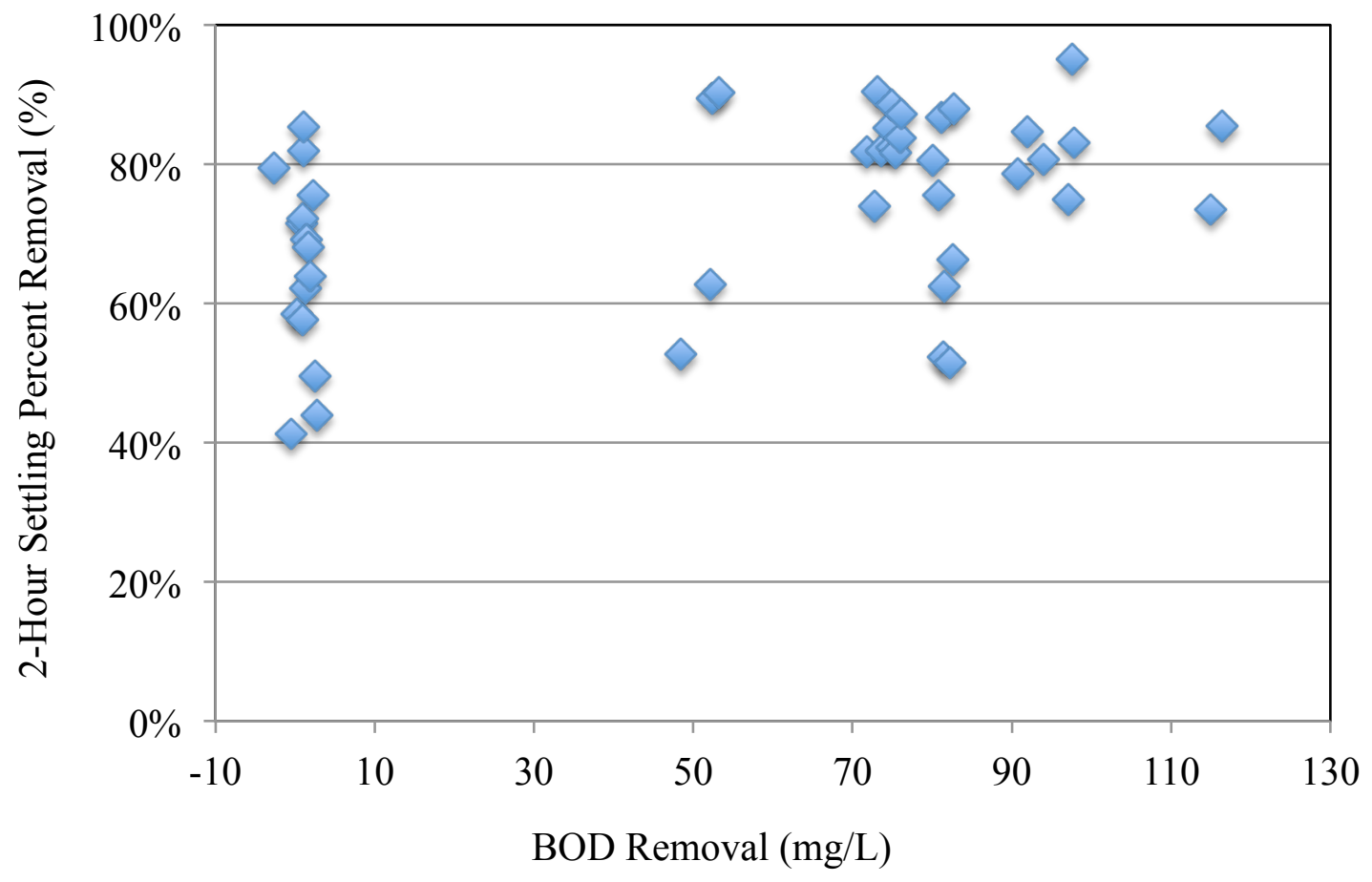

Figure 4-32: The correlation of TSS percent removal over a 2-hour settling period and BOD removal. The data are from all pond sets during March 2013 to August 2014. The vertical cluster of data points showing roughly $0 \mathrm{mg} / \mathrm{L}$ of $\mathrm{BOD}_{5}$ removal is from the Round-2 pond set, where influent BOD concentrations were low. 


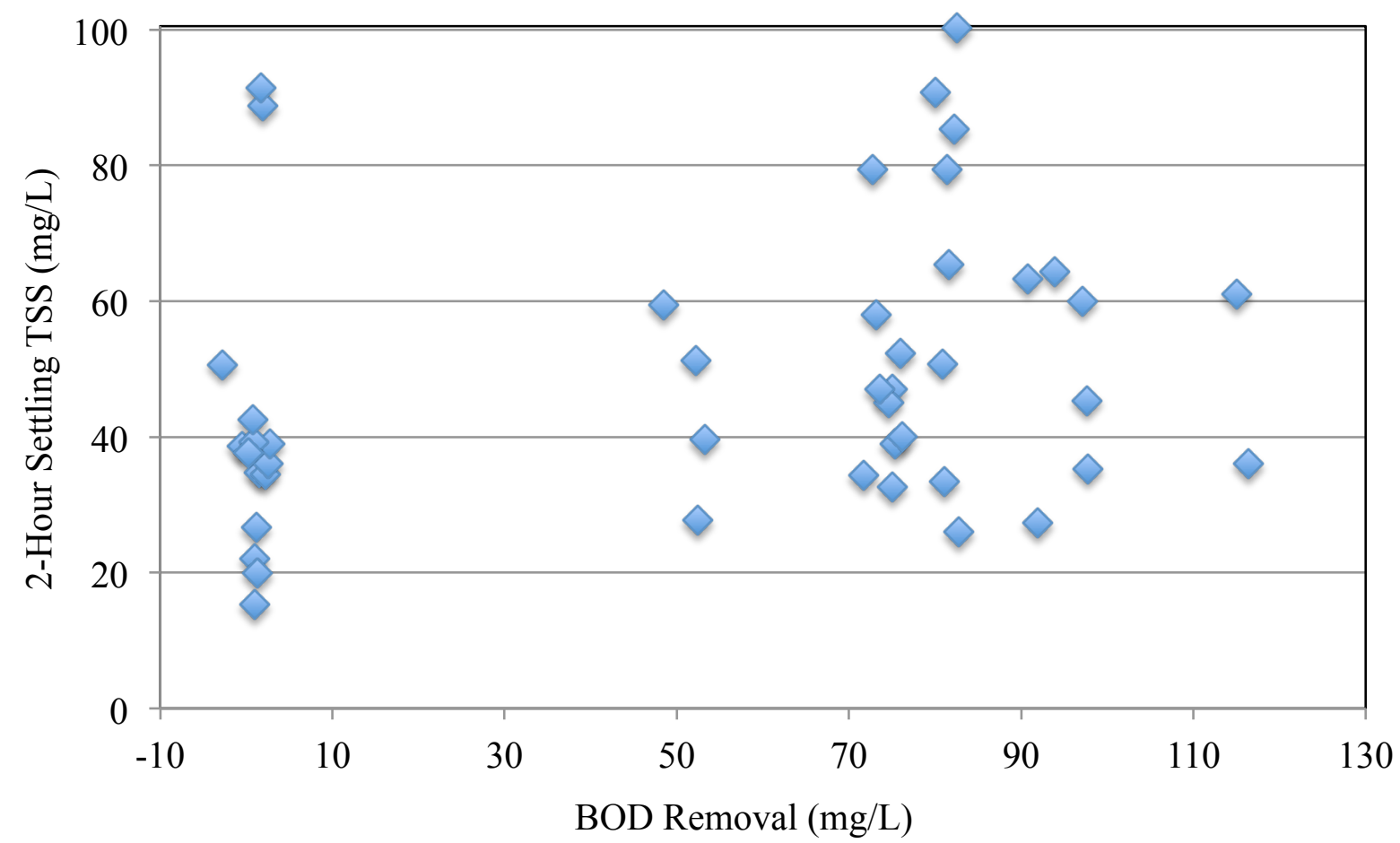

Figure 4-33: The graph presents the correlation of residual TSS over 2-hour settling period and BOD removal. The featured data are from all pond sets and from March 2013 to August 2014. The vertical cluster of data points showing roughly $0 \mathrm{mg} / \mathrm{L}$ of $\mathrm{BOD}_{5}$ removal is comprised of data from the Round-2 pond set, where influent BOD concentrations were low.

The low BOD removal of the Round-2 ponds gives further evidence that high solids removal can be achieved through settling, regardless of bacterial content in the water. The lack of a correlation between BOD removal and settling indicates that bacterial content is not involved in settleability. Although round-two settling was poorer than the ponds receiving BOD load, the fact that BOD load is not a prerequisite for good settling is positive for the prospects to use recycled water in algae biofuel feedstock production.

\subsubsection{Algal Genera and Settling}

Specific genera of microalgae may be more inclined to flocculate and enhance natural settling. Selected periods of high percent removal in 2-hour Imhoff cones, as well as selected periods of 
low percent removal in 2-hour Imhoff cones have been compared in in terms of prominent algal genera (Tables 4-15 and 4-16). The genera of algae have been divided into two categories of filamentous and non-filamentous species to distinguish any correlation between the two categories.

The same genera of algae were found to be present both during periods of high and low settling.

Table 4-15: Prominent genera of algae are presented for periods of high settling performance.

\begin{tabular}{|c|c|c|c|c|c|}
\hline \multirow[b]{2}{*}{ Pond } & \multirow[b]{2}{*}{ Date } & \multirow{2}{*}{$\begin{array}{c}\text { 2-Hour Settling } \\
\text { Removal (\%) }\end{array}$} & \multirow{2}{*}{$\begin{array}{l}\text { Standard Deviations above } \\
\text { Average 2-Hour Removal }\end{array}$} & \multicolumn{2}{|c|}{ Prominent Algal Genera } \\
\hline & & & & Filamentous & Non-Filamentous \\
\hline 1 & $5 / 1 / 14$ & $100 \%$ & 3.0 & & $\begin{array}{l}\text { Chlorella, Chlorococcum } \\
\text { Scenedesmus }\end{array}$ \\
\hline 2 & $6 / 5 / 14$ & $100 \%$ & 3.0 & & $\begin{array}{l}\text { Chlorella, Cyclotella, } \\
\text { Scenedesmus }\end{array}$ \\
\hline 7 & $\begin{array}{c}5 / 22 / 2014- \\
7 / 3 / 2014\end{array}$ & $98 \%$ & 1.4 & $\begin{array}{l}\text { Stigioclonium, } \\
\text { Oscillatoria }\end{array}$ & $\begin{array}{l}\text { Chlorella, Cyclotella, } \\
\text { Nitzschia, Scenedesmus }\end{array}$ \\
\hline 8 & $\begin{array}{l}5 / 15 / 2014- \\
5 / 29 / 2014\end{array}$ & $92 \%$ & 0.9 & Stigioclonium & $\begin{array}{l}\text { Chlorella, Cyclotella, } \\
\text { Nitzschia, Scenedesmus }\end{array}$ \\
\hline
\end{tabular}

Table 4-16: Prominent genera of algae are presented for periods of low settling performance.

\begin{tabular}{cccccc} 
Pond & Date & $\begin{array}{c}\text { 2-Hour Settling } \\
\text { Removal (\%) }\end{array}$ & $\begin{array}{c}\text { Standard Deviations } \\
\text { below Average 2-Hour } \\
\text { Removal }\end{array}$ & $\begin{array}{c}\text { Prominent Algal Genera } \\
\text { Filamentous }\end{array}$ & Non-Filamentous \\
\hline 1 & $4 / 24 / 14$ & $65 \%$ & 1.2 & & Chlorella, Scenedesmus \\
2 & $5 / 29 / 14$ & $62 \%$ & 1.5 & Chlorella, Chlorococcum \\
7 & $7 / 24 / 14$ & $51 \%$ & 2.7 & Stigeoclonium & Chlorella, Cyclotella \\
8 & $7 / 3 / 14$ & $39 \%$ & 3.8 & Oscillatoria & Chlorella, Coelastrum, \\
\end{tabular}


Similarly, filamentous microalgae did not appear to be related to settling performance, being prominent in both periods of high and low settling.

\subsubsection{Grazer Content and Settling}

To further pursue correlations between settling performance the presence of zooplankton that feed on microalgae, known as grazers, have been compared to settling performance. The two types of grazers analyzed in this section are rotifers and ostracods.

The same time periods of high and low algal settling performance analyzed in the prior section on the algal genera were used in the present comparison. However, grazer density did not appear to relate to settling performance. High and low concentrations of grazers were found across the periods of both high and low settling performance (Table 4-17, Table 4-18).

Table 4-17: The prevalence of both rotifers and ostracods during periods of high settling performance.

\begin{tabular}{|c|c|c|c|c|c|}
\hline \multirow[b]{2}{*}{ Pond } & \multirow[b]{2}{*}{ Date } & \multirow{2}{*}{$\begin{array}{c}\text { 2-Hour Settling } \\
\text { Removal (\%) }\end{array}$} & \multirow{2}{*}{$\begin{array}{c}\text { Standard Deviations } \\
\text { above Average 2-Hour } \\
\text { Removal }\end{array}$} & \multicolumn{2}{|c|}{$\begin{array}{c}\text { Suspended Grazer } \\
\text { Concentration }(\text { Count } / \mathrm{mL})\end{array}$} \\
\hline & & & & Rotifers & Ostracods \\
\hline 1 & $5 / 1 / 14$ & $100 \%$ & 3.0 & 131 & 2 \\
\hline 2 & $6 / 5 / 14$ & $100 \%$ & 3.0 & 33 & 0 \\
\hline 7 & $5 / 22 / 2014-7 / 3 / 2014$ & $98 \%$ & 1.4 & 17 & 0 \\
\hline 8 & $5 / 15 / 2014-5 / 29 / 14$ & $92 \%$ & 0.9 & 3 & 0 \\
\hline
\end{tabular}


Table 4-18: The prevalence of both rotifers and ostracods during periods of low settling performance.

\begin{tabular}{cccccc} 
Pond & Date & $\begin{array}{c}\text { 2-Hour Settling } \\
\text { Removal (\%) }\end{array}$ & $\begin{array}{c}\text { Standard Deviations } \\
\text { Below Average 2-Hour } \\
\text { Settling Removal }\end{array}$ & \multicolumn{2}{c}{$\begin{array}{c}\text { Suspended Grazer } \\
\text { Concentration (Count/mL) } \\
\text { Rotifers }\end{array}$} \\
\hline 1 & $4 / 24 / 14$ & $65 \%$ & 1.2 & 25 & 0 \\
2 & $5 / 29 / 14$ & $62 \%$ & 1.5 & 22 & 1 \\
7 & $7 / 24 / 14$ & $51 \%$ & 2.7 & 2 & 1 \\
8 & $7 / 3 / 14$ & $39 \%$ & 3.8 & 0 & 0 \\
\hline
\end{tabular}

The number of zooplankton counted in the samples provide low statistical confidence and might not be representative of the entire raceway pond. In particular, ostracods can be benthic and thus not be collected in the water column samples. However, this analysis does serve to compare periods of high and low zooplankton counts, which appear to have little relationship to settling.

\subsubsection{Productivity and Settling}

For biofuel feedstock production, simultaneous and steady occurrence of high productivities and high settling efficiencies would be ideal. However, the comparison of 2-hour TSS percent removal and productivity illustrates that these two characteristics do not consistently follow the same correlation (Figure 4-35, Figure 4-36, Figure 4-37). 


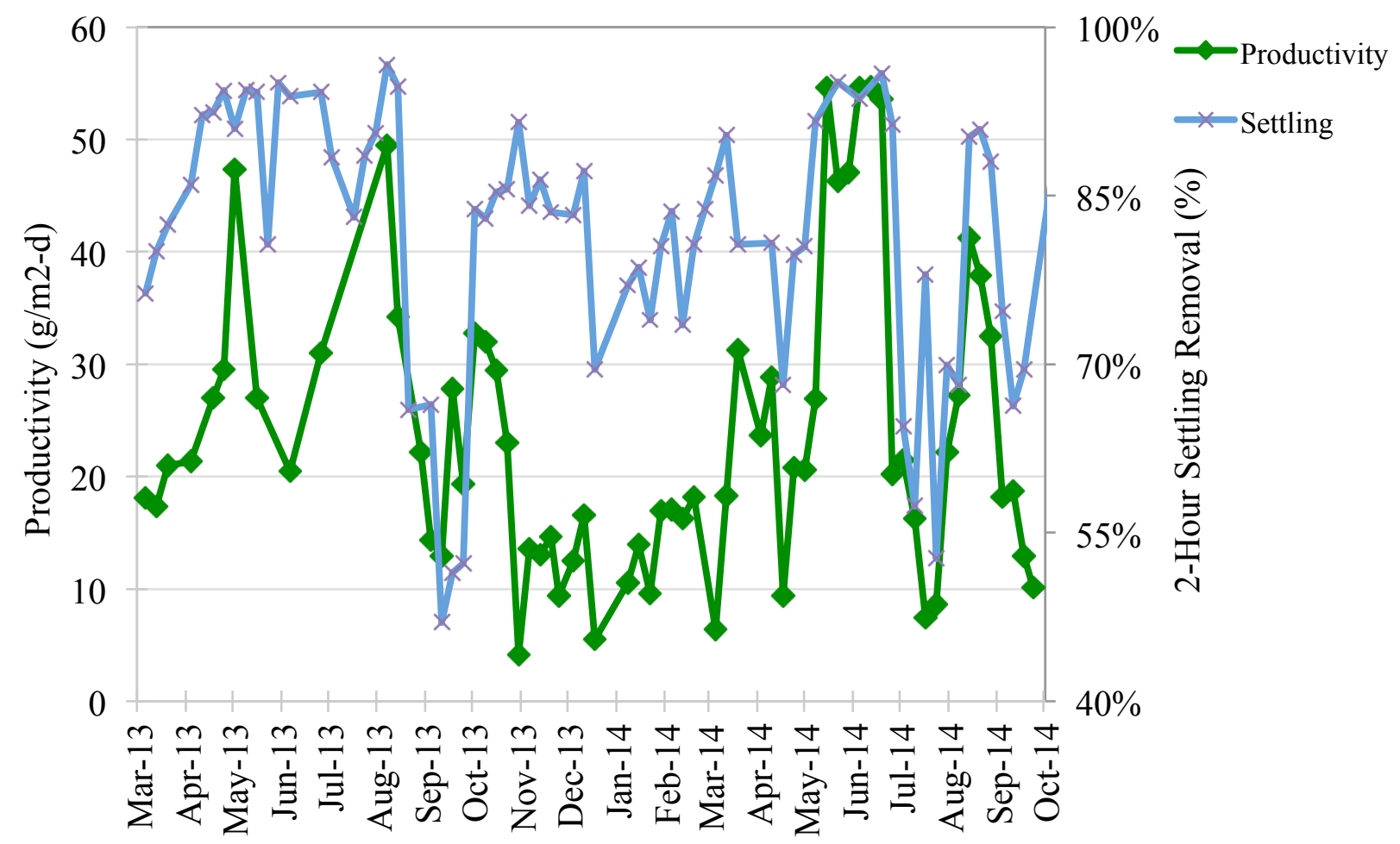

Figure 4-34: The overlay of 2-hour settling performance and productivity for the 2-day HRT pond set from March 2013 to October 2014. 


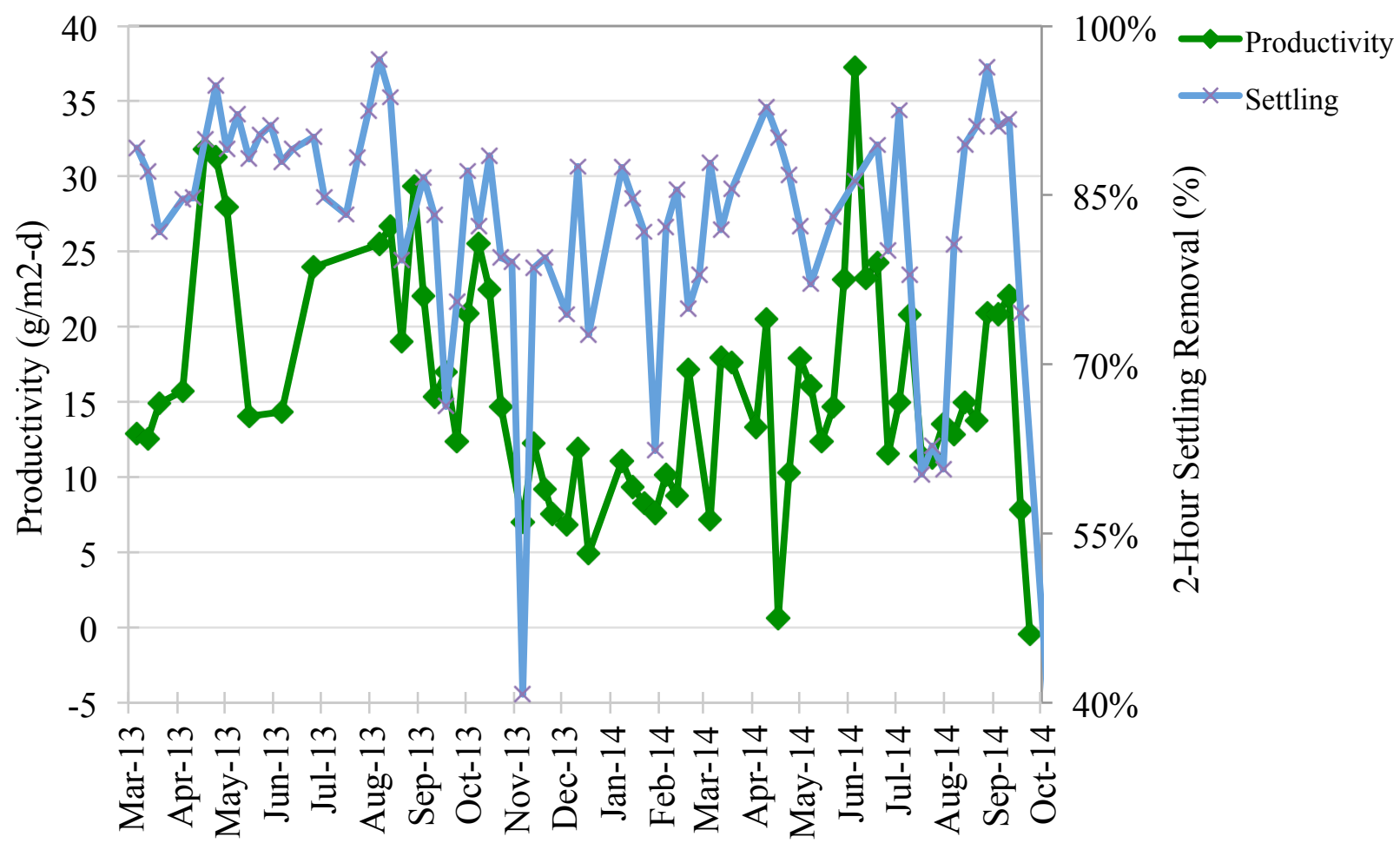

Figure 4-35: Overlay of 2-hour settling performance and productivity for the Round-1, 3-day HRT pond set from March 2013 to October 2014. 


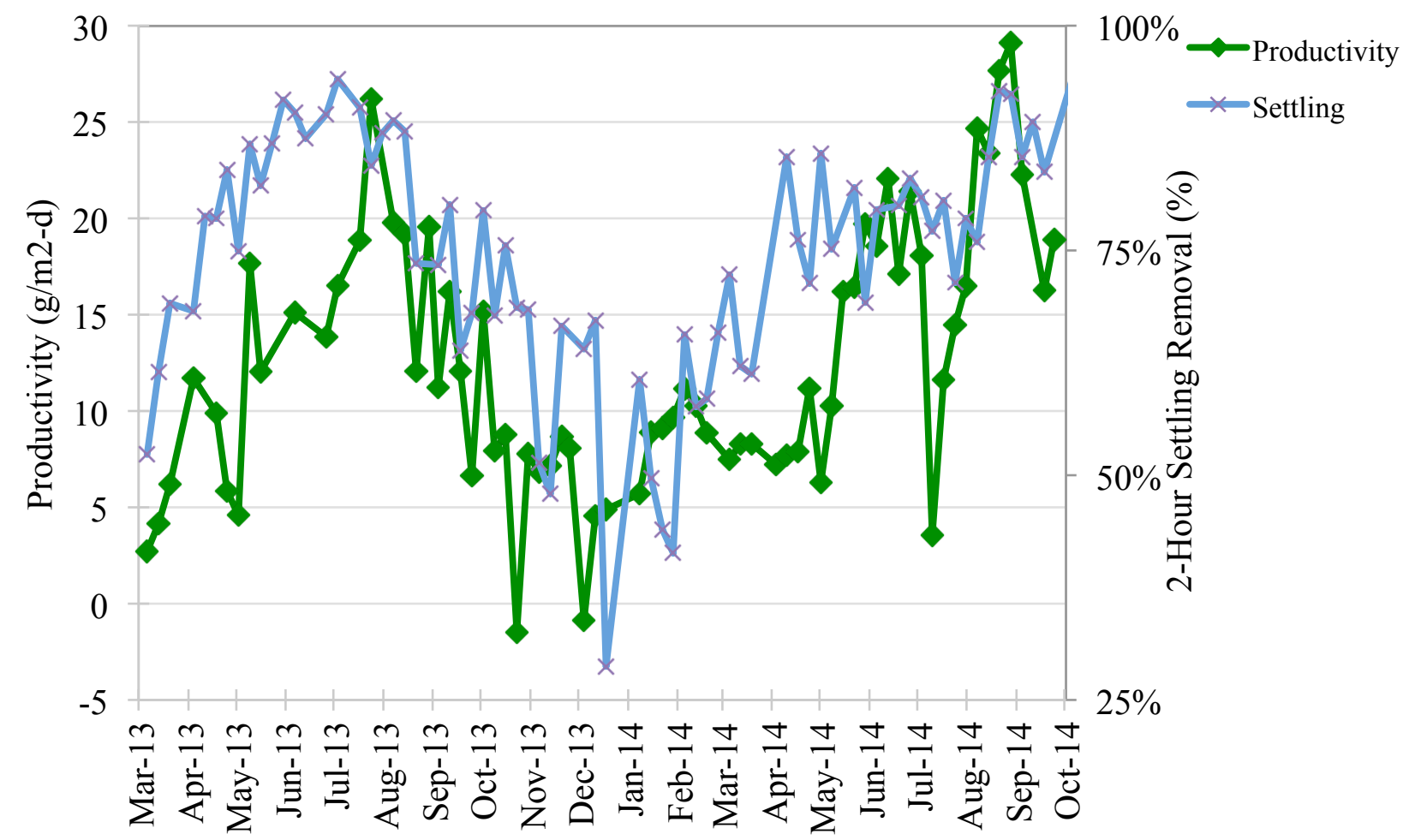

Figure 4-36: The overlay of settling performance and productivity for the Round-2, 3-day HRT pond set from March 2013 to October 2014.

While productivity and settling performance do not always follow the same correlation, the presented graphs do show both high productivity and settling can often occur simultaneously. This is a promising conclusion; however, the causes remain unknown considering the results of this study.

\subsection{Ostracod Population Crash}

On occasion, numerous ostracod exoskeletons would rise to the surface of the raceway ponds. The most notable instance occurred in Pond 6 around July 17, 2014 when a large amount of ostracod shells, or exoskeletons, rose to the surface (Figures 4-38). 


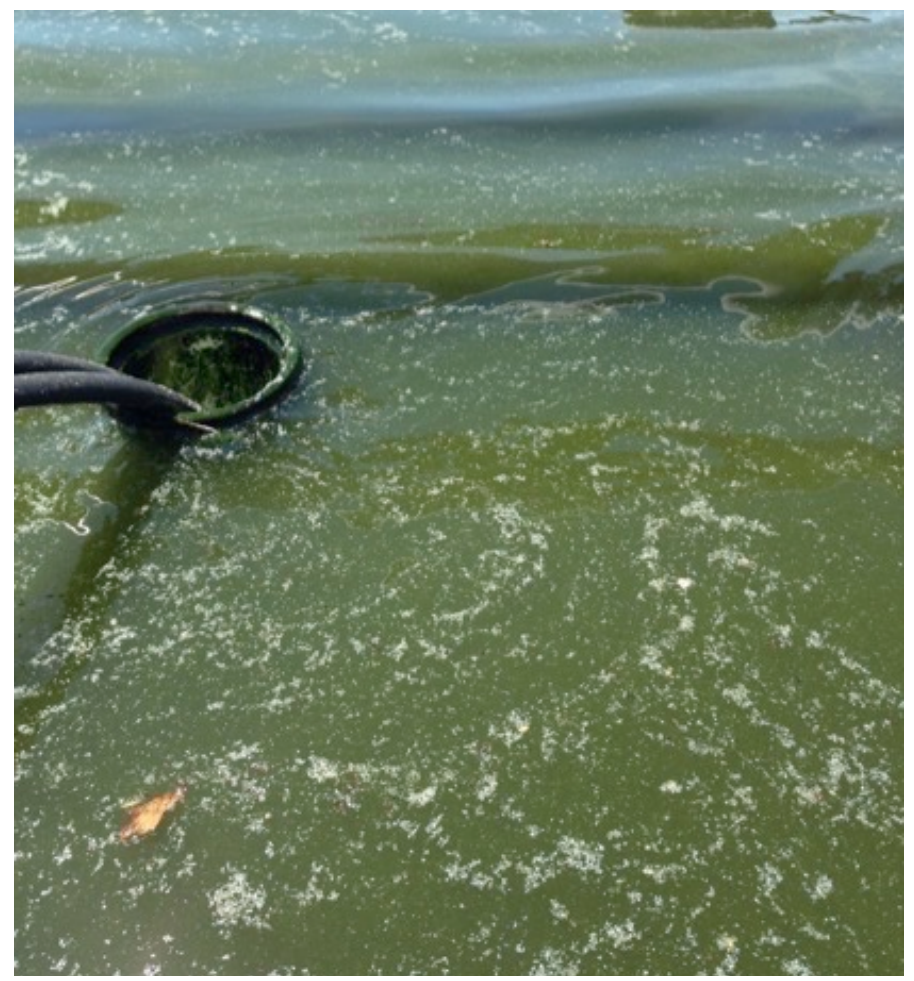

Figure 4-37: Pond 6 surface water with suspended ostracod exoskeletons on July 18, 2014.

These were confirmed to be ostracod exoskeletons from the microscopy analysis of Pond 6 during this time (Figure 4-39).

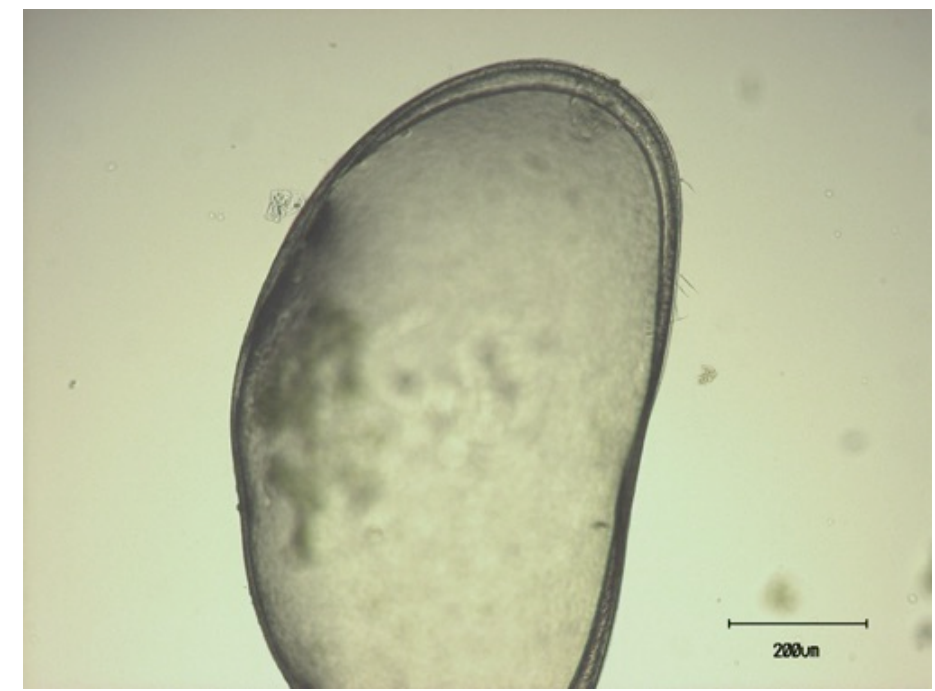

Figure 4-38: Ostracod exoskeleton from Pond 6 on July 17, 2014 at 100-fold magnification. 
Visual inspection of the pond samples during the time period leading up to, and following, the event, showed little correlation to the bloom of ostracod shells (Figure 4-39).
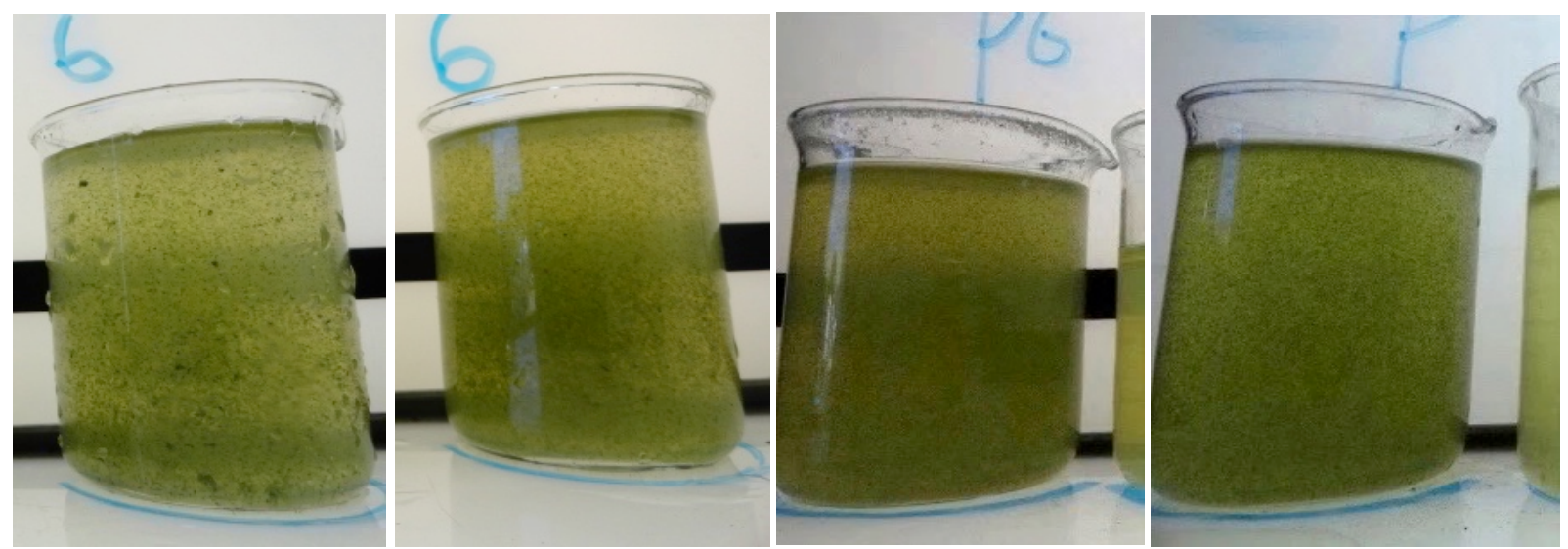

Figure 4-39: Beaker photos of pond 6 during the time period before and after the bloom of ostracod exoskeletons, from left to right: July 3, July 10, July 17, and July 22. All photos were from the year 2014.

However, during the time period from June $12^{\text {th }}$ to July $17^{\text {th }}$, ostracod numbers dropping from 7 counts $/ \mathrm{mL}$ to 2 counts $/ \mathrm{mL}$, and rotifers dropped from 10 counts $/ \mathrm{mL}$ to 3.5 counts $/ \mathrm{mL}$ (Table 419). This reduction of ostracods is likely related to the bloom of empty shells. 
Table 4-19: Pond 6 characteristics before and after the ostracod shell bloom during July 2014. For comparison purposes the average concentrations of DO, BOD, and COD were $6.0 \mathrm{mg} / \mathrm{L}, 3.3 \mathrm{mg} / \mathrm{L}$, and $367 \mathrm{mg} / \mathrm{L}$ respectively in Pond 6 over the course of the study.

DO BOD COD 2-Hour Settling Productivity Rotifers Ostracods

Date $\quad(\mathrm{mg} / \mathrm{L}) \quad(\mathrm{mg} / \mathrm{L}) \quad(\mathrm{mg} / \mathrm{L}) \quad \operatorname{Removal}(\%) \quad\left(\mathrm{g} / \mathrm{m}^{2}\right.$-day $) \quad($ count $/ \mathrm{mL}) \quad(\mathrm{count} / \mathrm{mL})$

\begin{tabular}{cccccccc}
\hline $6 / 12 / 14$ & 3 & - & - & - & 44 & 8 & 0 \\
$7 / 3 / 14$ & 7 & - & 410 & $96 \%$ & 16 & 0 & 7 \\
$7 / 10 / 14$ & 11 & - & - & $84 \%$ & 21 & 10 & 5 \\
$7 / 17 / 14$ & 10 & - & 686 & $42 \%$ & 10 & 3 & 2 \\
$7 / 24 / 14$ & 5 & 3 & - & $83 \%$ & 14 & 4 & 2 \\
\hline
\end{tabular}

The oxygen demand, during the incident on July 17, rose above average concentrations and then returned to a typical concentration with a reduced DO concentration. This comparison of oxygen demand was done across COD and BOD concentrations due to the challenge of producing accurate oxygen demand results in lab (shown in the heading for Table 4-19). These changes were also reflected in settling and productivity dropped during this time, and rose again after the incident had past.

During the time of the incident, the prominent algae genera expanded to include Closterium and Stigeoclonium (Table 4-20).

Table 4-20: Prominent genera of algae are presented for the dates before and after the ostracod shell bloom of July $17^{\text {th }}, 2014$ in Pond 6.

\begin{tabular}{cl} 
Date & \multicolumn{1}{c}{ Prominent Algal Genera Present } \\
\hline $7 / 3 / 14$ & Chlorella, Scenedesmus \\
$7 / 8 / 14$ & \\
$7 / 15 / 14$ & Chlorella, Closterium, Scenedesmus, Stigeoclonium \\
$7 / 22 / 14$ & Chlorella, Scenedesmus \\
\hline
\end{tabular}


This incident corresponded with a crash in productivity and settling performance and so ostracods blooms (and/or crashes) could have a significant impact on biofuel feedstock production. However, with many of the pond characteristics varying during this time period, it cannot be determined whether the ostracod die off was a cause of the other changes, or rather result of them. 


\section{CONCLUSION}

This section covers the relevant findings of microalgae raceway ponds in this study in regards to biomass production, algal settling and suggestions for further research.

\subsection{Diel Influent}

Influent wastewater characteristics can change greatly over the course of a day. The difference in the grab and composite samples measured in this study is a source of error in assessing the TSS, VSS, and BOD loading on the ponds. A precise average grab-composite correction factor could not be found. Because influent grab samples were taken on a consistent weekly basis throughout the present study in previous ones, the grab sample data were used for data analysis.

Composite sampling could be applied to not only influent, but also pond effluent because the water quality in the ponds also changes throughout the day (Ward, 2011).

\subsection{Solar Insolation}

The seasonal correlations of biomass productivity from the raceway ponds roughly track insolation. The frequent deviations from the insolation correlation led to a scattered correlation of productivity to insolation, with $\mathrm{r}^{2}$ values ranging from 0.28 for the Round-1, 3-day HRT ponds to 0.44 for the Round-2, 3-day HRT ponds. Although variable, high productivity periods occurred only in high insolation periods, but high insolation does not always result in high productivity. Due to the complexity of uncontrolled biological systems such as open raceway ponds, other factors can limit growth within the ponds, which are discussed in later sections. 


\subsection{Hydraulic Retention Time}

HRT can be selected to achieve maximum biomass productivity for biofuel production and wastewater treatment. On a net productivity basis, over one year, the 2-day HRT pond set produced an average of 83 metric tons per hectare-year, compared to the 52 metric tons per hectare-year produced in the Round-1, 3-day HRT pond set (Table 5-1).

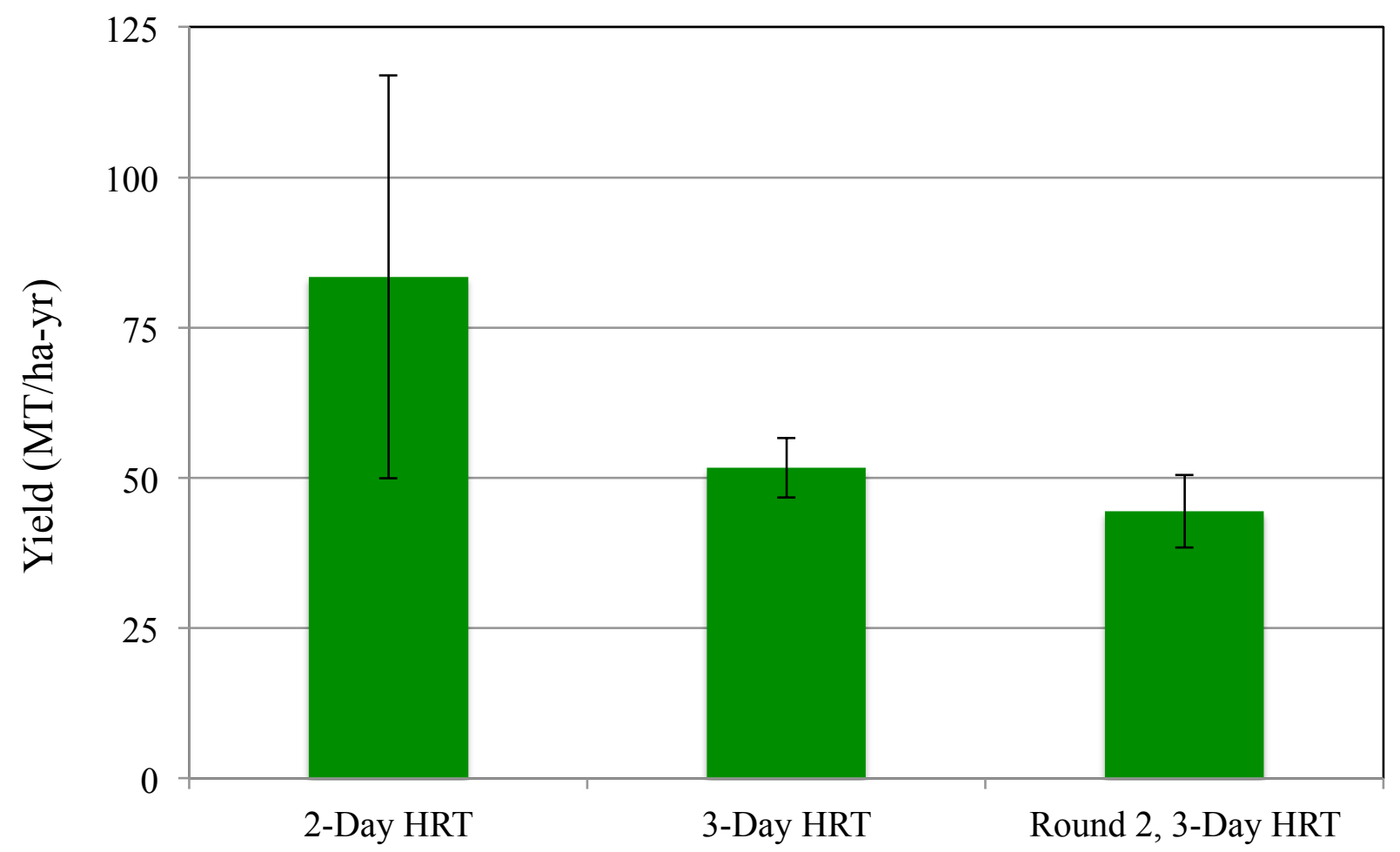

Figure 5-1: One year of net areal productivity. The presented data are averaged from September 25, 2013 to September 25, 2013. The error bars represent the standard deviation of the time series pond average where $\mathrm{n}=3$ for the triplicate ponds.

For the complete year of data, the 2-day HRT pond set showed a 61 percent higher productivity than the Round-1, 3-day HRT pond set. This comparison illustrates, that for increased biofuel production, a 2-day HRT would be the more efficient than a 3-day HRT under the conditions of this study. 


\subsection{Effects of Water Recycling on Productivity}

The recycling of water from the Round-1 pond set to the Round-2 pond set, both operating at a 3-day HRT, did result in a lower net areal productivity in the Round-2 ponds. However, the higher productivity of the Round-1 ponds was likely due to heterotrophic growth (Figure 5-2).

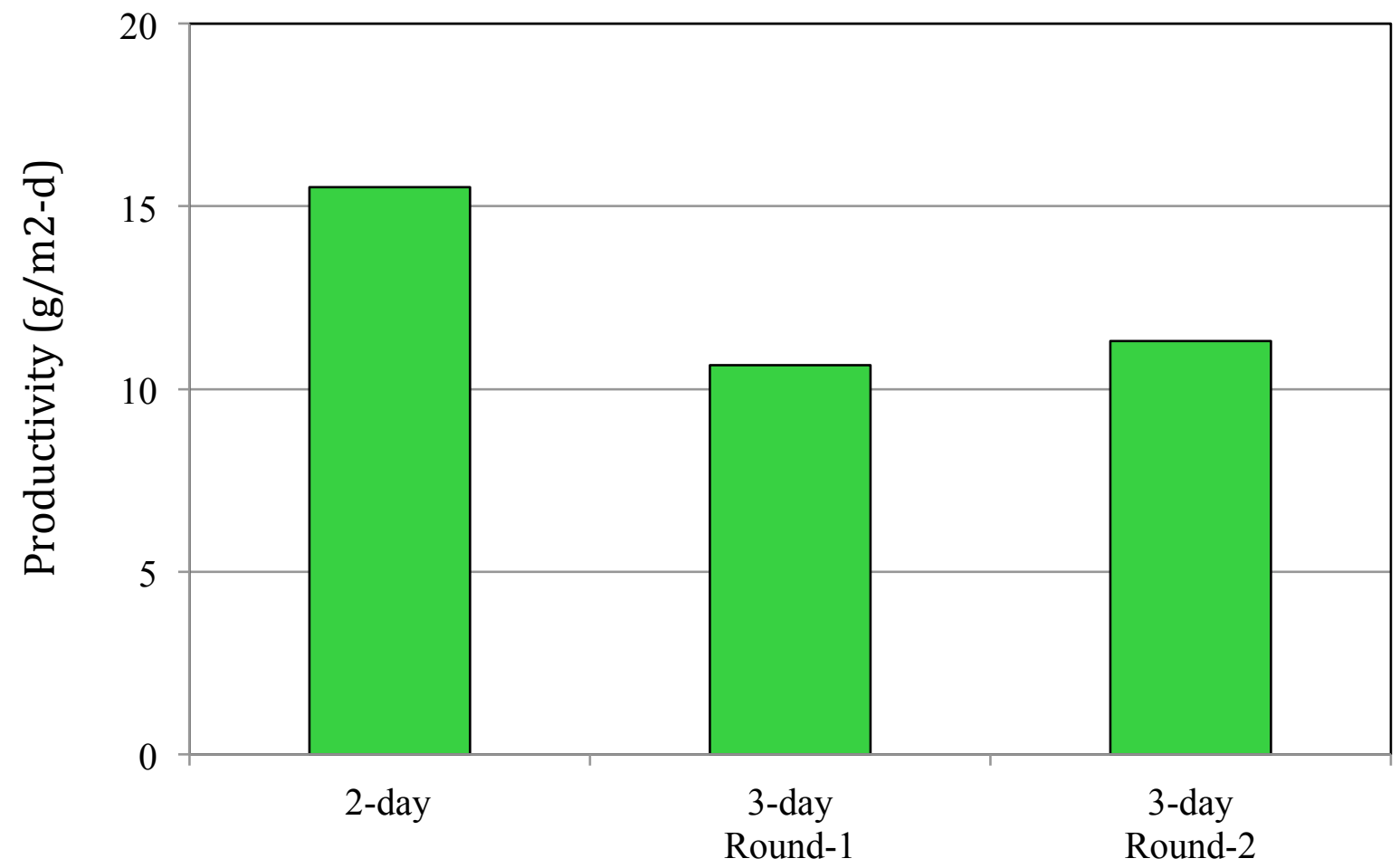

Figure 5-2: Averaged net areal autotrophic productivity represented in terms of conventional yield of metric tons per hectare per year, from March 2013 to August 2014. These results stem from dates when BOD quality control samples passed and thus represent a scattering of dates over a year rather than weekly sampling.

The autotrophic biomass productivity of the Round-2 pond set was higher on average than the Round-1 pond set. However, due to autotrophic productivity being indirectly calculated and the small amount of samples (approximately 20 sample dates per pond set from March 2013 to September 2014), it cannot be stated to a certainty that autotrophic productivity was greater in the Round-2 ponds. Still, this study suggests the one time recycling of water, has little effect on the production of algal biomass. 


\subsection{Maximum Operational Biomass Concentration}

During a period of abnormally high concentrations of suspended solids in the raceway ponds, a steep reduction of productivity occurred. Analysis of the data suggests biomass concentrations that can be sustained by given insolation levels, at least for the conditions of the specific experiment. Algal species, oxygen demand, grazers, and numerous other factors no doubt also play a role in determining the carrying capacity of a raceway pond.

\subsection{Inhibition}

No inhibition of growth could be detected for a single reuse of wastewater media. The estimates of autotrophic productivity in the Round-1 and Round-2 pond sets did not indicate inhibition.

\subsection{Algal Settling}

Several factors were analyzed for correlation with algal settle ability. The strongest, and potentially most important finding, was the correlation of insolation and settleability. However, this correlation was prominent only in the Round-2 pond set (Figures 5-4, Figure 5-5). 


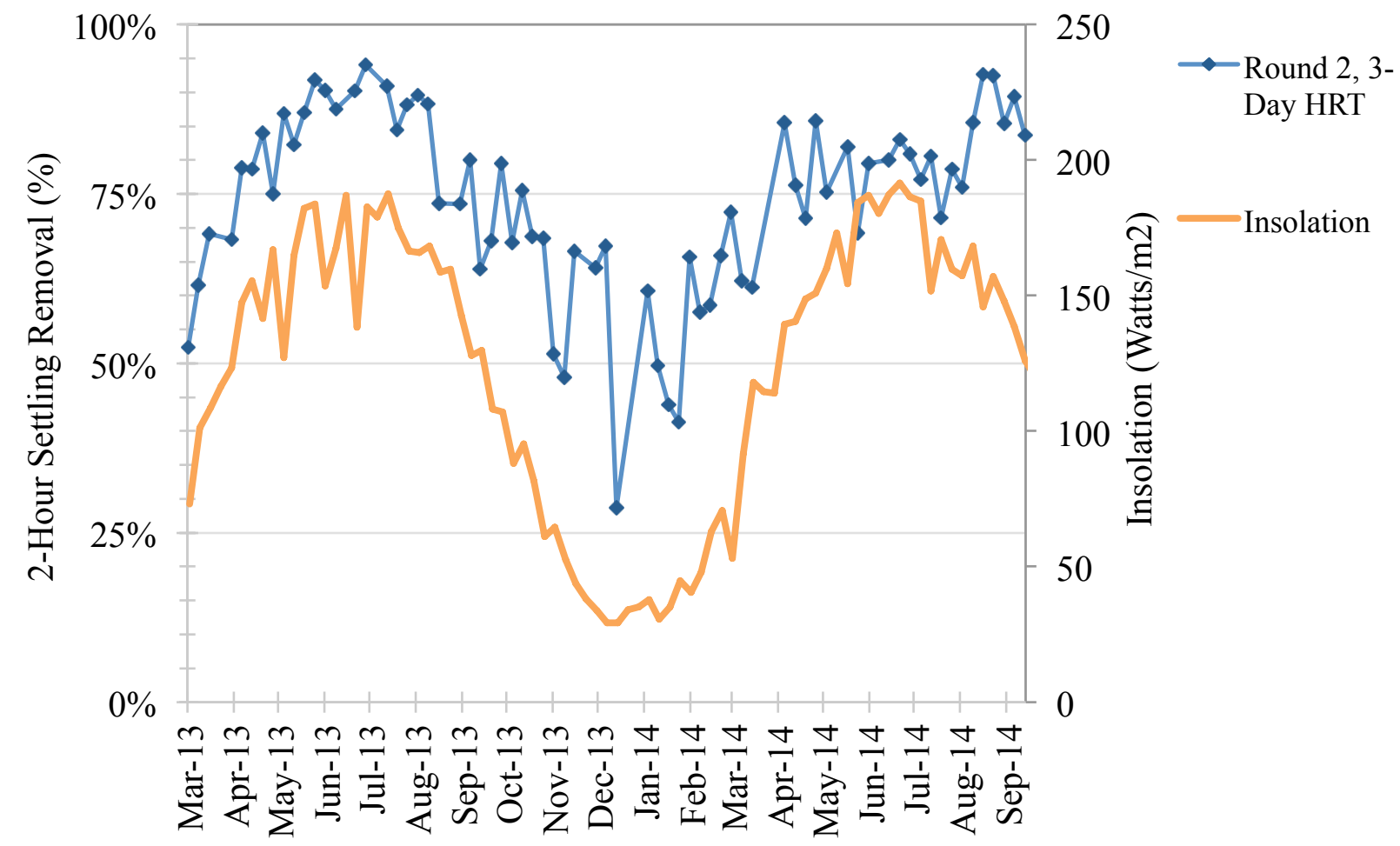

Figure 5-3: Comparison of 2-hour Imhoff cone percent TSS removal and insolation for the Round-2, 3day HRT pond set from March 2013 to September 2014. 


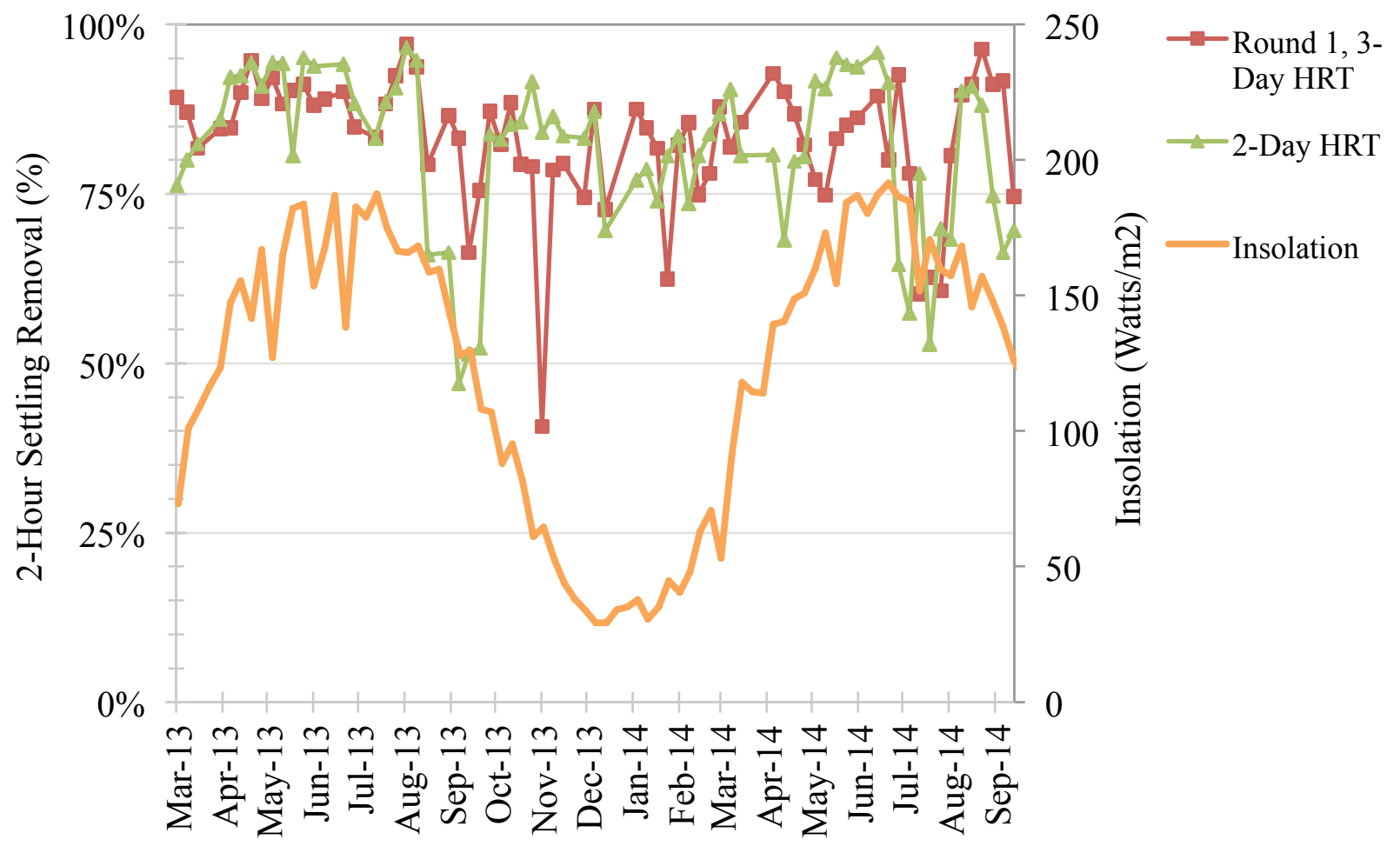

Figure 5-4: Comparison of 2-hour Imhoff cone percent TSS removal and insolation for the 2-day HRT and Round-1, 3-day HRT pond sets from March 2013 to September 2014.

A possible explanation for the seasonality of settleability is that the denser biomass cultures in summer allow for more frequent cell collisions leading to better flocculation. This could explain why the Round-1 pond set did not have a major seasonality in settleability. The Round-1 ponds typically had higher TSS concentrations than the Round-2 ponds which provided for high levels of cell collision and flocculation regardless of season. This collision theory might also help explain the decreased settling during the pond crash noted in section 4.7 Ostracod Population Crash, when productivity dropped from 44 to $10 \mathrm{~g} / \mathrm{m}^{2}$-day and 2-hour imhoff cone settling dropped 96 to 42 percent. Therefore, it is potential that an increase biomass density would aid in algal harvesting. If this is true an increased SRT might lead to greater settleability. 


\subsection{Effects of Microalgae and Grazers}

Microalgae genera or the density of algal-consuming zooplankton did not have a discernible effect on biomass productivity or settling. The high or low presence of ostracods and rotifers was found in ponds with both high and low productivities and settleability. Similarly, the prominent algae genera were the same during instances of both high and low productivity and settleability.

\subsection{Wastewater Treatment}

If algal biofuel production is to be combined with wastewater treatment in the same system, oxygen demand removal will be a crucial process. The national secondary treatment standards for wastewater generally limit the 30 -day average $\mathrm{BOD}_{5}$ concentration to $30 \mathrm{mg} / \mathrm{L}$ (USEPA, 2013). Assuming effluent filtration, soluble carbonaceous $\mathrm{BOD}_{5}$ is the relevant measure, and the $\mathrm{scBOD}_{5}$ concentrations in all raceway pond sets easily meet this requirement, with the highest recorded pond concentration being $7.9 \mathrm{mg} / \mathrm{L}$.

Suspended solids removal is another main constituent regulated in secondary treatment. Like $\mathrm{BOD}_{5}$, TSS effluent concentration limits are typically $30 \mathrm{mg} / \mathrm{L}$ (USEPA, 2013). The average 24hour Imhoff cone TSS concentrations were under $20 \mathrm{mg} / \mathrm{L}$ for each pond set (Figure 5-6), but achieving this on a full scale system would require larger settling basins compared to typical wastewater clarifiers. 


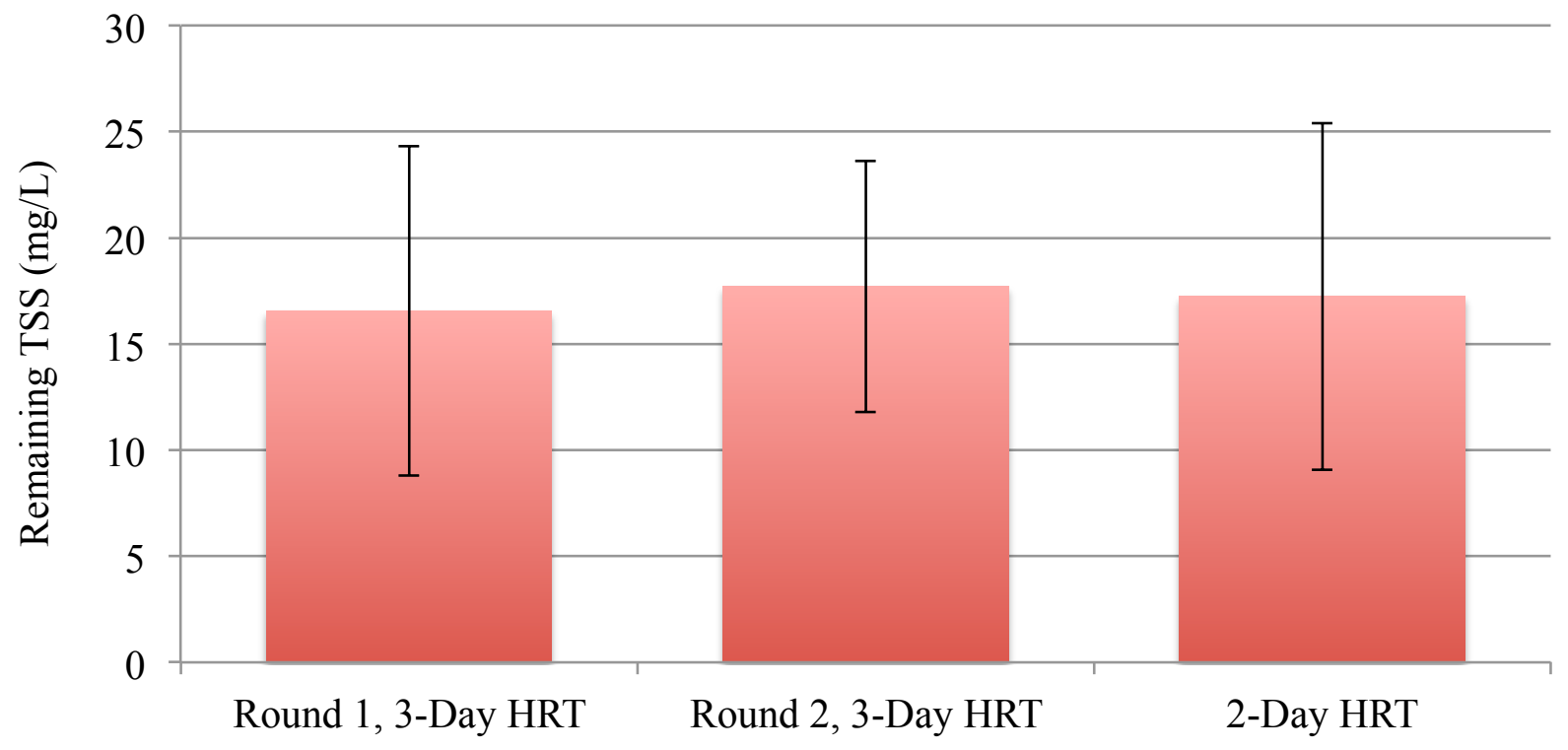

Figure 5-5: Residual TSS concentrations after 24-hour imhoff cone settling, from December 2013 to September 2014. The error bars represent the average standard deviation of the triplicate ponds in each pond set.

The Imhoff cone data represents ideal settling in perfectly still water, which would like require more time in the less controlled conditions of a settling basin. Also occasional outliers that are not represented in the average value, would exceed the $30 \mathrm{mg} / \mathrm{L}$ limit even with a 1-day HRT settling basin. Therefore, if used pond water is to be discharged, the addition of chemical-aided flocculation is recommended.

For all experimental pond sets in this study, ranging from December 2013 through September 2014 , only 10 percent of the time did a pond set not meet discharge limit of $30 \mathrm{mg} / \mathrm{L}$ given 24 hours of settling with only 8 percent of the values for the Round- 2 pond water not meeting the limit. Therefore the system could potentially operate with polymer addition on an as need basis for few periods that natural biofloccuation is not sufficient to the regulatory requirements. 


\subsection{Limitations of the Study}

During the course of research for this study, the project experienced problems on both pond operations and laboratory analyses. These limitations are listed in this section.

Pond Operational Limitations:

1. The Round-2 pond set had an occasionally varying HRT due to effluent pump malfunctions.

2. Grab sampling was used predominantly instead of diel composite sampling.

3. Samples were collected only once per week when more frequent sampling would give more complete data on performance.

Laboratory Analysis Limitations:

1. Quality control samples for BOD analysis frequently failed; which decreased the amount of BOD concentration data used in this study.

2. Algal species and grazer concentrations were rough estimates.

\subsection{Recommended Future Research}

To provide further insight to the topics presented in this study, additional research should be completed on the following:

1. For growth inhibition studies, operate raceway ponds with more extensive water recycling as would be needed in biofuel production.

2. Operate the raceway ponds with the same HRT but varying SRTs and determine the effect of biomass density on settling and productivity. 
3. Study the effect on productivity of insolation as distinct from temperature.

4. Determine concentrations of all algal species and grazers through $16 \mathrm{~s}$ and $18 \mathrm{~s}$ amplicon sequencing.

5. Perform analysis of grazer trends and their effect on settling and productivity to determine if there is a lag phase in the correlations. 


\section{REFERENCES}

Araki, Martín-Gomez, et al., (2001). Effect of High-Rate Algal Ponds on Viability of Cryptosporidium parvum Oocysts. American Society for Microbiology: Applied Environmental Microbiology. Retrieved June 26, 2015, from http://aem.asm.org/content/67/7/3322.full

Biller, Ross. (2010). Potential Yields and Properties of Oil from the Hydrothermal Liquefaction of Microalgae with Different Biochemical Content. Energy and Resources Research Insitute, University of Leeds, UK. Elsevier Ltd.

Boggess, C. (2014). Optimization of Growth Parameters for Algal Regrowth Potential Experiments. San Luis Obispo: Cal Poly Digital Commons.

Chang, M. (2014). Water and Nutrient Recycling by High Rate Algae Ponds Fed in Primary Treated Municipal Wastewater. San Luis Obispo: Cal Poly Digital Commons.

Christenson, L., \& Sims, R. (2011). Production and Harvesting of Microalgae for Wastewater Treatment, Biofuels, and Bioproducts. Biotechnology Advances, 686-702.

Christine, R., \& Posten, C. (n.d.). Introduction to the Thematic Focus. Retrieved June 1, 2015, from http://www.tatup-journal.de/english/tatup121_ropo12a.php

Committee on the Sustainable Development of Algal Biofuels; Board on Agriculture and Natural Resources; Board on Energy and Environmental Systems; Division on Earth and Life Studies; Division on Engineering and Physical Sciences; National Research Council. (2012). Summary. In Sustainable development of algal biofuels in the United States. Washington, D.C.: National Academies Press.

Cornell University. (n.d.). What are Biofuels?. Retrieved June 30, 2015, from http://www.greenchoices.cornell.edu/energy/biofuels/

Eddy, Metcalf, et all. \&. (2014). Wastewater Engineering Treatment and Resource Recovery. New York: McGraw-Hill Education.

EIA (U.S. Energy Information Administration). (n.d.). Independent Statistics and Analysis. Retrieved June 30, 2015, from http://www.eia.gov/todayinenergy/detail.cfm?id=12251 
EIA (U.S. Energy Information Administration). Internation Energy Statistics (n.d.). Retrieved June 30, 2015, from

http://www.eia.gov/cfapps/ipdbproject/iedindex3.cfm?tid=44\&pid=44\&aid=2\&cid=ww, \&syid=1980\&eyid=2012\&unit=QBTU

EPA (United States Environmental Protection Agency). (2013). Report on the Performance of Secondary Treatment Technology (Vol. EPA-821-R-13-001). Washington DC: United States Environmental Protection Agency, Office of Water.

DOE (United States Department of Energy). (n.d.). Energy 101: Algae-to-Fuel. Retrieved April 18, 2015, from http://energy.gov/eere/videos/energy-101-algae-fuel

Levin Institution. (n.d.). Fossil Fuels. The State University of New York. Retrieved June 30, 2015, from http://www.globalization101.org/fossil-fuels/

Fresco, E. (2015). Anaerobic Digestion of Microalgae for Methane Production and Nutrient Recycling. San Luis Obispo: Cal Poly Digital Commons.

Frost, D. T. (2008). Bioflocculation For Control of Wastewater Pond Microalgae. San Luis Obispo: Cal Poly Digital Commons.

Fulton, L. (2009). Nutrient Removal by Algae Grown in $\mathrm{CO}_{2}$-enriched Wastewater over a Range of Nitrogen-to-Phosphorus Ratios: A Master's Thesis. San Luis Obispo: Cal Poly Digital Commons.

Granéli, Edna, Salomon (2010). Factors Influencing Allelopathy and Toxicity in Prymnesium parvum. Journal of the American Water Resources Association (JAWRA) 46(1):108-120.

Hamilton, C., \& Rossmeissl, N. (2014). Exploring the Utilization of Complex Algal Communities to Address Algal Pond Crash and Increase Annual Biomass Production for Algal Biofuels. Energy Efficiency and Renewable Energy.

Hill, A. (2014). The Effect of Pretreatment Methods on Methane Yields and Nutrient Solubilization During Anaerobic Digestion of Microalgae. San Luis Obispo: Cal Poly Digital Commons. 
Hutton, M. (2014). Operations Manual SLO Ponds. San Luis Obispo, California.

Kelley, J. (2013). Lipid Production by Microalgae Treating Municipal Wastewater. San Luis Obispo: Cal Poly Digital Commons.

Lundquist, T., Woertz, I., Quinn, N., \& Benemann, J. (2010). A Realistic Technology and Engineering Assessment of Algal biofuel Production.

NREL. (2014). Solar Maps. Retrieved from National Renewable Energy Labratory: http://www.nrel.gov/gis/images/map_pv_us_annual10km_dec2008.jpg

Owen-Smith, N.; Mills, M.G. (2008). "Shifting prey selection generates contrasting herbivore dynamics within a large- mammal predator-prey web.” Ecology (89:4); pp. 1120-1133.

Oswald, W. (1990). Advanced Integrated Wastewater Pond Systems. Supplying Water and Saving the Environment for Six Billion People (pp. 74-77). San Francisco: ASCE.

Porter, K. (1976). Enhancement of Algal Growth and Productivity by Grazing Zooplankton. Science, 1332-1334.

Reiff, C. (2015). Nutrient transformations in algae raceway ponds fed municipal wastewater. San Luis Obispo: Cal Poly Digital Commons.

Ripley, E. B. (2013). Settling Performance in Wastewater Fed High Rate Algae Ponds. San Luis Obispo: Cal Poly Digital Commons.

Roberts, A. (2014). Velocity Report. San Luis Obispo.

Sazdanoff, N. (2006). Modeling and Simulation of the Algae to Biodiesel Fuel Cycle. Ohio State University.

Shah, A. (2011). Advantages and Disadvantages of Oil - Cons Disregarded by Powerful Lobbies. Retrieved June 30, 2015, from http://www.greenworldinvestor.com/2011/07/07/advantages-and-disadvantages-of-oilcons-disregarded-by-powerful-lobbies/

Surovov, Y. (2015). Optimization of Algae Productivity and Harvesting at Existing High-Rate Pond Municipal Wastewater Treatment Plant. San Luis Obispo: Cal Poly Digital Commons. 
Venteris, E. R., Skaggs, R. L., Coleman, A. M., \& Wignosta, M. S. (2014). A national-scale comparison of resource and nutrient demands for algae-based biofuel production by lipid extraction and hydrothermal liquefaction. Elsevier Ltd.. Biomass and Bioenergy (2014) 1-15.

Venteris, E. R., Skaggs, R. L., Coleman, A. M., \& Wignosta, M. S. (2013). A GIS Cost Model to Assess the vailability of Freshwater, Seawater, and Saline Groundwater for Algal Biofuel Production in the United States. Environmental Science and Technology, 4840-4849.

Ward, P. (2011). Bioflocculation and $\mathrm{CO}_{2}$ Supplementation in Wastewater Treatment by Algal High-Rate Ponds. San Luis Obispo: Cal Poly Digital Commons.

Washington State Department of Ecology. (n.d.). Information About Why Algae Grow in Lakes. Retrieved July 2, 2015, from http://www.ecy.wa.gov/programs/wq/plants/algae/lakes/AlgaeInformation.html

Woertz, I., Fulton, L., \& Lundquist, T. (2009). Nutrient Removal \& Greenhouse Gas Abatement with CO2 Supplemented Algal High Rate Ponds. San Luis Obispo: Cal Poly Digital Commons. 


\begin{abstract}
APPENDICES
The appendix section consists of additional information relevant to the study that was not included in the thesis. Sections A.1 Supervisory Control and Data Acquisition System and A.2 Complete List of Water Quality Analyses for the Algae Field Station were collaboratively written with Carter Reiff.
\end{abstract}

\title{
A.1 Supervisory Control and Data Acquisition System
}

A supervisory control and data acquisition (SCADA) system was used to monitor dissolved oxygen (Neptune Systems, Morgan Hill, California), pH (Sensorex, Garden Grove, California), and temperature (Neptune Systems) in each of the nine ponds at the AFS. Data-loggers (Apex Aqua Controllers, Neptune Systems) stored these data at designated intervals. $\mathrm{pH}$ was recorded every ten minutes from March 2013 to June 2014 when it was changed to hourly recordings in July 2014. The dissolved oxygen and temperature were recorded hourly throughout the duration of the AFS pond experiments. The SCADA system was controlled from a computer located in a shed onsite and connected to each Neptune unit for the ponds (Figure A-1). 


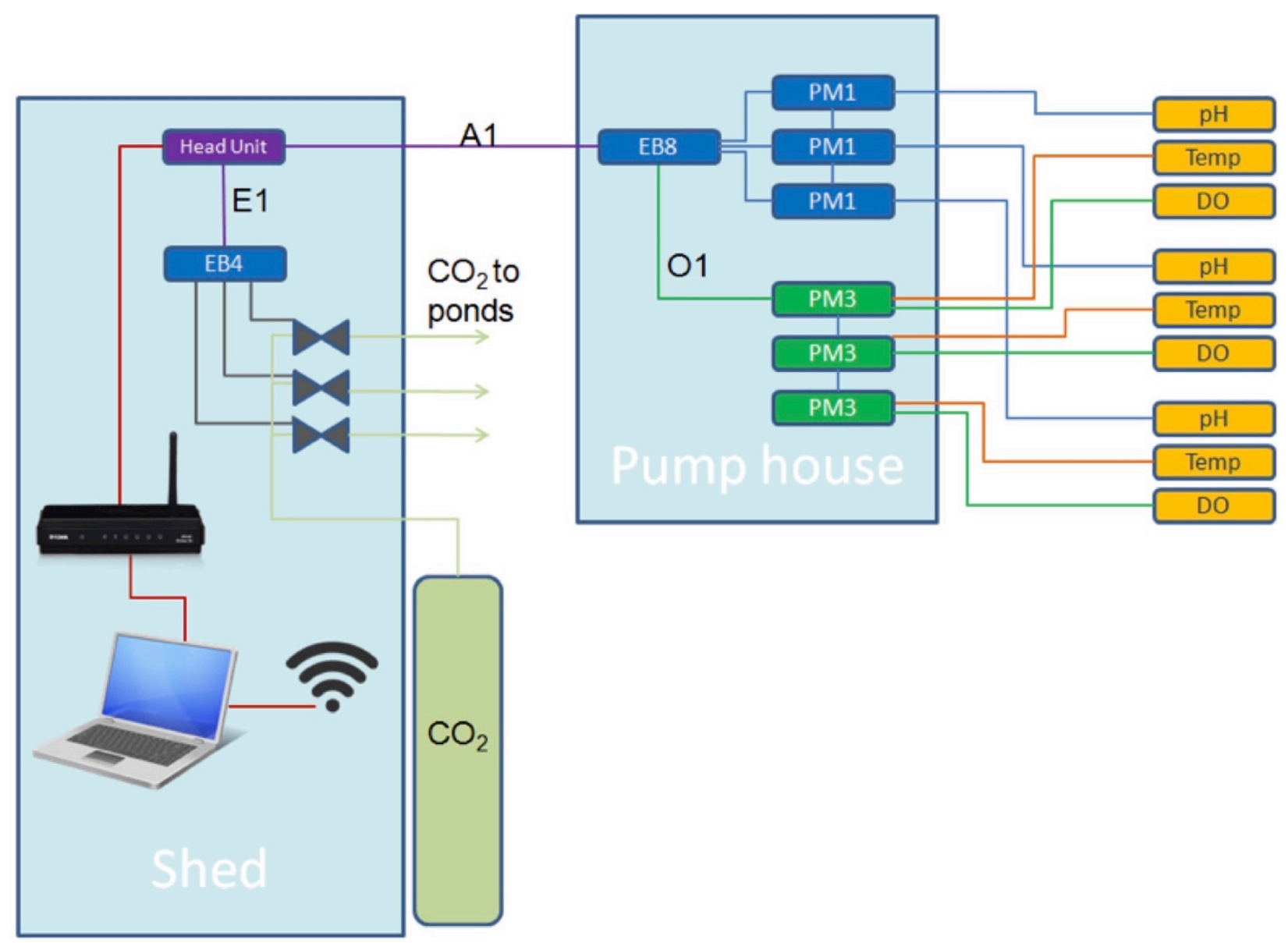

Figure A-1: Schematic of the SCADA system that measured and recorded $\mathrm{pH}, \mathrm{DO}$, and temperature data. Carbon dioxide sparging was controlled by the $\mathrm{pH}$ signal from the ponds (Hutton, 2014).

The three pond sets each had a pump house containing temperature and dissolved oxygen recording and $\mathrm{pH}$ recording and control units (Figure A-2).

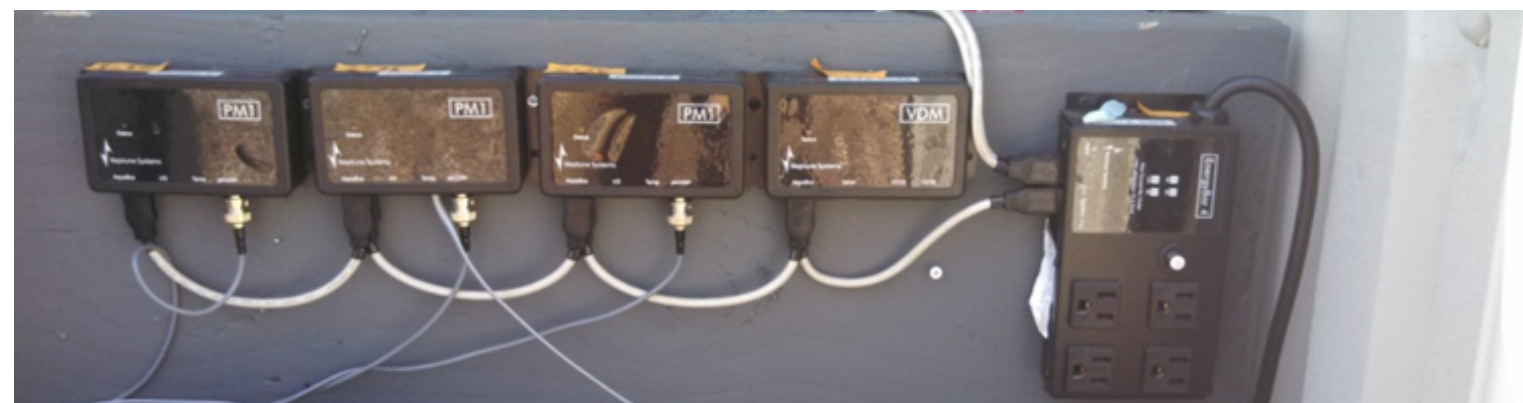

Figure A-2: The Neptune PM1 control units for $\mathrm{pH}$ data recording. This setup was the same for all triplicate pond sets (Chang, 2014). 
The DO reading modules were located in separate waterproof plastic containers next to the ponds (Figure A-3).

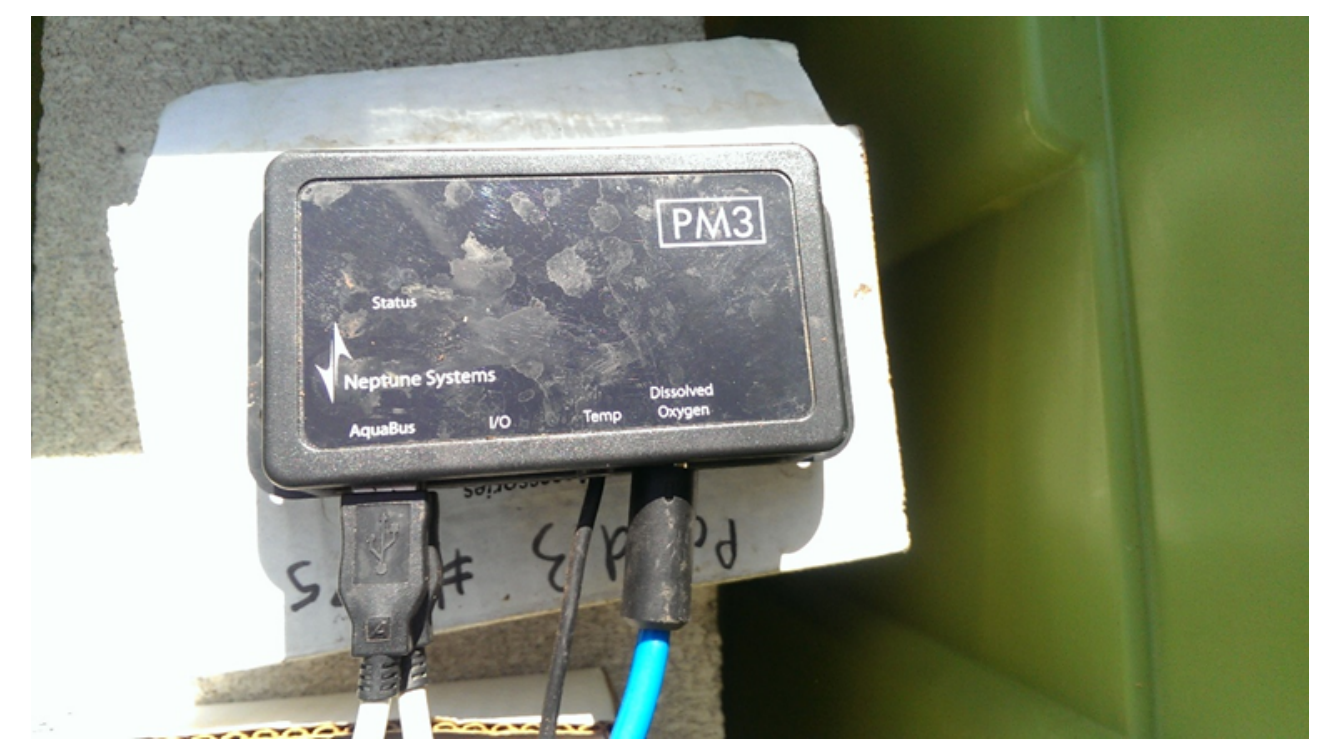

Figure A-3: A Neptune PM3 control unit for DO and temperature data recording. This setup was the same for all ponds (Chang, 2014).

The sensors for the temperature, $\mathrm{pH}$, and $\mathrm{DO}$ were kept in in the ponds using probe stands located on the east end of the ponds upstream of where the influent water entered the ponds (Figure A-4).

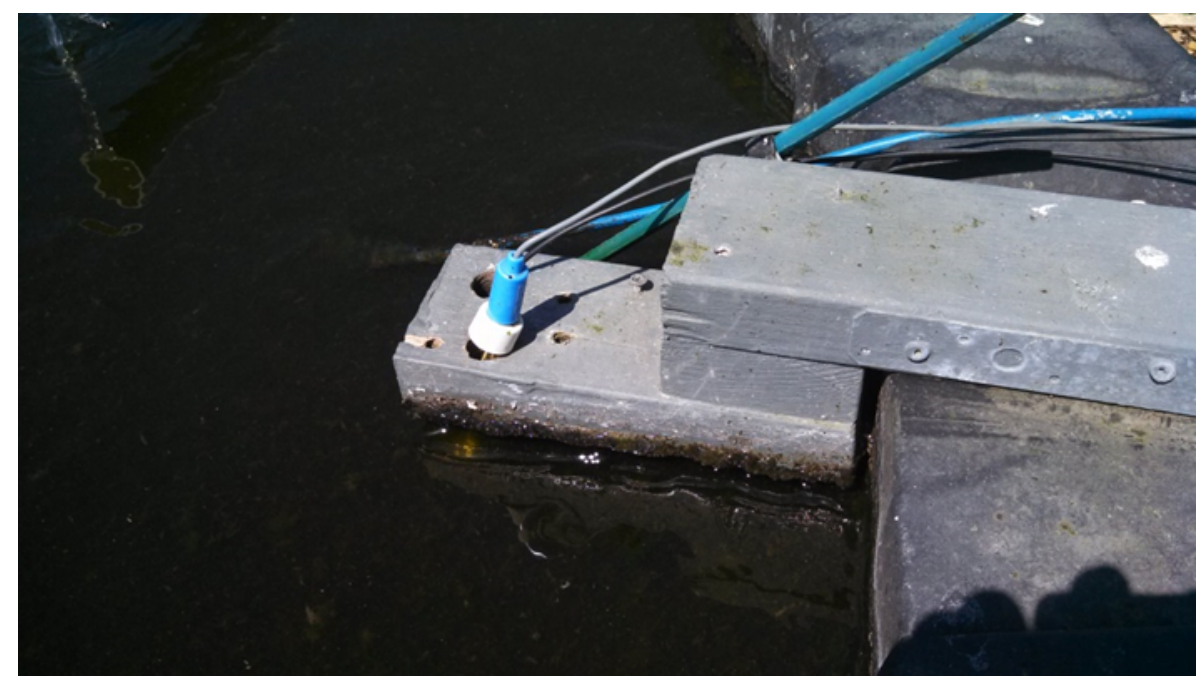


Figure A-4: A probe stand that held the $\mathrm{pH}, \mathrm{DO}$, and temperature probes in each pond (Chang, 2014). The data from these probes were recorded hourly and downloaded weekly. The DO and pH probes were calibrated weekly. DO was calibrated using a two-point calibration at $0 \%$ and $100 \%$ saturation. $\mathrm{pH}$ was also calibrated using a two-point calibration at $\mathrm{pH} 7$ and 10. On March 17, 2015, the temperature readings of the ponds were compared to a certified thermometer and less than a $0.1^{\circ} \mathrm{C}$ difference between the readings of the ponds and certified thermometer. The certified thermometer was an Ever-Safe with a certified accuracy of $\pm 1 \%$ of the total scale. The thermometer ranged from -20 to $150^{\circ} \mathrm{C}$, which equates to an accuracy of $\pm 1.7^{\circ} \mathrm{C}$.

\section{A.2 Complete List of Water Quality Analyses for the Algae Field Station}

Samples from each of the nine ponds were subjected to additional weekly water quality tests that were not presented in this thesis (Figure A-5). Results for the other analyses can be found in Kraetsch (2015). 


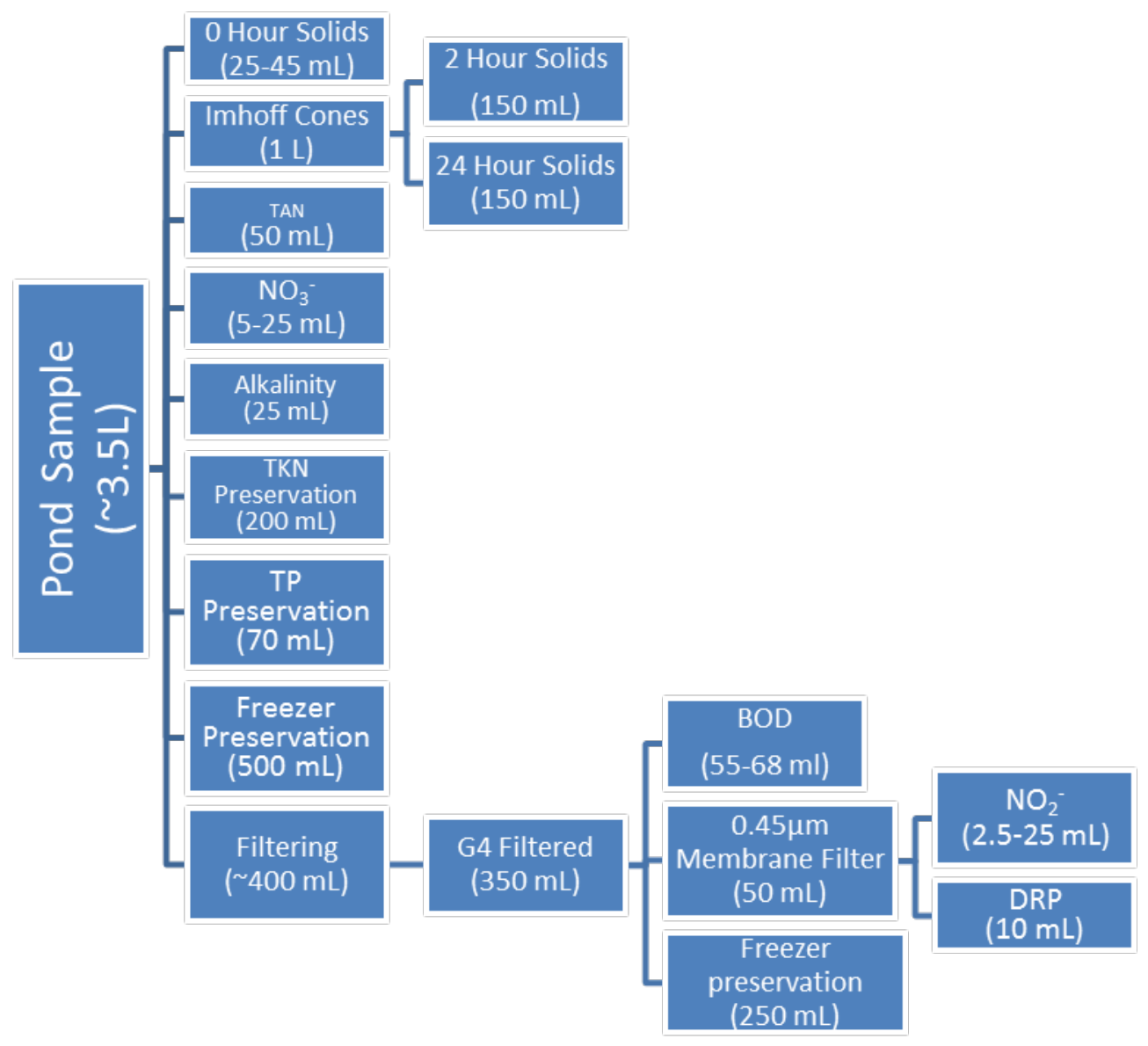

Figure A-5: Sample testing flow diagram with approximate sample volumes used (Chang, 2014).

Except for subsamples to be used for total Kjeldahl nitrogen (TKN), total phosphorus (TP), and chemical oxygen demand (COD) analyses, which were acidified within two hours, all samples were stored in a cooler and tests typically were performed within ten hours of sampling, or if not, they were filtered as needed, acidified, and refrigerated. All tests and sample preservation techniques were performed in accordance to Standard Methods for the Examination of Water and Wastewater (1995) unless otherwise stated (Table A-1). Refer to Kraetsch (2015) and Chang (2014) for detailed information about each testing methods used. 
Table A-1: The analytical methods used to run each constituent and the APHA Standard Methods title associated with each is listed. These methods were used for all pond and digestion experiments (Kraetsch, 2015).

\section{Constituent}

Nutrients

Total Ammonia Nitrogen

Nitrite

Nitrate

Total Kjeldahl Nitrogen

Dissolved Reactive

Phosphorus

Total Phosphorus

\section{Organics}

Total and Volatile Suspended Solids

Total and Soluble Carbonaceous Biochemical Oxygen Demand

\section{Other}

Microscopy for Algae ID

Alkalinity

\section{Analytical Method}

Ammonia Selective Electrode (APHA Method 4500$\left.\mathrm{NH}_{3} \mathrm{D}\right)$

Automated Selective Electrode (Based on APHA Method 4500- $\mathrm{NH}_{3}$ D)

Colorimetric, Fisherbrand 0.45- $\mu \mathrm{m}$ Multiple Cellulose

Ester filtration (APHA Method $4500-\mathrm{NO}_{2}{ }^{-} \mathrm{B}$ )

Nitrate Ion Selective Electrode with Interference

Suppression Solution (APHA Method $4500-\mathrm{NO}_{3}{ }^{-} \mathrm{D}$ )

Macro-Kjeldahl and manual titration (APHA Method $4500-\mathrm{N}_{\text {org }}$ B)

Ascorbic Acid, Fisherbrand 0.45- $\mu$ m Multiple

Cellulose Ester filtration (APHA Method 4500-P E)

Vanadomolybdophosphoric Acid Colorimetric (APHA Method 4500-P C)

Gravimetric with 1.2- $\mu \mathrm{m}$ Fisherbrand G4 Glass Fiber filters filtration (APHA Method $2540 \mathrm{D}$ and E)

5-day with $20^{\circ} \mathrm{C}$ incubation, 1.2- $\mu \mathrm{m}$ Fisherbrand G4 Glass Fiber filtration (APHA Method 5210 B)

Selected Taxonomic References, Optical Microscope (Method 10900 E. 2.)

Sulfuric Acid Titration (APHA Method 2320 B) 


\section{A.3 Compiled Experimental Data}

Experimental data collected over the course of this study is presented in this section. Data from Volatile Suspended Solids and Biological Oxygen Demand analyses are of significant importance for the calculations of net productivity and autotrophic productivity; therefore, this section includes data collected from under the same operating conditions, prior to this study. 


\section{A.3.1 Total Suspended Solids (mg/L)}

\begin{tabular}{|c|c|c|c|c|c|c|c|c|c|c|c|c|c|}
\hline \multicolumn{14}{|c|}{$\operatorname{TSS}(\mathrm{mg} / \mathrm{L})$} \\
\hline Date & $\begin{array}{c}\text { Influent } \\
\text { (primary) }\end{array}$ & Pond 1 & Pond 2 & Pond 3 & Average & Pond 4 & Pond 5 & Pond 6 & Average & Pond 7 & Pond 8 & Pond 9 & Average \\
\hline $12 / 4 / 13$ & 60 & 110 & 108 & 128 & 115 & 159 & 134 & 111 & 135 & 238 & 122 & 105 & 155 \\
\hline $12 / 11 / 13$ & 71 & \begin{tabular}{l|}
92 \\
\end{tabular} & \begin{tabular}{l|l}
112 \\
\end{tabular} & 102 & 102 & 217 & 215 & 193 & 208 & 318 & 155 & 135 & 203 \\
\hline $12 / 18 / 13$ & 77 & 83 & 85 & 88 & 86 & 70 & 137 & 127 & 111 & 175 & 62 & 117 & 118 \\
\hline $1 / 8 / 14$ & 69 & $\begin{array}{ll}123 \\
\end{array}$ & 118 & 127 & 123 & 150 & 210 & 202 & 187 & \begin{tabular}{l|l|}
196 \\
\end{tabular} & $\begin{array}{ll}124 \\
\end{array}$ & 114 & 145 \\
\hline $1 / 15 / 14$ & 61 & 170 & 122 & 100 & 131 & 182 & 148 & 220 & 183 & 202 & 150 & 162 & 171 \\
\hline $1 / 22 / 14$ & 74 & 125 & 142 & 153 & 140 & 184 & 160 & 220 & 188 & 190 & 126 & 132 & 149 \\
\hline $1 / 29 / 14$ & 84 & 152 & 154 & 157 & 154 & 158 & 170 & 198 & 175 & 292 & 178 & 192 & 221 \\
\hline $2 / 5 / 14$ & 71 & 160 & 147 & 257 & 188 & 170 & 192 & 154 & 172 & 238 & 152 & 182 & 191 \\
\hline $2 / 12 / 14$ & 55 & 138 & 126 & 163 & 142 & 172 & & 258 & 215 & 203 & 120 & 162 & 162 \\
\hline $2 / 19 / 14$ & 62 & 143 & 140 & 176 & 153 & 218 & 220 & 306 & 248 & 225 & 175 & 202 & 201 \\
\hline $2 / 26 / 14$ & 111 & 178 & 174 & 180 & \begin{tabular}{l|l|}
178 \\
\end{tabular} & 255 & 256 & 302 & 271 & 287 & 165 & \begin{tabular}{l|l}
168 \\
\end{tabular} & 207 \\
\hline $3 / 5 / 14$ & 140 & 110 & 110 & 140 & 120 & 215 & 192 & 292 & 233 & 312 & 138 & 155 & 202 \\
\hline $3 / 12 / 14$ & $\begin{array}{ll}66 \\
\end{array}$ & \begin{tabular}{l|l|}
142 \\
\end{tabular} & 149 & 164 & \begin{tabular}{l|l|}
152 \\
\end{tabular} & 262 & 234 & 346 & 281 & 263 & $\begin{array}{l}197 \\
\end{array}$ & 202 & 221 \\
\hline $3 / 19 / 14$ & 63 & 128 & 143 & 179 & 150 & 290 & 214 & 274 & 259 & 492 & 212 & 197 & 300 \\
\hline $4 / 3 / 14$ & 53 & 98 & 99 & 153 & 117 & 220 & 142 & 236 & 199 & 340 & 192 & 173 & 235 \\
\hline $4 / 10 / 14$ & 62 & 853 & 524 & 182 & 520 & 320 & 200 & 372 & 297 & 454 & 207 & 218 & 293 \\
\hline $4 / 17 / 14$ & 33 & 168 & 154 & 150 & \begin{tabular}{l|l|}
158 \\
\end{tabular} & 204 & 156 & & 180 & 134 & 207 & 188 & 176 \\
\hline $4 / 24 / 14$ & 130 & 251 & 209 & 192 & 217 & 330 & 206 & 164 & 233 & 206 & 408 & 190 & 268 \\
\hline $5 / 1 / 14$ & 74 & & 186 & 340 & 263 & 192 & 218 & 274 & 228 & 392 & 127 & 150 & 223 \\
\hline \begin{tabular}{|c|}
$5 / 8 / 14$ \\
\end{tabular} & 83 & 230 & 222 & 290 & 247 & 318 & 204 & 390 & 304 & 386 & \begin{tabular}{|l|l|}
87 \\
\end{tabular} & \begin{tabular}{l|l}
423 \\
\end{tabular} & 299 \\
\hline $5 / 15 / 14$ & 63 & 248 & 215 & 325 & 263 & 203 & 312 & 60 & 192 & 468 & 338 & 587 & 464 \\
\hline $5 / 22 / 14$ & 49 & 212 & 190 & 240 & 214 & 266 & 176 & 188 & 210 & 716 & 238 & 228 & 394 \\
\hline $5 / 29 / 14$ & 46 & 295 & 200 & 242 & 246 & 172 & 438 & 300 & 303 & 672 & 270 & 242 & 395 \\
\hline $6 / 5 / 14$ & 63 & 340 & 213 & 193 & 248 & 277 & 266 & 778 & 441 & 800 & 278 & 285 & 454 \\
\hline $6 / 12 / 14$ & 46 & 408 & 245 & 283 & 312 & 190 & 176 & 542 & 303 & 655 & 387 & 275 & 439 \\
\hline $6 / 19 / 14$ & 55 & 267 & 355 & \begin{tabular}{l|l|}
435 \\
\end{tabular} & 353 & 235 & 433 & 244 & 304 & 666 & 380 & 416 & 487 \\
\hline $6 / 26 / 14$ & 47 & 238 & 298 & 288 & 275 & 242 & 146 & 138 & 175 & 225 & 212 & 170 & 203 \\
\hline $\begin{array}{l}7 / 3 / 14 \\
\end{array}$ & 42 & 264 & 300 & 264 & 276 & 210 & 188 & 216 & 205 & 404 & 104 & 72 & 193 \\
\hline $7 / 10 / 14$ & 47 & 247 & 217 & 223 & 229 & 252 & 287 & 290 & 276 & 218 & 177 & 80 & 158 \\
\hline $7 / 17 / 14$ & 87 & 208 & 202 & 263 & 224 & 213 & 237 & 207 & 219 & 218 & 68 & 122 & 136 \\
\hline $7 / 24 / 14$ & 34 & 242 & 170 & 260 & 224 & 222 & 63 & 200 & 162 & 122 & 45 & 130 & 99 \\
\hline $7 / 31 / 14$ & 48 & 262 & 255 & 325 & 281 & 228 & 128 & 237 & 198 & 343 & 100 & 195 & 213 \\
\hline $8 / 7 / 14$ & 51 & 296 & 297 & 384 & 326 & 348 & 236 & 148 & 244 & 450 & 127 & 212 & 263 \\
\hline $8 / 14 / 14$ & 52 & 283 & 217 & 399 & 300 & 243 & 246 & 234 & 241 & 594 & 281 & 262 & 379 \\
\hline $8 / 21 / 14$ & \begin{tabular}{ll|}
66 \\
\end{tabular} & 347 & 259 & 400 & 335 & 223 & 191 & 271 & 228 & \begin{tabular}{ll|}
667 \\
\end{tabular} & 249 & \begin{tabular}{l|l|}
192 \\
\end{tabular} & 369 \\
\hline $8 / 28 / 14$ & 66 & 328 & 272 & 448 & 349 & 284 & 353 & 304 & 314 & 511 & 224 & 251 & 328 \\
\hline $\begin{array}{l}9 / 4 / 14 \\
\end{array}$ & 35 & 293 & 304 & 224 & 274 & $\begin{array}{l}167 \\
\end{array}$ & 313 & 367 & 282 & 216 & 141 & 184 & 180 \\
\hline 9/11/14 & 71 & 219 & 260 & \begin{tabular}{|l|}
197 \\
\end{tabular} & 225 & 347 & 348 & 303 & 332 & 255 & 224 & 168 & 216 \\
\hline $9 / 18 / 14$ & 60 & 249 & 213 & 147 & 203 & 216 & 43 & 203 & 154 & 119 & 175 & 189 & 161 \\
\hline $9 / 24 / 14$ & 55 & 240 & 249 & 196 & 228 & 140 & 53 & 85 & 93 & & & & \\
\hline $10 / 8 / 14$ & 143 & 297 & 476 & 564 & 446 & 312 & 411 & 380 & 368 & 348 & 379 & 432 & 386 \\
\hline $10 / 15 / 14$ & 60 & 227 & 216 & 283 & 242 & 136 & 85 & 158 & 126 & 167 & 204 & 233 & 201 \\
\hline $10 / 22 / 14$ & 62 & 140 & 184 & 229 & 184 & 168 & 209 & 556 & 311 & 179 & 215 & 201 & 198 \\
\hline $10 / 29 / 14$ & 68 & \begin{tabular}{l|l}
115 \\
\end{tabular} & 209 & 395 & 240 & 132 & 199 & \begin{tabular}{l|l|}
143 \\
\end{tabular} & 158 & 197 & 151 & 164 & 171 \\
\hline \begin{tabular}{|c|}
$11 / 1 / 14$ \\
\end{tabular} & & & & & & 109 & 137 & 42 & 96 & & & & \\
\hline $11 / 5 / 14$ & 82 & 139 & 245 & 143 & 176 & 103 & 123 & 175 & 133 & 272 & 179 & 191 & 214 \\
\hline $11 / 12 / 14$ & 84 & 113 & $\begin{array}{l}172 \\
\end{array}$ & 329 & 205 & 67 & 100 & 64 & $\begin{array}{l}77 \\
\end{array}$ & 176 & 172 & 124 & 157 \\
\hline $11 / 19 / 14$ & & & & & & 140 & 133 & 228 & 167 & & & & \\
\hline $11 / 24 / 14$ & 82 & & & & & 180 & 180 & 182 & 181 & 178 & 114 & 86 & 126 \\
\hline $12 / 3 / 14$ & 79 & 220 & 176 & 173 & & 152 & 153 & 159 & 155 & 153 & 143 & 120 & 139 \\
\hline
\end{tabular}


A.3.2 Volatile Suspended Solids (mg/L)

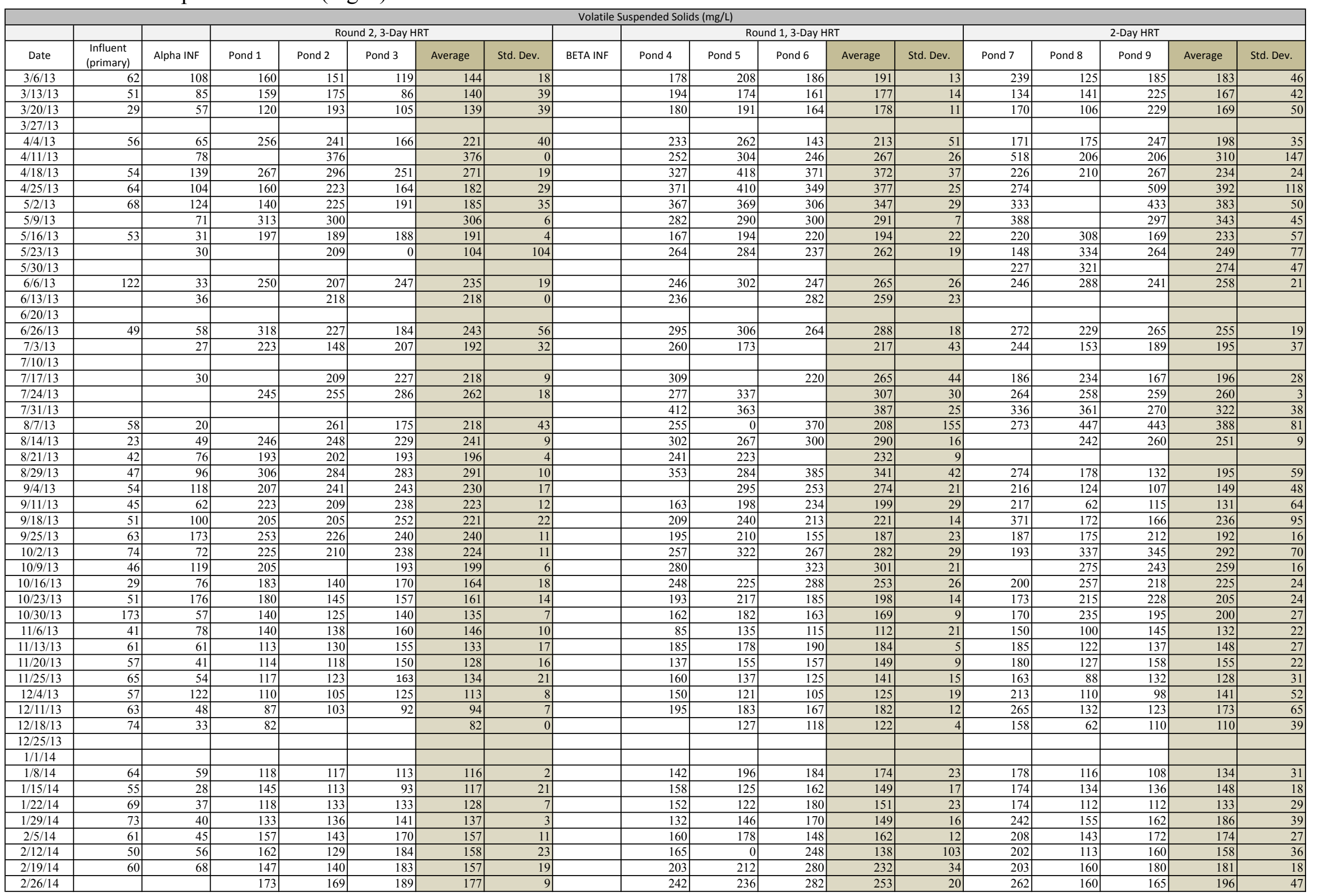




\begin{tabular}{|c|c|c|c|c|c|c|c|c|c|c|c|c|c|c|c|c|c|c|}
\hline \multicolumn{19}{|c|}{ Volatile Suspended Solids $(\mathrm{mg} / \mathrm{L})$} \\
\hline & & & & & d 2, 3-Day H & & & & & & d1,3-Day H & & & & & 2-Day HRT & & \\
\hline Date & $\begin{array}{l}\text { Influent } \\
\text { (primary) }\end{array}$ & Alpha INF & Pond 1 & Pond 2 & Pond 3 & Average & Std. Dev. & BETA INF & Pond 4 & Pond 5 & Pond 6 & Average & Std. Dev. & Pond 7 & Pond 8 & Pond 9 & Average & Std. Dev. \\
\hline $3 / 5 / 14$ & 133 & 37 & 102 & 100 & 134 & 112 & 16 & & 192 & 172 & 252 & 205 & 34 & 265 & 128 & 135 & 176 & 63 \\
\hline $3 / 12 / 14$ & 60 & 53 & 125 & 130 & 153 & 136 & 12 & & 225 & 200 & 294 & 240 & 40 & 220 & 160 & 165 & 182 & 27 \\
\hline $3 / 19 / 14$ & 59 & 53 & 118 & 129 & 161 & 136 & 18 & & 258 & 198 & 250 & 235 & 27 & 432 & 193 & 178 & 268 & 116 \\
\hline $4 / 3 / 14$ & 51 & 40 & 93 & 90 & 153 & 112 & 29 & & 200 & 138 & 214 & 184 & 33 & 298 & 168 & 158 & 208 & 64 \\
\hline $4 / 10 / 14$ & 56 & 56 & 117 & 113 & 170 & 133 & 26 & & 282 & 178 & 322 & 261 & 61 & 370 & 183 & 190 & 248 & 86 \\
\hline $4 / 17 / 14$ & 104 & 65 & 148 & 137 & 147 & 144 & 5 & & 192 & 140 & 0 & 111 & 81 & 124 & $\begin{array}{l}197 \\
\end{array}$ & 180 & 167 & 31 \\
\hline $4 / 24 / 14$ & 105 & 79 & 215 & 179 & 180 & 191 & 17 & & 296 & 180 & 148 & 208 & 64 & 186 & 375 & 170 & 244 & 93 \\
\hline $5 / 1 / 14$ & 62 & 128 & & 166 & 217 & 191 & 25 & & 288 & 194 & 242 & 241 & 38 & 348 & 112 & 138 & \begin{tabular}{l|l|}
199 \\
\end{tabular} & 106 \\
\hline $5 / 8 / 14$ & 75 & 122 & 212 & 193 & 270 & 225 & 33 & & 287 & 180 & 240 & 236 & 44 & 322 & 247 & 195 & 255 & 52 \\
\hline $5 / 15 / 14$ & 58 & 81 & 220 & 197 & 310 & 242 & 49 & & 195 & 284 & 66 & 182 & 89 & 422 & 305 & 538 & 422 & 95 \\
\hline $5 / 22 / 14$ & 49 & 52 & 210 & 193 & 245 & 216 & 22 & & 254 & 160 & 172 & 195 & 42 & 652 & 213 & 207 & 357 & 208 \\
\hline $5 / 29 / 14$ & 47 & 51 & 298 & 210 & 237 & 248 & 37 & & 166 & 390 & 280 & 279 & 91 & 616 & 250 & 216 & 361 & 181 \\
\hline $6 / 5 / 14$ & 60 & 64 & 342 & 210 & 198 & 250 & 66 & & 267 & 346 & \begin{tabular}{|l|l|}
683 \\
\end{tabular} & 432 & 180 & \begin{tabular}{|l|l|}
748 \\
\end{tabular} & 258 & 265 & 424 & 229 \\
\hline $6 / 12 / 14$ & 43 & 74 & 215 & & 375 & 295 & 80 & & 167 & 180 & 478 & 275 & 144 & 618 & 352 & 252 & 407 & 155 \\
\hline $6 / 19 / 14$ & 53 & 176 & 273 & 350 & 420 & 348 & 60 & & 238 & 312 & 336 & 295 & 42 & 536 & 334 & 360 & 410 & 90 \\
\hline $6 / 26 / 14$ & 43 & 58 & 248 & 304 & 266 & 273 & 23 & & 224 & 130 & 122 & 159 & 46 & 205 & 185 & 143 & 177 & 26 \\
\hline $7 / 3 / 14$ & 41 & $\begin{array}{l}73 \\
\end{array}$ & 238 & 276 & 248 & 254 & 16 & & 200 & 176 & 196 & 191 & 10 & 378 & 102 & 72 & 184 & 138 \\
\hline $7 / 10 / 14$ & 45 & 174 & 229 & 197 & 202 & 209 & 14 & & 237 & 263 & 258 & 253 & 12 & 217 & 165 & 78 & 153 & 57 \\
\hline $7 / 17 / 14$ & 76 & 81 & 183 & 180 & 230 & 198 & 23 & & 188 & 203 & 178 & 190 & 10 & 200 & 62 & 115 & 126 & 57 \\
\hline $7 / 24 / 14$ & 34 & 54 & 218 & 150 & 228 & 199 & 35 & & 200 & 63 & 178 & 147 & 60 & 113 & 45 & 117 & 92 & 33 \\
\hline $7 / 31 / 14$ & 37 & 77 & 233 & 223 & 268 & 242 & 19 & & 207 & 148 & 161 & 172 & 25 & 283 & 89 & 182 & 185 & 79 \\
\hline $8 / 7 / 14$ & 44 & 33 & 257 & 255 & 326 & 279 & 33 & & 187 & 211 & 120 & 173 & 39 & 388 & 113 & 176 & 226 & 118 \\
\hline $8 / 14 / 14$ & 51 & 34 & 255 & 196 & 352 & 268 & 64 & & 204 & 213 & 184 & 200 & 12 & 503 & 244 & 231 & 326 & 125 \\
\hline $8 / 21 / 14$ & 60 & 25 & 312 & 233 & 359 & 301 & 52 & & 195 & 165 & 232 & 197 & 27 & 556 & 212 & 169 & 312 & 173 \\
\hline $8 / 28 / 14$ & 57 & 21 & 299 & 243 & 396 & 312 & 63 & & 243 & 296 & 261 & 267 & 22 & 419 & 188 & 215 & 274 & 103 \\
\hline $9 / 4 / 14$ & 30 & 16 & 261 & 259 & 196 & 239 & 30 & & 141 & 267 & 307 & 238 & 70 & 181 & 116 & 156 & 151 & 27 \\
\hline $9 / 11 / 14$ & $\begin{array}{ll}63 \\
\end{array}$ & & 165 & 227 & 179 & 190 & 26 & & 293 & 307 & 251 & 284 & 24 & 216 & 193 & 153 & 188 & 26 \\
\hline $9 / 18 / 14$ & 54 & 15 & 219 & 180 & 133 & 177 & 35 & & 184 & 41 & 172 & 132 & 65 & 103 & 151 & 167 & 140 & 27 \\
\hline $9 / 24 / 14$ & 49 & 20 & 224 & 223 & 180 & 209 & 20 & & 84 & 12 & 37 & 44 & 30 & 109 & 113 & 125 & 116 & 7 \\
\hline $10 / 8 / 14$ & 131 & & 277 & 427 & 504 & 403 & 94 & & 285 & 316 & 337 & 313 & 21 & 299 & 313 & 351 & 321 & 22 \\
\hline $10 / 15 / 14$ & 57 & & 205 & 195 & 247 & 216 & 22 & & 123 & 77 & 133 & 111 & 24 & 149 & 175 & 197 & 174 & 20 \\
\hline $10 / 22 / 14$ & 59 & & 129 & 181 & 207 & 172 & 32 & & 153 & 181 & 453 & 263 & 135 & 159 & 181 & 169 & 170 & 9 \\
\hline $10 / 29 / 14$ & 59 & & 78 & 181 & 344 & 201 & 109 & & 113 & 169 & 121 & 135 & 25 & 160 & 121 & 132 & $\begin{array}{ll}138 \\
\end{array}$ & 16 \\
\hline
\end{tabular}




\section{A.3.3 2-Hour Imhoff Cone Total Suspended Solids (mg/L)}

\begin{tabular}{|c|c|c|c|c|c|c|c|c|c|c|c|c|c|c|c|}
\hline \multicolumn{16}{|c|}{ Two Hour Settling [TSS] (mg/L) from Imhoff Cones } \\
\hline & \multicolumn{5}{|c|}{ Round 2, 3-Day HRT } & \multicolumn{5}{|c|}{ Round 1, 3-Day HRT } & \multicolumn{5}{|c|}{ 2-Day HRT } \\
\hline Date & Pond 1 & Pond 2 & Pond 3 & Average & Std. Dev. & Pond 4 & Pond 5 & Pond 6 & Average & Std. Dev. & Pond 7 & Pond 8 & Pond 9 & Average & Std. Dev \\
\hline $12 / 4 / 13$ & 37 & 41 & 46 & 41 & 4 & 66 & 13 & 28 & 36 & 22 & 31 & 18 & 23 & 24 & 5 \\
\hline $12 / 11 / 13$ & 28 & 36 & 36 & 33 & 4 & 46 & 11 & 21 & 26 & 15 & 22 & 18 & 27 & 22 & 4 \\
\hline $12 / 18 / 13$ & 65 & 50 & 68 & 61 & 8 & 48 & 11 & 7 & 22 & 18 & 24 & 35 & 25 & 28 & 5 \\
\hline $1 / 8 / 14$ & 51 & 44 & 50 & 48 & 3 & 9 & 54 & 11 & 25 & 21 & 20 & 25 & 44 & 30 & 10 \\
\hline $1 / 15 / 14$ & 68 & 62 & 60 & 63 & 3 & 37 & 23 & 22 & 27 & 7 & 30 & 22 & 56 & 36 & 15 \\
\hline $1 / 22 / 14$ & 58 & 82 & 98 & 79 & 16 & 44 & 23 & 36 & 34 & 9 & 50 & 32 & 35 & 39 & 8 \\
\hline $1 / 29 / 14$ & 91 & 69 & 112 & 91 & 18 & 48 & 94 & 54 & 65 & 20 & 24 & 54 & 38 & 39 & 12 \\
\hline $2 / 5 / 14$ & 49 & 55 & 90 & 65 & 18 & 41 & 17 & 32 & 30 & 10 & 21 & 38 & 28 & 29 & 7 \\
\hline $2 / 12 / 14$ & 34 & 61 & 88 & 61 & 22 & 38 & 22 & 48 & 36 & 11 & 31 & 49 & 38 & 39 & 8 \\
\hline $2 / 19 / 14$ & 54 & 53 & 86 & 64 & 15 & 84 & 42 & 54 & 60 & 18 & 27 & 44 & 42 & 38 & 8 \\
\hline $2 / 26 / 14$ & 54 & 48 & 80 & 61 & 14 & 88 & 47 & 40 & 58 & 21 & 14 & 31 & 42 & 29 & 12 \\
\hline $3 / 5 / 14$ & 24 & 36 & 40 & 33 & 7 & 44 & 24 & 10 & 26 & 14 & 14 & 20 & 32 & 22 & 7 \\
\hline $3 / 12 / 14$ & 48 & 46 & 80 & 58 & 16 & 84 & 40 & 17 & 47 & 28 & 9 & 15 & 36 & 20 & 12 \\
\hline $3 / 19 / 14$ & 80 & 41 & 45 & 55 & 18 & 67 & 24 & 25 & 39 & 20 & 27 & 66 & 42 & 45 & 16 \\
\hline \multicolumn{16}{|l|}{$4 / 3 / 14$} \\
\hline $4 / 10 / 14$ & 24 & 24 & 66 & 38 & 20 & 47 & 8 & 11 & 22 & 18 & 17 & 50 & 65 & 44 & 20 \\
\hline $4 / 17 / 14$ & 22 & 26 & 62 & 37 & 18 & 44 & 13 & 13 & 23 & 15 & 21 & 49 & 62 & 44 & 17 \\
\hline $4 / 24 / 14$ & 89 & 46 & & 67 & 21 & 50 & 14 & 29 & 31 & 15 & 23 & 41 & 75 & 46 & 22 \\
\hline $5 / 1 / 14$ & 28 & 32 & 86 & 49 & 26 & 67 & 13 & 33 & 38 & 22 & 15 & 12 & 68 & 32 & 26 \\
\hline $5 / 8 / 14$ & 48 & 41 & 102 & 64 & 27 & 156 & 19 & 40 & 72 & 60 & 11 & 18 & 5 & 12 & 5 \\
\hline \multicolumn{16}{|l|}{$5 / 15 / 14$} \\
\hline $5 / 22 / 14$ & 44 & 44 & 48 & 45 & 2 & 44 & 34 & 28 & 35 & 7 & 17 & 17 & 11 & 15 & 3 \\
\hline $5 / 29 / 14$ & 68 & 76 & 76 & 73 & 4 & 52 & 41 & 15 & 36 & 16 & 19 & 25 & 14 & 19 & 4 \\
\hline $6 / 5 / 14$ & 41 & 1 & 94 & 45 & 38 & 78 & 28 & 21 & 42 & 25 & 12 & 38 & 11 & 20 & 12 \\
\hline \multicolumn{16}{|l|}{$6 / 12 / 14$} \\
\hline $6 / 19 / 14$ & 96 & 51 & 42 & 63 & 24 & 49 & 40 & 4 & 31 & 19 & 10 & 23 & 20 & 18 & 6 \\
\hline $6 / 26 / 14$ & 55 & 33 & 48 & 45 & 9 & 57 & 36 & 16 & 36 & 17 & 6 & 35 & 11 & 18 & 13 \\
\hline $\begin{array}{ll}7 / 3 / 14 \\
\end{array}$ & 62 & 33 & 50 & 48 & 12 & 85 & 36 & 25 & 49 & 26 & 13 & 63 & 31 & 36 & 21 \\
\hline $7 / 10 / 14$ & 76 & 50 & 33 & 53 & 18 & 73 & 61 & 46 & 60 & 11 & 49 & 92 & 43 & 61 & 22 \\
\hline $7 / 17 / 14$ & 54 & 43 & 29 & 42 & 10 & 63 & 75 & 120 & 86 & 25 & 57 & 27 & & 42 & 15 \\
\hline $7 / 24 / 14$ & 65 & 75 & 38 & 59 & 16 & 84 & 36 & 34 & 51 & 23 & 60 & 28 & 39 & 42 & 13 \\
\hline $7 / 31 / 14$ & 58 & 82 & 32 & 57 & 20 & 82 & 72 & 61 & 72 & 9 & 21 & 66 & 35 & 41 & 19 \\
\hline $\begin{array}{l}8 / 7 / 14 \\
\end{array}$ & 62 & 96 & 72 & 77 & 14 & 27 & 61 & 36 & 41 & 14 & 25 & 88 & 44 & 52 & 27 \\
\hline $8 / 14 / 14$ & 52 & 41 & 26 & 40 & 11 & 26 & 7 & 50 & 28 & 17 & 11 & 48 & 21 & 27 & 16 \\
\hline $8 / 21 / 14$ & 33 & 28 & 7 & 22 & 11 & 33 & 9 & 19 & 20 & 10 & 15 & 22 & 31 & 23 & 6 \\
\hline $8 / 28 / 14$ & 33 & 17 & 29 & 26 & 6 & 9 & 9 & 12 & 10 & 1 & 20 & 45 & 21 & 29 & 11 \\
\hline $9 / 4 / 14$ & 53 & 40 & 28 & 40 & 10 & 20 & 24 & 19 & 21 & 2 & 25 & 41 & 62 & 43 & 15 \\
\hline $9 / 11 / 14$ & 35 & 14 & 21 & 23 & 9 & 23 & 10 & 34 & 22 & 10 & 22 & 52 & 52 & 42 & 14 \\
\hline $9 / 18 / 14$ & 62 & 24 & 19 & 35 & 19 & 23 & 11 & 31 & 22 & 8 & 30 & 66 & 70 & 55 & 18 \\
\hline $10 / 8 / 14$ & 21 & 9 & 23 & 18 & 6 & 242 & 238 & 222 & 234 & 9 & 39 & 40 & 46 & 42 & 3 \\
\hline $\begin{array}{ll}10 / 15 / 14 \\
\end{array}$ & 41 & 13 & 8 & 21 & 15 & 13 & 10 & 13 & 12 & 2 & 18 & 39 & 40 & 32 & 10 \\
\hline $10 / 22 / 14$ & 15 & 24 & 24 & 21 & 4 & 20 & 20 & 17 & 19 & 1 & 15 & 26 & 15 & 19 & 5 \\
\hline
\end{tabular}




\section{A.3.4 24-Hour Imhoff Cone Total Suspended Solids (mg/L)}

\begin{tabular}{|c|c|c|c|c|c|c|c|c|c|c|c|c|c|c|c|}
\hline \multicolumn{16}{|c|}{ 24-Hour Settling [TSS] (mg/L) from Imhoff Cones } \\
\hline & \multicolumn{5}{|c|}{ Round 2, 3-Day HRT } & \multicolumn{5}{|c|}{ Round 1, 3-Day HRT } & \multicolumn{5}{|c|}{ 2-Day HRT } \\
\hline Date & Pond 1 & Pond 2 & Pond 3 & Average & Std. Dev. & Pond 4 & Pond 5 & Pond 6 & Average & Std. Dev. & Pond 7 & Pond 8 & Pond 9 & Average & Std. Dev. \\
\hline $12 / 4 / 13$ & 17 & 11 & 18 & 15 & 3 & 46 & 3 & 19 & 22 & 18 & 8 & 15 & 11 & 12 & 3 \\
\hline $12 / 11 / 13$ & 15 & 16 & 19 & 17 & 2 & 31 & 3 & 9 & 14 & 12 & 13 & 9 & 8 & 10 & 2 \\
\hline $12 / 18 / 13$ & 19 & 21 & 25 & 22 & 3 & 29 & 2 & 3 & 11 & 13 & 7 & 21 & 15 & 15 & 6 \\
\hline $1 / 8 / 14$ & 13 & 14 & 11 & 12 & 1 & 3 & 26 & 4 & 11 & 11 & 22 & 24 & 27 & 24 & 2 \\
\hline $1 / 15 / 14$ & 10 & 12 & 15 & 12 & 2 & 9 & 10 & 11 & 10 & 1 & 15 & 11 & 28 & 18 & 7 \\
\hline $1 / 22 / 14$ & 11 & 15 & 22 & 16 & 4 & 29 & 15 & 17 & 21 & 6 & 27 & 22 & 18 & 22 & 4 \\
\hline $1 / 29 / 14$ & 15 & 7 & 23 & 15 & 6 & 18 & 15 & 26 & 20 & 5 & 8 & 28 & 17 & 18 & 8 \\
\hline $2 / 5 / 14$ & 9 & 16 & 68 & 31 & 26 & 21 & 5 & 15 & 14 & 6 & 8 & 18 & 15 & 14 & 4 \\
\hline $2 / 12 / 14$ & 13 & 12 & 22 & 16 & 5 & 19 & 17 & 11 & 16 & 3 & 9 & 25 & 17 & 17 & 7 \\
\hline $2 / 19 / 14$ & 13 & 8 & 13 & 12 & 3 & 58 & 22 & 27 & 36 & 16 & 12 & 15 & 15 & 14 & 1 \\
\hline $2 / 26 / 14$ & 14 & 10 & 29 & 18 & 8 & 24 & 7 & 15 & 15 & 7 & 4 & 6 & 11 & 7 & 3 \\
\hline $3 / 5 / 14$ & 9 & 4 & 16 & 10 & 5 & 11 & 3 & 7 & 7 & 3 & 1 & 5 & 9 & 5 & 3 \\
\hline $3 / 12 / 14$ & 14 & 9 & 40 & 21 & 14 & 12 & 9 & 7 & 10 & 2 & 2 & 5 & 19 & 8 & 7 \\
\hline $3 / 19 / 14$ & 4 & 9 & 11 & 8 & 3 & 7 & 2 & 6 & 5 & 2 & 10 & 21 & 17 & 16 & 5 \\
\hline $4 / 3 / 14$ & 15 & 14 & 15 & 15 & 1 & 10 & 7 & 5 & 7 & 2 & 5 & 18 & 27 & 16 & 9 \\
\hline $4 / 10 / 14$ & 14 & 15 & 14 & 14 & 0 & 13 & 4 & 3 & 7 & 4 & 5 & 26 & 27 & 19 & 10 \\
\hline $4 / 17 / 14$ & 5 & 9 & 16 & 10 & 4 & 23 & 3 & 7 & 11 & 9 & 2 & 26 & 35 & 21 & 14 \\
\hline $4 / 24 / 14$ & 8 & 16 & 13 & 12 & 3 & 24 & 6 & 11 & 14 & 8 & 1 & 15 & 63 & 27 & 27 \\
\hline $5 / 1 / 14$ & 8 & 13 & 21 & 14 & 5 & 18 & 17 & 15 & 17 & 1 & 3 & 4 & 31 & 13 & 13 \\
\hline $5 / 8 / 14$ & 9 & 19 & 21 & 16 & 5 & 15 & 7 & 11 & 11 & 3 & 1 & 4 & 4 & 3 & 1 \\
\hline $\begin{array}{l}5 / 15 / 14 \\
\end{array}$ & 11 & 5 & 10 & 8 & 3 & 8 & 11 & 7 & 9 & 1 & 4 & 1 & 2 & 2 & 1 \\
\hline $5 / 22 / 14$ & 7 & 8 & 13 & 9 & 3 & 19 & 7 & 5 & 10 & 6 & 3 & 3 & 5 & 3 & 1 \\
\hline $5 / 29 / 14$ & 19 & 21 & 25 & 22 & 3 & 35 & 11 & -2 & 14 & 15 & 2 & 17 & 4 & 8 & 7 \\
\hline $6 / 5 / 14$ & 17 & 11 & 22 & 17 & 4 & 29 & 12 & 1 & 14 & 12 & 3 & 18 & 4 & 8 & 7 \\
\hline $6 / 12 / 14$ & 56 & 13 & 26 & 32 & 18 & 26 & 12 & -4 & 11 & 12 & 5 & 37 & 29 & 24 & 14 \\
\hline $6 / 19 / 14$ & 37 & 38 & 15 & 30 & 11 & 23 & 22 & 9 & 18 & 6 & 5 & 16 & 9 & 10 & 4 \\
\hline $6 / 26 / 14$ & 28 & 12 & 23 & 21 & 7 & 21 & 9 & 11 & 14 & 5 & 3 & 19 & 3 & 8 & 8 \\
\hline $7 / 3 / 14$ & 16 & 12 & 17 & 15 & 2 & 16 & 11 & 13 & 13 & 2 & 5 & 20 & 9 & 11 & 6 \\
\hline $7 / 10 / 14$ & 36 & 19 & 21 & 25 & 8 & 24 & 15 & 15 & 18 & 4 & 23 & 42 & 25 & 30 & 8 \\
\hline $7 / 17 / 14$ & 43 & 28 & 18 & 30 & 10 & 17 & 29 & 30 & 25 & 6 & 42 & 22 & 28 & 31 & 8 \\
\hline $7 / 24 / 14$ & 30 & 40 & 16 & 29 & 10 & 58 & 37 & 28 & 41 & 13 & 50 & 29 & 25 & 35 & 11 \\
\hline $7 / 31 / 14$ & 33 & 57 & 15 & 35 & 17 & 104 & 34 & 51 & 63 & 30 & 7 & 51 & 19 & 25 & 19 \\
\hline $8 / 7 / 14$ & 31 & 30 & 29 & 30 & 1 & 21 & 49 & 23 & 31 & 13 & 11 & 79 & 30 & 40 & 29 \\
\hline $8 / 14 / 14$ & 21 & 15 & 9 & 15 & 5 & 17 & 6 & 27 & 17 & 9 & 5 & 44 & 11 & 20 & 17 \\
\hline $8 / 21 / 14$ & 16 & 8 & 3 & 9 & 5 & 12 & 1 & 15 & 9 & 6 & 0 & 15 & 14 & 10 & 7 \\
\hline $8 / 28 / 14$ & 23 & 15 & 15 & 18 & 4 & 13 & 8 & 8 & 10 & 3 & 17 & 27 & 15 & 20 & 5 \\
\hline $9 / 4 / 14$ & 19 & 15 & 11 & 15 & 3 & 9 & 5 & 5 & 6 & 2 & 6 & 13 & 38 & 19 & 14 \\
\hline $9 / 11 / 14$ & 12 & 4 & 3 & 6 & 4 & 14 & 5 & 60 & 26 & 24 & 4 & 23 & 36 & 21 & 13 \\
\hline $9 / 18 / 14$ & 33 & 17 & 10 & 20 & 9 & 15 & 20 & 22 & 19 & 3 & 52 & 52 & 45 & 50 & 3 \\
\hline $9 / 24 / 14$ & & & & & & & & & & & & & & & \\
\hline $10 / 8 / 14$ & 21 & 9 & 23 & 18 & 6 & 242 & 238 & 222 & 234 & 9 & 39 & 40 & 46 & 42 & 3 \\
\hline $10 / 15 / 14$ & & & & & & & & & & & & & & & \\
\hline $10 / 22 / 14$ & 15 & 24 & 24 & 21 & 4 & 20 & 20 & 17 & 19 & 1 & 15 & 26 & 15 & 19 & 5 \\
\hline
\end{tabular}




\section{A.3.5 Biological Oxygen Demand (mg/L)}

\begin{tabular}{|c|c|c|c|c|c|c|c|c|c|c|c|c|c|c|c|c|c|}
\hline \multicolumn{18}{|c|}{ scBOD5 (mg/L) } \\
\hline & & & \multicolumn{5}{|c|}{ Round 2, 3-Day HRT } & \multicolumn{5}{|c|}{$\begin{array}{l}\text { Round 1, 3-Day HRT } \\
\end{array}$} & \multicolumn{5}{|c|}{ 2-Day HRT } \\
\hline Date & Inf-TBOD & INF- CSBOD & Pond 1 & Pond 2 & Pond 3 & Average & Std. Dev. & Pond 4 & Pond 5 & Pond 6 & Average & Std. Dev. & Pond 7 & Pond 8 & Pond 9 & Average & Std. Dev. \\
\hline $3 / 20 / 13$ & 135.7 & 80.6 & 3.5 & 3.9 & 3.8 & 4 & 0 & 6.3 & 5.4 & 3.9 & 5 & 1 & 5.4 & 6.9 & 4.5 & 6 & \\
\hline $6 / 13 / 13$ & 120.5 & 100.2 & & & & & & 3.0 & & & 3 & & 2.3 & 3.0 & & 3 & 0 \\
\hline $8 / 29 / 13$ & 87.2 & 49.5 & 4.7 & 2.8 & 3.2 & 4 & 1 & 4.7 & 4.2 & 2.9 & 4 & 1 & 7.2 & 4.5 & 4.8 & 6 & 1 \\
\hline $9 / 11 / 13$ & 93.8 & 64.5 & & & & & & 3.7 & 5.3 & 2.5 & 4 & 1 & 3.5 & 5.7 & 6.6 & 5 & 1 \\
\hline 9/18/13 & 108.9 & 88.2 & 4.1 & 3.9 & 3.2 & 4 & 0 & 8.2 & 5.5 & 3.4 & 6 & 2 & 3.7 & 6.4 & 7.7 & 6 & 2 \\
\hline $9 / 25 / 13$ & 120.5 & 85.5 & 2.7 & 3.4 & 2.8 & 3 & 0 & 4.4 & 5.8 & 3.8 & 5 & 1 & 4.0 & 3.6 & 4.6 & 4 & 0 \\
\hline $10 / 2 / 13$ & 105.8 & 79.7 & 7.3 & & 5.3 & 6 & 1 & 4.8 & 3.3 & 2.7 & 4 & 1 & 6.1 & 2.3 & 2.9 & 4 & 2 \\
\hline $10 / 16 / 13$ & 121.6 & 79.5 & 2.5 & & 2.2 & 2 & 0 & 4.0 & 5.4 & 4.3 & 5 & 1 & 6.8 & 3.9 & 4.3 & 5 & 1 \\
\hline $10 / 30 / 13$ & 73.4 & 91.1 & & & 2.2 & 2 & & & & & 7 & 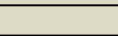 & & 2.4 & 2.8 & 3 & 0 \\
\hline $11 / 6 / 13$ & & & & & 2.2 & 2 & & 5.7 & 3.1 & 3.2 & 4 & 1 & 3.0 & 2.8 & 2.5 & 3 & 0 \\
\hline $11 / 13 / 13$ & & & & & 3.8 & 4 & & 4.1 & 2.6 & 3.1 & 3 & 1 & 3.1 & 2.7 & 3.9 & 3 & 0 \\
\hline $11 / 20 / 13$ & & & 2.8 & & 2.4 & 3 & 0 & 5.3 & 3.3 & 2.7 & 4 & 1 & 4.0 & 3.4 & 3.6 & 4 & 0 \\
\hline $1 / 15 / 14$ & 107.3 & 96.7 & 2.0 & 2.3 & & 2 & 0 & 5.5 & 6.1 & 2.6 & 5 & 1 & 6.5 & 6.4 & 5.0 & 6 & 1 \\
\hline $1 / 22 / 14$ & 117.7 & 77.4 & 3.3 & 2.6 & & 3 & 0 & 7.3 & 6.5 & 3.1 & 6 & 2 & 4.9 & 4.5 & 4.6 & 5 & 0 \\
\hline $1 / 29 / 14$ & 128.9 & 86.2 & 3.4 & 6.0 & 6.1 & 5 & 1 & 6.5 & 4.7 & 2.9 & 5 & 1 & & 6.3 & 6.1 & 6 & 0 \\
\hline $2 / 5 / 14$ & 117.0 & 92.4 & 4.3 & 3.4 & 3.6 & 4 & 0 & & 5.8 & 5.5 & 6 & 0 & & & & 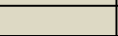 & \\
\hline $2 / 12 / 14$ & 160.8 & 120.0 & 2.2 & 2.9 & 2.9 & 3 & 0 & 4.2 & 3.4 & 3.2 & 4 & 0 & 5.2 & 4.9 & 4.7 & 5 & 0 \\
\hline $2 / 19 / 14$ & 121.4 & 100.5 & 2.3 & 3.9 & 3.1 & 3 & 1 & 4.0 & 3.2 & 2.9 & 3 & 0 & 6.4 & 6.3 & 7.0 & 7 & 0 \\
\hline $2 / 26 / 14$ & 129.8 & 83.5 & 2.3 & 2.2 & 4.1 & 3 & 1 & 5.7 & 2.6 & 2.7 & 4 & 1 & 5.3 & 7.1 & 5.9 & 6 & 1 \\
\hline $3 / 5 / 14$ & 134.8 & 86.2 & & & 2.5 & 2 & & 3.9 & 3.7 & 2.7 & 3 & 1 & 5.3 & 4.8 & 5.2 & 5 & 0 \\
\hline $3 / 12 / 14$ & 112.4 & 77.4 & 2.1 & & 2.9 & 2 & 0 & 4.6 & 3.6 & 3.4 & 4 & 1 & 4.2 & 3.8 & 4.8 & 4 & 0 \\
\hline $5 / 22 / 14$ & 140.6 & 101.0 & 2.2 & & 2.3 & 2 & 0 & & 3.2 & & 3 & & 2.9 & 4.1 & 3.0 & 3 & \\
\hline $6 / 26 / 14$ & 57.1 & 41.5 & & & & & & 2.8 & & & 3 & & & & & & \\
\hline $7 / 24 / 14$ & 91.6 & 55.5 & & 2.5 & & 3 & & 2.7 & 4.1 & 3.2 & 3 & 1 & 7.3 & 8.0 & 5.9 & 7 & \\
\hline $8 / 14 / 14$ & 95.9 & 55.6 & & 2.0 & & 2 & & 3.3 & 2.9 & 3.3 & 3 & 0 & 3.3 & & 3.8 & 4 & 0 \\
\hline $8 / 28 / 14$ & 126.5 & 68.7 & & & & & & 3.8 & 2.3 & 2.2 & 3 & 1 & 3.8 & 5.9 & 5.3 & 5 & 1 \\
\hline $9 / 4 / 14$ & 141.0 & 105.7 & 2.2 & & & 2 & & 4.7 & 2.8 & 6.1 & 5 & 1 & 5.4 & 7.9 & & 7 & 1 \\
\hline $11 / 19 / 14$ & 171.6 & 77.4 & & & & & & & 2.1 & 2.1 & 2 & 0 & & & & & \\
\hline $12 / 3 / 14$ & 133.2 & 93.2 & & 4.6 & 3.7 & 4 & 0 & & & & & & 4.3 & 4.2 & 4.4 & 4 & 0 \\
\hline
\end{tabular}

\section{A.3.6 Chemical Oxygen Demand (mg/L)}

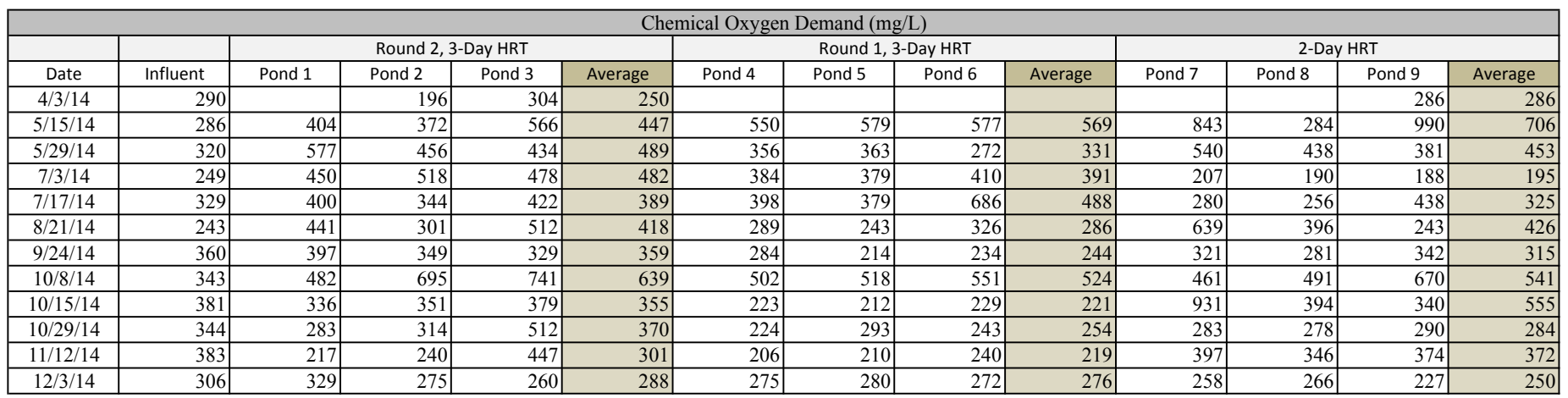




\section{A.3.7 Dissolved Oxygen (mg/L)}

\begin{tabular}{|c|c|c|c|c|c|c|c|c|c|c|c|c|c|c|c|c|}
\hline \multicolumn{17}{|c|}{ Dissolved Oxygen (mg/L) } \\
\hline & & \multicolumn{5}{|c|}{ Round 2, 3-Day HRT } & \multicolumn{5}{|c|}{ Round 1, 3-Day HRT } & \multicolumn{5}{|c|}{ 2-Day HRT } \\
\hline Date Range & Date & Pond 1 & \begin{tabular}{l|l} 
Pond 2 \\
Pon
\end{tabular} & Pond 3 & Average & Std. Dev. & \begin{tabular}{l|l} 
Pond 4 \\
\end{tabular} & \begin{tabular}{l|l} 
Pond 5 \\
\end{tabular} & Pond 6 & Average & Std. Dev. & \begin{tabular}{l|l} 
Pond 7 \\
\end{tabular} & \begin{tabular}{l|l} 
Pond 8 \\
\end{tabular} & \begin{tabular}{l|l|} 
Pond 9 \\
\end{tabular} & Average & Std. Dev. \\
\hline $28 / 13-12 / 4$ & $12 / 4 / 13$ & & & & & & 5.1 & 3.6 & 4.1 & 4.3 & 0.6 & 1.8 & 4.9 & 3.2 & 3.3 & 1.3 \\
\hline $\mid 5 / 13-12 / 11$ & $12 / 11 / 13$ & & & & & & 5.6 & 5.0 & 5.6 & 5.4 & 0.3 & 3.3 & 5.4 & 5.3 & 4.7 & 1.0 \\
\hline $19 / 13-12 / 25$ & $12 / 25 / 13$ & 16.8 & 13.0 & 11.5 & 13.7 & 2.2 & 2.0 & 2.1 & 2.4 & 2.1 & 0.2 & 0.2 & 0.4 & 0.2 & 0.3 & 0.1 \\
\hline$/ 26 / 13-1 / 1 /$ & $1 / 1 / 14$ & 11.2 & 13.1 & 11.7 & 12.0 & 0.8 & 2.2 & 2.1 & 2.8 & 2.3 & 0.3 & 0.5 & 0.9 & 0.5 & 0.6 & 0.2 \\
\hline$/ 2 / 14-1 / 8 / 1$ & $1 / 8 / 14$ & 10.2 & 13.5 & 7.2 & 10.3 & 2.6 & 2.3 & 2.6 & 3.0 & 2.6 & 0.3 & 0.7 & 0.8 & 0.7 & 0.7 & 0.1 \\
\hline $9 / 14-1 / 15 / 1$ & $1 / 15 / 14$ & 11.4 & 13.6 & 5.9 & 10.3 & 3.2 & 3.4 & 3.7 & 3.1 & 3.4 & 0.3 & 1.5 & 1.7 & 1.6 & 1.6 & 0.1 \\
\hline $16 / 14-1 / 22$ & $1 / 22 / 14$ & 12.3 & \begin{tabular}{ll|}
12.9 \\
\end{tabular} & 11.1 & 12.1 & 0.7 & 4.1 & 3.7 & 3.1 & 3.7 & 0.4 & 2.0 & 2.2 & 2.4 & 2.2 & 0.2 \\
\hline $23 / 14-1 / 29$ & $1 / 29 / 14$ & 12.3 & \begin{tabular}{|l|}
12.7 \\
\end{tabular} & 13.1 & 12.7 & 0.3 & 3.7 & 3.9 & 2.8 & 3.5 & 0.5 & 1.2 & 1.5 & 1.4 & 1.4 & 0.1 \\
\hline $30 / 14-2 / 5 / 1$ & $2 / 5 / 14$ & \begin{tabular}{|l|}
13.1 \\
\end{tabular} & \begin{tabular}{ll|}
14.0 \\
\end{tabular} & \begin{tabular}{l|l}
14.7 \\
\end{tabular} & 13.9 & 0.6 & 5.1 & 3.8 & 3.6 & 4.2 & 0.7 & 1.9 & 2.3 & 1.7 & 2.0 & 0.3 \\
\hline $6 / 14-2 / 12 / 1$ & $2 / 12 / 14$ & \begin{tabular}{ll|}
11.7 \\
\end{tabular} & 12.9 & 13.6 & 12.7 & 0.8 & 4.8 & 2.7 & 3.0 & 3.5 & 0.9 & 1.3 & 1.8 & 1.3 & 1.5 & 0.2 \\
\hline $13 / 14-2 / 19$ & $2 / 19 / 14$ & 12.3 & 12.8 & 13.5 & 12.9 & 0.5 & 5.5 & 2.7 & 3.1 & 3.8 & 1.3 & 1.5 & 2.7 & 2.3 & 2.2 & 0.5 \\
\hline $20 / 14-2 / 26$ & $2 / 26 / 14$ & 12.5 & 13.4 & 12.8 & 12.9 & 0.4 & 6.4 & 3.4 & 3.0 & 4.3 & 1.5 & 2.5 & 3.8 & 3.3 & 3.2 & 0.5 \\
\hline $\mid 27 / 14-3 / 5 / 1$ & $3 / 5 / 14$ & 14.0 & 13.3 & 14.5 & 13.9 & 0.5 & 9.4 & $\frac{1.4}{4.1}$ & 3.3 & 5.5 & 2.5 & 3.3 & 3.0 & 3.5 & 3.4 & 0.1 \\
\hline $\mid 6 / 14-3 / 12 / 1$ & $3 / 12 / 14$ & 12.8 & 15.6 & 15.3 & 14.6 & 1.2 & 9.1 & 3.3 & 5.0 & 5.8 & 2.5 & 3.0 & 3.5 & 3.8 & 3.5 & 0.4 \\
\hline $13 / 14-3 / 19$ & $3 / 19 / 14$ & \begin{tabular}{l|l|}
12.7 \\
\end{tabular} & \begin{tabular}{l|l|}
15.0 \\
\end{tabular} & 15.2 & 14.3 & 1.1 & 8.9 & 2.6 & 3.5 & 5.0 & 2.8 & 2.6 & 3.8 & 4.0 & 3.5 & 0.6 \\
\hline $20 / 14-3 / 26 /$ & $3 / 26 / 14$ & 13.5 & 13.9 & 15.8 & 14.4 & $\frac{1.1}{1.0}$ & 8.2 & 3.4 & 2.4 & 4.7 & 2.5 & 2.7 & 4.3 & 4.6 & 3.9 & 0.9 \\
\hline $28 / 14-4 / 3 / 1$ & $4 / 3 / 14$ & 14.1 & 15.2 & 15.7 & 15.0 & 0.7 & 9.5 & 3.5 & 3.5 & 5.5 & 2.8 & 3.5 & 4.8 & 5.9 & 4.7 & 1.0 \\
\hline $4 / 14-4 / 10 / 1$ & $4 / 10 / 14$ & 12.0 & 13.1 & 14.2 & 13.1 & 0.9 & 8.3 & 3.5 & 3.8 & 5.2 & 2.2 & 3.0 & 4.7 & 5.7 & 4.5 & 1.1 \\
\hline $11 / 14-4 / 17 /$ & $4 / 17 / 14$ & 13.5 & 15.1 & 16.1 & 14.9 & 1.1 & 4.6 & 2.7 & 3.3 & 3.5 & 0.8 & 2.3 & 3.9 & 4.6 & 3.6 & 1.0 \\
\hline $18 / 14-4 / 24 /$ & $4 / 24 / 14$ & 13.7 & 14.3 & 15.9 & 14.6 & 1.0 & 6.6 & 3.0 & 4.7 & 4.8 & 1.5 & 2.5 & 4.1 & 5.0 & 3.9 & 1.1 \\
\hline $25 / 14-5 / 1 / 1$ & $5 / 1 / 14$ & 11.9 & 12.4 & 14.5 & 12.9 & 1.1 & 7.4 & 5.4 & 5.4 & 6.1 & 0.9 & 2.7 & 3.3 & 4.7 & 3.5 & 0.8 \\
\hline$/ 2 / 14-5 / 8 / 1$ & $5 / 8 / 14$ & 13.2 & 14.1 & 14.5 & 13.9 & 0.5 & 5.2 & 7.8 & 5.8 & 6.3 & 1.1 & 4.2 & 3.9 & 2.5 & 3.6 & 0.7 \\
\hline $9 / 14-5 / 15 / 1$ & $5 / 15 / 14$ & 12.2 & 13.4 & 6.7 & 10.8 & 2.9 & 5.1 & 6.6 & 7.1 & 6.2 & 0.8 & 3.0 & 4.7 & 4.3 & 4.0 & 0.7 \\
\hline $16 / 14-5 / 22 /$ & $5 / 22 / 14$ & 13.9 & 15.3 & 18.9 & 16.0 & 2.1 & 9.9 & 6.3 & 4.4 & 6.9 & 2.3 & 3.2 & 4.5 & 3.1 & 3.6 & 0.6 \\
\hline $23 / 14-5 / 29$ & $5 / 29 / 14$ & 16.1 & 16.7 & 14.9 & 15.9 & 0.8 & 8.2 & 5.9 & 2.7 & 5.6 & 2.3 & 2.7 & 5.4 & 2.8 & 3.6 & 1.2 \\
\hline $30 / 14-6 / 5 / 1$ & $\frac{3 / 2 / 14}{6 / 14}$ & 15.2 & 17.0 & 15.5 & 15.9 & 0.8 & 6.9 & 5.0 & 3.2 & 5.0 & 1.5 & 2.4 & 4.8 & 6.1 & 4.5 & 1.6 \\
\hline $6 / 14-6 / 12 / 1$ & $6 / 12 / 14$ & 5.1 & 5.3 & 15.4 & 8.6 & 4.8 & 5.6 & 4.2 & 2.9 & 4.2 & 1.1 & 2.1 & 5.3 & 2.9 & 3.4 & 1.4 \\
\hline $13 / 14-6 / 19 /$ & $6 / 19 / 14$ & 12.9 & 5.1 & 13.6 & 10.5 & 3.9 & 7.1 & 5.3 & 4.2 & 5.5 & 1.2 & 5.3 & 4.5 & 4.9 & 4.9 & 0.4 \\
\hline $20 / 14-6 / 26 /$ & $6 / 26 / 14$ & 10.3 & 4.9 & 9.1 & 8.1 & 2.3 & 9.3 & 7.1 & 5.4 & 7.2 & 1.6 & 5.5 & 4.5 & 6.9 & 5.6 & 1.0 \\
\hline $27 / 14-7 / 3 / 1$ & $7 / 3 / 14$ & 4.0 & 11.1 & 9.3 & 8.1 & 3.0 & 7.9 & 10.9 & 7.4 & 8.7 & 1.5 & 4.7 & 5.2 & 5.3 & 5.1 & 0.2 \\
\hline $4 / 14-7 / 10 / 1$ & $7 / 10 / 14$ & 3.6 & 8.3 & 8.0 & 6.6 & 2.2 & 8.5 & 12.4 & 10.5 & 10.5 & 1.6 & 2.8 & 4.8 & 4.0 & 3.9 & 0.8 \\
\hline $11 / 14-7 / 17 /$ & $7 / 17 / 14$ & 12.6 & 4.4 & 9.9 & 9.0 & 3.4 & 5.3 & 7.8 & 10.5 & 7.8 & 2.1 & 1.3 & 3.0 & 3.1 & 2.5 & 0.8 \\
\hline $18 / 14-7 / 24 /$ & $7 / 24 / 14$ & 5.4 & 4.6 & 14.6 & 8.2 & 4.5 & 6.9 & 1.8 & 5.0 & 4.6 & 2.1 & 1.1 & 0.5 & 2.8 & 1.5 & 1.0 \\
\hline $25 / 14-7 / 31$ & $7 / 31 / 14$ & 5.4 & 4.5 & 12.7 & 7.5 & 3.7 & 7.3 & 2.1 & 5.2 & 4.9 & 2.1 & 1.4 & 1.1 & 2.5 & 1.7 & 0.6 \\
\hline $8 / 1 / 14-8 / 7 / 1$ & $8 / 7 / 14$ & 7.4 & $\begin{array}{l}5.0 \\
\end{array}$ & 10.4 & 7.6 & 2.2 & 3.4 & 2.6 & 3.2 & 3.1 & 0.4 & 1.3 & 2.1 & 2.8 & 2.1 & 0.6 \\
\hline $8 / 14-8 / 14 / 1$ & $8 / 14 / 14$ & $\begin{array}{c}1 . .9 \\
11.9\end{array}$ & \begin{tabular}{|r|r}
13.0 \\
\end{tabular} & 13.8 & 12.9 & 0.8 & $\begin{array}{l}3.4 \\
3.4\end{array}$ & 2.0 & $\frac{5.2}{5.0}$ & $\begin{array}{l}3.1 \\
3.7\end{array}$ & $\frac{0.4}{1.0}$ & 0.3 & $\frac{2.1}{2.0}$ & 3.4 & $\frac{2.1}{1.9}$ & $\begin{array}{l}0.0 \\
1.3\end{array}$ \\
\hline $15 / 14-8 / 21 /$ & $8 / 21 / 14$ & 14.5 & 16.4 & 31.9 & 20.9 & 7.8 & 6.3 & 5.0 & 6.4 & 5.9 & 0.6 & 1.8 & 3.1 & 5.3 & 3.4 & 1.5 \\
\hline $22 / 14-8 / 28 /$ & $8 / 28 / 14$ & 11.4 & 17.6 & 17.0 & 15.3 & 2.8 & 5.6 & 5.9 & 7.1 & 6.2 & 0.6 & 2.9 & 3.7 & 4.9 & 3.8 & 0.8 \\
\hline $\mid 29 / 14-9 / 4 / 1$ & $9 / 4 / 14$ & 14.2 & 8.5 & 12.7 & 11.8 & 2.4 & 5.8 & 7.7 & 4.3 & 5.9 & 1.4 & 3.3 & 4.5 & 4.8 & 4.2 & 0.6 \\
\hline $5 / 14-9 / 11 / 1$ & $9 / 11 / 14$ & 12.5 & \begin{tabular}{ll|}
12.7 \\
\end{tabular} & 12.2 & 12.4 & 0.2 & 2.8 & 4.2 & 4.6 & 3.9 & 0.8 & 1.8 & 3.1 & 3.1 & 2.7 & 0.6 \\
\hline $12 / 14-9 / 18 /$ & $9 / 18 / 14$ & 11.8 & 12.7 & 10.2 & 11.5 & 1.0 & 2.7 & 3.5 & 3.6 & 3.3 & 0.4 & 2.3 & 4.5 & 4.2 & 3.7 & 1.0 \\
\hline $18 / 14-9 / 24$ & $9 / 24 / 14$ & 9.8 & 10.3 & 9.6 & 9.9 & 0.3 & 2.3 & 1.9 & 2.9 & 2.4 & 0.4 & 2.1 & 2.9 & 3.4 & 2.8 & 0.5 \\
\hline $25 / 14-10 / 1$ & $10 / 1 / 14$ & 10.2 & \begin{tabular}{ll|}
8.9 \\
\end{tabular} & 10.3 & 9.8 & 0.6 & 3.2 & 3.7 & 3.2 & 3.4 & 0.2 & 1.5 & 2.6 & \begin{tabular}{l|l}
15.3 \\
\end{tabular} & 6.5 & 6.3 \\
\hline$/ / 2 / 14-10 / 8$ & $10 / 8 / 14$ & 12.2 & $\begin{array}{ll}11.2 \\
\end{array}$ & 9.2 & 10.9 & 1.2 & $\frac{3.2}{3.9}$ & 8.3 & \begin{tabular}{|l|l|}
9.7 \\
\end{tabular} & $\begin{array}{l}7.4 \\
7.3\end{array}$ & 2.5 & 0.7 & $\begin{array}{c}.0 \\
1.7 \\
\end{array}$ & 1.1 & $\frac{5}{1.2}$ & 0.4 \\
\hline $9 / 14-10 / 15$ & $10 / 15 / 14$ & 5.3 & 6.5 & 5.6 & 5.8 & 0.5 & 1.8 & 2.6 & 2.3 & 2.2 & 0.3 & 0.8 & 1.8 & 1.2 & 1.2 & 0.4 \\
\hline $\mid \frac{114-10 / 12}{16 / 14-10 / 22}$ & $\frac{10 / 1 / 1 / 14}{10 / 2 / 14}$ & $\begin{array}{l}3.5 \\
3.7\end{array}$ & 5.5 & 4.0 & 4.5 & 0.6 & 11.7 & 11.3 & 29.2 & 17.4 & 8.3 & 0.9 & 1.2 & 1.5 & 1.2 & 0.2 \\
\hline $23 / 14-10 / 29$ & $10 / 29 / 14$ & 5.6 & 5.6 & 5.0 & 5.4 & 0.3 & 12.9 & 12.6 & 13.6 & 13.1 & 0.4 & 0.8 & 1.9 & 1.4 & 1.4 & 0.4 \\
\hline $30 / 14-11 / 5$ & $11 / 5 / 14$ & 5.1 & 4.9 & 4.1 & 4.7 & 0.4 & 12.3 & 13.0 & 11.8 & 12.4 & 0.5 & 1.1 & 1.8 & 19.5 & 7.4 & 8.5 \\
\hline $6 / 14-11 / 12$ & $11 / 12 / 14$ & 3.1 & 3.6 & 3.0 & 3.2 & 0.2 & 10.4 & 11.2 & 12.6 & 11.4 & 0.9 & 0.3 & 1.0 & 6.3 & 2.5 & 2.7 \\
\hline $13 / 14-11 / 19$ & $11 / 19 / 14$ & 3.3 & 1.0 & 3.8 & 2.7 & 1.2 & 10.9 & 11.5 & 13.6 & 12.0 & 1.2 & 16.0 & 3.3 & 3.2 & 7.5 & 6.0 \\
\hline $20 / 14-11 / 26$ & $11 / 26 / 14$ & 3.7 & 3.7 & 4.1 & 3.8 & 0.2 & 10.9 & 10.8 & 11.2 & 11.0 & 0.2 & 9.9 & 6.0 & 3.4 & 6.4 & 2.7 \\
\hline $27 / 14-12 / 3$ & $12 / 3 / 14$ & 2.7 & 2.5 & 2.6 & 2.6 & 0.1 & 10.9 & 11.0 & 11.0 & 11.0 & 0.0 & 5.0 & 4.6 & 3.7 & 4.4 & 0.5 \\
\hline $4 / 14-12 / 10$ & $12 / 10 / 14$ & 2.7 & 2.2 & 2.7 & 2.6 & 0.2 & 8.8 & 10.2 & 11.2 & 10.0 & 1.0 & 7.3 & 11.4 & 10.2 & 9.6 & 1.7 \\
\hline
\end{tabular}




\begin{tabular}{|c|c|c|c|c|c|c|c|c|c|c|c|c|c|c|c|c|}
\hline \multicolumn{17}{|c|}{$\mathrm{pH}$} \\
\hline & & \multicolumn{5}{|c|}{ Round 2, 3-Day HRT } & \multicolumn{5}{|c|}{ Round 1, 3-Day HRT } & \multicolumn{5}{|c|}{ 2-Day HRT } \\
\hline \begin{tabular}{|l|} 
Date Range \\
\end{tabular} & Date & Pond 1 & \begin{tabular}{l|l} 
Pond 2 \\
\end{tabular} & \begin{tabular}{l|l|} 
Pond 3 \\
\end{tabular} & Average & Std. Dev. & $\begin{array}{l}\text { Pond } 4 \\
\end{array}$ & \begin{tabular}{l|l|} 
Pond 5 \\
\end{tabular} & \begin{tabular}{l|l|} 
Pond 6 \\
\end{tabular} & Average & Std. Dev. & Pond 7 & Pond 8 & Pond 9 & Average & Std. Dev. \\
\hline $28 / 13-12 / 4$ & $12 / 4 / 13$ & 8.9 & 8.9 & 8.2 & 8.7 & 0.3 & 7.2 & 7.1 & 7.5 & 7.3 & 0.1 & 7.0 & & 7.4 & 7.2 & 0.2 \\
\hline $\mid 5 / 13-12 / 11$ & $12 / 11 / 13$ & 8.7 & 8.6 & 7.3 & 8.2 & 0.6 & 6.9 & 7.2 & 7.5 & 7.2 & 0.3 & 7.0 & & 7.2 & 7.1 & 0.1 \\
\hline $12 / 13-12 / 18$ & $12 / 18 / 13$ & 8.5 & 8.5 & 6.9 & 7.9 & 0.8 & 6.7 & 7.5 & 7.5 & 7.2 & 0.4 & 7.0 & 6.2 & 7.7 & 7.0 & 0.6 \\
\hline $19 / 13-12 / 25$ & $12 / 25 / 13$ & 8.5 & 8.4 & 8.6 & 8.5 & 0.0 & 7.5 & 9.0 & 7.2 & 7.9 & 0.8 & 7.0 & 7.4 & 6.3 & 6.9 & 0.5 \\
\hline /2/14-1/8/1 & $1 / 8 / 14$ & 8.2 & 8.2 & 8.3 & 8.2 & 0.1 & 7.5 & 9.5 & 6.6 & 7.9 & 1.2 & 7.0 & 7.4 & 6.2 & 6.9 & 0.5 \\
\hline $9 / 14-1 / 15 / 1$ & $1 / 15 / 14$ & 8.4 & 8.3 & 6.9 & 7.9 & 0.7 & 6.8 & 9.0 & 7.2 & 7.7 & 1.0 & 7.0 & 7.5 & 6.4 & 7.0 & 0.4 \\
\hline $16 / 14-1 / 22 /$ & $1 / 22 / 14$ & 8.4 & 8.5 & 6.8 & 7.9 & 0.8 & 6.7 & 9.1 & 6.9 & 7.6 & 1.1 & 7.0 & 7.4 & 7.8 & 7.4 & 0.3 \\
\hline $13 / 14-2 / 19 /$ & $2 / 19 / 14$ & 8.6 & & 7.3 & 8.0 & 0.7 & 7.1 & 7.6 & 7.0 & 7.2 & 0.3 & 7.0 & 7.5 & 7.8 & 7.4 & 0.3 \\
\hline $20 / 14-2 / 26 /$ & $2 / 26 / 14$ & 8.8 & & 6.8 & 7.8 & 1.0 & 6.7 & 8.2 & 7.4 & 7.4 & 0.6 & 7.0 & 7.6 & 8.4 & 7.6 & 0.6 \\
\hline $27 / 14-3 / 5 / 1$ & $3 / 5 / 14$ & & & 6.7 & 6.7 & 0.0 & 6.6 & 7.4 & 7.4 & 7.1 & 0.4 & 7.0 & 7.4 & 8.5 & 7.6 & 0.7 \\
\hline$|11 / 14-4 / 17|$ & $4 / 17 / 14$ & 9.8 & 6.9 & 6.7 & 7.8 & 1.4 & 6.9 & 8.6 & 6.1 & 7.2 & 1.0 & 7.0 & 7.4 & 4.6 & 6.3 & 1.2 \\
\hline $18 / 14-4 / 24 /$ & $4 / 24 / 14$ & \begin{tabular}{c|c|}
9.9 \\
\end{tabular} & 6.6 & 5.5 & 7.3 & 1.9 & 6.8 & 8.2 & 6.1 & 7.0 & 0.9 & 7.0 & 7.4 & 7.9 & 7.4 & 0.4 \\
\hline $25 / 14-5 / 1 / 1$ & $5 / 1 / 14$ & 9.9 & 7.0 & 4.4 & 7.1 & 2.3 & 6.9 & 8.7 & 6.9 & 7.5 & 0.8 & 7.0 & 7.3 & 10.6 & 8.3 & 1.6 \\
\hline$/ 2 / 14-5 / 8 / 1$ & $5 / 8 / 14$ & 9.9 & 8.3 & 3.0 & 7.0 & 3.0 & 7.0 & 2.2 & 7.0 & 5.4 & 2.3 & 7.0 & & 10.5 & 8.7 & 1.7 \\
\hline $9 / 14-5 / 15 / 1$ & $5 / 15 / 14$ & 9.8 & 8.8 & 2.7 & 7.1 & 3.1 & 7.6 & 8.5 & 7.0 & 7.7 & 0.6 & 7.0 & & 10.9 & 8.9 & 2.0 \\
\hline $16 / 14-5 / 22 /$ & $5 / 22 / 14$ & 9.6 & 8.1 & 7.9 & 8.5 & 0.7 & 7.4 & 9.6 & 7.1 & 8.0 & 1.1 & 7.5 & 7.5 & 5.2 & 6.7 & 1.1 \\
\hline $23 / 14-5 / 29 /$ & $5 / 29 / 14$ & 7.9 & 8.7 & 7.9 & 8.1 & 0.4 & 7.1 & 8.0 & 7.2 & 7.4 & 0.4 & 7.6 & 7.7 & 9.5 & 8.3 & 0.8 \\
\hline $30 / 14-6 / 5 / 1$ & $6 / 5 / 14$ & 8.0 & 8.6 & 7.9 & 8.2 & 0.3 & 7.2 & 7.8 & 7.8 & 7.6 & 0.3 & 7.6 & 7.9 & 10.2 & 8.6 & 1.2 \\
\hline $\mid 6 / 14-6 / 12 / 1$ & $6 / 12 / 14$ & 7.9 & 8.0 & 8.1 & 8.0 & 0.1 & 7.7 & 7.7 & 7.6 & 7.6 & 0.1 & 7.5 & 7.9 & 4.4 & 6.6 & 1.6 \\
\hline $\mid 13 / 14-6 / 19 /$ & $6 / 19 / 14$ & 8.0 & 8.0 & 8.1 & 8.0 & 0.0 & 7.8 & 7.7 & 7.6 & 7.7 & 0.0 & 7.9 & 7.9 & 9.5 & 8.4 & 0.8 \\
\hline $20 / 14-6 / 26 /$ & $6 / 26 / 14$ & 7.9 & 8.0 & 7.9 & 8.0 & 0.0 & 7.8 & 7.7 & 7.7 & 7.7 & 0.0 & 8.0 & 7.8 & 9.6 & 8.4 & 0.8 \\
\hline $27 / 14-7 / 3 / 1$ & $7 / 3 / 14$ & 8.0 & 8.0 & 8.0 & 8.0 & 0.0 & 7.8 & 7.8 & 7.7 & 7.7 & 0.0 & 7.9 & 7.8 & 9.1 & 8.3 & 0.6 \\
\hline $4 / 14-7 / 10 / 1$ & $7 / 10 / 14$ & 8.0 & 7.9 & 8.0 & 8.0 & 0.0 & 7.8 & 7.7 & 7.6 & 7.7 & 0.1 & 7.6 & 7.5 & 7.6 & 7.6 & 0.0 \\
\hline $\mid 11 / 14-7 / 17 /$ & $7 / 17 / 14$ & 8.4 & 8.3 & 8.4 & 8.3 & 0.1 & 7.8 & 7.8 & \begin{tabular}{l|l}
9.9 \\
\end{tabular} & 8.5 & 1.0 & 7.5 & 7.1 & 8.9 & 7.8 & 0.8 \\
\hline $\mid 18 / 14-7 / 24 /$ & $7 / 24 / 14$ & 8.0 & 7.8 & 7.9 & 7.9 & 0.1 & 7.6 & 7.6 & 8.0 & 7.8 & 0.2 & 7.3 & 7.5 & 7.0 & 7.2 & 0.2 \\
\hline $25 / 14-7 / 31 /$ & $7 / 31 / 14$ & 8.4 & 8.3 & 7.2 & 8.0 & 0.6 & 3.8 & 7.5 & 7.7 & 6.3 & 1.8 & 7.1 & 7.4 & 7.0 & 7.2 & 0.2 \\
\hline $8 / 1 / 14-8 / 7 / 1$ & $8 / 7 / 14$ & 8.0 & 8.0 & 7.7 & 7.9 & 0.1 & 6.8 & 7.4 & 7.5 & 7.3 & 0.3 & 7.3 & 7.4 & 7.0 & 7.2 & 0.2 \\
\hline $8 / 14-8 / 14 / 1$ & $8 / 14 / 14$ & 8.1 & 8.0 & 8.1 & 8.1 & 0.0 & 7.4 & 7.4 & 7.0 & 7.3 & 0.2 & 7.3 & 7.4 & 7.0 & 7.2 & 0.2 \\
\hline $15 / 14-8 / 21 /$ & $8 / 21 / 14$ & 8.5 & 8.5 & 8.5 & 8.5 & 0.0 & 7.7 & 7.6 & 7.0 & 7.4 & 0.3 & 7.4 & 7.4 & 7.0 & 7.3 & 0.2 \\
\hline $22 / 14-8 / 28 /$ & $8 / 28 / 14$ & 7.9 & 7.9 & 7.9 & 7.9 & 0.0 & 7.6 & 7.6 & 7.5 & 7.5 & 0.0 & 7.5 & 7.2 & 7.0 & 7.2 & 0.2 \\
\hline $29 / 14-9 / 4 / 1$ & $9 / 4 / 14$ & 8.2 & 8.3 & 8.3 & 8.2 & 0.1 & 7.6 & 7.8 & 7.7 & 7.7 & 0.1 & 7.5 & 7.9 & 7.0 & 7.5 & 0.4 \\
\hline $\mid / 5 / 14-9 / 11 / 1$ & 9/11/14 & 8.0 & 8.1 & 8.1 & 8.1 & 0.0 & 7.6 & 7.6 & 7.6 & 7.6 & 0.0 & 7.5 & 7.9 & 7.3 & 7.5 & 0.3 \\
\hline $12 / 14-9 / 18 /$ & 9/18/14 & 7.9 & 7.9 & 7.9 & 7.9 & 0.0 & 7.5 & 7.6 & 7.5 & 7.5 & 0.0 & 7.5 & 7.9 & 8.6 & 8.0 & 0.5 \\
\hline $\mid 18 / 14-9 / 24 /$ & $9 / 24 / 14$ & 7.9 & 7.9 & 7.9 & 7.9 & 0.0 & 7.4 & 7.5 & 7.4 & 7.5 & 0.0 & 7.6 & 7.7 & 7.0 & 7.4 & 0.3 \\
\hline $25 / 14-10 / 1 /$ & $10 / 1 / 14$ & 7.9 & 7.9 & 8.0 & 7.9 & 0.0 & 7.6 & 7.6 & 7.6 & 7.6 & 0.0 & 7.5 & 7.6 & 7.0 & 7.4 & 0.3 \\
\hline$/ / 2 / 14-10 / 8 /$ & $10 / 8 / 14$ & 8.4 & 7.8 & 8.0 & 8.1 & 0.3 & 8.6 & 8.5 & 8.5 & 8.5 & 0.0 & 7.5 & 7.5 & 7.0 & 7.3 & 0.3 \\
\hline $9 / 14-10 / 15$ & $10 / 15 / 14$ & 7.8 & 7.8 & 7.9 & 7.9 & 0.0 & 7.7 & 7.6 & 7.7 & 7.6 & 0.0 & 7.4 & 7.5 & 7.4 & 7.5 & 0.1 \\
\hline $16 / 14-10 / 22$ & $10 / 22 / 14$ & 7.8 & 8.0 & 7.9 & 7.9 & 0.1 & 7.9 & 8.1 & 8.2 & 8.1 & 0.2 & & 7.6 & 7.8 & 7.7 & 0.1 \\
\hline $23 / 14-10 / 29$ & $10 / 29 / 14$ & 7.8 & 8.1 & 8.0 & 7.9 & 0.1 & 8.1 & 8.1 & 8.1 & 8.1 & 0.0 & 7.5 & 7.6 & 7.8 & 7.7 & 0.1 \\
\hline $30 / 14-11 / 5$ & $11 / 5 / 14$ & 7.7 & 7.8 & 7.7 & 7.7 & 0.1 & 7.8 & 7.9 & 7.9 & 7.9 & 0.1 & 7.5 & 7.6 & 7.7 & 7.6 & 0.1 \\
\hline $\mid 6 / 14-11 / 12$ & $11 / 12 / 14$ & 7.5 & 7.5 & 7.5 & 7.5 & 0.0 & 7.6 & 7.7 & 7.6 & 7.6 & 0.0 & 7.5 & 7.6 & 7.6 & 7.6 & 0.1 \\
\hline $13 / 14-11 / 19$ & $11 / 19 / 14$ & 7.5 & 7.5 & 7.4 & 7.4 & 0.0 & 7.7 & 7.7 & 7.7 & 7.7 & 0.0 & 7.5 & 7.6 & 7.6 & 7.6 & 0.0 \\
\hline $20 / 14-11 / 26$ & $11 / 26 / 14$ & 7.3 & 7.2 & 7.2 & 7.3 & 0.0 & 7.7 & 7.6 & 7.2 & 7.5 & 0.2 & 7.5 & 7.5 & 7.6 & 7.6 & 0.0 \\
\hline $27 / 14-12 / 3$ & $12 / 3 / 14$ & 7.4 & 7.5 & 7.5 & 7.5 & 0.0 & 7.7 & 7.7 & 7.1 & 7.5 & 0.3 & 7.5 & 7.5 & 7.6 & 7.5 & 0.0 \\
\hline $\mid 4 / 14-12 / 10$ & $12 / 10 / 14$ & 5.7 & 7.5 & 7.6 & 6.9 & 0.9 & 7.6 & 7.7 & 7.7 & 7.6 & 0.0 & 7.5 & 7.5 & \begin{tabular}{c|}
7.7 \\
\end{tabular} & 7.6 & 0.1 \\
\hline
\end{tabular}




\section{A.3.9 Pond Temperature (Degrees Celsius)}

\begin{tabular}{|c|c|c|c|c|c|c|c|c|c|c|c|c|c|c|c|c|}
\hline \multicolumn{17}{|c|}{ Pond Temperature (C) } \\
\hline & & \multicolumn{5}{|c|}{ Round 2, 3-Day HRT } & \multicolumn{5}{|c|}{ Round 1, 3-Day HRT } & \multicolumn{5}{|c|}{ 2-Day HRT } \\
\hline Date Range & Listed Date & Pond 1 & \begin{tabular}{l|l} 
Pond 2 \\
\end{tabular} & \begin{tabular}{l|l} 
Pond 3 & \\
\end{tabular} & Average & Std. Dev. & Pond 4 & Pond 5 & \begin{tabular}{l|l} 
Pond 6 \\
\end{tabular} & Average & Std. Dev. & Pond 7 & Pond 8 & Pond 9 & Average & Std. Dev. \\
\hline $28 / 13-12 / 4$ & $12 / 4 / 13$ & & & & & & 50.3 & 15.1 & 15.3 & 15.2 & 16.6 & 15.7 & 15.8 & 15.7 & 15.8 & 0.0 \\
\hline $5 / 13-12 / 11$ & $12 / 11 / 13$ & & & & & & \begin{tabular}{c|c|c|}
50.3 \\
\end{tabular} & 11.6 & 11.4 & 11.5 & 18.3 & 12.0 & 12.1 & 12.0 & 12.1 & 0.0 \\
\hline $19 / 13-12 / 25$ & $12 / 25 / 13$ & 13.3 & 13.0 & 13.1 & 13.1 & 13.1 & 50.3 & 14.0 & 14.2 & 14.1 & 17.1 & 14.7 & 14.7 & 14.6 & 14.7 & 0.0 \\
\hline $2 / 26 / 13-1 / 1 /$ & $1 / 1 / 14$ & 12.7 & 12.4 & 12.5 & 12.5 & 12.5 & 50.3 & 13.4 & 13.6 & 13.5 & 17.3 & 14.1 & 14.2 & 14.1 & 14.1 & 0.1 \\
\hline$/ 2 / 14-1 / 8 / 1$ & $1 / 8 / 14$ & 13.8 & 13.5 & 13.6 & 13.6 & 13.6 & 50.3 & 14.5 & 14.7 & 14.6 & 16.8 & 15.1 & 15.1 & 15.0 & 15.1 & 0.0 \\
\hline 9/14 - 1/15/1 & $1 / 15 / 14$ & 14.2 & 13.9 & 14.0 & 14.0 & 14.0 & 50.3 & 14.7 & 14.8 & 14.7 & 16.8 & 15.2 & 15.3 & 15.2 & 15.2 & 0.1 \\
\hline $16 / 14-1 / 22 /$ & $1 / 22 / 14$ & 13.8 & 13.5 & \begin{tabular}{|c|}
13.7 \\
\end{tabular} & 13.7 & 13.7 & 50.3 & 14.5 & \begin{tabular}{l|l}
14.7 \\
\end{tabular} & 14.6 & 16.8 & 15.1 & 15.2 & 15.1 & 15.2 & 0.0 \\
\hline $23 / 14-1 / 29 /$ & $1 / 29 / 14$ & 15.6 & \begin{tabular}{l|l|}
15.3 \\
\end{tabular} & 15.4 & 15.4 & 15.4 & 50.3 & 16.0 & 16.2 & 16.1 & 16.1 & 16.6 & 16.6 & 16.6 & 16.6 & 0.0 \\
\hline $30 / 14-2 / 5 / 1$ & $2 / 5 / 14$ & 14.0 & \begin{tabular}{|c|}
13.7 \\
\end{tabular} & \begin{tabular}{|c|}
13.8 \\
\end{tabular} & 13.8 & 13.8 & 50.3 & 14.5 & \begin{tabular}{l|l}
14.7 \\
\end{tabular} & 14.6 & 16.8 & 15.2 & 15.2 & 15.1 & 15.2 & 0.0 \\
\hline $6 / 14-2 / 12 / 1$ & $2 / 12 / 14$ & 16.0 & 15.7 & 15.8 & 15.8 & 15.8 & 50.3 & 16.4 & 16.6 & 16.5 & 15.9 & 17.0 & 17.0 & 16.9 & 17.0 & 0.0 \\
\hline $13 / 14-2 / 19 /$ & $2 / 19 / 14$ & 16.2 & \begin{tabular}{l|l|}
15.9 \\
\end{tabular} & \begin{tabular}{l|l|}
15.9 \\
\end{tabular} & 16.0 & 16.0 & 50.3 & 16.4 & 16.5 & 16.5 & 16.0 & 16.9 & 17.0 & 16.9 & 16.9 & 0.0 \\
\hline $20 / 14-2 / 26 /$ & $2 / 26 / 14$ & 16.5 & 16.2 & \begin{tabular}{l|l|}
16.3 \\
\end{tabular} & 16.3 & 16.3 & 50.3 & 16.6 & 16.8 & 16.7 & 15.8 & 17.2 & 17.2 & 17.1 & 17.2 & 0.0 \\
\hline $27 / 14-3 / 5 / 1$ & $3 / 5 / 14$ & 18.3 & 18.0 & 18.0 & 18.1 & 18.1 & 50.3 & 18.4 & 18.5 & 18.4 & 15.0 & 18.9 & 18.9 & 18.8 & 18.8 & 0.0 \\
\hline$/ 6 / 14-3 / 12 / 1$ & $3 / 12 / 14$ & 17.6 & 17.4 & 17.4 & 17.5 & 17.5 & 50.3 & \begin{tabular}{ll|}
17.7 \\
\end{tabular} & 17.9 & 17.8 & 15.3 & 18.2 & 18.2 & 18.1 & 18.2 & 0.1 \\
\hline $13 / 14-3 / 19 /$ & $3 / 19 / 14$ & 18.0 & \begin{tabular}{|c|}
17.7 \\
\end{tabular} & 17.8 & 17.8 & 17.8 & 50.3 & 18.1 & 18.3 & 18.2 & 15.1 & 18.6 & 18.6 & 18.5 & 18.6 & 0.1 \\
\hline $20 / 14-3 / 26 /$ & $3 / 26 / 14$ & 18.0 & \begin{tabular}{|c|}
17.7 \\
\end{tabular} & \begin{tabular}{ll|}
17.8 \\
\end{tabular} & 17.9 & 17.9 & 50.3 & 18.2 & 18.4 & 18.3 & 15.1 & 18.7 & 18.7 & 18.6 & 18.6 & 0.1 \\
\hline $28 / 14-4 / 3 / 1$ & $4 / 3 / 14$ & 17.5 & 17.1 & 17.2 & 17.3 & 17.3 & 50.3 & 17.7 & 17.8 & 17.8 & 15.3 & 18.1 & 18.1 & 17.9 & 18.0 & 0.1 \\
\hline$/ 4 / 14-4 / 10 / 1$ & $4 / 10 / 14$ & 19.1 & 18.7 & 18.9 & 18.9 & 18.9 & 50.3 & 19.2 & 19.3 & 19.3 & 14.6 & 19.6 & 19.6 & 19.4 & 19.5 & 0.1 \\
\hline $11 / 14-4 / 17 /$ & $4 / 17 / 14$ & 19.3 & \begin{tabular}{ll|}
18.9 \\
\end{tabular} & 19.0 & 19.0 & 19.0 & 50.3 & 19.3 & \begin{tabular}{ll|}
19.4 \\
\end{tabular} & 19.4 & 14.6 & 19.8 & 19.8 & 19.7 & 19.7 & 0.0 \\
\hline $18 / 14-4 / 24 /$ & $4 / 24 / 14$ & 18.8 & 18.4 & 18.5 & 18.6 & 18.6 & 50.3 & 18.9 & 19.0 & 19.0 & 14.8 & 19.4 & 19.4 & 19.3 & 19.4 & 0.0 \\
\hline $25 / 14-5 / 1 / 1$ & $5 / 1 / 14$ & 19.4 & 19.1 & 19.2 & 19.2 & 19.2 & 50.3 & 19.5 & 19.6 & 19.5 & 14.5 & 20.0 & 19.9 & 19.8 & 19.9 & 0.1 \\
\hline $5 / 2 / 14-5 / 8 / 1$ & $5 / 8 / 14$ & 19.4 & 19.0 & 19.2 & 19.2 & 19.2 & 50.3 & 19.5 & $\begin{array}{ll}19.6 \\
\end{array}$ & 19.5 & 14.5 & 19.9 & \begin{tabular}{l|l|}
19.9 \\
\end{tabular} & \begin{tabular}{l|l|}
19.9 \\
\end{tabular} & 19.9 & 0.0 \\
\hline $9 / 14-5 / 15 / 1$ & $5 / 15 / 14$ & 19.7 & 19.3 & 19.5 & 19.5 & 19.5 & 50.3 & 21.1 & 21.2 & 21.1 & 13.8 & 21.5 & 21.5 & 21.4 & 21.4 & 0.0 \\
\hline $16 / 14-5 / 22 /$ & $5 / 22 / 14$ & 19.8 & 19.4 & 19.6 & 19.6 & 19.6 & 50.3 & 20.1 & 20.2 & 20.2 & 14.2 & 20.5 & 20.5 & 20.5 & 20.5 & 0.0 \\
\hline $23 / 14-5 / 29 /$ & $5 / 29 / 14$ & 21.4 & 21.0 & 21.2 & 21.2 & 21.2 & 50.3 & 21.3 & 21.4 & 21.3 & 13.6 & 21.7 & 21.7 & 21.7 & 21.7 & 0.0 \\
\hline $30 / 14-6 / 5 / 1$ & $6 / 5 / 14$ & 20.7 & 20.3 & 20.5 & 20.5 & 20.5 & 50.3 & 20.7 & 20.9 & 20.8 & 13.9 & 21.2 & 21.2 & 21.2 & 21.2 & 0.0 \\
\hline $6 / 14-6 / 12 / 1$ & $6 / 12 / 14$ & 22.4 & 22.0 & 22.2 & 22.2 & 22.2 & 50.3 & 22.4 & 22.5 & 22.4 & 13.1 & 22.7 & 22.7 & 22.7 & 22.7 & 0.0 \\
\hline $13 / 14-6 / 19 /$ & $6 / 19 / 14$ & 21.8 & 21.3 & 21.6 & 21.6 & 21.6 & 50.3 & 21.7 & 21.7 & 21.7 & 13.5 & 21.6 & 21.7 & 21.6 & 21.6 & 0.0 \\
\hline $20 / 14-6 / 26$ & $6 / 26 / 14$ & 21.6 & 21.1 & 21.4 & 21.4 & 21.4 & 50.3 & 21.6 & 21.7 & 21.7 & 13.5 & 21.9 & 21.9 & 21.9 & 21.9 & 0.0 \\
\hline $27 / 14-7 / 3 / 1$ & $7 / 3 / 14$ & 22.6 & 22.2 & 22.4 & 22.4 & 22.4 & 50.3 & 22.4 & 22.6 & 22.5 & 13.1 & 22.6 & 22.6 & 22.6 & 22.6 & 0.0 \\
\hline$/ 4 / 14-7 / 10 / 1$ & $7 / 10 / 14$ & 23.4 & 23.0 & 23.2 & 23.2 & 23.2 & 50.3 & 23.6 & 23.7 & 23.7 & 12.5 & 23.5 & 23.5 & 23.5 & 23.5 & 0.0 \\
\hline $11 / 14-7 / 17 /$ & $7 / 17 / 14$ & 23.1 & 22.8 & 22.9 & 22.9 & 22.9 & 50.3 & 23.1 & 23.3 & 23.2 & 12.8 & 23.3 & 23.3 & 23.2 & 23.3 & 0.0 \\
\hline $18 / 14-7 / 24 /$ & $7 / 24 / 14$ & 23.7 & 23.3 & 23.4 & 23.5 & 23.5 & 50.3 & 23.5 & 23.6 & 23.6 & 12.6 & 23.8 & 23.8 & 23.7 & 23.8 & 0.1 \\
\hline $25 / 14-7 / 31$ & $7 / 31 / 14$ & 23.8 & 23.4 & 23.5 & 23.6 & 23.6 & 50.3 & 23.8 & 23.7 & 23.8 & 12.5 & 24.0 & 24.0 & 23.9 & 24.0 & 0.1 \\
\hline$\beta / 1 / 14-8 / 7 / 1$ & $8 / 7 / 14$ & 23.8 & 23.5 & 23.6 & 23.6 & 23.6 & 50.3 & 23.4 & 23.6 & 23.5 & 12.6 & 23.8 & 23.9 & 23.7 & 23.8 & 0.1 \\
\hline $8 / 14-8 / 14 / 1$ & $8 / 14 / 14$ & 9.9 & 23.0 & 23.1 & 23.0 & 23.0 & 50.3 & 23.3 & 23.5 & 23.4 & 12.7 & 23.4 & 23.6 & 23.4 & 23.5 & 0.1 \\
\hline $15 / 14-8 / 21$ & $8 / 21 / 14$ & 22.9 & 22.4 & 22.6 & 22.6 & 22.6 & 50.3 & 22.7 & 22.9 & 22.8 & 13.0 & 23.1 & 23.1 & 23.0 & 23.1 & 0.0 \\
\hline $22 / 14-8 / 28 /$ & $8 / 28 / 14$ & 23.0 & 22.6 & 22.8 & 22.8 & 22.8 & 50.3 & 22.9 & 23.1 & 23.0 & 12.9 & 23.2 & 23.2 & 23.2 & 23.2 & 0.0 \\
\hline$/ 29 / 14-9 / 4 / 1$ & $9 / 4 / 14$ & 22.6 & 22.3 & 22.4 & 22.4 & 22.4 & 50.3 & 22.7 & 22.9 & 22.8 & 13.0 & 22.9 & 23.0 & 22.9 & 22.9 & 0.0 \\
\hline $\mid 5 / 14-9 / 11 / 1$ & 9/11/14 & 21.7 & 21.5 & 21.5 & 21.6 & 21.6 & 40.3 & 21.7 & 21.9 & 21.8 & 8.7 & 22.2 & 22.3 & 22.2 & 22.2 & 0.0 \\
\hline $12 / 14-9 / 18$ & $9 / 18 / 14$ & 22.1 & 22.0 & 22.0 & 22.0 & 22.0 & 22.7 & 22.3 & 22.4 & 22.5 & 0.2 & 22.9 & 22.9 & 22.8 & 22.9 & 0.0 \\
\hline $18 / 14-9 / 24$ & $9 / 24 / 14$ & 22.6 & 22.4 & 22.4 & 22.5 & 22.5 & 23.2 & 22.7 & 22.9 & 22.9 & 0.2 & 23.2 & 23.2 & 23.1 & 23.2 & 0.0 \\
\hline $25 / 14-10 / 1 /$ & $10 / 1 / 14$ & 20.8 & 20.7 & 20.7 & 20.8 & 20.8 & 22.1 & 21.6 & 21.8 & 21.9 & 0.2 & 21.5 & 21.6 & 19.1 & 21.6 & 1.2 \\
\hline$/ / 2 / 14-10 / 8 /$ & $10 / 8 / 14$ & 22.4 & 22.0 & 22.0 & 22.1 & 22.1 & 22.2 & 21.8 & 21.9 & 21.9 & 0.2 & 22.6 & 22.6 & 7.1 & 22.6 & 7.3 \\
\hline /9/14 - $10 / 15$ & $10 / 15 / 14$ & 21.3 & 21.0 & 20.9 & 21.1 & 21.1 & 21.3 & 20.9 & 21.1 & 21.1 & 0.2 & 21.8 & 21.8 & 6.9 & 21.8 & 7.0 \\
\hline $16 / 14-10 / 22$ & $10 / 22 / 14$ & 20.4 & 20.1 & 20.2 & 20.2 & 20.2 & 19.7 & 19.3 & 19.4 & 19.5 & 0.2 & 20.7 & 20.8 & 28.7 & 20.8 & 3.7 \\
\hline $23 / 14-10 / 29$ & $10 / 29 / 14$ & 19.3 & 19.0 & 19.1 & 19.1 & 19.1 & 18.4 & 18.0 & 18.1 & 18.2 & 0.2 & 19.7 & 19.9 & 32.5 & 19.8 & 6.0 \\
\hline $30 / 14-11 / 5$ & $11 / 5 / 14$ & 18.1 & 17.9 & 18.0 & 18.0 & 18.0 & 17.5 & 17.1 & 17.5 & 17.3 & 0.2 & 18.8 & 18.9 & 32.2 & 18.9 & 6.3 \\
\hline $6 / 14-11 / 12$ & $11 / 12 / 14$ & 18.6 & 18.4 & 18.5 & 18.5 & 18.5 & 17.8 & 17.4 & 17.6 & 17.6 & 0.2 & 19.2 & 19.4 & 32.4 & 19.3 & 6.2 \\
\hline $13 / 14-11 / 19$ & $11 / 19 / 14$ & 17.7 & 17.4 & 17.4 & 17.5 & 17.5 & 16.8 & 16.4 & 16.6 & 16.6 & 0.2 & 18.2 & 18.4 & 32.1 & 18.3 & 6.5 \\
\hline $20 / 14-11 / 26$ & $11 / 26 / 14$ & 16.4 & 16.1 & 16.3 & 16.3 & 16.3 & 15.2 & 14.8 & 15.0 & 15.0 & 0.1 & 16.1 & 16.1 & 31.5 & 16.1 & 7.3 \\
\hline $27 / 14-12 / 3$ & $12 / 3 / 14$ & 16.7 & 16.4 & 16.6 & 16.6 & 16.6 & 15.6 & 15.2 & 15.4 & 15.4 & 0.2 & 16.5 & 16.6 & 31.7 & 16.5 & 7.1 \\
\hline $4 / 14-12 / 10$ & $12 / 10 / 14$ & 18.4 & 18.1 & 18.3 & 18.3 & 18.3 & 17.5 & 17.1 & 17.2 & 17.3 & 0.2 & 17.5 & 17.6 & 31.9 & 17.5 & 6.8 \\
\hline
\end{tabular}

